\title{
CONFIANÇA E SOLIDARIEDADE: A FUNÇÃO SISTÊMICA DO DIREITO E DOS MEIOS DE COMUNICAÇÃO DE MASSA NA (DES)CONSTRUÇÃO DAS POLÍTICAS DE SEGURIDADE SOCIAL NO BRASIL
}

Tese apresentada à Faculdade de Direito da Universidade de São Paulo para obtenção do título de Doutor em Direito do Trabalho e da Seguridade Social

Área de concentração:

Direito do Trabalho e da Seguridade Social

Orientador: Prof. Ass. Marcus Orione Gonçalves Correia

Universidade de São Paulo

Faculdade de Direito

São Paulo - 2011 
Autorizo a reprodução e divulgação total ou parcial deste trabalho, por qualquer meio convencional ou eletrônico, para fins de estudo e pesquisa, desde que citada a fonte.

Cruz, Renato Negretti

Confiança e solidariedade: a função sistêmica do direito e dos meios de comunicação de massa na (des)construção das políticas de Seguridade Social no Brasil / Renato Negretti Cruz ; orientador Marcus Orione Gonçalves Correia. São Paulo, 2011.

$306 \mathrm{p}$.

Tese (Doutorado) - Faculdade de Direito da Universidade de São Paulo. Departamento de Direito do Trabalho e da Seguridade Social.

1 Sistemas autopoiéticos. 2 Constituição.

3 Seguridade Social. 4 direitos sociais. 5 mídia. 6 confiança. 7 solidariedade. 8 políticas públicas.

I. Universidade de São Paulo. Faculdade de Direito. Departamento de Direito do Trabalho e da Seguridade Social.

Apoio de fomento: CAPES - Coordenação de Aperfeiçoamento de Pessoal de Nível Superior 
À Sublime Aline,

cujo Amor e Amizade vivificam nossa caminhada e me encorajam a superar todos obstáculos!

$\&$

Mais (mil e) uma vez(es) aos meus Queridos

Pais, Vivaldo e Sueli, pelo incentivo e carinho em todos os meus passos... 


\section{AGRADECIMENTOS}

Ao Prof. Ass. Marcus Orione Gonçalves Correia, por mais esta oportunidade, pela confiança depositada e liberdade garantida na realização deste trabalho;

À Banca Examinadora do trabalho de qualificação, pelas observações e sugestões criteriosas;

Aos Profs. Ronaldo Lima dos Santos e Paulo Thadeu Gomes da Silva, pela disposição em discutir as ideias deste trabalho, pelos livros e, sobretudo, pela amizade;

Mais uma vez ao Sr. Alberto e à Sra. Celeste que me acolheram com amor fraternal e que tanto me apoiaram nos momentos mais difíceis desse percurso acadêmico;

À minha família, em especial à minha amada irmã Adriana, que sempre foi tão zelosa com meu crescimento, pelo carinho e leitura criteriosa dessas tortuosas páginas;

A minha querida amiga Lucyla, por sua generosidade, pelo sincero companheirismo, pelos livros e sugestões, pelas risadas ... ;

Ao meu querido casal de amigos André e Andréa não só pela revisão atenta e fundamental ajuda na finalização desta tese, como também pelo incentivo e pela descontração;

Ao Ricardo, à Marli, ao Leandro e à Giselle pela amizade e carinho com que sempre me receberam;

Aos meus colegas da Universidade São Judas Tadeu, por propiciarem tanto os importantes momentos de reflexão quanto de singela descontração, em especial aos Professores Caparroz, Fulvio, Elaine, Micheline, Carol, Amália, Tony, Caio e José Ricardo que me ajudaram nesta etapa, cada qual a sua maneira, todos com atenciosa amizade;

Agradeço, por fim à Capes (Coordenação de Aperfeiçoamento de Pessoal de Nível Superior) e à Universidade de São Paulo pelo apoio institucional. 
"Lutar com palavras

é a luta mais vã.

Entanto lutamos

mal rompe a manhã.

São muitas, eu pouco.

Algumas, tão fortes

como o javali.

Não me julgo louco.

Se o fosse, teria

poder de encantá-las.

Mas lúcido e frio,

apareço e tento

apanhar algumas

para meu sustento

num dia de vida.

[‥]

Palavra, Palavra

(digo exasperado),

se me desafias,

aceito o combate."

Carlos Drummond de Andrade - O Lutador 


\section{RESUMO}

O presente trabalho discute as funções sistêmicas do direito e dos meios de comunicação de massa na definição e generalização para a sociedade brasileira de expectativas sociais relacionadas à implementação das políticas públicas de Seguridade Social. Objetivou-se identificar o funcionamento desses sistemas sociais e sua relação com o processo comunicacional de construção dos sentidos de tais políticas previstas na Constituição da República Federativa do Brasil de 1988. Para tanto, por meio do estudo interdisciplinar e eminentemente bibliográfico, foi empreendida a revisão da teoria dos sistemas sociais autopoiéticos de Niklas Luhmann e a adaptação do Modelo de Propaganda de Edward S. Herman e Noam Chomsky à realidade brasileira. A Constituição foi identificada como o ponto de convergência dos processos comunicacionais de toda sociedade e de institucionalização de suas expectativas normativas, resultantes do amplo acoplamento estrutural dos sistemas sociais nacionais. Incorpora-se à compreensão da Seguridade Social a função dos programas e princípios constitucionais e o conflito entre as expectativas sistêmicas em matéria de direitos sociais. Foram delimitados, ainda, os acoplamentos estruturais entre os sistemas econômico, político e dos meios de comunicação de massa, bem como o decorrente condicionamento da seleção de informações realizada pelas organizações midiáticas brasileiras através dos filtros/programas de notícias presentes em seu processo comunicacional sistêmico. Destacou-se o favorecimento e disseminação pela mídia nacional das expectativas dos sistemas sociais parciais que financiam suas organizações no sentido da redução das políticas públicas de Seguridade Social e do fomento do mercado privado de serviços de saúde, previdência e assistência. Assim, foi demonstrada a tese de que a atual lógica sistêmica dos meios de comunicação de massa delimita seu processo de seleção das informações relativas à saúde, previdência e assistencial social, de modo a reduzir a esfera da opinião pública e instrumentalizar a quebra de confiança no Sistema de Seguridade Social brasileiro, solapando a solidariedade, essencial para a construção desse sistema de proteção e para o sucesso de suas políticas públicas.

Palavras-chaves: Sistemas autopoiéticos; Constituição; Seguridade Social; direitos sociais; mídia, confiança, solidariedade, políticas públicas. 


\begin{abstract}
The present work discusses the systemic functions of Law and mass media on the definition and generalization of social expectations related to the implemention of public policies of Social Security for the Brazilian society. It aimed to identify the functioning of these social systems and its relation with the communicational process of meanings construction of such policies foreseen in the 1988 Constitution of Federative Republic of Brazil. To this end, a review of Niklas Luhmann's autopoietic social systems theory and the adaptation of Edward S. Herman's and Noam Chomsky's propaganda model to the Brazilian reality was carried out through an interdisciplinary and eminently bibliographic study. The Constitution was identified as the converting point of the whole society and the institutionalization of its normative expectations, resulting from the wide structural connection of national social systems. The comprehension of Social Securitiy was incorporated to programs roles and constitutional principles and the conflict between the systemic expectations in terms of social rights. Moreover, the structural connections between economical, political and mass media systems were delimited, as well as the conditioning decorrent from the information selection carried out by Brazilian mediatic organization through news filters present on its systemic communicational process. It was noticed, through the national media, that partial social systems expectation which finance their organizations aiming the reduction of Social Security public policies and foment of health, pension and assistance services private market were favoured and disseminated. Thus, it was demonstrated the thesis of the present systemic logic of mass communication means delimits its process of information selection related to health, public pension and social assistance, as to reduce public opinion range and instrumentalize trust rupture in the Brazilian Social Security System, impairing solidarity, essential for the construction of this protection system and the success of its public policies.
\end{abstract}

Key words: Autopoietic systems; Constituition; Social Security; social rights; media, trust, solidarity, public policies. 


\section{RESUMÉ}

Cette thèse traite les fonctions systémiques du droit et des moyens de communication de masse en relation à la définition et la généralisation des attentes sociales en relation à la mise en œuvre des politiques publiques de la Sécurité Sociale pour la société brésilienne. L'objectif est d'identifier le fonctionnement de ces systèmes sociaux et leur rapport avec le processus de communication en relation à l'importance de telles politiques prévues dans la Constitution de la République Fédérative du Brésil de 1988. Pour cela, à travers des études interdisciplinaires et surtout bibliographiques, cette thèse comprend une révision de la théorie des systèmes sociaux autopoétiques de Niklas Luhmann et l'adaptation du Modèle de Propagande d'Edward S. Herman et Noam Chomsky à la réalité brésilienne. La Constitution est identifiée comme point de convergence entre les processus de communication de chaque société et de l'institutionnalisation de ses attentes normatives provenant de l'intégration structurelle des systèmes sociaux nationaux. La compréhension de la Sécurité Sociale englobe également la fonction des programmes et principes constitutionnels et le conflit entre les attentes systémiques par rapport aux droits sociaux. De plus, les rapports structurels ont été délimités entre les systèmes économiques, politiques et des moyens de communication de masse, et encore le conditionnement provenant de la sélection des informations réalisée par les organisations médiatiques brésiliennes à travers des filtres/ programmes d'informations instaurés auprès des processus de communication systémiques. On remarque que les médias favorisent et diffusent clairement les attentes des systèmes sociaux partenaires qui financent leurs organisations en réduisant les politiques publiques de Sécurité Sociale et le soutien du marché privé aux services de santé, d'assurance sociale et d'assistance. Par conséquent, la thèse s'impose selon laquelle la logique systémique actuelle des moyens de communication de masse délimite son processus de sélection d'informations en relation à la santé, l'assurance et l'assistance sociales pour réduire l'espace de l'opinion publique et instrumentaliser la chute de confiance dans le système de Sécurité Sociale brésilienne, ce qui nuit à la solidarité essentielle pour la construction de ce système de protection et pour le succès de ses politiques publiques.

Mots-clés: Systèmes autopoétiques; Constitution; Sécurité Sociale; droits sociaux; médias ; confiance; solidarité; politiques publiques. 


\section{SUMÁRIO}

INTRODUÇÃO

CAPÍTULO 1 TEORIA DOS SISTEMAS SOCIAIS

1.1 A visão sistêmica e sua peculiar epistemologia

1.1.1 Características essenciais do pensamento sistêmico

1.1.2 A concepção biológica de autopoiese e sua compreensão inicial de sociedade

1.2 A Teoria dos Sistemas Sociais de Niklas Luhmann e sua arquitetura conceitual

1.2.1 A sociedade em termos comunicacionais e sua distinção enquanto sistema do ambiente

1.2.2 Autopoiese social: sentido e fechamento operacional

1.2.3 A relação entre dupla contingência, expectativas e programação sistêmicas e o desenvolvimento dos meios de comunicação simbolicamente generalizados

1.2.4 Inter-relações sistêmicas e a criação e generalização de expectativas sociais

1.2.5 As interações e organizações como sistemas parciais e a emergência de 76 novos processos comunicacionais

\section{CAPÍTULO 2 A VISÃO SISTÊMICA DO DIREITO E SUA RELAÇÃO COM A FORMAÇÃO DE CONFIANÇA SISTÊMICA}

2.1 A função do sistema jurídico frente às expectativas cognitivas e normativas

2.2 Desdobramentos teóricos da autopoiese do sistema jurídico e a tese referente à alopoiese do sistema jurídico brasileiro 
2.3 Contextualização e críticas referentes à visão funcional-estruturalista da 107 sociedade e à inserção do pensamento sistêmico no direito

2.4 A Constituição Federal de 1988 como acoplamento estrutural da sociedade 131 brasileira não limitado aos sistemas jurídico e político nacionais

2.4.1 A força normativa constitucional e a teoria dos sistemas

2.4.2 Constituição, expectativas normativas e o papel desempenhado pela confiança na redução da complexidade social

\section{$\begin{array}{llllllll}\text { CAPÍTULO } 3 & \text { A } & \text { LÓGICA } & \text { SISTÊMICA } & \text { DOS } & \text { MEIOS } & \text { DE } & 143\end{array}$ COMUNICAÇÃO DE MASSA}

3.1 Desenvolvimento histórico e a teorização dos meios de comunicação de massa

3.2 O Modelo de Propaganda e sua aplicabilidade ao estudo da Mídia brasileira

3.2.1 O $1^{\circ}$ programa ou "filtro de notícias": porte, propriedade e orientação para o lucro da mídia de massa

3.2.2 O $2^{\circ}$ programa ou "filtro de notícias": a propaganda como principal fonte de recursos da mídia de massa

3.2.3 O $3^{\circ}$ programa ou "filtro de notícias": a dependência da mídia de informações fornecidas pelo governo, por empresas e por "especialistas"

3.2.4 O $4^{\mathrm{o}}$ programa ou "filtro de notícias": a bateria de reações negativas como forma de disciplinar a mídia

3.2.5 O $5^{\circ}$ programa ou "filtro de notícias": o "anticomunismo" como religião nacional e mecanismo de controle

\section{CAPÍTULO 4}
AS TENSÕES ENTRE OS SENTIDOS DAS POLÍTICAS
PÚBLICAS DE SEGURIDADE SOCIAL E A DISTORÇÃO COMUNICACIONAL DOS MEIOS DE COMUNICAÇÃO DE MASSA NO BRASIL 
4.1 Sistema político, políticas públicas e a conformação jurídica das expectativas 201 sociais acerca do Estado de Bem-Estar Social

4.1.1 Direito da Seguridade Social e sua função sistêmica no direcionamento das políticas públicas de saúde, previdência e assistência social no Brasil

4.1.2 Os sentidos da solidariedade social e a manutenção da confiança no Sistema 226 de Seguridade frente às propostas de desconstrução de suas políticas públicas

4.2 Os meios de comunicação de massa e a desconstrução das políticas públicas de 238 proteção social

4.2.1 Cobertura midiática e a simulação do consenso acerca das reformas 244 neoliberais de redução dos direitos sociais previstos constitucionalmente 


\section{INTRODUÇÃO}

O tema desenvolvido nesta tese de doutorado diz respeito às funções sistêmicas dos meios de comunicação de massa e do sistema jurídico nacionais acerca da definição e generalização para toda a sociedade de quais expectativas sociais devem ser mantidas contrafactualmente quanto ao papel do Estado e à abrangência de suas políticas públicas relativas especificamente à implementação do Sistema de Seguridade Social, projetado na Constituição da República Federativa do Brasil de 1988.

Propõe-se que a conformação histórica do sistema midiático de massa brasileiro condiciona de tal forma o processo de seleção das informações que compõem suas notícias e reportagens acerca das questões relacionadas à saúde, previdência e assistência sociais, de modo que as mesmas sejam veiculadas, em sua grande parte, no sentido de reduzir a esfera da opinião pública e instrumentalizar, através da banalização das injustiças sociais, a quebra de confiança na Seguridade Social. Dessa forma, prejudicase a consolidação da solidariedade social essencial para a construção desse sistema de proteção e para o sucesso de suas políticas públicas.

Fora, assim, realizada uma abordagem interdisciplinar e eminentemente bibliográfica do tema proposto através da revisão da teoria dos sistemas sociais autopoiéticos (LUHMANN, 1998) e da adaptação do Modelo de Propaganda (HERMAN; CHOMSKY, 2003) à realidade brasileira. Por fim, empreendeu-se a discussão de algumas notícias da mídia impressa disponíveis em meio eletrônico a fim de se exemplificar a efetividade da tese apresentada.

Em termos epistemológicos, a base teórica do presente trabalho compreende a Teoria da Sociedade de Niklas Luhmann (1998), funcional-estruturalista, com as devidas revisões bibliográficas e visões críticas acerca de seus limites para o estudo da Seguridade Social (CRUZ, 2007), a qual não se confunde com a abordagem teórica estruturalfuncionalista de Talcott Parsons (1966; 1974).

No que diz respeito à aplicação dessa teoria ao estudo do direito, tal fora inicialmente empreendida pelo próprio Luhmann (1989a, 1990a, 1992, 1998), sendo posteriormente rediscutida com novas contribuições por diversos autores como Gunther 
Teubner (1989b), Celso Fernandes Campilongo (2000b, 2002), Germano Schwartz (2004), Paulo Thadeu Gomes da Silva $(2001 ; 2005 ; 2010)$, dentre outros.

De acordo com a referida teoria sistêmica, a dinâmica da sociedade moderna e das inter-relações entre seus diversos sistemas sociais tornariam impossível sua análise, no sentido técnico tradicional referente à observação e fragmentação do objeto de estudo em partes para se alcançar, no momento seguinte, a sua compreensão como um todo.

Por essa razão, buscou-se compreender o tema em questão em sua complexidade, através dos processos de comunicação que diferenciaram os sistemas sociais envolvidos de maneira autorreferencial. Isto porque, como discutido já no primeiro capítulo, tais sistemas que compõem a sociedade utilizam a comunicação como seu modo particular de reprodução autopoiética. Seus elementos são, portanto, formas de comunicação, produzidas e reproduzidas em rede, fora da qual não podem existir. (LUHMANN, 1992, p. 1423-1424).

Por sua vez, conforme detidamente examinado no terceiro capítulo, levando-se em conta a existência de diferentes "modelos teóricos para o estudo das comunicações" (LIMA, 2001), cumpre esclarecer que a específica abordagem funcionalista e comunicacional utilizada não considera, de forma alguma, os meios de comunicação de massa nos mesmos moldes em que estes são analisados na "teoria funcionalista da comunicação de massa" ou "sociologia funcionalista da mídia", desenvolvidas por Lasswell, Merton e Lazarsfeld e Wright (LIMA, 2001, p. 44-45).

Os meios de comunicação são aqui considerados, frise-se desde já, como parte da sociedade, enquanto um de seus sistemas sociais, cuja comunicação interna se dá em termos autorreferenciais, a partir do código informação/não-informação ou, simplesmente, informativo/não-informativo, como o comumente adotado no meio jornalístico.

O referido código é responsável pela operacionalização de suas distinções e seleções de sentidos desse sistema. Sob esse mecanismo funcional interno, generalizam-se informações sobre os mais diversos temas, contribuindo funcionalmente para a conformação de expectativas sociais.

Porém, sob essa peculiar perspectiva sistêmica, diferentemente do que é exteriorizado pelo próprio sistema midiático para creditá-lo, deve-se considerar que tais informações não correspondem necessariamente à verdade, enquanto descrição objetiva e 
unívoca da realidade, isto porque, diferentemente do sistema científico, o sistema dos meios de comunicação não trabalha a partir do código verdade/não-verdade.

Mais do que simplesmente a exposição do código binário informação/nãoinformação, destacou-se no trabalho acadêmico em tela, como seu elemento primordial, a compreensão e discussão dos diferentes programas internos desse sistema midiático.

Dessa sucinta apresentação, pode ser depreendido o corte metodológico realizado, sendo que no trabalho em questão não se desenvolveu de modo exaustivo a discussão sobre os efeitos dos meios de comunicação de massa sobre a cultura, a arte e nem sequer sobre seus polêmicos "poderes de manipulação" direta sobre o comportamento social, embora seja contextualizada, no decorrer desta tese, toda a gama de teorias voltadas à discussão destes supostos efeitos concretos.

Dentro dos pressupostos teóricos dessa singular teoria comunicacional apenas introduzida, a discussão proposta circunscreveu-se ao conflito, em si, existente entre, de um lado, as expectativas e os sentidos da comunicação disseminados pelos meios de comunicação de massa brasileiros, através de suas organizações empresariais midiáticas e, de outro, os sentidos das expectativas normativas sobre os direitos sociais, cuja função essencial de generalização social pertence ao sistema jurídico.

A função midiática neste conflito comunicacional objeto de estudo foi discutida valendo-se dos "filtros de notícias" apresentados pelo do citado Modelo de Propaganda, elaborados inicialmente para a crítica dos meios de comunicação norte-americanos.

Tal modelo pressupõe a concentração das organizações midiáticas num pequeno número de empresas privadas orientadas para o lucro, tendo a propaganda como sua principal fonte de financiamento, o que permitiu sua extensão para a compreensão do funcionamento da mídia brasileira. (HERMAN; CHOMSKY, 2003; ARBEX JR, 2002; LIMA, 2001, 2008).

Apreendido sob a visão sistêmica, o citado padrão interpretativo permitiu uma compreensão mais aproximada dos atuais mecanismos internos de dotação de sentido e seleção de informação do sistema dos meios de comunicação de massa, ainda que tais programas sistêmicos sejam inicialmente teorizados sob a perspectiva de "filtros", a partir dos quais, de qualquer forma, se estabelecem as premissas do discurso e da interpretação midiática sobre a realidade, como uma espécie de programação sistêmica.

A partir dessas premissas, a Constituição Federal de 1988 foi identificada, já no segundo capítulo, como o ponto de convergência dos processos comunicacionais de toda 
sociedade e de institucionalização de suas expectativas normativas, resultantes do amplo acoplamento estrutural dos sistemas sociais nacionais.

Como possível contribuição do tema à ciência jurídica brasileira, pode ser apontada a incorporação à compreensão da Seguridade Social da função dos programas e princípios constitucionais e do conflito entre as expectativas sistêmicas em matéria de direitos sociais. Nesse sentido, procurou-se problematizar, sob uma diferente perspectiva epistemológica, os desafios à efetivação dos direitos sociais da Seguridade Social através de políticas públicas democráticas e ao mesmo tempo constitucionais.

Isto porque, a tese em questão relacionou as funções desempenhadas pelos meios de comunicação de massa nacionais, na delimitação e difusão das principais questões do citado sistema de proteção social, ao atual estágio de transição da ciência jurídica brasileira para além do paradigma jurídico positivista, fundamentado em sua grande parte nas teorias analítico-formalistas, cujo expoente é a Teoria Pura de Hans Kelsen (1998), caracterizada por uma visão científica do sistema jurídico alheia à sua relação com a sociedade. (ANTUNES, 1989, p. xix).

O positivismo jurídico oriundo dessa orientação restringe a ciência do direito à "análise crítica de afirmações normativas e linguístico-conceituais, deixando boa parte das investigações empíricas e interdisciplinares de lado”. (MAZUREK, 2002, p. 370).

Contudo, manifesta-se a insuficiência desse modelo analítico frente ao grau crescente de complexidade das relações sociais, sobretudo, no que diz respeito ao campo altamente dinâmico e interdisciplinar dos conflitos sociais com o quais se relaciona à Seguridade Social brasileira.

Buscou-se, assim, neste trabalho a reformulação da metodologia de estudo do Direito da Seguridade Social, desenvolvendo-se um modelo capaz de trabalhar, em termos tanto teóricos quanto práticos, suas inter-relações sistêmicas com os demais sistemas sociais, com especial atenção para os conflitos comunicacionais e as tensões sistêmicas em relação às informações e expectativas generalizadas pelos meios de comunicação de massa acerca dos sentidos da Seguridade Social e da forma de atuação do Estado na implementação das políticas públicas correspondentes.

Cumpre, porém, ressaltar que, ao contrário da defesa de uma hipotética supremacia do modelo teórico proposto em relação a outro, esta tese procurou contribuir com originalidade para a ciência jurídica brasileira no sentido de demonstrar a função 
imprescindível da confiança social para a construção da solidariedade e, consequentemente, para a efetivação das políticas públicas de Seguridade Social, sob uma perspectiva interdisciplinar, instrumentalizada através da revisão do pensamento sistêmico luhmanniano sob a ótica constitucional e do Sistema de Seguridade Social, ao mesmo tempo relacionada aos estudos críticos de mídia (FONSECA, 2005; LUHMANN, 2005a; HERMAN; CHOMSKY, 2003; ARBEX JR, 2002; 2003).

Este entendimento foi construído através da interpretação constitucional, bem como da compreensão do novo paradigma científico sistêmico, empreendidas a partir da releitura crítica da Teoria dos Sistemas de Niklas Luhmann (1998), ajustada à evolução histórica dos sistemas sociais brasileiros e à identificação da Constituição Federal de 1988 como o ponto de convergência de seus processos comunicacionais, não restritos, de modo algum, aos sistemas jurídico e político.

Foram, ainda, delimitados neste trabalho os acoplamentos estruturais entre os sistemas econômico, político e dos meios de comunicação de massa, demonstrando-se o decorrente condicionamento da seleção de informações realizada pelas organizações midiáticas brasileiras através dos filtros/programas de notícias presentes em seu processo comunicacional sistêmico.

Como conclusão, foi possível criticar o favorecimento e disseminação pela mídia nacional das expectativas dos sistemas sociais parciais que financiam suas organizações no sentido da redução das políticas públicas de Seguridade Social e do fomento do mercado privado de serviços de saúde, previdência e assistência.

Assim, através da presente tese, discutiu-se como a atual lógica sistêmica dos meios de comunicação de massa delimita seu processo de seleção das informações relativas à saúde, previdência e assistencial social, de modo a reduzir a esfera da opinião pública e instrumentalizar a quebra de confiança no sistema de Seguridade Social brasileiro, solapando a solidariedade, essencial para a construção desse sistema de proteção e para o sucesso de suas políticas públicas. 


\section{TEORIA DOS SISTEMAS SOCIAIS}

A Teoria da Sociedade de Niklas Luhmann (1998), com as seguintes revisões e críticas acerca de seus limites para o estudo da Seguridade Social brasileira iniciado na dissertação de mestrado (CRUZ, 2007) que precede esta tese, constitui a base teórica do presente trabalho em razão de suas potencialidades explicativas sobre as funções dos meios de comunicação de massa e do sistema jurídico nacionais na definição e generalização para toda a sociedade de quais expectativas sociais devem ser mantidas contrafactualmente quanto ao papel do Estado e à abrangência de suas políticas públicas relativas especificamente à implementação do Sistema de Seguridade Social, projetado na Constituição da República Federativa do Brasil de 1988. ${ }^{1}$

Objetiva-se assim, neste capítulo inicial, a partir do estudo preliminar realizado (CRUZ, 2007), delimitar os principais aspectos da compreensão luhmanniana da sociedade como sistema de comunicação para, nas seções seguintes, desenvolver-se o estudo do Direito, em si, como um de seus subsistemas e das inter-relações entre os meios de comunicação de massa e os subsistemas econômicos que operam no mercado privado de saúde, previdência e de serviços parciais de assistência.

A partir dessas questões, espera-se, ao final, comprovar a tese de que essas interrelações sistêmicas promoveriam, em seu processo interno de seleção de informações, certa distorção midiática da realidade, antidemocrática e inconstitucional, no sentido de fomentar a quebra da confiança social no sistema público de proteção social e de generalizar expectativas relativas ao Sistema de Seguridade Social, contrárias àquelas normatizadas em 1988, no processo constitucional de reordenação comunicacional da sociedade brasileira.

\footnotetext{
${ }^{1}$ A opção por essa teoria comunicacional decorre, outrossim, da reestruturação das premissas científicas em que a construção do saber jurídico, enquanto ciência social, não pode se restringir ao idealizado Positivismo científico naturalista, incompatível com a peculiaridade dos objetos de estudo sociais - suas inter-relações; a impossibilidade de sua análise, no sentido técnico de fragmentação e observação do objeto de estudo em partes, a partir das quais se atingiria a compreensão do todo — e da própria relação subjetiva do observador com tais objetos.
} 


\subsection{A visão sistêmica e sua peculiar epistemologia}

A Teoria dos Sistemas Sociais insere-se no pensamento sistêmico, originário das ciências naturais, com destaque para as pesquisas relacionadas ao processo de cognição no domínio da biologia e decorrente ênfase na concepção dos organismos vivos como totalidades integradas nos estudos neurofisiológicos de Humberto Maturana e Francisco Varela (1980, 1997, 2005).

$\mathrm{O}$ pensamento sistêmico teria ainda se expandido, durante o século $\mathrm{XX}$, para diversas áreas do conhecimento, paralelamente aos referidos estudos biológicos, desenvolvendo-se em trabalhos acerca dos padrões de comunicação em laços fechados e em redes, empreendidos por ciberneticistas e pesquisadores de várias áreas, da matemática à neurociência, passando pela engenharia e sociologia, como Heinz von Foerster, George Spencer-Brown e Gottard Günther (LUHMANN, 2009, p. 77-78).

Nesse contexto, os resultados relacionados ao mecanismo de cognição e aos referidos padrões de comunicação propiciaram o questionamento das próprias bases do conhecimento humano e a busca de novos fundamentos para o método científico, cujo fator de validação, a partir de então, não poderia permanecer restrito à observação de um objeto externo ao ser cognoscente.

A extensão desse questionamento epistemológico com a adaptação da teoria sistêmica para o campo das ciências sociais pode ser considerada como traço marcante da evolução científica interdisciplinar do final do século passado, na medida em que alcançou as mais diversas áreas do conhecimento como a linguística, lógica, biologia, física, matemática, cibernética, psicologia, sociologia, ciência política, ética e a ciência jurídica. (ANTUNES, 1989, p. ix).

Não obstante, a efetiva transposição dessa nova teoria sistêmica para o estudo da sociedade como um mecanismo gerador abstrato de uma hipótese teórica explicativa dos sistemas sociais é atribuída por diversos autores ao sociólogo alemão Niklas Luhmann. ${ }^{2}$

\footnotetext{
${ }^{2}$ Nesse sentido, apontam José Engrácia Antunes (1989, p. x), Gunther Teubner (1989b, p. 737), Marcelo Neves (2007, p. 128), Jean Clam (2006, p. 19), Germano Schwartz (2004. p. 27), Fritjof Capra (1996, p. 172), Dário
} 
Como será delimitado a seguir, a partir do sentido de diferença, surgido no âmbito da matemática de George Spencer Brown (1979), reflexividade da consciência de Edmund Husserl e de autopoiese proposto por Maturana e Varela (1980), Luhmann (1998; 2009) procurou reposicionar a sociologia como uma teoria social com pretensões de universalidade, capaz de superar a inexistência "de uma descrição teórica coerente sobre a situação dos problemas da sociedade contemporânea" nas teorias sociológicas de médio alcance em voga até, ao menos, a metade do século XX (LUHMANN, 2009, p. 35).

Propôs, assim, sua Teoria da Sociedade como um modelo teórico alternativo voltado à consideração da complexidade da sociedade moderna, de modo a superar os impasses do método tradicional científico, reduzindo seu distanciamento de discussões transdisciplinares e dos resultados científicos obtidos em outras áreas do conhecimento.

$\mathrm{O}$ referido pensamento sistêmico foi então adaptado às ciências sociais como sistemas autorreferenciais de comunicação, repercutindo numa nova forma de entender as relações entre os sistemas sociais que compõe a sociedade e, por conseguinte, a própria função do direito como sistema. ${ }^{3}$

Para que se possa compreender a dimensão em que se insere o pensamento sistêmico e sua ruptura com o atual paradigma científico, é preciso, inicialmente, tecer algumas considerações sobre suas origens e o contexto cultural no qual se desenvolveu. ${ }^{4}$

Rodríguez Mansilla e Javier Torres Nafarrate (2003, p. 106 e 122), Orlando Villas Bôas Filho (2006a, p. 12 e p. 101), Celso Fernandes Campilongo (2000a, p. 73), dentre outros autores.

${ }^{3}$ Não obstante, inspirado inicialmente nos trabalhos Talcott Parsons (1966; 1974) e em sua peculiar teoria funcional-estruturalista, que segundo Luhmann (2009, p. 58) ofereceria "uma das arquiteturas conceituais mais grandiosas na sociologia contemporânea", seu pensamento distingue-se da Teoria dos Sistemas parsonsiana, na qual, em linhas gerais, destacam-se a tentativa de conciliar uma abordagem sociológica sistêmica à teoria da ação e a definição dos sistemas a partir da adesão coletiva a normas e padrões compartilhados.

${ }^{4}$ A noção de paradigma científico a que nos referimos se relaciona àquela desenvolvida por Thomas S. Kuhn (1989, p. 218), utilizada em sentido mais amplo para designar "toda a constelação de crenças, valores, técnicas etc., partilhadas pelos membros de uma comunidade determinada", correspondendo, em linhas gerais, ao conjunto global de incumbências reconhecidas pelo grupo ou comunidade que pratica a ciência organizada em certos moldes. Em que pese às críticas ao seu uso generalizado e à perda do original sentido, decorrentes de sua transferência para a esfera das Ciências Sociais (ASSIS, 1993), o questionamento proposto por Kuhn (1989) não teve sua importância reduzida enquanto síntese do conjunto de transformações a que o conhecimento científico está sujeito em seu contínuo movimento de (r)evolução. Assim, a despeito das fortes críticas que suas iniciais considerações sobre o tema suscitaram, a pertinência das ideias depreendidas do conceito mais amplo de paradigma teria levado o citado autor a propor o conceito de "matriz disciplinar", tendo em vista diferenciar esse 


\begin{abstract}
Nesse sentido, a ascensão do pensamento sistêmico — introduzido no campo da biologia e posteriormente enriquecido pela psicologia da Gestalt ${ }^{5}$ — situa-se na mudança do paradigma mecanicista para o ecológico, a partir da década de 1920, ocorrida de forma não uniforme em diversos campos científicos, tendo por tensão básica a dicotomia entre as partes e o todo. ${ }^{6}$
\end{abstract}

"sentido amplo" do "sentido preciso" e inicialmente proposto de paradigma, de modo que desse novo conceito se podem depreender quatro elementos: (i) generalizações simbólicas; (ii) partes metafísicas do paradigma; (iii) exemplares (que representariam o próprio paradigma em seu sentido preciso), e, por fim, (nem por isso menos importante) (iv) valores. Não cabe ao presente estudo aprofundar a explicação e implicações desses quatro elementos, sendo, por ora, relevante apenas destacar o seu impacto na compreensão do sistema social "ciência", responsável pela "observação de segunda ordem" dos demais sistemas sociais na concretização dos processos sobrecomunicacionais que compõem as operações de observação dos sistemas autopoiéticos (NEVES, 2005, p. 36-38). Nessa específica questão, se insere a noção kuhniana de paradigma, mais especificamente, de seu elemento "valor", posto que, segundo o destaque de Simone Petraglia Kropf e Nísia Trindade Lima (1999), "[...] este último elemento [valorativo] é, para Kuhn, o que confere o sentido de pertencimento dos cientistas a uma comunidade global e específica, garantindo o compromisso profundo destes com uma determinada maneira coletiva de praticar a ciência. A ideia de valores como elementos que legitimam o cumprimento de um conjunto de normas é, portanto, de fundamental importância para compreender-se de que maneira Kuhn concebe a ciência normal como atividade de pesquisa fundada numa sólida rede de compromissos e adesões a um paradigma compartilhado por uma determinada comunidade de praticantes da ciência". Nesse sentido, embora ainda estejamos vivendo um período de transição em que o paradigma mecanicista em sua vertente positivista esteja sendo fortemente questionado, sem, contudo, se ter consolidado um novo paradigma, é justamente pela propositura de novos valores a que, especialmente, o direito está condicionado - do ponto de vista da efetivação dos valores e princípios constitucionais que são inerentes a este trabalho - que a teoria dos sistemas, desde que readaptada para cumprir essa específica função explicativa, nos afigura como uma "escola de pensamento" (embora não se possa falar da existência de apenas uma única, ou dominante corrente sistêmica) que compete fortemente para esse processo de ruptura.

${ }^{5}$ O significado do termo Gestalt, em si, é de grande valia para a compreensão de como a ruptura com o paradigma cientifico em discussão se estende pelos diversos campos do conhecimento. Segundo Mapheus Smith (1974, p. 150), trata-se de "palavra alemã que significa forma. Exprime-se, por ela, um todo indiviso e articulado, composto de partes interdependentes. O todo está formado por integração, mais do que por simples adição das partes. Cada parte é um membro do todo e a natureza da parte depende do fato de pertencer ao todo". Ademais, tal conjunto de ideias é muito utilizado no campo da psicologia, como concepção básica da escola psicológica chamada Gestalt. Insere-se, pois, no movimento da Gestalt, que conforme explica Frederich W. Killian (1974, p. 150), corresponde ao "método de estudo dos fenômenos no campo das Ciências Sociais cuja particular aspiração consiste em encontrar nos fenômenos de massa, todos coerentes, funcionais e plenos de sentido, bem como estudar a conduta dêsses todos, e a das partes que o constituíam, e as relações entre as partes e os todos. [...] Como movimento dentro das Ciências Sociais, o método da Gestalt foi iniciado pela primeira vez no campo da Psicologia, à altura de 1895, por Carlos von Ehrenfelds, na Alemanha [...]".

${ }^{6}$ A ênfase nas partes tem sido chamada de mecanicista, reducionista ou atomística, ao passo em que a ênfase no todo, de holística, organísmica ou ecológica, sendo que esta perspectiva holística, na ciência do século XX, tornou-se conhecida tecnicamente como sistêmica. (CAPRA, 1996, p. 33). A importância dessa mudança de paradigma não se resume às ciências biológicas ou naturais, sendo destacada no presente estudo por suas repercussões em toda a base filosófica e analítica que sustenta o pensamento científico ocidental e, por conseguinte, as ciências sociais e jurídicas. Assim, conclui enfaticamente Fritjof Capra (1996, p. 41): "A emergência do pensamento sistêmico representou uma profunda revolução na história do pensamento científico ocidental. A crença segundo a qual em todo sistema complexo o comportamento do todo pode ser entendido 
Foi justamente nesse novo contexto científico, que o sociólogo alemão Niklas Luhmann (1927-1998) dedicou-se, em quase três décadas de trabalho acadêmico, para a construção de uma (nova) teoria da sociedade moderna, que fosse capaz de reposicionar a sociologia, enquanto ciência, como a Teoria da Sociedade. ${ }^{7}$

O referido autor teria, assim, se afastado da sociologia alemã vigente no começo do século XX, cuja identidade esconderia sua relação com a sociedade, em razão de sua inclinação para o objetivismo empirista das ciências naturais, "com sua ênfase na causalidade e na descoberta de leis", centrando sua estrutura conceitual básica numa insuficiente "teoria de entidades sociais, com categorias tais como papéis, interação, intenção e ação social" (BECHMANN; STEHR, 2001, p. 187).

Ademais, segundo Gotthard Bechmann e Nico Stehr (2001, p. 191), além de romper com o referido paradigma centrado na relação "sujeito-objeto", própria da metodologia científica clássica, Luhmann teria, também, se distanciado da "velha tradição europeia teórica ontológica" que seria insuficiente "para captar a sociedade moderna em toda sua complexidade", de modo que a unidade deixaria de ser "o ponto de referência definitiva" de

inteiramente a partir das propriedades de suas partes é fundamental no paradigma cartesiano. Foi este o célebre método de Descartes do pensamento analítico, que tem sido uma característica essencial do moderno pensamento científico. $\mathrm{Na}$ abordagem analítica, ou reducionista, as próprias partes não podem ser analisadas ulteriormente, a não ser reduzindo-as a partes menores. De fato, a ciência ocidental tem progredido dessa maneira, e em cada passo tem surgido um nível de constituintes fundamentais que não podia ser analisado posteriormente. $\mathrm{O}$ grande impacto que adveio com a ciência do século XX foi a percepção de que os sistemas não podem ser entendidos pela análise. As propriedades das partes não são propriedades intrínsecas, mas só podem ser entendidas dentro do contexto do todo mais amplo. Desse modo, a relação entre as partes e o todo foi revertida. Na abordagem sistêmica, as propriedades das partes podem ser entendidas apenas a partir da organização do todo. Em consequência disso, o pensamento sistêmico concentra-se não em blocos de construção básicos, mas em princípios de organização básicos. O pensamento sistêmico é 'contextual', o que é o oposto do pensamento analítico. A análise significa isolar alguma coisa a fim de entendê-la; o pensamento sistêmico significa colocá-la no contexto de um todo mais amplo."

${ }^{7}$ A dimensão da obra de Luhmann é considerada por certos autores como uma "[...] superteoria, com pretensões de universalidade, valer dizer, que reclama aplicabilidade para todo fenômeno social”. O que não implicaria, de forma alguma, a exclusão de outras teorias explicativas do fenômeno social, nem mesmo a impossibilidade de um diálogo interdisciplinar entre elas: “[...] Esta pretensão de universalidade não deve ser entendida, no entanto, com a intenção de excluir outras possibilidades de interpretações teóricas que — desde a própria sociologia até outras disciplinas; desde a ciência ou outros subsistemas da sociedade — possam levantar-se com alternativas. Pelo contrário, a teoria dos sistemas de Niklas Luhmann tem se constituído em diálogo constante com diferentes esforços conceitualizadores provenientes da filosofia, sociologia, lógica formal, do direito, teologia, biologia, física etc." (RODRÍGUEZ; TORRES, 2003, p. 107). 
sua teoria da sociedade passando a ser destacada a consideração da diversidade e da dispersão das identidades. ${ }^{8}$

Embora venha a ser discutido mais à frente, cumpre desde já assinalar que a estas profundas rupturas conceituais não ficaram imunes as possíveis formas de se compreender o Direito, abrindo-se não apenas novos espaços de saber-poder (FOUCAULT, 1997) — que o envolve enquanto prudência-, como também a oportunidade de se compreender sua dinâmica, seus limites e suas possibilidades relacionadas ao cumprimento de sua função principiológica e valorativa constitucional, para além de sua mera constitucionalização simbólica (NEVES, 2007), em face da complexa conformação das relações (comunicacionais) internas à sociedade e desta com seu ambiente. ${ }^{9}$

\footnotetext{
${ }^{8}$ Sobre a inflexão e ruptura com a tradição europeia teórica ontológica por Niklas Luhmann, Gotthard Bechmann e Nico Stehr (2001, p. 191-192) entendem que: “[...] Ele [Luhmann] caracteriza o velho estilo europeu de pensamento pela preocupação com a identificação de unidade sob a diversidade. A sociedade, na visão clássica, consiste de sujeitos de ação cuja unidade fundamental baseia-se na partilha de um entendimento comum. A ontologia refere-se a um mundo existindo objetivamente, separado dos sujeitos que são conscientes de sua existência e capazes de uma representação linguística não ambígua. Contra isso, Luhmann apresenta um mundo que temporaliza, diferencia e descentraliza todas as identidades. Identidades são produtos de eventos passados. A unidade não mais é o ponto de referência definitivo da teoria. Quando ele relativiza até o esquema ontológico da existência/ não existência como apenas um dos muitos esquemas observáveis, Luhmann ataca as bases de poderosas tradições do pensamento. O paradoxo, de acordo com ele, é que a velha tradição europeia emergiu numa sociedade que, hoje, não existe mais, seja em termos de sistema de comunicação ou em termos de formas de diferenciação. [...] [Sendo assim, sua] teoria da sociedade está localizada em dois níveis: no nível semântico ela se distingue da velha tradição europeia, enquanto no nível da estrutura social faz-se referência à evolução, diferenciação e ao desenvolvimento da mídia”. No mesmo sentido, se posicionam Dário Rodríguez e Javier Torres (2003, p. 125): "A dimensão da qual se depreende que a sociedade seja uma ordem emergente autopoiética deve ser sopesada com todo cuidado, já que contradiz toda a tradição filosófica e sociológica que se sustenta na conceituação do sujeito [...] Desde o momento em que Luhmann opta pela conceituação de autopoiesis, rompe com a tradição de pensamento europeu”. Já Rômulo Figueira Neves (2005), ao dissertar sobre Luhmann e a tradição sociológica, embora contemporize com os demais autores acima citados interpretando a teoria luhmanniana como uma "tentativa de superar os déficits da capacidade da tradição sociológica na explicação da sociedade [em sua modernidade e em face da complexidade das novas formas de relações sociais emergentes]", por sua vez, acrescenta que tal distanciamento "não significa que ele [Luhmann] não tenha tido conhecimento e domínio das teorias clássicas, mas sim que a elaboração da teoria dos sistemas sociais não pode ser tributada a um diálogo específico com este ou aquele autor, apesar de ser possível realizar uma análise genética e identificar algumas aproximações com diversos deles" (NEVES, 2005, p.10).

${ }^{9}$ As referências a Michel Foucault e às relações entre poder e saber por ele desvendadas em A Arqueologia do Saber (1997), se fazem não no sentido de negar, ou de menosprezar, sua profícua discussão acerca das "verdades científicas" enquanto produtos de um sistema de poder vigente em determinado período. Justamente por considerar tais estudos que denunciam a possibilidade (comprovada historicamente) da validação do conhecimento científico remeter a uma questão de poder, na medida em que este determinaria os enunciados científicos como verdadeiros ou falsos em uma época, é que, justamente, defende-se, aqui, a necessidade do estudo crítico desse novo paradigma científico sistêmico em vias de consolidação (mais do que sua simples negação ou a sua adesão modista e acrítica), por meio de sua confrontação com a evolução dos direitos sociais,
} 


\subsubsection{Características essenciais do pensamento sistêmico}

Dada suas rupturas epistemológicas e importantes distinções conceituais, antes de se iniciar o detalhamento da visão sistêmica luhmanniana da sociedade e do direito, faz-se necessário considerar alguns aspectos gerais das teorias sistêmicas relacionados especificamente ao estudo dos sistemas vivos e dos mecanismos de cognição (teoria biológica do conhecimento) para, em seguida, serem abordadas suas possíveis implicações e desdobramentos no campo das ciências sociais.

Como fora adiantado, as origens do pensamento sistêmico remontam às pesquisas desenvolvidas durante todo o século XX por biólogos organísmicos e ciberneticistas de diversas áreas do conhecimento "preocupados com um diferente nível de descrição, concentrando-se em padrões de comunicação, e especialmente em laços fechados e em redes" (CAPRA, 1996, p. 56).

Dentre esses estudos, destaca-se o considerável avanço na compreensão dos sistemas vivos a partir de dois questionamentos centrais: "qual é a organização da vida?" e "o que ocorre no fenômeno de percepção?” (MATURANA; VARELA, 1980, p. xii).

A partir dessas indagações e com o auxílio de Francisco J. Varela, o neurocientista chileno Humberto R. Maturana (1980) pode desenvolver a concepção de organização circular, denominando-a inovadoramente de autopoiese - termo que passou a ser amplamente difundido nas mais diversas áreas do conhecimento - e, posteriormente, em resposta à segunda questão citada, formular sua Teoria da Cognição de Santiago.

Essa teoria marcou o desenvolvimento dos estudos biológicos do conhecimento, graças à constatação empírica da impossibilidade de se distinguir entre ilusão e percepção em meio a experiências, que levou Humberto R. Maturana (1996, p. 30) à desafiadora afirmação

no qual despontam a Seguridade Social, de modo a influir, de alguma forma, na disseminação e reelaboração desse conhecimento, reduzindo, consequentemente, o poder e, quem sabe, os riscos sociais, que se concentrariam com a persistência da distorção midiática de seus sentidos e de seu abandono à formulação por teóricos atualmente alheios à luta diária pela concretização dos direitos sociais — tão sujeita às tensões com os demais sistemas sociais como o econômico e o político. Busca-se, assim, aferir as possibilidades de sua utilização como uma teoria de resistência do Direito contra os extrapolamentos das próprias fronteiras sistêmicas (sua alopoiese) e as hodiernas tentativas de subversão de sua lógica operativa interna por outros subsistemas sociais que, dessa forma, obstam a sua efetivação. 
de que "as explicações científicas não explicam um mundo independente, explicam a experiência do observador". ${ }^{10}$

Reforçou-se, desse modo, o profundo questionamento dos fundamentos do conhecimento humano e a busca de uma nova base para o método científico, cujo fator de validação não mais se centrasse na observação de um objeto externo.

O conceito de autopoiese assumiria, assim, uma "radicalidade explosiva" ao questionar uma série de "certezas" com que se atua na sociedade contemporânea, propondo a sua reconsideração a partir de "outra perspectiva possível". ${ }^{11}$

Nesse contexto, tem-se observado certo deslocamento da atenção dos cientistas das partes para o todo, conformando certo modo de pensar contextual, característico do pensamento sistêmico, qual seja, a compreensão de que os sistemas vivos, enquanto totalidades integradas, possuem propriedades essenciais que nenhuma das partes possui.

Esse pensamento contextual rompe, portanto, com a crença cartesiana na análise das propriedades das partes para se atingir a compreensão do comportamento do todo em qualquer sistema complexo. Destaca-se, nesse ponto, que tal mudança "das partes para o todo" implica uma considerável mudança de foco de objetos para relações. ${ }^{12}$

Outra característica do pensamento sistêmico diz respeito à "capacidade de deslocar a própria atenção de um lado para o outro entre níveis sistêmicos”, sendo possível

\footnotetext{
${ }^{10}$ Cumpre ainda destacar que, no sentido kuhniano de paradigma (KUHN, 1989), além do aspecto reflexivo do conhecimento construído pelo observador, do ponto de vista de sua própria externalização, uma "explicação é sempre uma proposição que reformula ou recria as observações de um fenômeno, num sistema de conceitos aceitáveis para um grupo de pessoas que compartilham um critério de validação". (MATURANA; VARELA, 2005, p. 34).

${ }^{11}$ Observe-se, que tal proposta - enquanto alternativa para a compreensão da forma e dos limites envolvidos na interpretação da realidade - se justifica, por si só, justamente por ser uma "outra perspectiva possível", e não tanto por um hipotético juízo valorativo, não aferível, que a elegeria como "a melhor" teoria do conhecimento (RODRÍGUEZ; TORRES, 2003, p. 110).

${ }^{12}$ Seria, assim, vencida a visão mecanicista do mundo enquanto uma coleção de objetos, na medida em que, na visão sistêmica compreende-se que os próprios objetos são redes de relações, inseridas em redes maiores, sendo por tal razão o pensamento sistêmico também denominado pensamento em rede (vernetztes Denken). (CAPRA, 1996, p. 47).
} 
encontrar, por toda parte, sistemas "aninhados" dentro de outros sistemas, sendo tais diferentes níveis representações de diferentes complexidades (CAPRA, 1996, p. 46). ${ }^{13}$

Essa nova abordagem do pensamento sistêmico implica fortes abalos na estrutura do conhecimento científico, especialmente se for considerada a metáfora do conhecimento, vigente por milhares de anos e até hoje predominante entre os cientistas e filósofos ocidentais, que associa o conhecimento a um edifício. ${ }^{14}$

Segundo Fritjof Capra (1996, p. 58), essa nova noção do conhecimento científico estaria substituindo a metáfora do conhecimento como um "edifício" pela metáfora da "rede", assim entendida como um conjunto de concepções e de modelos em que nenhuma parte ou propriedade é mais fundamental do que as outras, mas todas resultantes das propriedades das outras partes, sendo a consistência global de suas inter-relações determinante da estrutura de toda a "teia da vida". 15

${ }^{13}$ Observe-se, ainda, que não haveria uma relação de hierarquia entre esses níveis, mas, sim, de interdependência, sendo que, em cada nível, os fenômenos observados demonstram propriedades que não existem em níveis inferiores, as quais são denominadas "propriedades emergentes", pois surgem nesse nível em particular. (CAPRA, 1996, p. 46).

${ }^{14}$ Daí falar-se em "leis fundamentais", "princípios fundamentais", sendo sempre afirmado que o "edifício" da ciência deve ser construído sobre "alicerces" sólidos. (CAPRA, 1996, p. 47). Não obstante, cumpre ressaltar, neste trabalho, a continuidade e a pertinência do emprego de termos como "leis fundamentais" e "princípios fundamentais", tão caros ao Constitucionalismo Social, que, aparentemente, "deveriam" ser abandonadas em face da criticada metáfora do conhecimento como edificio, há que se ter em mente que, pelo contrário, os mesmos serão reafirmados e mantidos neste trabalho levando-se em conta seu distinto significado em direito, uma vez incorporados à sua linguagem e ao seu processo comunicativo auto-referencial, portanto não apenas inseridas na explicação teórica do direito, fruto de sua observação externa e "científica", mas propriamente organizacional e auto-reprodutivo decorrente da diferenciação do próprio sistema jurídico. Assim, ao tratarmos de suas especificidades como, por exemplo, de seu acoplamento estrutural com os demais sistemas sociais, e, do ponto de vista de seu fechamento operacional, da função peculiar desempenhada pelos princípios na interpretação constitucional dos direitos sociais, enquanto "direitos fundamentais", será possível a compreensão do redimensionamento que se pretende dar a essa terminologia, sem deixar de considerar a referida substituição dessa forma de entender a estruturação das inter-relações dos sistemas vivos e sociais (comunicacionais) expressa pela transição da metáfora do conhecimento como edifício (hierarquia) para a da rede, visto que o nível jurídico dos princípios fundamentais, bem como dos direitos e garantias fundamentais de nossa sociedade, corresponderia, grosso modo, a uma espécie de tratamento diferenciado da elevada complexidade social a que o direito não pode se eximir de responder em fase da autopoiese do sistema jurídico brasileiro.

${ }^{15}$ As limitações e problemas decorrentes da compreensão dos sistemas a partir da ideia de rede serão detidamente considerados ao tratarmos, mais à frente, das críticas a que está sujeita a teoria autopoiética dos sistemas sociais. Nesse sentido, cumpre salientar que a extensão dessa concepção de rede e a substituição das relações hierárquicas por relações de interdependência (não apenas entre os sistemas, mas também no interior de boa parte deles) será em certa medida relativizada ao se tratar da autopoiese dos sistemas sociais, especialmente do sistema jurídico, restringindo-se esta parte inicial do capítulo à descrição da evolução do pensamento sistêmico em suas linhas gerais. 
Porém, deve-se, desde já, destacar que de tais considerações não se pode depreender, de forma alguma, uma total horizontalização das "inter-relações" sistêmicas, quer sejam biológicas e/ou sociais.

Mesmo sob esse novo enfoque relacional se, de um lado, não é possível sua redução a uma abordagem meramente hierárquica, de outro, não implica, todavia, em sua total horizontalização justamente por ser reconhecida a possibilidade de diferenciação sistêmica em graus e níveis diversos de complexidade, permanecendo circularmente interligados em contínuas e recíprocas inter-relações.

Tem-se, portanto, que uma importante consequência dessa visão da realidade como uma rede inseparável de relações consiste na mencionada ruptura do paradigma científico cartesiano, na medida em que questiona a concepção tradicional de objetividade científica até mesmo no campo das ciências naturais, as quais não podem mais prescindir da epistemologia, que, por sua vez, passa a ser parte integral das teorias científicas. ${ }^{16}$

Por fim, acerca das características essenciais do pensamento sistêmico, devem ainda ser consideradas algumas peculiaridades, no pensamento sistêmico, das ideias de padrão, estrutura e processo uma vez constituem as principais características do fenômeno de auto-organização em diversos sistemas, imprescindíveis para a formulação de uma teoria unificada dos sistemas vivos (CAPRA, 1996, p. 79).

Esse novo arcabouço conceitual desenvolveu-se, sobretudo, nas décadas de 1970 e 1980, graças ao trabalho de pesquisadores de vários países e de diversas áreas, como Ilya Prigogine na Bélgica; Hermann Haken e Manfred Eigen na Alemanha; James Lovelock na Inglaterra; Lynn Margulis nos Estados Unidos da América do Norte, e Humberto R. Maturana e Francisco J. Varela no Chile.

\footnotetext{
${ }^{16}$ Elucidativas são as seguintes observações de Humberto R. Maturana e Francisco J. Varela (2005, p. 265) no sentido de que "[...] De nossas heranças linguísticas diferentes surgem todas as diferenças de mundos culturais, que como homens podemos viver e que, dentro dos limites biológicos, podem ser tão diversas quanto se queria. [sendo que] Todo conhecer humano pertence a um desses mundos e é sempre vivo numa tradição cultural". Nesse sentido, pode ainda ser citada a conclusiva afirmação de Fritjof Capra (1996, p. 49): "No novo paradigma, é reconhecido que todas as concepções e todas as teorias científicas são limitadas e aproximadas. A ciência nunca pode fornecer uma compreensão completa e definitiva".
} 
Nesse contexto, a concepção de auto-organização originou-se do reconhecimento da rede como o padrão geral de organização da vida. ${ }^{17}$

Quanto à estrutura de um sistema vivo, esta consiste na incorporação física dos componentes daquele padrão de organização citado. ${ }^{18}$

Haveria, nestes termos, uma junção entre a tradicional dicotomia entre substância (matéria, estrutura, quantidade) e forma (padrão, ordem, qualidade), presente em toda a história da filosofia e das ciências ocidentais. (CAPRA, 1996, p. 33).

Desse modo, ao menos no âmbito dos sistemas biológicos, o padrão de organização corresponde ao mapeamento abstrato de relações, ao passo em que a estrutura consiste nos componentes físicos efetivos do sistema, ou seja, em matérias, composições químicas, que o integram.

Por sua vez, o terceiro componente relacionado à compreensão dos sistemas vivos denomina-se "processo vital", sendo entendido como a atividade envolvida na contínua incorporação do padrão de organização dos sistemas à sua estrutura dissipativa. (CAPRA, 1996, p. 134).

Em razão desse processo, nos sistemas vivos, torna-se possível que seus componentes mudem continuamente através de um fluxo incessante de matéria, diferentemente do que ocorre com máquinas e outros sistemas fechados, caracterizados por meio de uma estrutura de componentes fixos. ${ }^{19}$

\footnotetext{
${ }^{17}$ Nesse sentido, acrescenta Fritjof Capra (1996, p. 134) que o "padrão de organização de qualquer sistema vivo ou não vivo, é a configuração de relações entre os componentes do sistema que determinam as características essenciais desse sistema".

${ }^{18}$ Segundo Humberto R. Maturana e Francisco J. Varela (2005, p. 54): "Entende-se por organização as relações que devem ocorrer entre os componentes de algo, para que seja possível reconhecê-lo como membro de uma classe específica. Entende-se por estrutura de algo os componentes e relações que constituem concretamente uma unidade particular e configuram sua organização".

${ }^{19}$ De acordo com os estudos de Ludwig von Bertalanffy (1968, p. 121), biólogo vienense, os sistemas vivos seriam sistemas abertos, pois necessitam se alimentar de um contínuo fluxo de matéria e de energia extraída do seu meio ambiente para permanecerem vivos.
} 


\subsubsection{A concepção biológica de autopoiese e sua compreensão inicial de sociedade}

A palavra autopoiese foi empregada pelo neurocientista Humberto R. Maturana (1980) como um novo termo técnico para se referir aos resultados de seus estudos relacionados à organização característica dos sistemas vivos. ${ }^{20}$

Em suas investigações sobre a percepção da cor, pode concluir que o sistema nervoso funciona como uma rede fechada de interações, nas quais cada mudança das relações interativas entre certos componentes implica, por conseguinte, numa mudança de suas demais relações interativas ou das relações de outros componentes. ${ }^{21}$

Tais resultados levaram Maturana (1980) a responder os dois questionamentos centrais de seu estudo dos sistemas vivos, anteriormente citados: "Qual é a organização da vida?" e "O que ocorre no fenômeno de percepção?".

Pressupôs, assim, que essa organização circular do sistema nervoso é a organização básica de todos os sistemas vivos, podendo concluir, nesse sentido, que a organização dos sistemas vivos se dá num processo circular causal fechado que considera a mudança evolutiva no modo como a circularidade é mantida, sem, contudo, permitir a perda da própria circularidade global de rede, sendo esta a organização, ou "padrão", básico da vida. $^{22}$

${ }^{20}$ A respeito da centralidade dos estudos de Humberto R. Maturana para a formulação do conceito base de autopoiese convergem diferentes autores: Niklas Luhmann (1995, 2009), Gunther Teubner (1989a, 1989b), Gotthard Bechmann e Nico Stehr (2001), Marcelo Neves (2007), Fritjof Capra (1996), Celso Fernandes Campilongo (2000a, 2000b, 2002), , Dário Rodríguez; Javier Torres (2003), Germano Schwartz (2004), dentre outros.

${ }^{21}$ Nesse sentido, segundo o próprio Maturana e Varela (2005, p. 183): "Sob esse ângulo, é evidente que o sistema nervoso pode ser definido, no que se refere à sua organização, como dotado de uma clausura operacional. Isto é, está constituído de tal maneira que, quaisquer que sejam suas mudanças, elas geram outras modificações dentro dele mesmo. Assim, seu modo de operar consiste em manter certas relações entre seus componentes invariantes diante das perturbações que geram, tanto na dinâmica interna quanto nas interações do organismo de que faz parte. Em outras palavras, o sistema nervoso funciona como uma rede fechada de mudanças de relações de atividade entre seus componentes."

${ }^{22}$ Nas palavras do referido pesquisador chileno: “[...] A característica mais peculiar de um sistema autopoiético é que ele se levanta por seus próprios cordões, e se constitui como diferente do meio por sua própria dinâmica, de tal maneira que ambas as coisas são inseparáveis. O que caracteriza o ser vivo é sua organização autopoiética. Seres vivos diferentes se distinguem porque têm estruturas distintas, mas são iguais em organização." (MATURANA; VARELA, 2005, p. 55). 
Por sua vez, a segunda conclusão a que chegou Maturana (1980) foi também essencial para fechar seu conceito inovador de autopoiese. Isto porque, do fechamento circular do sistema nervoso, depreendeu uma compreensão inovadora de cognição.

Tem-se, assim, que o sistema nervoso não é somente auto-organizador, mas também continuamente autorreferente, sendo que a percepção não pode ser vista como a representação de uma realidade externa, mas deve ser entendida como a criação contínua de novas relações dentro da rede neural.

A percepção e a cognição não representariam uma realidade exterior, mas sim especificariam uma realidade por meio do processo de organização circular do sistema. ${ }^{23}$

Com base nestes postulados e com a ajuda de Francisco J. Varela, na década de 70, Maturana formulou uma descrição mais completa dessa concepção de organização circular, denominando-a autopoiese (autocriação), a partir da junção dos termos auto, que significa "si mesmo" e se refere à autonomia dos sistemas auto-organizadores, e poiese, que compartilha a mesma raiz grega com a palavra "poesia" e significa "criação", "produção" (MATURANA; VARELA, 1980, p. XVII).

Firmou-se, então, uma estreita relação entre autopoiese e teoria do conhecimento sendo possível, a partir dessas teorias biológicas de Maturana e Varela (1980; 2005), desvendar-se possíveis armadilhas do conhecimento presentes na teoria clássica, na disputa histórica entre racionalismo versus empirismo (representacionismo). ${ }^{24}$

\footnotetext{
${ }^{23}$ Daí porque afirmam os referidos neurocientistas: "O que dissemos mostra que o funcionamento do sistema nervoso é plenamente consistente com sua participação numa unidade autônoma, na qual todo estado de atividade leva a outro estado de atividade nela mesma, dado que seu modo de operar é circular, ou em clausura operacional. Portanto, por sua própria arquitetura, o sistema nervoso não viola, e sim enriquece, esse caráter autônomo do ser vivo. Começam a tornar-se claros os modos pelos quais todo processo de conhecer está necessariamente baseado na organização como uma unidade no fechamento operacional do sistema nervoso. Daí se segue que todo conhecer é fazer, como correlações sensório-efetoras nos domínios de acoplamento estrutural em que existe o sistema nervoso.” (MATURANA; VARELA, 2005, p. 185).

${ }^{24}$ Nesse sentido, tem-se, em linhas gerais, que para a corrente racionalista, o conhecimento não poderia partir da imediatez da realidade, senão de um processo eminentemente dedutivo, isento de paradoxos, que se desenvolve por meio de conceitos iniciais e axiomas. Por sua vez, para o empirismo, de maneira radicalmente contrária, prevalece o entendimento de que a realidade é que decidiria o que é verdadeiro ou falso, sendo a verdade, presente nos dados brutos do mundo fenomênico, aclarada através de um método experimental rigoroso. (RODRÍGUEZ; TORRES, 2003, p. 118).
} 
Dentre as "armadilhas do conhecer", apontadas na crítica ao racionalismo, estaria o abandono do conhecimento à ameaça do caos e da arbitrariedade em face da obscura interioridade das possibilidades do pensamento, posto que sobre este não existiria um controle imediato da certeza. Tal postura, porém, tende a negar o meio circundante e a supor que o sistema nervoso funciona totalmente no vazio, reduzindo a sua clausura operativa ao "extremo da solidão cognitiva absoluta, ou solipsismo (da tradição filosófica clássica, que afirmava que só existe a interioridade de cada um)". Portanto, se torna incapaz de "explicar a adequação ou comensurabilidade entre o funcionamento do organismo e o de seu mundo" (MATURANA; VARELA, 2005, p. 149- 150).

Outra armadilha do conhecimento estaria na crença oposta de que o mundo dos objetos pode dar instruções ao conhecimento, sendo inexistente um mecanismo que confirme tal pretensão. Tal se afigura na medida em que esta posição empirista pressupõe que o sistema nervoso trabalhe com representações do mundo, considerando-o "um instrumento por meio do qual o organismo obtém informações do ambiente, que a seguir utiliza para construir uma representação do mundo que lhe permita computar um comportamento adequado à sua sobrevivência nele" quando, de fato, as pesquisas em neurofisiologia demonstram que o modo de operar do sistema nervoso está determinado, em cada momento, por sua interna clausura operacional, sendo que "a estrutura do meio não pode especificar suas mudanças, mas sim apenas desencadeá-las”. (MATURANA; VARELA, 2005, p. 146-147).

Frente a essa disputa, os autores citados propõe a superação de tais contradições aparentes, deixando o plano da oposição para se modificar a própria natureza da pergunta e, dessa forma, reposicioná-la em um contexto mais abrangente, fundado na distinção entre operação/observação. (MATURANA; VARELA, 2005, p. 150).

Destacam-se, nessa nova abordagem, as interações entre o "sistema observado" cujas operações internas se pretende descrever e relacionar às inter-relações específicas desse sistema com seu ambiente e seu acoplamento estrutural com os demais sistemas vivos - e o 
próprio "sistema observador", por exemplo, do cientista que se dedica ao "conhecimento" daquele "objeto". ${ }^{25}$

Cumpre frisar que a perspectiva revelada pelos estudos citados aumentam a complexidade em torno da compreensão das possibilidades acerca da percepção humana, sendo imprescindível para o entendimento da nova epistemologia, a partir da qual se desenvolve toda teoria sistêmica luhmanniana, a seguir detalhada.

A distinção entre "operação/observação" introduz ao "observador" todo um conjunto de novas inter-relações (internas e externas), posto que o mesmo apresenta-se como um sistema autopoiético próprio que processará os dados (entendidos como estímulos e não os elementos da realidade em si) apreensíveis do seu ambiente (no caso em questão: o sistema observado e suas relações com o entorno), com a peculiaridade de assim atuar a partir dos próprios elementos internos à sua rede neural e ao seu sistema de consciência - linguístico emergente do sistema metacelular que é o ser humano, sem contar o seu próprio acoplamento estrutural, em termos de sistemas sociais comunicativos, com o sistema científico.

25 Deve-se frisar que, embora se fale em "observação" e se faça a distinção entre "sistema observado" e "sistema(s) observador(es)" - no caso desses últimos, sistemas psíquico do pesquisador e social científico com que se relacionam —, não se quer com isso reduzir esse modelo ao já criticado positivismo científico naturalista, centrado na completa separação entre sujeito-objeto. A esse respeito esclarecem Humberto R. Maturana e Francisco J. Varela (2005, p. 150-151): "Na realidade, a situação é simples. Como observadores, podemos ver uma unidade em domínios diferentes, a depender das distinções que fizermos. Assim, por um lado podemos considerar um sistema no domínio de funcionamento de seus componentes, no âmbito de seus estados internos e modificações estruturais. Partindo-se desse modo de operar, para a dinâmica interna do sistema o ambiente não existe, é irrelevante. Por outro lado, também podemos considerar uma unidade segundo suas interações com o meio, e descrever a história de suas inter-relações com ele. Nessa perspectiva — na qual o observador pode estabelecer relações entre certas características do meio e o comportamento da unidade — a dinâmica interna desta é irrelevante. Nenhum desses dois domínios possíveis de descrição é problemático em si. Ambos são necessários para o pleno entendimento de uma unidade. É o observador quem os correlaciona a partir de sua perspectiva externa. É ele quem reconhece que a estrutura do sistema determina suas interações, ao especificar que configurações do meio podem desencadear no sistema mudanças estruturais. É ele quem reconhece que o meio não específica ou instrui as mudanças estruturais do sistema. O problema começa quando passamos, sem perceber, de um domínio para o outro, e começamos a exigir que as correspondências que podemos estabelecer entre eles - pois podemos ver os dois ao mesmo tempo - façam de fato parte do funcionamento da unidade: nesse caso, o organismo e o sistema nervoso. Se mantivermos límpida a nossa contabilidade lógica, essa complicação se dissipará. Tomaremos consciência dessas duas perspectivas e as relacionaremos num domínio mais abrangente por nós estabelecido. Dessa maneira, não precisaremos recorrer às representações nem negar que o sistema nervoso funciona num meio que lhe é comensurável, como resultado de uma história de acoplamento estrutural". 
Com os avanços científicos citados, propiciados em parte pela própria cosmologia cartesiana e o desafio de seus limites, atinge-se, paradoxalmente, a sua própria superação. Os subjetivismos e suas decorrentes arbitrariedades que se pretendia afastar da ciência através do método positivista podem e devem agora ser incorporados ao campo científico como condição (ou elemento) próprio de seu funcionamento cogniscente.

Retomando as distinções entre os três critérios essenciais e interdependentes para a compreensão da teoria dos sistemas vivos e sua repercussão na própria teoria do conhecimento, graças principalmente aos estudos de Humberto R. Maturana e Francisco J. Varela (2005): “estrutura, padrão de organização e processo vital”.

Dessa forma, é possível acrescentar que o pensamento sistêmico, ao menos em sua origem, relaciona-se ao estudo e diferenciação dos sistemas vivos, às bases biológicas da compreensão humana e na coordenação entre as ideias de autopoiese, enquanto padrão de organização dos sistemas vivos, circular, auto-organizador e autorreferente; estrutura dos sistemas vivos e processo vital, neste incluídos a dinâmica de suas interações (acoplamentos estruturais) e as demais relações desses sistemas com o seu ambiente.

Por sua vez, a extensão da autopoiese biológica ao campo das ciências sociais é apontada como uma "nova revolução coperniciana" e como traço marcante da evolução científica interdisciplinar das últimas décadas, sobretudo a partir da década de 1980, abrangendo as mais diversas áreas do conhecimento como a linguística, lógica, biologia, física, matemática, cibernética, psicologia, sociologia, ciência política, ética e a ciência jurídica. (ANTUNES, 1989, p. IX).

Nesse contexto, os fenômenos sociais passaram a ser compreendidos sob a perspectiva autopoiética, inicialmente atrelada à concepção biológica de sistemas vivos, como espécies de metassistemas autopoiéticos de segunda e terceira ordem, construídos a partir de "bio-sistemas" de primeiro grau, reduzindo-se as sociedades humanas a sistemas biológicos de seres humanos interligados. $^{26}$

\footnotetext{
${ }^{26}$ Nesse sentido se apresenta a citada teoria sobre a organização dos seres vivos de Humberto R. Maturana e Francisco J. Varela (2005, p. 220) que identifica já em nível celular a configuração de um sistema autopoiético do qual podem emergir outros sistemas de maior complexidade como os organismos e as sociedades, inclusive as
} 
Assim, o fenômeno social poderia ser explicado através da história das mudanças estruturais destes organismos biológicos (sua ontogenia), enquanto unidades autopoiéticas que mantém sua organização própria a despeito de suas interações recorrentes e estáveis (seus acoplamentos estruturais).

Segundo essa abordagem inicial, tal modificação estrutural ocorre na unidade a cada momento, seja como uma alteração desencadeada por interações provenientes do meio onde se encontra, seja como o resultado de sua dinâmica interna.

Destaca-se, já nessa visão biológica dos sistemas sociais humanos, a existência de uma clausura operacional e acoplamentos estruturais entre seus componentes de forma diversa do nível sistêmico dos organismos, considerados metassistemas formados pela agregação de unidades celulares, com autonomia mínima em face da pouca ou nenhuma existência independente de seus componentes. ${ }^{27}$

De modo diverso, "as sociedades" - enquanto metassistemas formados pela agregação de unidades metacelulares - seriam não só dotadas de componentes com maior autonomia como também de um domínio linguístico essencial para a estabilidade operacional de tal sistema e para o acoplamento estrutural dos elementos que o compõem. ${ }^{28}$

humanas, tidos como metassistemas pela agregação de unidades autônomas que podem ser tanto celulares, v.g. o organismo humano, quanto metacelulares, nesta hipótese, as sociedades humanas.No caso dos fenômenos sociais, a constituição desses metassistemas seria, porém, o resultado de acoplamentos estruturais de terceira ordem, decorrentes da coordenação de condutas entre seus elementos. Diferenciam-se dos acoplamentos de primeira e segunda ordem, que conformam, por exemplo, as células e os organismos vivos respectivamente, em função de uma fenomenologia interna e específica baseada "[...] no fato de que os organismos participantes satisfazem suas ontogenias individuais principalmente por meio de seus acoplamentos mútuos, na rede de interações recíprocas que formam ao constituir as unidades de terceira ordem". (MATURANA; VARELA, 2005, p. 214).

${ }^{27}$ Um acoplamento estrutural se configura à medida que interações adquirem um caráter recorrente e estável desencadeando apenas as modificações estruturais das unidades autopoiéticas sem, contudo, determinar nem informar tais modificações. (MATURANA; VARELA, 2005, p. 86-87).

${ }^{28}$ Segundo Humberto R. Maturana e Francisco J. Varela (2005, p. 220-221): "Nos sistemas sociais humanos o quadro é diferente. Como comunidades humanas eles também têm clausura operacional, que ocorre no acoplamento estrutural de seus componentes. No entanto, os sistemas sociais humanos também existem como unidades para seus componentes no domínio da linguagem. A identidade dos sistemas sociais humanos depende, portanto, da conservação e adaptação dos seres humanos não apenas como organismos — num sentido geral —, mas também como componentes dos domínios linguísticos que eles constituem. Pois bem: por estar associada a seus comportamentos linguísticos, a história evolutiva do homem é uma história na qual se selecionou a plasticidade comportamental ontogênica que torna possível os domínios linguísticos - e na qual a conservação da adaptação do ser humano como organismo requer que ele funcione nesses domínios e conserve essa plasticidade." 
Depreende-se desse primeiro modelo ainda biológico que, como qualquer unidade autopoiética, os sistemas sociais humanos dependeriam da "estabilidade operacional" de seus componentes em acoplamentos estruturais em seus diferentes níveis, inclusive linguístico. ${ }^{29}$

Ganha destaque o domínio linguístico, mesmo sob o enfoque biológico, como elemento crucial para a operação de um sistema social humano, sendo resultante de seus componentes e da ampliação de suas propriedades.

Sob este enfoque, a linguagem já é concebida como a característica que permite aos seres humanos operarem como observadores do funcionamento do próprio sistema social e dos demais sistemas autopoiéticos, sendo, ainda, a condição necessária para a realização da linguagem que constitui seu domínio de existência. ${ }^{30}$

Contudo, a efetiva transposição dessa teoria dos sistemas autopoiéticos do campo biológico para o social é atribuída por diversos autores ao sociólogo Niklas Luhmann. ${ }^{31}$

${ }^{29}$ Esta "estabilidade operacional" se aperfeiçoaria com a "plasticidade operacional (comportamental) desse sistema", ou seja, por meio da coexistência de diferentes interações em níveis de complexidade diversos e sobrepostos. Assim se apresentam, de um lado, seus elementos, os seres humanos, como organismos que exigem um acoplamento estrutural não-linguístico entre seus próprios componentes (nível celular), e, de outro, os sistemas sociais resultantes de suas interações e dependentes de acoplamentos estruturados em domínios linguísticos, "nos quais os indivíduos possam operar com a linguagem e ser observadores". (MATURANA; VARELA, 2005, p. 220-221).

${ }^{30}$ Ademais, segundo Humberto R. Maturana e Francisco J. Varela (2005), daí decorreria a explicação para o fato do sistema social humano ampliar em benefício próprio a criatividade individual de seus componentes posto que "a coerência e harmonia nas relações e interações dos integrantes de um sistema social devem-se à coerência e harmonia de seu crescimento em meio a ele". Contudo, sendo os referidos autores, por incorporar mecanismos coercivos de estabilização a todas as dimensões do comportamento de seus membros, pode se propiciar a constituição de "sistemas sociais desvirtuados, que perderam suas características específicas e despersonalizaram seus componentes". Tais sistemas, com esse desvirtuamento de suas funções autopoiéticas, "Assumiram, assim, a forma de organismos, como foi o caso de Esparta. Organismos e sistemas sociais humanos não podem, pois, equiparar-se sem distorcer ou negar as características próprias de seus respectivos componentes" (MATURANA; VARELA, 2005, p. 221).

${ }^{31}$ Nesse sentido, apontam Fritjof Capra (1996, p. 172), José Engrácia Antunes (1989, p. x), Gunther Teubner (1989b, p. 737), Germano Schwartz (2004. p. 27), Celso Fernandes Campilongo (2000a, p. 73, 2002, p. 18 e p. 66), Dário Rodríguez Mansilla e Javier Torres Nafarrate (2003, p. 106 e 122), Orlando Villas Bôas Filho (2006a, p. 12 e p. 101), Jean Clam (2006, p. 19), dentre outros autores. 


\subsection{A Teoria dos Sistemas Sociais de Niklas Luhmann e sua arquitetura conceitual}

A Teoria dos Sistemas Sociais de Niklas Luhmann (1998) tem como ponto central a compreensão da sociedade moderna em toda sua complexidade a partir de uma abordagem cognitiva e reflexiva capaz de identificar seus processos sociais como processos de comunicação que a diferenciam de maneira autorreferencial.

Luhmann (1992) postulou que a ideia de autorreferência poderia ser ampliada para além de suas raízes biológicas e elevada a um mecanismo gerador abstrato, servindo de hipótese teórica explicativa para o estudo do sistema social. ${ }^{32}$

O referido sociólogo alemão agrega à sua teoria algumas inovações da descrita teoria autopoiética biológica como a ênfase no caráter não somente auto-organizador, mas principalmente autorreprodutivo e autorreferente, isto é, na capacidade do sistema de produzir seus elementos, bem como suas próprias condições originárias de produção, tornando-se desse modo, em termos comunicacionais, independente do respectivo meio envolvente.

Destacam-se, em seu trabalho, referências à lógica operativa de George SpencerBrown (1979), ao construtivismo radical e à cibernética de segunda ordem de Heinz von Foerster (1984) e, embora de forma contrastante, menções à teoria funcionalista de Talcott

\footnotetext{
${ }^{32}$ Luhmann (1992), inclusive, reconhece que a transposição de tal teoria ao campo social não é compreendida por seus principais formuladores nas áreas naturais e biológicas, contudo, defende ainda assim tal possibilidade desde que sejam consideradas características próprias do sistema social, inapreensíveis para o campo de conhecimento de seus iniciais formuladores. Nesse sentido contra-argumenta: "The first surprise will be that the famous protagonists of operational closure at the level of general systems theory strongly reject its application to social systems. Heinz Von Foerster finds this idea shocking; nor would Humberto Maturana and Francisco Varela join in calling social systems autopoietic systems. Why not? The answer is easy. Not being sociologists, these authors think of social systems as consisting of concrete people, individuals with bodies and minds. Of course, it is impossible to admit the closure of social systems which include the reproduction of molecules in cells, or of cells in bodies, or of thoughts in minds, as social operations within the social system. But this mistake simply points to unexplored possibilities of clarification. We have to be very precise in defining the type of operation which reproduces, within a closed network of its own productions, the unity of a social system. This operation can never be defined as the biochemical production of life, nor can it be defined as the reproduction of thoughts by thoughts within the internal darkness of a conscious system. The operation we are looking for can only be communication". (LUHMANN, 1992, p. 1.422).
} 
Parsons (1966, 1974), além dos estudos de Ludwig von Bertalanffy (1968) e de Humberto R. Maturana e Francisco J. Varela (1980) sobre os sistemas vivos. ${ }^{33}$

Conforme inicialmente introduzido, Luhmann (1998) procurou reposicionar a sociologia como uma teoria da sociedade com pretensões de universalidade. Seu objetivo consistia na propositura de um modelo teórico alternativo passível de ser aplicado inclusive, de modo reflexivo, à própria sociologia. Esta deveria ser capaz de considerar a complexidade da sociedade moderna, vencendo, assim, os impasses do método tradicional científico, de modo a reduzir seu distanciamento de discussões transdisciplinares e do diálogo com os avanços obtidos em outras áreas do conhecimento. ${ }^{34}$

Para o mencionado teórico, a sociedade moderna pode ser compreendida em toda sua complexidade através dos processos de comunicação que a diferenciam de maneira autorreferencial. Os subsistemas sociais que a compõem usam a comunicação como seu modo particular de reprodução autopoiética. Seus elementos são comunicações produzidas e reproduzidas por uma rede de comunicações que, fora dela, não podem existir. (LUHMANN, 1992, p. 1423-1424).

\footnotetext{
${ }^{33}$ Nesse mesmo sentido, apontam Bechann e Stehr (2001, p. 187), Rodrígues e Torrez (2003, p. 134), Teubner (1989b, p. 736-737) e Neves (2007, p. 127-134).

${ }^{34}$ Sobre a reflexividade imposta pela teoria dos sistemas para o campo dos estudos científicos, bem como acerca do criticado fechamento da sociologia ao diálogo com outras áreas do conhecimento é pertinente a seguinte citação: "[...] A partir de este concepto inicial se anulan las posibilidades descriptivas de la lógica clásica bivalente y la teoría del conocimiento que la sustenta. Al igual que en la cosmología de Einstein (movimiento y aceleración) la observación del mundo con ayuda de la distinción entre sistema y entorno depende de la ubicación del observador. Esta ubicación sólo puede darse en un lugar del mundo. El observador tiene que operar con secuencias y ser capaz de unir la observación a la observación, es decir, la operación a la operación, lo cual le obliga a llegar a una conclusión 'autológica': si observa en el mundo sistemas que se reproducen a sí mismos, está obligado a considerarse a sí mismo como uno de ellos, pues de otro modo no podría observar su propia observación. El observador se convierte, así, en uno de sus propios objetos de observación. Es esta la única manera de que la teoría de sistemas se universalice, es decir, se convierta en una teoría del mundo que no incluya todo, aun a sí misma, obligada a concebir todo lo que observa como sistema o como entorno. Hasta ahora estas reflexiones fundamentales han sido poco usuales en la sociología. es necesario consultar a físicos como Heinz von Foerster, o a biólogos como Humberto Maturana o a psicólogos como Jean Piaget para constatar que una epistemología operativa con esta estructura no es nada extraordinaria, sino que dispone de argumentos convincentes y referencias empíricas. Sólo la sociología, por carecer de competencia teórica, no ha participado, hasta ahora, en estas discusiones transdiciplinarias. La teoría de sistemas sociales que se presenta aquí trata de anular esa distancia”. (LUHMANN, 1998, p. 14).
} 
Cumpre destacar que a escolha da comunicação como elemento fundamental desses sistemas perfaz mais um ponto de ligação da teoria luhmanniana com o próprio conteúdo da teoria dos sistemas vivos de Maturana e Varela $\left(2005\right.$, p. 217). ${ }^{35}$

Porém, para Luhmann (1998), a comunicação é entendida como síntese do processo comunicacional constituído de três etapas indissociáveis: informação, participação e compreensão, que são o produto das seleções realizadas não pelos indivíduos isoladamente (ou por seus “sistemas psíquicos”), mas no interior do próprio sistema social.

Tem-se como elemento essencial para a compreensão do pensamento luhmanniano o fato de que, em seu peculiar arcabouço teórico, o conceito de comunicação não está restrito à "metáfora tradicional da "transmissão", centrada no ato de comunicação, segundo a qual se entenderia que "a comunicação transmite notícias ou informação do emissor ao receptor". (LUHMANN, 1998, p. 141).

Ao contrário de uma simples troca entre emissor e receptor, em que a informação transmitida de um ao outro seria a mesma e dependente da habilidade do emissor, segundo Luhmann (1998, p. 142): o ato de comunicar "não é mais do que uma proposta de seleção, uma sugestão". A esse respeito cumpre frisar:

[...] A comunicação é o processamento da seleção [...]. O que se comunica não só é selecionado, como também já é seleção e, por isso mesmo, é comunicado. [Assim], a comunicação não deve ser entendida como processo seletivo de duas, mas de três seleções. [...] a primeira designa a própria seletividade da informação; a segunda, a seleção de seu conteúdo; a terceira, a expectativa de êxito, ou seja, a expectativa de uma seleção de aceitação. (LUHMANN, 1998, p. 142-143). ${ }^{36}$

35 Para os referidos neurocientistas chilenos, enquanto observadores, entende-se por comunicativos os comportamentos que ocorrem num acoplamento social, e por comunicação a coordenação comportamental resultante desse acoplamento, sendo a própria noção de comportamento entendida a partir de uma observação exterior e relacional (sistema-ambiente). Nesse sentido, segundo Maturana e Varela (2005, p. 153): "O que chamamos de comportamento, ao observar as mudanças de um estado de um organismo em seu meio, corresponde à descrição que fazemos dos movimentos do organismo num ambiente que assinalamos. A conduta não é alguma coisa que o ser vivo faz em si, pois nele só correm mudanças estruturais internas, e não algo assinalado por nós."

${ }^{36}$ Cf. o original: "[...] La comunicación es el procesamiento de la selección [...] Lo que comunica no sólo es seleccionado, sino que ya es selección y, por eso mismo, es comunicado. Por ello, la comunicación no se debe entender como proceso selectivo de dos, sino de tres selecciones. [...] El primer término designa la propia 
Por conseguinte, a sociedade deixa de ser considerada como um simples objeto de análise o que implica uma perspectiva totalmente diversa de compreensão dos fenômenos sociais. A esse respeito, destaca Javier Torres Nafarrate (1998, p. 20):

A consequência imediata resultante de que o social é uma operação de comunicação é que a sociedade não existe como objeto. A sociedade é pura comunicação e, portanto, só é possível dela se aproximar mediante distinções. A sociedade não opera como uma gigantesca estrutura objetiva que ninguém vê. Mas antes de tudo, as relações que se apresentam entre os seres humanos concretos se fazem dependentes de uma orientação que se refere às formas de comunicação. Por conseguinte, os sistemas sociais (e com muito mais razão a sociedade) não são propriamente objetos situados num lugar no espaço e tempo. Trata-se decisivamente de uma distinção, mas uma distinção que é real e que produz efeitos reais. ${ }^{37}$

Afastando-se das posições epistemológicas fundadas na dicotomia do paradigma sujeito-objeto, Luhmann (1998) questiona a análise da sociedade do ponto de vista objetivo externo a ela, considerando inexistente a possibilidade de haver um objeto "sociedade" acessível à observação independente. ${ }^{38}$

Dentro dos limites acima descritos, o referido autor não propõe sua nova teoria como capaz de revelar verdades absolutas que esgotem todas as possibilidades de compreensão dos fenômenos sociais. Seu objetivo concentra-se na tentativa de transpor os

selectividad de la información; el segundo, la selección de su contenido; el tercero, la expectativa de éxito, es decir, la expectativa de una selección de aceptación" (LUHMANN, 1998, p. 142-143)

${ }^{37}$ Cf. o original: "La consecuencia inmediata que se deriva de que lo social es una operación de comunicación, es que la sociedad no existe como objeto. La sociedad es pura comunicación y por tanto es sólo posible acercarse a ella mediante distinciones. La sociedad no opera como una gigante estructura objetiva que nadie ha visto. Más bien las relaciones que se aprecian entre los seres humanos concretos se hacen dependientes de una orientación que se refiere a formas de comunicación. Por consiguiente, los sistemas sociales (y con mucho más razón la sociedad) no son propiamente objetos que estén situados en un lugar en el espacio y en el tiempo. Se trata decisivamente de una distinción, pero una distinción que es real y que produce efectos reales". (TORRES, 1998, p. 20).

${ }^{38}$ A esse respeito, cumpre a transcrição de um pequeno excerto em que Luhmann faz menção específica às potencialidades da distinção entre sistema/ambiente para a própria compreensão das teorias científicas: "Aquí tenemos, también, una superación de la diferencia antigua por una teoría más completa que permite hablar en los sistemas de introducción de autodescripciones, autobservaciones, autosimplificaciones. Ahora se puede distinguir la diferencia sistema/entorno desde la perspectiva de un observador (por ejemplo, la de un cientifico), $y$ distinguirla también de la diferencia sistema/entorno que se realiza en el sistema mismo: el observador, a su vez, puede ser pensado como un sistema autorrefencial. Relaciones de reflexión de este tipo no sólo revolucionan la epistemología clásica de sujeto-objeto; no sólo desdogmatizan y 'naturalizan' la teoría científica, sino que producen también una comprensión más compleja del objeto por medio de un diseño de teoría, a su vez, más complejo". (LUHMANN, 1998, p. 34). 
impasses e obscuridades a que chegou a sociologia a partir do amálgama de teorias parciais, de médio alcance, resultantes de diversas e equivocas combinações de seus autores clássicos. ${ }^{39}$

Dessa forma, situa seu trabalho em face de uma suposta estagnação teórica que teria reduzido a sociologia a um jogo retórico das mais altas pretensões de análise de seus textos clássicos. ${ }^{40}$

Em sua nova teoria, a sociologia passa a ser entendida como um "sujeito que lida consigo mesmo", e o significado operacional da sociedade, como a "condição de possibilidade para a própria cognição social" ao passo em que transfere claramente "a estrutura do modo de operação auto-referencial [cognitivo] do sujeito à teoria dos sistemas sociais”. (BECHMANN; STEHR, 2001, p. 188). ${ }^{41}$

${ }^{39}$ Nesse sentido, afirma categoricamente Luhmann $(2009$, p. 35$)$ : "A sociologia se encontra em uma crise de
caráter teórico. Tanto na literatura especializada, como nas reuniões convocadas sob essa disciplina, a referência
fundamental se volta para seus clássicos: Karl Marx, Max Weber, Georg Simmel, Durkheim. A impressão que
resulta daí é a de que toda a teia conceitual da sociologia esgotou-se com esses nomes. Evidentemente, com eles,
disponibilizam-se algumas teorias de médio alcance (middle range), principalmente no campo da pesquisa
empírica, mas não existe uma descrição teórica coerente sobre a situação dos problemas da sociedade
contemporânea. Isso é válido, entre muitas outras coisas, para a descrição dos problemas ecológicos, para
entender o incremento do individualismo e a crescente necessidade de tratamentos psicológico-terapêuticos". ${ }^{40}$ Assim, sintetiza o próprio Luhmann (1998, p. 08): "La unidad de la sociología no aparece, pues, como teoría ni mucho menos como conceptualización de su objeto, sino como complejidad pura. La disciplina no sólo se vuelve intransparente: encuentra su unidad en la intransparencia. La complejidad se afronta sólo desde la perspectiva: cada intento de asirla la hace variar tanto que no puede ser controlada. Aun cuando se pudiera contar que, tarde o temprano, uno llegara a agotar el conjunto del pensamiento de los clásicos, tendría que vérselas con la propia oscuridad producida. Se trata, entonces, de una relación entre complejidad y transparencia; se podría decir también: de una relación entre complejidad transparente e intransparente. La renuncia a la edificación de una teoría específica en su campo no elude el problema, evita sólo el plantearlo. Justamente aqui empieza el trabajo de dicha teoría. Sitúa la relación con su objeto de investigación como una relación entre complejidad intransparente y complejidad transparente. Nunca reclama para sí misma el reflejo total de la realidad del objeto ni el agotamiento de todas las posibilidades de conocimiento del objeto. Y por eso mismo, tampoco la exclusividad en la pretensión de verdad en relación con otras empresas teóricas que entren en competencia. Sí reclama, en cambio, la universalidad en la aprehensión del objeto, en el sentido de que como teoría sociológica trata el todo social y no sólo segmentos (como, por ejemplo, estratos y movilidad, particularidades de la sociedad moderna, patrones de interacción, etcétera).

${ }^{41}$ Em sua dissertação sobre o tema, afirma Rômulo Figueira Neves (2005, p. 08): "A teoria dos sistemas sociais tem a ambição de ser uma teoria abrangente e de dar conta da análise das diversas formas de organização da sociedade complexa. Seus instrumentos de análise não são, no entanto, conceitos significativos fechados, mas modelos abstratos que descrevem as fronteiras dos sistemas e a forma pela qual os processos comunicativos internos aos sistemas sociais operam. Assim, não existe um processo comunicativo, a priori que funcione em todos os sistemas sociais, mas uma forma de organização e de delimitação dos sistemas que se dá a conhecer apenas com a observação de cada um deles". 
É possível identificar ainda, em termos gerais, a busca pela superação do realismo epistemológico e individualismo metodológico legados por Max Weber (2001). Nesse sentido, Gunther Teubner (1989b) destaca como elemento comum às teorias de Niklas Luhmann, Michel Foucault e Jürgen Habermas a tentativa de reposicionar a sociologia no campo do conhecimento por meio da substituição dessa forma de realismo por um construtivismo epistemológico e do referido individualismo metodológico, por construções teóricas como auto-organização, discurso e autorreflexão social. ${ }^{42}$

Porém, como será discutido mais adiante, apesar dessa pertinente observação, Teubner (1989b) a direciona de acordo com uma leitura construtivista que, em essência, é adotada claramente apenas por Luhmann. ${ }^{43}$

Na teoria luhmanniana, a diferenciação social e formação de sistemas passam a ser vistas como características básicas da sociedade moderna, sendo a Teoria dos Sistemas e sua Teoria da Sociedade mutuamente dependentes. ${ }^{44}$

\footnotetext{
${ }^{42}$ Sobre a construção de novas percepções da realidade social, afirma Gunther Teubner (1989b, p. 729): “[...] This, at least, is what the following new theories on law - post-structuralism, critical theory, and autopoiesis have in common. It is true that Michael Foucault, Jürgen Habermas, and Niklas Luhmann 'gyre and gymble in the wabe', but they do so because the imagine social realities whose reconstruction clearly goes beyond the limits of ordinary language. What makes them seemingly incomprehensible is their radical departure from epistemological premises that are deeply embedded in contemporary thinking on law and society, particularly, from Pizzorno (1989) polemically calls the reification of a 'metafisica quotidiana'-epistemological realism and methodological individualism. Although poststructuralism, critical theory, and the theory of autopoiesis develop quite different visions of modern law, they converge in their antirealism and their anti-individualism". Nesse sentido, ainda segundo Gunther Teubner (1989b), o ponto de convergência entre o pós-estruturalismo de Michel Foucault, a teoria crítica de Jürgen Habermas e a teoria autopoiética de Niklas Luhmann seria a substituição da autonomia individual por processos comunicativos e não por entidades supra individuais. Seria, contudo, na identificação da nova unidade cognitiva desses processos comunicacionais que esses autores diferem entre si, posto que: “[...] In Habermas's version of critical theory correspondence theories of truth are overturned by consensus theories and 'intersubjectivity' takes the place of the epistemic subject. Foucault and Luhmann are even more radical in their disenchantment of the human individual. For Foucault, the human individual is nothing but an ephemeral construction of an historically contingent power/discourse constellation, which dictates the epistème of a historical epoch. Luhmann completely separates psychic processes from social ones and perceives the human individual in society as a communicative artifact, as a product of self-observation of social autopoiesis. The new epistemic subjects are autopoietic social systems". (TEUBNER, 1989b, p. 732).

${ }^{43}$ Ainda a esse respeito afirma Orlando Villas Bôas Filho (2006a, p. 45): "Sob vários aspectos a interpretação de Teubner acerca das inovações trazidas por Foucault, Habermas e Luhmann à epistemologia tradicional da teoria social apresenta-se como correta e, por esse motivo, não merece qualquer reparo. Contudo, há que se ter em mente que Teubner interpreta Foucault e Habermas a partir de um construtivismo que é próprio da teoria de Luhmann, o que não deixa de acarretar certos problemas, na medida em que tende a obnubliar contornos próprios desses dois pensamentos, impondo-lhes demandas que nem sempre são suas".
} 
Luhmann (1998) distingue, portanto, três níveis de formação de sistemas, a partir da teoria geral em que pretende inserir os sistemas sociais (Figura 1).

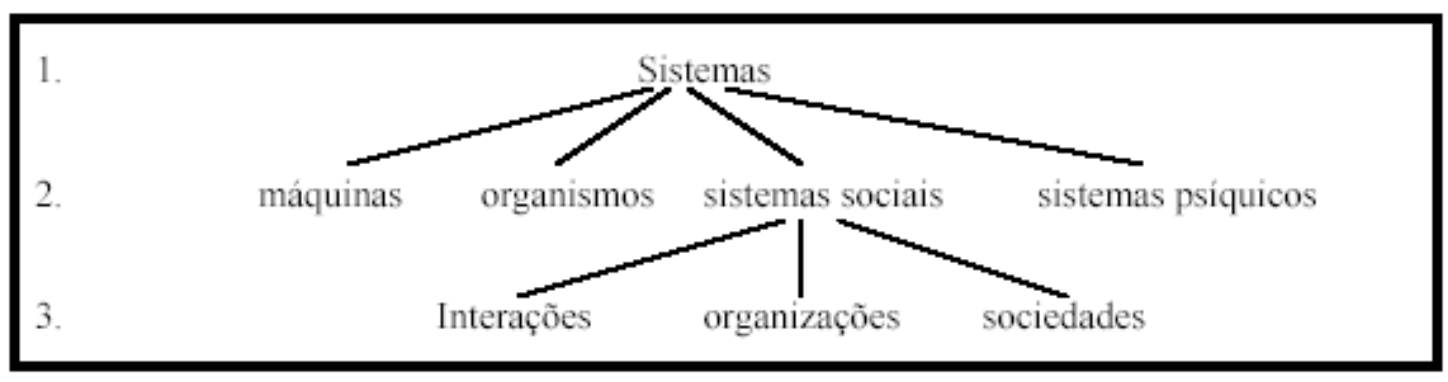

Figura 1 - Níveis de formação dos sistemas. (LUHMANN, 1998, p. 27).

Como se pretende discutir a seguir, com a distinção entre sistema e ambiente, a sociedade passa a ser entendida como uma ordem emergente e diversa das especificidades da vida orgânica e do interior das consciências, sendo "a irrupção de uma nova ordem da realidade que não pode ser explicada (nem reduzida) em sua totalidade, a partir das características da infraestrutura [comunicacional] sobre a qual se encontra sustentada." (RODRÍGUEZ; TORRES, 2003).

\subsubsection{A sociedade em termos comunicacionais e sua distinção enquanto sistema do ambiente}

A teoria luhmanniana parte da consideração de que o mundo fenomênico abrange um número indeterminado de ações, atividades, seleções de sentido e de relações possíveis que tendem a aumentar no decorrer da história, tornando-se o próprio mundo, enquanto unidade, cada vez mais complexo, inapreensível e contingencial. ${ }^{45}$

\footnotetext{
${ }^{44}$ Segundo a observação de Gotthard Bechmann e Nico Stehr (2001, p. 187): “a sociedade [para Luhmann] não é a soma de todas as interações presentes, mas um sistema de uma ordem maior, de tipo diferente, determinada pela diferenciação entre sistema e ambiente".

${ }^{45} \mathrm{O}$ conceito luhmanniano de contingência será detalhado no tópico referente à "dupla contingência" dos sistemas sociais autopoiéticos. Contudo, é necessário já advertir a sua importância para a compreensão de como a complexidade do mundo é tratada e, paradoxalmente, aumentada pelos processos seletivos de sentido dos sistemas psíquicos e sociais em função de sua contingencialidade. De qualquer forma, a fim de introduzir uma noção menos abstrata que a desenvolvida nessa fase inicial do trabalho, segue a transcrição do seguinte excerto que, embora referente a uma obra anterior à fase autopoiética de Niklas Luhmann, contém em si as ideias embrionárias desse conceito a partir de uma visão ainda voltada ao indivíduo e seu agir: "O homem vive em um
} 
Esse aumento considerável de complexidade relaciona-se ao contínuo processo de formação e diferenciação de sistemas de sentido, sociais e psíquicos, cuja função é tentar organizar parte dessa complexidade no curso desse processo histórico e reduzir essa contingência presente nessa ampla possibilidade de relações e sentidos. ${ }^{46}$

Embora não seja unívoco, o conceito de mundo adotado por Luhmann (1998, p. 197) destaca-se como constitutivo das relações sistêmicas. Rompe, portanto, com a tradicional centralidade do conceito de mundo, tido como um "meio" em relação ao sujeito, para situá-lo de modo multicêntrico que, em cada diferenciação, integra todas as diferenças de sistemas/ambiente. Em sua visão, possibilitar-se-ia dessa forma a investigação sociológica que relaciona a semântica do mundo com o desenvolvimento sócio-estrutural do sistema social. ${ }^{47}$

mundo constituído sensorialmente, cuja relevância não é inequivocamente definida através do seu organismo. Desta forma o mundo apresenta ao homem uma multiplicidade de possíveis experiências e ações, em contraposição ao seu limitado potencial em termos de percepção, assimilação de informação, e ação atual e consciente. Cada experiência concreta apresenta um conteúdo evidente que remete a outras possibilidades que são ao mesmo tempo complexas e contingentes. Com complexidade queremos dizer que sempre existem mais possibilidades do que se pode realizar [ou atribuir sentido]. Por contingência entendemos o fato de que as possibilidades apontadas para as demais experiências poderiam ser diferentes das esperadas; ou seja, que essa indicação pode ser enganosa por referir-se a algo inexistente, inatingível, ou a algo que após tomadas as medidas necessárias para a experiência concreta (por exemplo, indo-se ao ponto determinado) não mais lá está. Em termos práticos, complexidade significa seleção forçada, e contingência significa perigo de desapontamento e necessidade de assumir riscos". (LUHMANN, 1983, p. 45-46).

${ }^{46}$ Niklas Luhmann ressalta que embora o termo "história" possa se constituir como a dimensão específica da ideia de tempo, ao ser relacionado ao processo de formação dos sentidos, tal designação assume uma conotação diversa da ideia pura e simples de causalidade e desencadeamento de acontecimentos relacionados, mas sim estritamente ligada ao emprego específico de um sentido de maneira diversa de seu uso anterior ou futuro. Nesse sentido, expressamente adverte: “[...] Bajo la designación historia no debe entenderse simplemente la secuencia de los acontecimientos en virtud de la cual se puede concebir lo presente como efecto de causas pasadas o como causa de efectos futuros. Lo específico de la historia del sentido radica, más bien, en que posibilita el asimiento discrecional del sentido en los acontecimientos pasados o futuros, es decir, posibilita el saltar la secuencia. La historia tiene lugar cuando las secuencias quedan desligadas. Un sistema de sentido tiene historia en la medida en que limita, ya sea mediante asimientos discrecionales, sean estos determinados acontecimientos pasados (la destrucción del templo, la coronación del Emperador por el Papa, la derrota de Sedán; o hechos más pequeños: una boda, la interrupción de los estudios, la primera condena a pena menor de prisión; el 'destape' de los homosexuales), mediante la finalización del futuro. La historia, por lo tanto, es siempre pasado-presente o futuropresente, y siempre significa tomar distancia respecto de la secuencia pura, y además, reducción de la ganada libertad de asimiento versátil de todo lo pasado y de todo lo venidero". (LUHMANN, 1998, p. 94).

\footnotetext{
${ }^{47}$ Sob esse ponto, o referido autor trabalha as seguintes considerações: "Naturalmente, o conceito de mundo pode ser concebido de maneiras muito distintas, por exemplo, como totalidade nociva para a salvação fora do próprio grupo, ou como interlocutor do sujeito (necessariamente extramundano). A ideia, muito atraente para os sociólogos, de uma constituição intersubjetiva não ajuda muito: é demasiada evidente e, desde o ponto de vista teórico, não é suficientemente produtiva. Inserimos aqui o conceito de mundo como unidade de sentido da diferença entre sistema e entorno [ambiente] e o utilizamos como conceito último sem diferenças. Sob essa perspectiva, o conceito de mundo não designa nenhuma totalidade objetiva (como queira que se conceba essa
} 
A diferenciação entre sistemas e ambiente seria estimulada pela complexidade social, sua contingência e a referida necessidade de sistemas capazes de representar e dar sentido ao mundo e a suas relações. A função dos sistemas consistiria, então, na diminuição da complexidade do ambiente de modo a propiciar a delimitação de seus sentidos e estruturas, sem com isso negar a existência do ambiente, cuja complexidade é sempre maior que a interna dos sistemas. (LUHMANN, 1998, p. 50). ${ }^{48}$

Porém, deve-se ressaltar que o termo estrutura empregado na teoria luhmanniana apresenta um significado peculiar, sobretudo em sua identificação da sociedade como comunicação. Para Luhmann (1998, p. 258), “de forma abstrata, o termo estrutura pode se referir à comunicação ou à ação".

Assim, como o referido autor mesmo adverte, seu entendimento do conceito de estrutura "contradiz a abordagem usual, que considera a estrutura no eixo da distinção estrutura/processo, na qual a estrutura significa a estabilidade e o processo, a mudança". Levando em conta que seu pensamento sistêmico se baseia em operações, "as estruturas só existem e produzem efeitos no momento em que o sistema põe em funcionamento suas próprias operações.” (LUHMANN, 2009, p. 113).

totalidade), nenhuma universitas rerum que pode ser pensada sem diferenças. Original e fenomenologicamente, o mundo está dado como unidade inapreensível. No terreno da formação dos sistemas, e em relação com dita formação, é determinável como unidade de uma diferença. Em ambos sentidos, o conceito de mundo indica uma unidade só real para os sistemas de sentido capazes de se distinguir de seu entorno e que, em consequência, reflitam a unidade desta diferença como unidade que abarca duas infinitudes, a interior e a exterior. O mundo, desde esta perspectiva, está, portanto, constituído pelo processo de diferenciação entre os sistemas de sentido, pela diferença entre o sistema e o entorno. Este mundo (distinto do que se concebe fenomenologicamente) não é nada original, nada arcaico, é a representação ligada a uma diferença da unidade final. É o mundo depois do pecado original" (LUHMANN, 1998, p. 197-198).

${ }^{48} \mathrm{O}$ sentido do termo complexidade relacionado à referida necessidade sua redução pelos sistemas sociais consiste em "medida de indeterminação ou na carência de informação". A esse respeito, explica o referido sociólogo alemão: “[...] La complejidad es, vista de este modo, aquella información que le hace falta al sistema para poder aprehender y describir con justeza a su entorno (complejidad del entorno) y a sí mismo (complejidad del sistema). Desde el punto de vista de los elementos particulares - por ejemplo, para determinadas acciones o procesamientos de información del sistema -, la complejidad sólo es relevante en este segundo sentido, es decir, sólo como horizonte de selección. Esta segunda versión puede ser usada en los sistemas de sentido para reintroducir la complejidad del sistema dentro del sistema: como concepto, como magnitud desconocida, como factor de miedo, como concepto de inseguridad y riesgo, como planeación, como problema de decisión u como excusa”. (LUHMANN, 1998, p. 50). 
As estruturas que relacionam comunicação com comunicação, próprias dos sistemas sociais, compreendem tudo o que neles pode ser relevante. Uma primeira característica desse conceito está relacionada ao problema da complexidade social com que o sistema tem que lidar.

A formação de suas estruturas procura realizar a transição de uma complexidade não estruturada, "entrópica" e tendente à incoerência, para uma complexidade estruturada. (LUHMANN, 1998, p. 259). ${ }^{49}$

Dessa forma, enquanto "limitação das relações possíveis no sistema" (LUHMANN, 2009, p. 113), suas estruturas autorreferenciais definem não apenas o relacionamento entre seus elementos como consideram essa relação de maneira constitutiva para a qualificação de tais elementos que, no caso dos sistemas sociais, remete à própria qualificação pela estrutura dos sentidos das ações selecionados pelo processo comunicacional, como será tratado a seguir.

Por sua vez, faz-se importante frisar que, na Teoria dos Sistemas Sociais de Niklas Luhmann (1998), as referências à história e ao desenvolvimento dos sistemas autopoiéticos partem de um conceito próprio de evolução.

Nesse contexto, a evolução dos sistemas sociais não se relaciona, de modo algum, às ideias de progresso, desenvolvimento linear ou de avanço em sentido valorativo, nem mesmo à existência de etapas hierarquizadas de evolução, mas sim ao aumento da complexidade dos sistemas e ao modo de organização assumido por suas estruturas.

\footnotetext{
${ }^{49}$ Em outras palavras: "Somente por meio de uma estruturação limitante, um sistema adquire direção interna que torna possível a autorreprodução" (LUHMANN, 2009, p. 113). Ainda a ese respeito, explica, detalhadamente, Luhmann (1998, p. 259-260) "Estas relaciones sólo obtienen valor estructural si las relaciones que se establecen en cada caso forman una selección de un gran número de posibilidades combinatorias, con las ventajas y los riesgos de una reducción selectiva, y únicamente si esta selección puede mantenerse constante, es decir, reproducida con elementos nuevos, al cambiar los elementos. Así, una estructura es, aparte de todo lo demás que puede ser, la limitación de las relaciones permitidas en el sistema. Esta limitación constituye el sentido de las acciones, y dentro del funcionamiento de los sistemas autorreferenciales, el sentido de una acción que motiva y hace plausible aquello que salta a la vista como posibilidad de enlace. [...]. Traducido a la terminología de la teoría de los sistemas autopoiéticos (no obstante que esta utiliza el término estructura de otra manera), esto quiere decir que únicamente por medio de una estructuración limitante un sistema adquiere la suficiente ‘dirección interna' que hace posible la autorreproducción”.
} 
Em outras palavras, tal evolução decorre da forma de diferenciação com que a sociedade lida com seu ambiente, a sociedade, como sistema geral, composta de eventos improváveis e imprevisíveis, que geram, ao final do processo, um ganho evolutivo indeterminável a priori, ainda que, em seu próprio curso evolutivo, restrinjam-se alguns caminhos, tornando o sistema mais previsível em alguns aspectos. Porém, nesse mesmo processo, outros caminhos tornam-se também possíveis, reafirmando, dessa forma, o sentido "indeterminável" do funcionamento do sistema social. ${ }^{50}$

Enquanto comunicação, a sociedade teria evoluído diferenciando-se em pelo menos quatro estágios possíveis e adaptados aos diferentes graus de complexidade neles existentes: (i) diferenciação segmentária; (ii) diferenciação centro/periferia; (iii) diferenciação estratificada, e (iv) diferenciação funcional. (LUHMANN, 1998, p. 379). ${ }^{51}$

${ }^{50}$ A esse respeito, em sua dissertação sobre os conceitos da teoria luhmanniana, sintetiza Rômulo Figueira Neves (2005, p. 44): “As condições para que alguns elementos se encontrem e tornem possível determinada evolução são incertas e improváveis. A evolução, no entanto, restringe alguns caminhos, tornando o sistema mais previsível em alguns aspectos, ao mesmo tempo em que torna outros caminhos possíveis, reafirmando a imprevisibilidade do funcionamento do sistema. Esse processo de formação de premissas e abertura de novas possibilidades pode desencadear diferenciações internas mais constantes, dando início, assim, à formação de outros sistemas. [...] A evolução dos sistemas é o resultado do funcionamento de seus elementos, do crescimento da complexidade interna e da eficácia e suas diferenciações. A estabilização e a sobrevivência dos sistemas geram, progressivamente, ainda mais aumento da complexidade interna, entrando em um ciclo que resulta, muitas vezes, em uma nova diferenciação interna e na fragmentação do sistema em sub-sistemas". Acrescente-se ainda que, conforme compara Celso Fernandes Campilongo (2002, p. 23): “[...] Como todas as grandes teorias da sociedade - confira-se Durkheim, Marx, Weber e Parsons - Luhmann também adota uma perspectiva evolutiva". Contudo, embora a sociedade para Luhmann tenha sido sempre uma rede de comunicações, Campilongo destaca que para o referido teórico sistêmico a evolução da sociedade não pode ser entendida "como sinônimo de progresso ou qualquer outra referência valorativa", sendo a chave de seu modelo evolutivo a noção de diferenciação funcional como o modo de organização alcançado pela sociedade moderna para lidar com sua complexidade, ou seja o ponto central de sua teoria evolutiva seria a variação histórica dos modos de organização do processo comunicacional da sociedade.

${ }^{51}$ De maneira sucinta, uma vez que essa questão é incidente e não constitui o objeto desse trabalho, essa evolução pode ser descrita a partir do seguinte resumo de alguns artigos de Niklas Luhmann (1990b) presentes em sua coletânea: Essays on self-reference. A diferenciação segmentária da sociedade pode ser entendida como uma característica das sociedades arcaicas, com baixa seletividade de seus processos comunicacionais frente a um grau ainda não muito elevado de complexidade do ambiente, com poucas possibilidades de variação, sendo em sua grande parte as expectativas ligadas às relações pessoais, à conservação da vida em face do perigo de extinção demográfica, sendo "estabilizadas" por meio da força.Seus subsistemas sociais, familiares, tribais, organizados em torno de clãs e aldeias, não estariam ainda diferenciados em termos funcionais mas em torno de valores tradicionais centrados nos referidos critérios naturais - gênero e idade, por exemplo nas sociedades primitivas - que compunham seus meios de comunicação simbolicamente generalizados presentes em seu processo comunicacional de diferenciação interna. Por sua vez, a diferenciação centro/periferia seria própria das sociedades organizadas a partir de cidade, nas quais o critério geográfico passa a preponderar sobre o natural como forma de seleção e de redução da complexidade emergente dessa diferenciação social. Assim, o princípio 
Em cada um desses momentos, a sua comunicação esteve organizada e, por conseguinte a própria sociedade restou assim diferenciada, a partir de diversos critérios fundamentais, como, por exemplo, gênero e idade (critérios naturais nas sociedades primitivas); campo e cidade (critérios geográficos das cidades-estados da Grécia clássica), nobre e plebeu, cidadão e escravo (critérios hierárquicos, sobretudo, no "antigo regime"), e critérios funcionais com a estabilização de sistemas especializados, como o direito, a política e a economia, na atual sociedade.

Desse descompasso inicial entre a comunicação produzida por diferentes sistemas sociais, ainda não diferenciados funcionalmente, resultaria um acréscimo de complexidade decorrente da desigual comunicação e da capacidade dos sistemas hierarquicamente organizados de impor sobre os demais suas autodescrições como pretensões globais e prevalentes. (LUHMANN, 1990b, p. 125).

A diferenciação funcional da sociedade surgiria, então, como uma característica adaptativa da sociedade moderna em resposta ao grau insustentável de complexidade com que modelos anteriores, segmentários e estratificados, não poderiam lidar.

Para Luhmann (1992), a diferença histórica crucial entre a sociedade passada e a moderna consistiria no abandono da representação "da sociedade na sociedade" ocorrido em sua transição para o modo primário de diferenciação funcional.

Segundo esse entendimento, a característica marcante e inevitável da sociedade moderna seria a perda da representação natural entendida como a impossibilidade da representatio identitatis. A esse respeito, esclarece Luhmann (1992, p. 1434-1435):

[...] Em sociedades tradicionais encontramos modelos para representar a ordem social como relações entre subsistemas, como por exemplo, as relações entre centro e periferia, cidade e campo; ou relações de classe entre

da territorialidade se torna indispensável e a cidade passa a ser considerada o centro de maior difusão da comunicação. Contudo, a centralidade e o isolamento da comunicação aí produzida em relação à periferia desse sistema, bem como o desenvolvimento de novas formas de diferenciação no próprio centro provoca e reflete ao mesmo tempo o aumento de complexidade. Nesse contexto, a estratificação hierárquica, fundada na desigualdade de classes, faz com que a comunicação ali produzida novamente se diferencie de modo estratificado. Os subsistemas dominantes passariam a exercer a representação de todo o sistema de modo a considerar como subsistemas inferiores os demais presentes em seu ambiente que, em boa parte, continuariam ainda estruturando sua comunicação a partir de diferenciações segmentárias e territoriais. Como exemplo dessa tipo de diferenciação estratificada e desigual, tem-se a formação da nobreza nos centros dessas sociedades assim diferenciadas. 
classes sociais ou estamentos. A transição para a sociedade moderna dissolveu essa ordem sem substituí-la - Foucault cita a "perda de representação" ocorrida no século XVIII. Sob o regime da diferenciação funcional, o sistema social perde sua capacidade integrativa. Reduzido aos seus mecanismos de acoplamento estrutural, continua se autorreproduzindo de forma autopoiética através de comunicação. ${ }^{52}$

A diferenciação funcional teria prevalecido frente às demais formas segmentárias, centro/periferia ou estratificada/hierárquica por ser capaz de fornecer ao sistema uma maior possibilidade de redução da complexidade, uma vez que "a totalidade da sociedade nunca está completamente presente nem pode ser realizada como uma totalidade". (LUHMANN, 1990b, p. 125).

A sociedade moderna teria, assim, assumido uma forma sistêmica completamente nova posto que se estrutura em um padrão "significativamente diverso de diferenciação sistêmica utilizando funções específicas como fator para a diferenciação de seus subsistemas". (LUHMANN, 1990b, p. 177).

Desse modo, é possível situar a distinção entre sistema e ambiente na referida teoria como o resultado desse peculiar modelo de evolução social e, com isso, entender porque Luhmann (1998, p. 11) descreve acentricamente a sociedade moderna como policontextual e estruturada de maneira funcionalmente diferenciada em subsistemas comunicacionais, autopoiéticos e autorreferenciais.

A partir do conceito de diferença utilizado por George Spencer-Brown (1979) na formulação de sua teoria da forma e da função da diferenciação nos processos de autorreferenciais estudada por Heinz von Foerster (1973), Luhmann (1998, p. 40) destaca a diferença entre sistema e entorno (ambiente), como o "ponto de partida para qualquer análise teórico-sistêmica". Sobre esse ponto, afirma o referido sociólogo alemão:

[...] Os sistemas estão estruturalmente orientados ao entorno [ambiente], e sem ele, não poderiam existir; portanto, não se trata de um contato ocasional

\footnotetext{
${ }^{52}$ Cf. original: "[...] In traditional societies we find devices to represent social order as relations between subsystems, for example, as relations of center and periphery, city and country; or as relations of rank between castes or estates. The transition to modern society dissolved this order without replacing it - Foucault cites a 'loss of representation' occurring in the eighteenth century. Under the regime of functional differentiation, the societal system loses its integrative capacity. Reduced to its mechanism of structural coupling, it continues to autopoietically reproduce itself by communication". (LUHMANN, 1992, p. 1434 -1435).
} 
nem tampouco de uma mera adaptação. Os sistemas se constituem e se mantém mediante a criação e a conservação da diferença com o entorno, e utilizam seus limites para regular esta diferença. Sem diferença referente ao entorno não haveria autorreferência já que a diferença é a premissa para a função de todas as operações autorreferenciais. Nesse sentido, a conservação dos limites (boundary maintenance) é a conservação do sistema. (LUHMANN, 1998, p. 40). ${ }^{53}$

Observe-se, porém, que essa diferenciação entre sistema e ambiente não deve ser entendida, de forma alguma, como uma "diferenciação de uma parte do todo", nem mesmo relacionada à "divisão do todo em fragmentos organizados" como equivocadamente já se interpretou essas sutis distinções luhmannianas. (NEVES, 2005, p. 13). ${ }^{54}$

Para a referida teoria, os limites que demarcam a fronteira entre ambiente e sistema não representam em si uma "ruptura de contexto", não sendo possível se afirmar que as interdependências internas sejam, de maneira geral, maiores que as existentes entre sistema e ambiente. $^{55}$

A diferenciação sistêmica e a própria organização dos processos comunicacionais em seu interior dependem de um mecanismo de seleção capaz de distinguir os elementos que o integrarão daqueles presentes em seu ambiente e, assim, superar a contingência do mundo,

\footnotetext{
${ }^{53}$ Cf. o original: "[...] Los sistemas están estructuralmente orientados al entorno, y sin él, no podrían existir: por lo tanto, no se trata de un contacto ocasional ni tampoco de una mera adaptación. Los sistemas se constituyen y se mantienen mediante la creación y la conservación de la diferencia con el entorno, y utilizan sus límites para regular dicha diferencia. Sin diferencia, con respecto al entorno no habría autorreferencia ya que la diferencia es la premisa para la función de todas las operaciones autorreferenciales. En este sentido, la conservación de los límites (boundary maintenance) es la conservación de sistema”. (LUHMANN, 1998, p. 40).

${ }^{54}$ Frente a esses equívocos, adverte Luhmann (1998, p. 42): “A diferença entre sistema e entorno [ambiente] obriga, como paradigma da teoria dos sistemas, a substituição da diferença entre o todo e as partes por uma teoria da diferenciação dos sistemas". Assim, ressalta que tal diferenciação seria simplesmente a "repetição da formação de sistemas dentro de outros sistemas", no interior dos quais se poderia ainda encontrar "diferenciações de diferenças adicionais da distinção sistema/entorno".

${ }^{55}$ Sobre essas nuances, esclarece Niklas Luhmann (1998, p. 41): “[...] Pero lo que designa al concepto de límite es que los procesos, al rebasar los límites previamente fijados (por ejemplo, en el intercambio de energía o de información), se colocan bajo situaciones distintas de continuidad (por ejemplo, bajo otras situaciones de aplicabilidad o de consenso). Esto significa, a su vez, que la contingencia del curso del proceso, la apertura a otras posibilidades, varia para el sistema según se lleve a cabo dentro del sistema o en el entorno. Precisamente porque así sucede, existen límites, existen sistemas".
} 
cuja complexidade consubstancia-se na dificuldade de se estabelecer processos comunicacionais sem a estruturação de um sistema social no espaço desorganizado. ${ }^{56}$

Esse mecanismo de seleção seria, portanto, um meio (medium), específico em cada sistema, do qual fazem parte os meios de comunicação.

Considerando o tema deste trabalho, é de suma relevância destacar, neste ponto, que, por "meios" em termos gerais e relacionados à comunicação, Luhmann (1998, p. 156) designa os ganhos evolutivos que permitiram que a noção de comunicação rompesse com sua tradicional conceituação restrita às ideias de seleção de signos e à troca de informações. No combatido conceito tradicional, pressupõem-se a ocorrência dessas seleções e trocas entre seres vivos autônomos e capazes de processar tais informações sem que desse processo idealizado resultassem perdas de sentido, de compreensão e a produção de outros desperdícios.

A superação da referida visão idealizada teria sido possível tão somente com o aperfeiçoamento da compreensão dos processos cognoscitivos e comunicacionais. Sob essa nova perspectiva seria possível redimensionar o que se entende por comunicação, transformando funcionalmente a comunicação “improvável em provável”, na medida em que se agregam à sua nova teorização os impasses entre os sentidos atribuídos e percebidos, o problema da "acessibilidade dos destinatários" à comunicação e a questão de seu êxito em termos do conteúdo selecionado da comunicação como premissa para sua conduta. (LUHMANN, 1998, p. 156-157). ${ }^{57}$

56 Segundo Rômulo Figueira Neves (2005), essa contingência dos processos comunicacionais do espaço desorganizado seria, em si, um estímulo para a formação dos sistemas, sendo que "quanto mais um sistema se fecha e evolui, mais ele pode organizar, direcionar e limitar as possibilidades de caminhos de seu próprio funcionamento, em um processo de diminuição, dentro do sistema, da extrema contingência e complexidade do mundo desorganizado" (NEVES, 2005, p. 32).

57 Seriam, portanto, três as "impossibilidades", apontadas por Luhmann (1998, p. 156.157), que tornariam improvável a efetividade da comunicação em sentido tradicional: (i) os impasses entre os sentidos atribuídos e percebidos - "que o ego [receptor] entenda o que pretende o alter [emissor]"; (ii) o problema da "acessibilidade dos destinatários" à comunicação, e (iii) questão de seu êxito em termos de aceitação pelo ego do conteúdo selecionado da comunicação como premissa para sua conduta. Os termos ego e alter são em sua dimensão social utilizados por Luhmann (1998) para designar perspectivas diversas de entendimento que podem ser tanto internas a um sistema social quanto entre sistemas diferentes. Nesse sentido, esclarece o referido autor: “[...] Por lo tanto, los conceptos ego y alter no designan aqui papeles, personas o sistemas, sino horizontes especiales que agregan y cargan peso las remisiones plenas de sentido. La dimensión social, por consiguiente, está constituida por un horizonte doble y se vuelve relevante en la medida en que en la vivencia y en la acción se perfila el que las perspectivas de entendimiento que el sistema refiere a si mismo no pueden ser separadas de otras, es decir, que 
A consideração desses impasses e sua superação teriam ocorrido com a evolução, sobretudo, da linguagem que se destaca por intensificar a compreensão da comunicação para além do perceptível. ${ }^{58}$

Com base na linguagem teria sido possível o desenvolvimento dos meios de comunicação, como a escrita, a imprensa e as telecomunicações. Estes, tal como será abordado, detalhadamente, no capítulo seguinte, distinguem-se "do sistema dos meios de comunicação" diferenciado socialmente dos demais subsistemas comunicacionais da sociedade como a política, econômica e o direito, tendo por código funcional interno "a distinção entre informação e não-informação" (LUHMANN, 2005, p. 39). ${ }^{59}$

Nesse processo evolutivo, o enfrentamento do problema de aceitação da comunicação teria êxito com o desenvolvimento dos meios de comunicação simbolicamente generalizados, que, segundo Luhmann (1998, p. 159), seriam "aqueles meios que utilizam generalizações para simbolizar a relação entre seleção e motivação, quer dizer, para representar a unidade". A esse respeito, acrescenta ainda: "são importantes exemplos: verdade, amor, propriedade/dinheiro, poder/direito, e até certo ponto também a fé religiosa, a arte e atualmente, talvez, os 'valores básicos' civilizatoriamente padronizados". (LUHMANN, 1998, p. 159).

la horizontalidad del ego y del alter es imposible como resultado de una exploración ulterior". (LUHMANN, 1998, p. 95).

${ }^{58}$ Conforme explica Luhmann (1998, p. 158): “[...] El lenguaje es un medio que se caracteriza por el uso de signos; utiliza signos acústicos y ópticos referentes al sentido. Esto conduce a problemas complejos que se resuelven por medio de las reglas para el uso de los signos, mediante la reducción de la complejidad, la habituación de una combinatoria limitada. El procedimiento básico, no obstante, continúa siendo la regulación de la diferencia entre el acto de comunicar y la información. Tomada como signo, esta diferencia puede ser la base para la comunicación entre alter y de ego, y ambos pueden, en el uso univoco de los signos, confirmar su opinión de que pretenden lo mismo. Se trata, entonces, de una técnica muy especial cuya función es ampliar prácticamente al infinito el repertorio de la comunicación comprensible, asegurando así que casi cualquier acontecimiento pueda aparecer y ser trabajado como información".

${ }^{59}$ Em sentido amplo, sobre os meios de comunicação, afirma Luhmann (1998, p. 159): “[...] Estos medios se basan en una descomposición, en una recombinación incongruente de unidades linguísticas que no pueden disolverse más. Así se logra una expansión inmensa de la amplitud del proceso comunicacional que reactúa, a su vez, sobre lo que se comprueba como contenido de la comunicación. Los medios de comunicación seleccionan mediante su propia técnica, crean sus propias posibilidades de conservación, comparación y mejoramiento, las cuales, no obstante, sólo pueden ser utilizadas con base en estandarizaciones. En comparación con la tradición oral, sujeta a la interacción y a la memoria, los medios de comunicación se expanden y a la vez se limitan, y a asi la comunicación sirve como base para las comunicaciones siguientes". 
Os meios de comunicação simbolicamente generalizados diferem-se dos meios de comunicação em acepção ampla, uma vez que se formam a partir de uma evolução histórica do sistema em que se consolidam premissas de diferenciação relacionadas ao ambiente e, assim, possibilitam a condensação mais forte dos sentidos através de uma peculiar codificação binária da linguagem.

Nesse contexto, como exemplo de tal evolução, poderia ser citada, ainda que em linhas gerais nessa parte inicial do trabalho, a formação do sistema jurídico como um subsistema social. O direito, assim, estaria funcionalmente diferenciado em razão do desenvolvimento de um código binário próprio, lícito/ilícito (recht/unrecht), que lhe asseguraria a originária autorreprodução reflexiva de seus elementos básicos e a sua autonomia frente aos demais subsistemas sociais, ao passo em que operaria como centro gravitacional de uma rede circular e fechada de operações sistêmicas. ${ }^{60}$

A importância desses códigos binários com que os sistemas sociais operacionalizam seus processos comunicacionais consiste na síntese de sentidos neles presentes. Facilita-se, desse modo, o estabelecimento de ligações entre as premissas de decisões e os processos comunicacionais posteriores do sistema.

\footnotetext{
${ }^{60}$ Acerca do código binário do sistema jurídico, "lícito/ilícito", também expresso em língua portuguesa como "direito/não-direito", a sua definição parte da difícil tradução dos termos alemães recht e unrecht, que mesmo em sua língua de origem não seriam unívocos,. (VILLAS BÔAS FILHO, 2006b, p. 159). Em traduções inglesas de textos de Luhmann (1989a, 1995), por exemplo, esse código aparece referenciado tanto por lawful/unlawful quanto justice/injustice (LUHMANN, 1989a, p. 139) sem contar o recurso à reducionista terminologia legal/ilegal (LUHMANN, 1995, p. 286). Em francês, os tradutores, em geral, equivalem recht/unrecht aos termos légal/illégal (LUHMANN, 1989b, p. 56). Por sua vez, neste trabalho de doutoramento, diferentemente de trabalhos anteriores (CRUZ, 2007; CORREIA; CRUZ, 2007) será empregada a versão lícito/ilícito, pois, conforme Marcelo Neves (2007, p. xii), seria imprópria a utilização da expressão "direito/não-direito" na medida em o código em questão (recht/unrecht) diz respeito a uma diferença interna ao sistema jurídico. Opta-se, assim, por uma maior precisão terminológica, não obstante se reconheça a expressão "direito/não-direito" como não restrita a conteúdos morais nem legalistas, como as verões "justo/injusto" ou "legal/ilegal", e que a primeira ("direito/não-direito") seja usualmente empregada nas traduções espanholas das obras de Luhmann (2009, 1998), bem como por diversos de seus comentadores em língua portuguesa como Antunes (1989) Campilongo (2002), Schwartz (2004) e Villas Bôas Filho (2006b).
} 
No entanto, o surgimento de códigos binários não exclui de todo a complexidade do processo de seleção de sentidos e de diferenciação entre o sistema e seu ambiente, sendo, contingencial ao estágio evolutivo desse sistema. ${ }^{61}$

A sociedade se utilizaria desses mecanismos em seus processos comunicacionais internos de organização e diferenciação. Sistema e ambiente podem então ser entendidos como dois campos complementares que compõem a complexidade social.

Nesse sentido, os sistemas sociais e a própria sociedade, enquanto sistema social global, seriam o resultado de processos comunicacionais de suas interações com o ambiente e da diferenciação que perante este estabelecem. Dessa forma, não podem ser identificados com outros tipos de sistemas como os sistemas vivos e os sistemas psíquicos, nos quais se inserem os seres humanos, estes últimos entendidos como sistemas "não sociais" e ambiente da sociedade.

Esta distinção entre ser humano e sociedade corresponde a uma das questões mais polêmicas levantadas pela teoria luhmanniana. Refere-se ao deslocamento do ser humano para a esfera exterior do sistema social, para seu ambiente, uma vez que entende a sociedade, enquanto sistema, apenas como comunicação.

Tem-se, assim, a tese da separação entre os sistemas sociais e os sistemas psíquicos de modo que o relacionamento entre sociedade e humanidade se daria no acoplamento estrutural entre esses sistemas autopoiéticos, sendo que o primeiro opera na base da comunicação e o segundo na base da consciência. ${ }^{62}$

\footnotetext{
${ }^{61}$ Sobre essa peculiaridade, Rômulo Figueira Neves (2005) chama a atenção para o seguinte: "É importante notar que apenas sistemas que desenvolvem uma alta complexidade de seus elementos e uma alta complexidade na utilização da linguagem conseguem desenvolver um meio de comunicação simbolicamente generalizado. Apenas depois de gerar um grande número de possibilidades de produção de sentido e processos comunicativos internos o sistema pode condensar em código binário os sentidos sistêmicos. Os meios de comunicação simbolicamente generalizados estão, portanto, ligados à evolução dos sistemas sociais.” (NEVES, 2005, p. 27).

${ }^{62}$ Diferenciada dos sistemas psíquicos e orgânicos, a sociedade como sistema engloba um intrincado processo de comunicações que visa à redução da complexidade existente fora de si. Nesse sentido, Gotthard Bechmann e Nico Stehr (2001, p. 193) consideram a comunicação "uma operação genuinamente social (e a única que é conjunta socialmente) [...] porque pressupõe uma maioria de sistemas de consciência colaboradora ao mesmo tempo em que não pode (exatamente por essa mesma razão) ser atribuída como uma unidade a nenhuma consciência individual".
} 
A teoria luhmanniana, por empreender essa distinção, é acusada de difundir uma ideia de sociedade "radicalmente anti-humanista, não ontológica e construtivista" ${ }^{63}$

De fato, Luhmann (1998, p. 199) postula uma ruptura com a tradição humanista que considera o ser humano como elemento último da sociedade, que se encontraria dentro e não fora da ordem social.

O referido autor argumenta que, de forma similar, fora inicialmente impensável a separação entre alma e corpo e a própria decomposição de ambos que se seguiram com os desenvolvimentos sócio-estruturais decorrentes das revoluções políticas e industriais e com a diversificação das ciências, como a biologia, psicologia e sociologia, que passaram a se ocupar do ser humano de maneira separada e cada vez mais distanciada das regulações normativas do direito, dos conceitos religiosos e dos valores e fins políticos anteriores, centrados na referida normatividade natural da tradição humanista. ${ }^{64}$

Por sua vez, a reconstrução semântica de humanidade, para além daquela relacionada à ideia de ordem em sentido estrito e de sua normatividade natural, teve como seu primeiro passo as doutrinas contratuais do "direito racional tardio". ${ }^{65}$

Contudo, já no século XIX, com o desenvolvimento científico e sua gradual desvinculação do direito, política e religião, com especial atenção para os progressos da

${ }^{63}$ Conforme Bechmann e Stehr (2001, p. 189): “A suposição mais radical do enfoque teórico maduro de Luhmann é sua ênfase nas diferenças, mais precisamente nas distinções que não são mais vistas como diferenças objetivas, mas como construções. A substituição do conceito de sujeito e a transferência da diferenciação sujeitoobjeto para uma distinção entre sistema e ambiente levam Luhmann a uma teoria pós-ontológica da sociedade, desenvolvida numa base naturalística e empírica como uma teoria da observação. Esse questionamento fundamental da filosofia moderna do sujeito e sua distinção entre as ciências naturais e as humanidades (acrescido da rejeição de um conceito humanístico-antropocêntrico para definir a sociedade) atraiu um grande número de críticas, e mais incompreensão ainda, ao enfoque de Luhmann."

${ }^{64}$ A mencionada tradição não só considerava o homem como dependente da ordem social, mas que este estava ligado de uma maneira específica ao viver social de modo que "sua existência só poderia realizar-se em sociedade". Assim, segundo o autor citado, durante a Idade Média o caráter político (urbano) foi substituído pelo caráter social de ordem da sociedade, sendo esse princípio ampliado com a passagem do zoon politikon para o animal sociale, de modo que, em ambos os casos, a natureza do ser humano passou a ser concebida como determinada por requisitos normativos da ordem social. (LUHMANN, 1998, p. 199).

${ }^{65}$ Com essa terminologia, Luhmann (1998, p. 200) refere-se ao contratualismo iluminista que concebe a sociedade como um contrato e, assim, formula uma nova máxima para a consideração do homem em sociedade durante esse período de transição: livre, mas subordinada à autoridade da razão. 
biologia, as analogias da sociedade como organismo social, do qual o homem faria parte, parecem cada vez menos naturais, reforçando-se a crítica dessa visão humanista-naturalista. ${ }^{66}$

Por essas razões, Luhmann (1998, p. 201) rompe com as premissas do humanismo clássico e procura reposicionar o ser humano em sua teoria não como integrante do sistema social, mas sim de seu ambiente, o que, por sua vez, "não quer dizer que o homem deva ser considerado [neste novo paradigma sistêmico] como menos importante em comparação com a tradição".

O referido autor pretendeu demonstrar o equívoco das interpretações contrárias à consideração do humano como parte do ambiente da sociedade, sustentando a importância do ambiente para os sistemas sociais e as potencialidades cognitivas que esse reenquadramento oferece para a compreensão do próprio ser humano e de suas liberdades. A esse respeito, segundo o próprio Niklas Luhmann (1998, p. 201):

A teoria dos sistemas parte da unidade da diferença entre sistema e ambiente. O ambiente é um momento constitutivo desta diferença e, portanto, não é menos importante que o sistema em si. Nesse nível de abstração, a disposição da teoria permanece completamente aberta para valorizações distintas. O ambiente pode conservar aspectos que para o sistema podem ser mais importantes (seja qual for o ponto de vista) que os componentes do próprio sistema, mas a alternativa contrária é também teoricamente compreensível. Graças à distinção entre sistema e ambiente ganha-se a possibilidade de conceber o homem como parte do ambiente social de maneira mais complexa e, por sua vez, mais livre do que se lhe concebesse como parte da sociedade, posto que o ambiente, em comparação com o sistema, é o campo de distinções de maior complexidade e menor ordem. Assim, se concede ao ser humano mais liberdade em relação ao seu ambiente, particularmente certas liberdades de comportamento irracional e imoral. O ser humano não é já a medida da sociedade; é necessário descartar esta velha ideia do humanismo.

\footnotetext{
${ }^{66}$ Ainda a esse respeito, destaca-se na obra de Luhmann (1998, p. 200): “[...] Las ciencias mismas se distancian de las regulaciones normativas del derecho, de los conceptos religiosos, de los valores y los fines políticos. En el siglo XIX, el concepto de analogía del organismo da la impresión de encogimiento; sobre todo en relación con los progresos de la 'biología', da la impresión de no ser natural. Desde entonces se ha mantenido esta crítica. El humanismo emprende la retirada de la naturaleza hacia el espíritu. La sociología se pregunta por las bases no contractuales de la vinculación de los contratos. El hombre ya no es siquiera capaz de efectuar un contrato. Esto se lo debe a la sociabilidad, a la sociedad". Por essa razão, em outro trabalho, ao responder de forma irônica e ao mesmo tempo crítica aos seus opositores, o referido autor chega a afirmar: "In fact the theory of autopoietic systems could bear the title Taking Individuals Seriously, certainly more seriously than our humanistic tradition. Taken individual, no human being can be part of any other systems. Critics frequently miss this point". (LUHMANN, 1992, p. 1.422).
} 
Quem poderia sustentar, séria e ponderadamente, que a sociedade pode ainda configurar-se à imagem e semelhança do ser humano? ${ }^{67}$

Nesse mesmo sentido, Celso Fernandes Campilongo (2002, p. 68), ao tratar desse deslocamento dos seres humanos para o ambiente da sociedade, destaca: "Ao contrário do que imaginam os críticos mais apressados dessa tese, isso não comporta, de modo algum, desvalorização do homem perante a sociedade". Para justificar tal advertência, o referido autor reitera, em primeiro lugar, que a diferenciação entre sistema e ambiente, própria da teoria luhmanniana, por si, tem por consequência a atribuição de uma importância tão grande ao ambiente quanto aquela do sistema. ${ }^{68}$

\subsubsection{Autopoiese social: sentido e fechamento operacional}

Luhmann (1998), com base na descrita evolução ontogênica dos domínios linguísticos, destaca o papel fundamental do sentido como ganho evolutivo que possibilitou o desenvolvimento conjunto dos sistemas sociais e psíquicos para além da visão biológica. ${ }^{69}$

Os sistemas sociais e os próprios sistemas psíquicos teriam uma autopoiese própria e particular: o sentido, responsável tanto pela autorreferencialidade das operações internas

\footnotetext{
${ }^{67}$ Cf. o original: "La teoría de sistemas parte de la unidad de la diferencia entre sistema y entorno. El entorno es un momento constitutivo de esta diferencia y, por lo tanto, no es menos importante que el sistema mismo. En este nivel de abstracción, la disposición de la teoría queda completamente abierta para valoraciones distintas. El entorno puede conservar aspectos que para el sistema pueden ser más importantes (sea cual sea el punto de vista) que los componentes mismos del sistema, pero también la alternativa contraria es teóricamente comprensible. Gracias a la distinción entre sistemas y entorno se gana la posibilidad de concebir al hombre como parte del entorno social de manera más compleja y, a la vez, más libre que si se le concibiera como parte de la sociedad, puesto que el entorno, en comparación con el sistema, es el campo de distinción de mayor complejidad y menor orden. Así, se conceden al ser humano más libertades en relación con su entorno, particularmente ciertas libertades de comportamiento irracional e inmoral. El ser humano no es ya la medida de la sociedad; es necesario descartar esta vieja idea del humanismo. ¿Quién podría sostener, seria y ponderadamente, que la sociedad puede aún configurarse a imagen y semejanza del ser humano?" (LUHMANN, 1998, p. 201).

${ }^{68}$ Ainda a esse respeito, Campilongo (2002) afasta a possibilidade de que por essa distinção se considere que "o sistema possa manobrar ou conduzir os homens ao seu bel prazer", sendo que, dado a diversidade de possibilidades das relações entre eles estabelecidas, "o sistema não pode determinar o ambiente (do mesmo modo que a sociedade também é mais complexa do que os sistemas psíquicos e nunca é inteiramente determinada ou compreendida pelos indivíduos)". (CAMPILONGO, 2002, p. 68-69).

${ }^{69}$ Conforme anteriormente explicitado, para Humberto R. Maturana e Francisco J. Varela (2005, p. 220-221), a referida evolução ontogênica dos domínios linguísticos teria possibilitado o acoplamento estrutural de terceira ordem entre os seres humanos e a formação dos sistemas sociais.
} 
desses sistemas quanto pela ocorrência de suas interações. Diferenciam-se, dessa forma, dos sistemas biológicos, para os quais a construção das relações entre sistema e ambiente só seria possível através das seleções de comportamento por outro sistema observador. (LUHMANN, 1998, p. 58-59).

Apesar de diversos, ambos os sistemas autopoiéticos (sociais e psíquicos) são considerados pela teoria luhmanniana como imprescindíveis um para o outro, servindo cada qual de ambiente necessário para sua evolução. ${ }^{70}$

Nesse contexto, a ideia de sentido não se limita unilateralmente à de consciência, em sua existência psíquica, restrita ao consenso e à harmonia do comportamento como seu próprio fundamento consciente. De maneira mais abrangente, "o fenômeno do sentido aparece sob a forma de um excedente de referências a outras possibilidades de vivência e de ação" presente em seu processo de seleção desses sistemas. (LUHMANN, 1998, p. 78).

Enquanto forma de seleção, os mecanismos de dotação de sentido dos processos comunicacionais e psíquicos permitem a estabilização sistêmica, ao passo em que restringem a complexidade a ser considerada, possibilitando a utilização dos sentidos selecionados pelos próprios sistemas em suas operações futuras.

Trata-se assim de redução, e não de exclusão, da complexidade, mesmo porque seria contraditório à própria finalidade de sua nova teoria sociológica supor que Luhmann (1998) estivesse propondo sua exclusão a despeito de considerar tal complexidade como a característica essencial da sociedade moderna.

A esse respeito, ao tratar do caráter reflexivo da compreensão autopoiética não só da sociedade como da própria ciência, tece as seguintes observações:

[...] A apresentação da teoria, portanto, aplica a si mesma o que aconselha: redução da complexidade. Contudo, complexidade reduzida não significa complexidade excluída, mas sim complexidade elevada. Deixa aberto o acesso a outras possibilidades sempre que suas definições sejam levadas em consideração ou sejam substituídas no justo lugar que a teoria exige. Se

\footnotetext{
${ }^{70}$ As razões dessa interdependência relacionam-se à evolução de um instrumental comum: “[...] As pessoas não podem permanecer nem existir sem os sistemas sociais e vice e versa. A coevolução é conduzida através desse ganho comum [o sentido] que é utilizado tanto pelos sistemas psíquicos como sociais". (LUHMANN, 1998, p. 77).
} 
abandonasse o nível das definições, desapareceria na neblina o acesso a outras possibilidades de traços lineares e se cairia novamente na complexidade indefinida e impossível de processar. (LUHMANN, 1998, p. 10). ${ }^{71}$

Seria, então, possível destacar a presença em cada sentido de uma complexidade "inconcebivelmente alta (complexidade do mundo) que, se mantém disponível para a operação dos sistemas psíquicos e sociais”. Assim, segundo a forma e não o conteúdo, o sentido é entendido como "reprodução de complexidade, uma forma de reprodução que permite o uso pontual onde é empregado, e que por sua vez identifica qualquer uso como seleção e o faz, se é possível assim dizer, responsável”. (LUHMANN, 1998, p. 79).

Acrescente-se que a produção de sentido presente em todos os sistemas psíquicos e sociais permite não só seus processos autorreferenciais como implica em consequências para as relações que se estabelecem entre sistema e ambiente. A esse respeito afirma Luhmann (1998, p. 79):

\begin{abstract}
Nem todos os sistemas processam a complexidade e a autorreferência em forma de sentido. Contudo para aqueles que o fazem, só existe essa possibilidade de processamento. Para esses, o sentido se constitui na forma de mundo com que se transcende a diferença entre sistema e ambiente. $\mathrm{O}$ ambiente se dá em forma de sentido e os limites do ambiente são limites de sentido; [...] O sentido, em geral, e os limites de sentido, em particular, garantem o nexo insuperável entre sistema e ambiente mediante uma forma especial de sentido: remissões redundantes. ${ }^{72}$
\end{abstract}

Tais "remissões redundantes" que compõe o processo de dotação de sentido devem ser entendidas com base no fechamento operacional dos sistemas autorreferenciais e

\footnotetext{
${ }^{71}$ Cf. o original: "[...] La presentación de la teoría, por lo tanto, aplica a sí misma lo que aconseja: reducción de complejidad. Pero complejidad reducida no significa complejidad excluida, sino complejidad elevada. Deja abierto el acceso a otras posibilidades siempre que sus definiciones sean tomadas en cuenta o sean sustituidas en el lugar preciso que requiere la teoría. Si se abandonara el nivel de las definiciones, desaparecería en la neblina el acceso a otras posibilidades de trazos lineales y se caería de nuevo en la complejidad indefinida e imposible de procesar". (LUHMANN, 1998, p. 10).

${ }^{72}$ Cf. o original: "[...] No todos los sistemas procesan la complejidad y la autorreferencia en forma de sentido. Pero para aquellos que lo hacen, solo existe esa posibilidad de procesamiento. Para ellos, el sentido se constituye en la forma del mundo con lo cual se trasciende la diferencia entre sistema y entorno. El entorno se da en forma de sentido y los límites del entorno son límites de sentido; por consiguiente, se remiten, al mismo tiempo, hacia afuera y hacia dentro. El sentido, en general, y los límites del sentido, en particular, garantizan el nexo insuperable entre sistema y entorno mediante la forma especial del sentido: remisiones redundantes". (LUHMANN, 1998, p. 79).
} 
em seu processo interno de diferenciação. Essa clausura operativa dos sistemas sociais é que lhes permitiria produzir de maneira recursiva a seleção desses sentidos e, ao mesmo tempo, tornar possível a geração de novos elementos a partir das informações que se depreendem de seu ambiente.

Luhmann (1998, p. 90) decompõe o sentido em três dimensões: a objetiva, a temporal e a social.

A primeira relaciona-se, nos sistemas psíquicos, a todos os objetos com intenção de sentido e, no caso dos sistemas sociais, aos temas de comunicação plena de sentido. Torna, então, possível que sua estrutura remissiva decomponha aquilo a que se refere em "este" e o "outro", como pontos de referência operacionalizados de referências do mundo, sendo horizontes que intervém na constituição objetiva do sentido. (LUHAMNN, 1998, p. 91-92).

Por sua vez, a segunda dimensão do sentido, temporal, refere-se à “diferença entre o antes e o depois", e permite aos sistemas de sentido lidarem com horizontes especiais que se prolongam em direção ao passado e ao futuro, diferenciando-se entre o presente e o ausente. ${ }^{73}$

Nesse contexto, como fora apenas introduzida, a "designação história não deve ser entendida como simples sequencia real de acontecimentos em razão da qual se pode conceber o presente como efeito de causas passadas ou como causa de efeitos futuros". Para a referida teoria sistêmica, a história constitui uma dimensão específica do sentido de tempo relacionada ao estabelecimento discricionário de sentido e aos acontecimentos passados ou futuros que permitem saltar a sua sequencia temporal, tendo lugar "quando as sequencias são desligadas". (LUHMANN, 1998, p. 94).

\footnotetext{
${ }^{73}$ Cumpre, então, destacar que, segundo Luhmann (1998, p. 93): “El tiempo es para los sistemas de sentido, la interpretación de la realidad en relación con la diferenta entre pasado y futuro. Aquí, el horizonte del pasado (y también el del futuro) no representa el principio (o el final) del tiempo. El concepto de horizonte excluye precisamente la idea de principio o de final. Más bien, todo el pasado y todo el futuro fungen como horizontes del tiempo - independientemente de que sean representados cronológicamente y en forma lineal o no, De cualquier manera, es imposible experimentar o actuar en alguna parte del pasado o del futuro, pues los horizontes del tiempo cambian de sitio con el avance del tiempo. Futuros y pasados —en ese sentido, completamente idénticos - pueden intentarse o todavía mejor tematizarse, pero no experimentarse o manejarse".
} 
Por fim, a dimensão social, enquanto terceira dimensão de sentido citada, diz respeito ao "que se supõe respectivamente igual, como alter ego e articula a relevância desta suposição para cada experiência do mundo e fixação de sentido”. (LUHMANN, 1998, p. 94).

O social seria então parte do sentido não porque se vincula a determinados objetos, mas por ser portador de uma reduplicação particular de possibilidades de entendimento. Isto porque os conceitos ego e alter, empregados por Luhmann (1998, p. 95), "não designam aqui papéis, pessoas ou sistemas senão horizontes especiais que agregam e atribuem peso às remissões plenas de sentido".

Uma vez redimensionada na teoria luhmanniana para a compreensão dos processos comunicacionais e conscientes autorreferenciais de dotação de sentido, a dimensão social apresenta-se como um horizonte duplo que se torna relevante na medida em que as perspectivas de entendimento referidas pelo sistema decorrem da vivência e da ação, mesmo que estas não possam ser separadas uma das outras. ${ }^{74}$

Contudo, é a partir de sua clausura operativa que os sistemas sociais podem produzir de maneira recursiva a seleção desses sentidos gerando novos elementos com base nas informações que se depreendem de seu ambiente.

Assim, essa recursividade dos sentidos que compõe o seu repertório autorreferencial possibilita não só sua reprodução e a auto-observação de seus elementos internos como, também, a observação externa e o acoplamento com outros sistemas que

\footnotetext{
${ }^{74}$ Para o referido sociólogo alemão, o social não se deixa reduzir aos resultados de consciência de um sujeito monádico, o que indicaria o fracasso de todas as tentativas teóricas de constituição subjetiva ou da intersubjetividade. Sobre essa diferenciação conceitual, adverte Luhmann (1998, p. 94-95): “Es importante evitar cualquier tipo de amalgama entre dimensión social y dimensión objetiva. Este ha sido y es el error cardinal del humanismo. El hombre ha sido conceptuado en distintas versiones por su diferencia con el animal, y dotado de sociabilidad (animal social) y de temporalidad (memoria, phantasia, prudentia) y así finalmente declarado sujeto. Aun la teoría del sujeto ubica la relación interna/externa donde deberían distinguirse con base en el doble horizonte, la dimensión objetiva u la dimensión social. A pesar de ello, sin embargo, el hombre sigue siendo un objeto preferido junto al cual existen otros - lo que es evidente en la tendencia hacia la reantropologización de la filosofia trascendental y en su concepto de sujeto. El humanismo también reproduce un concepto de naturaleza y, por lo tanto, debe enfrentarse al dilema de su propia limitación. Es necesario no interpretar la distinción entre dimensión objetiva e dimensión social como distinción entre naturaleza y hombre. El progreso teórico estriba precisamente en evitar este angostamiento humanista".
} 
compõem o seu ambiente, posto que permite ao sistema social referenciá-los como informação para seus processos comunicacionais. ${ }^{75}$

Os sentidos, na teoria social luhmanniana, contribuem dessa forma para o processo de diferenciação do sistema, estando presentes em todas as suas operações. ${ }^{76}$

O fechamento operacional dos sistemas sociais se perfaz graças à criação e reprodução de seus elementos de funcionamento em seu interior sem a interferência ou influência de elementos externos, os quais podem contribuir apenas indireta e eventualmente para esse processo em face da recursividade daqueles mecanismos de seleção que compõem processos comunicacionais desses sistemas autopoiéticos.

Dessas considerações, segundo Gotthard Bechmann e Nico Stehr (2001, p. 189), resulta a descrição dos fenômenos sociais como interações e a ideia de que "o mundo (como

${ }^{75}$ Essas três dimensões de sentido exercem na teoria de luhmanniana uma função importante em relação à destautologização da auto-referência do sentido. A esse respeito, discorre Luhmann (1998, p. 91): "[...] El sentido tiene sentido: esto permanece como un hecho (correspondientemente no se ponen en duda afirmaciones como: todo sentido tiene sentido, sólo el sentido tiene sentido). Al mismo tiempo, la autorreferencialidad del sentido se reespecifica dimensionalmente con ayuda de las diferencias de cada una de las dimensiones especificas. El futuro es futuro sólo respecto de un presente con pasado; pero no es el pasado y tampoco retorna a él (como lo sugería el modelo circular). Mi consenso sólo lo es en relación con tu consenso, y no hay ninguna clase de argumento objetivo o racional que finalmente pudiera asegurar esa coincidencia (de nuevo, desde la dimensión objetiva). Las autorreferencias deben articularse dentro de cada dimensión del sentido, no puede ser producida por los horizontes de otra dimensión. Por ejemplo, el consenso no puede sustituir al futuro ni ser sustituido por el horizonte objetivo interno del sistema (en esto, por ejemplo, el psicoanálisis, reclama su competencia). Sin embargo, en la medida en que se establecen las diferencias en las dimensiones del sentido (las diferencias de las diferencias de las dimensiones específicas), las interdependencias entre las dimensiones pueden servir para la condicionalización y destautologización de las autorreferencias. Los círculos se romperán. El mundo objetivo obliga a pensar al tiempo asimétricamente, y este obliga a pensar asimétricamente, como gradiente de complejidad, a la relación entre mundo externo y mundo interno. Sólo de esta manera se puede extraer del mundo complejidad estructurada plena de sentido, en la que las operaciones de los sistemas de sentido pueden encontrar su lugar".

${ }^{76}$ Segundo Rômulo Figueira Neves (2005, p. 40): “[...] Para completar o processo comunicativo, o sistema necessita dotar as informações e os acontecimentos de sentido referenciando a um repertório existente e a um meio de comunicação simbolicamente generalizado. Para existir sentido é necessário um sistema que organize formas de relacionar e selecionar as informações e os processos comunicativos. A principal característica da dotação de sentido, para o sistema, é a concepção da virtualidade, ou seja, a capacidade de intelecção de que dada informação ou evento tinha outras possibilidades, outros caminhos possíveis e que, em virtude de uma seleção, outras possibilidades foram abandonadas. Esta característica envolve por um lado o reconhecimento de outras possibilidades no passado e por outro, e por isso mesmo, a manutenção de alternativas para o futuro. Assim, o mecanismo de dotação de sentido dos processos comunicativos restringe a finalização do processo a uma compreensão, ao mesmo tempo em que também abre a possibilidade para outras operações, que se utilizam daquela como pressuposto. O processo de dotação de sentido também torna permanente a capacidade dos sistemas de se auto-reproduzirem, na medida em que mantém como possíveis todas essas operações que fazem parte do repertório do sistema e que dão lugar a novas operações." 
horizonte de descrições possíveis) é expresso por meio de uma rede de distinções e rótulos contingentes que sempre devem ser entendidos dentro do contexto". Nesse sentido, acrescentam os autores citados:

Sistema, para Luhmann, quer dizer uma série de eventos relacionados um ao outro, ou de operações. No caso dos seres vivos, por exemplo, esses são processos fisiológicos; no caso de sistemas psíquicos, os processos são ideias; e em termos de relações sociais, são comunicações. Os sistemas se formam ao se distinguirem do ambiente, no qual esses eventos e operações ocorrem, e que não pode ser integrado a suas estruturas internas. (BECHMANN; STEHR, 2001, p. 190).

Essa ênfase no aspecto relacional dos sistemas e a ideia correlata de sua separação do ambiente distinguem a teoria sistêmica de Luhmann (1998) daquela proposta por Talcott Parsons (1974) que, em linhas gerais, em seu funcionalismo de persuasão, destaca a adesão coletiva a normas e padrões compartilhados como definição de sistemas.

Por sua vez, para a teoria luhmanniana, essa fronteira operacional (não espacial) dos sistemas sociais é vista, sobretudo, em relação aos sistemas psíquicos (individuais) e demais sistemas que fazem parte de seu ambiente ou entorno. (LUHMANN, 1998).

Essa diferenciação operacional e as estruturas dos sistemas sociais emergentes não seriam, porém, um dado pré-estabelecido ou pré-ordenado, muito menos autoevidente, mas um processo contínuo de novas construções do ponto de vista existencial de sua forma, portanto, contingenciais e relacionados ao aumento da complexidade social. No mais, diferentemente do funcionalismo de persuasão parsoniano, Luhmann, com essa teorização, não estaria comprometido com a preservação dos sistemas sociais. (BECHMANN; STEHR, 2001, p. 191).

A sociedade vista como um sistema autopoiético de comunicação, caracterizado pela organização autorreprodutiva e circular de processos comunicacionais, permitiu, assim, a Niklas Luhmann (1998) explicar a evolução das sociedades modernas desenvolvidas através de um fenômeno de diferenciação funcional. 


\subsubsection{A relação entre dupla contingência, expectativas e programação sistêmicas e o desenvolvimento dos meios de comunicação simbolicamente generalizados}

O descrito fechamento operacional dos sistemas sociais corresponde a todo um processo de criação e reprodução de elementos de funcionamento em seu interior.

Essa dinâmica autopoética, por sua vez, torna impossível a sua total compreensão através de uma observação externa, tanto a partir do ambiente quanto do interior de outros sistemas de sentidos, sejam eles também sociais, como, por exemplo, o sistema científico; ou psíquicos, como, da mesma forma exemplificada, a consciência do pesquisador.

Disso decorreria uma segunda noção de contingência desses processos comunicacionais relacionada, para além do sentido de complexidade do mundo, à referida impossibilidade de se prever completamente suas condições de existência e as operações internas realizadas por esses sistemas.

Tanto essas condições como as operações citadas são passíveis de mudança em qualquer momento em razão da ampla possibilidade de decisões e de escolhas de sentido que caracterizam a própria complexidade social que o sistema visa reduzir.

Dessa forma, destaca-se, como importante característica da Teoria dos Sistemas Sociais autopoiéticos em estudo, a existência de uma dupla contingência. (LUHMANN, 1998, p. 113).

Para maior clareza, essa dupla contingência não se restringe à dificuldade do sistema em lidar com a complexidade desorganizada presente no ambiente, a qual o leva a se diferenciar recorrendo à autorreferência e ao fechamento operacional de seus processos comunicacionais. Seu caráter dúplice decorre, sim, dessa própria diferenciação funcional que tornaria o sistema não totalmente decifrável ("não-transparente") a seus próprios elementos e ao ambiente.

Em razão dessa "não-transparência", não apenas o ambiente, como os próprios elementos do sistema restariam impossibilitados de prever as respostas sistêmicas aos estímulos selecionados de seu exterior ou mesmo àqueles resultantes de suas inter-relações 
com outros sistemas de sentido (acoplamentos estruturais e interpenetrações, a serem discutidos na seção seguinte). ${ }^{77}$

Essa dupla contingência é reconhecida pelos sistemas, os quais criam mecanismos de seleção em suas operações, sendo que estes passam a fazer parte de seu repertório sistêmico visando à sua proteção frente a mais essa improbabilidade de comunicação.

Por sua vez, nessa nova tentativa de redução e estruturação da complexidade através do desenvolvimento do repertório comunicativo próprio do sistema, a mesma volta paradoxalmente a se potencializar com a formação de expectativas operacionais seja, do ponto de vista interno ao sistema, entre seus elementos, seja entre os sistemas de sentido (sociais e psíquicos).

As referidas expectativas vinculam-se nesse processo, ao desenvolvimento dos meios de comunicação simbolicamente generalizados e de sua aparente previsibilidade.

A relação entre esses meios e a criação de expectativas comunicacionais resulta da aparente previsibilidade gerada pelos meios de comunicação, simbolicamente generalizados, que permitirem ao sistema facilitar suas operações seguintes, conectando-as às operações internas pré-existentes e, assim, eventualmente reiterar suas mensagens, repetições e decodificações anteriores em seus processos de dotação de sentido e de seleção das informações. ${ }^{78}$

Nessa fase inicial do trabalho, cumpre destacar que tais expectativas e as operações reflexas delas decorrentes são geradas pela observação mútua entre os sistemas, sendo, muitas vezes, conflitantes e contraditórias entre si. Justamente nesse contexto, como se

77 Acerca do conceito de contingência na teoria dos sistemas luhmannianos disserta Rômulo Figueira Neves (2005, p. 17): "Essa impossibilidade de previsão pelo ambiente externo das respostas do sistema social a irritações externas, para as quais há uma gama de possibilidades, gera o conceito de contingência, ou seja, não há como uma informação externa pré-determinar uma resposta visto que também internamente há contingências [dupla contingência] que possibilitam processos evolutivos do sistema. Assim, qualquer estímulo externo, como irritação ou ruído, que interesse ao sistema social operacionalmente fechado, é internalizado a partir de processos internos de dotação de sentido".

${ }^{78}$ Sobre essa aparente previsibilidade, assinala Rômulo Figueira Neves (2005, p. 33): "Os sistemas não têm a expectativa de que suas operações sejam adotadas igualmente por outro sistema e sabem que o mesmo ocorre com a expectativa do outro sistema. As referências [e essas próprias expectativas] do sistema são voltadas para si, já que não podem prever ou definir a operação dos outros sistemas. Forma-se, nessa relação, uma equação com muitas variáveis que têm de ser levadas em conta pelos sistemas, como a expectativa de Alter sobre as operações de Ego e as expectativas de Ego em relação às operações de Alter." 
pretende discutir, que as relações de interação, interpenetração e acoplamento estrutural podem ocorrer. Porém, de início, cabe ressaltar que essa observação entre os sistemas e as inter-relações dela decorrentes não pressupõe necessariamente qualquer cooperação, coordenação ou simbiose entre os mesmos. (NEVES, 2005, p. 35).

Paralelamente a essa observação realizada pelo sistema do ambiente e dos demais sistemas que compõe seu entorno, ocorre também, internamente aos sistemas sociais em seu processo autorreferencial e autopoiético, uma constante auto-observação de seu funcionamento, relacionada à sua própria capacidade de controle e ao grau de programação de algumas de suas funções. Nesse sentido:

Deve-se mencionar, com particular ênfase, uma consequência estrutural importante que resulta, forçosamente, da construção dos sistemas autorreferenciais: a renúncia à possibilidade de controle unilateral. Pode haver diferenças na capacidade de influência, hierarquias, assimetrizações, mas nenhuma parte do sistema pode controlar a outra sem sucumbir ao mesmo tempo ante o controle. Sob tais circunstâncias é possível, e ainda muito provável, nos sistemas que têm orientação de sentido, realizar um controle mediante a antecipação de um contra-controle. Apesar disso, a garantia de uma estrutura todavia assimétrica (por exemplo, nas condições internas do poder de um sistema) sempre necessita de disposições particulares. Essa problemática do controle se nivela, em parte, ao acentuar a auto-observação. Nesse contexto, isto é, no nível da teoria geral dos sistemas, observação não significa outra coisa que manejo de distinções. Só no caso dos sistemas psíquicos, o conceito pressupõe consciência (se poderia dizer também que, motivado pela observação, surge o meio próprio do sistema, a consciência). Outros sistemas têm que agregar suas próprias possibilidades de observação. A auto-observação é a introdução da diferença entre sistema e entorno no sistema que se constitui através desta diferença. Dita diferença é, por sua vez, um momento operativo da autopoiese, já que na reprodução dos elementos deve assegurar sua reprodução como elementos do sistema e não como qualquer coisa distinta. (LUHMANN, 1998, p. 58). ${ }^{79}$

\footnotetext{
${ }^{79}$ Cf. original: "Se debe mencionar, con particular énfasis, una consecuencia estructural importante que resulta, forzosamente, de la construcción de los sistemas autorreferenciales: la renuncia a la posibilidad de control unilateral. Puede haber diferencias en la capacidad de influencia, jerarquías, asimetrizaciones, pero ninguna parte del sistema puede controlar a otro sin sucumbir él mismo ante el control. Bajo tales circunstancias es posible, y aún muy probable, en los sistemas que tienen una orientación de sentido, llevar a cabo cualquier control mediante la anticipación de un contracontrol. A pesar de esto, la garantía de una estructura todavía asimétrica (por ejemplo, en las condiciones internas del poder de un sistema) siempre necesita de disposiciones particulares. Esta problemática del control se nivela, en parte, al acentuar la autobservación. En este contexto, es decir, en el nivel de la teoría general de sistemas, observación no significa otra cosa que manejo de distinciones. Sólo en el caso de los sistemas psíquicos, el concepto presupone la conciencia (se podría decir también que, motivado por la observación, surge el medio propio del sistema, la conciencia). Otros sistemas
} 
Nessa dimensão funcional, os programas surgem como forma de controle interno das operações sistêmicas. Através deles é que os sistemas sociais estabelecem as condições sob as quais certos processos comunicacionais podem ocorrer e quais processos devem suceder a ocorrência de determinadas operações internas.

Esse segundo nível de contingência sistêmica seria parcialmente reduzido em função dessa programação na medida em que, por meio dos referidos programas, os sistemas poderiam verificar o direcionamento de suas operações a despeito de sua evolução indeterminada e contingente. ${ }^{80}$

Essa programação do sistema seria complementar à função desempenhada pelo código binário na evolução do sistema. Contudo, ao contrário destes e dos meios de comunicação simbolicamente generalizados, os programas dependeriam do direcionamento que o sistema social assume ao longo de seu processo de evolução, sendo, por isso, flexíveis. (NEVES, 2005, p. 30).

Para a descrita teoria luhmannina, os programas mais encontrados nos sistemas sociais são de caráter finalístico ou condicional. (LUHMANN, 1998, p. 290).

Nesse sentido, os programas finalísticos têm por função coordenar as operações sistêmicas para determinados resultados estipulados internamente e que, por esse motivo, constituem o objetivo da programação.

Estabelecem, assim, quais seleções devem ser consideradas como válidas para se atingir determinados fins. Tais programas finalísticos coordenam ainda a participação das

tienen que allegarse sus propias posibilidades de observación. La autobservación es la introducción de la diferencia entre sistema y entorno en el sistema que se constituye a través de esta diferencia. Dicha diferencia es, a la vez, un momento operativo de la autopoiesis, ya que en la reproducción de los elementos debe asegurarse su reproducción como elementos del sistema y no como cualquier cosa distinta”. (LUHMANN, 1998, p. 58).

${ }^{80}$ Segundo a síntese explicativa proposta por Rômulo Figueira Neves (2005, p. 30): “As expectativas de operações de Alter e Ego são bastante delineáveis no âmbito dos programas. Além disso, as expectativas podem ser conectadas em uma cadeia de operações que dependem entre si, tanto na dimensão da ocorrência propriamente dita, quanto na ordem e na determinação temporal dos diversos processos comunicativos. Dessa forma, os programas servem para diminuir sensivelmente a contingência dos processos comunicativos do sistema no qual operam o programa. Isso não significa que a contingência foi eliminada, nem que os resultados dos processos sobrecomunicativos possam ser previstos, mas apenas que objetivos prévios ou requisitos mínimos foram definidos". 
pessoas, no curso das interpenetrações entre os sistemas sociais e psíquicos, em seus diversos processos comunicacionais. (NEVES, 2005, p. 31).

Já os programas condicionais definem situações e requisitos em que processos comunicacionais deverão ser realizados. Essas definições disponibilizam aos elementos do sistema critérios sob os quais devem ser organizadas as operações do sistema social em que esse programa é desenvolvido. Em outras palavras, permitem ao sistema, em sua autoobservação, avaliar a conformação dos procedimentos às condições fixadas pelo programa.

Paralelamente, no que diz respeito à outra característica dessa teoria luhmanniana dos sistemas sociais autopoiéticos, tem-se que a diferenciação dos sistemas não se restringe ao ambiente, mas pode também ocorrer, ainda que de forma um pouco diversa, no interior do próprio sistema social.

Sob o ponto de vista das diferenciações funcionais internas, em sua Teoria da Sociedade, Niklas Luhmann (1998, p. 182) sustenta que, a partir desse processo comunicacional geral, novos e específicos circuitos comunicativos vão sendo gerados e desenvolvidos até que estes, enquanto processos comunicacionais emergentes, atinjam um determinado grau de complexidade e perficiência na sua própria organização auto-reprodutiva que os levam a se autonomizarem do sistema social geral, originando subsistemas sociais autopoiéticos.

O referido processo em que surgem subsistemas sociais autopoiéticos é de suma importância para a compreensão de toda a teoria sistêmica social ora estudada, posto que se objetiva, neste trabalho, delinear as potencialidades e limitações de tal teoria para a compreensão do funcionamento dos sistemas jurídico e dos meios de comunicação de massa e suas inter-relações na definição e generalização dos sentidos das políticas públicas de seguridade social de maneira conflitante para toda sociedade. ${ }^{81}$

\footnotetext{
${ }^{81}$ Ressalte-se porém que Luhmann, seguindo uma continuidade em sua obra, ao que tudo indica direcionou seus estudos para a busca da compreensão do funcionamento interno dos sistemas sociais, presente já em seus trabalhos anteriores como em Legitimação pelo procedimento (1980), do que teria resultado uma supervalorização dessa dinâmica interna em detrimento da exploração das potencialidades das inter-relações comunicativas externas, entre os sistemas. (CAMPILONGO, 2000a, p. 81-82). Ademais, em sua dissertação de mestrado intitulada Acoplamento estrutural, fechamento operacional e processos sobrecomunicativos na Teoria dos Sistemas Sociais de Niklas Luhmann, Rômulo Figueira Neves (2005, p. 72) esclarece que "pesquisas nesse
} 
A autonomização do sistema social geral em subsistemas pressupõe a constituição de novos processos comunicacionais através da elevação da complexidade e completude da comunicação produzida em alguns de seus circuitos emergentes. Nesses circuitos especializados surgem novos códigos binários e eventualmente programas sistêmicos próprios que passam a guiar as suas operações auto-reprodutivas de subsistemas sociais a partir da consolidação de novos meios de comunicação simbolicamente generalizados.

Ressalta-se neste ponto que o processo de diferenciação funcional do sistema social global implica no pressuposto teórico de que nenhum dos vários subsistemas emergentes - v.g. os sistemas jurídico, político ou econômico — pode reivindicar a supremacia sobre os demais sistemas sociais, nem sequer pretender substituí-los em suas respectivas funções. (LUHMANN, 1992, p. 1434-1435).

Dessa forma, a teoria sistêmica, nos termos até aqui desenvolvidos, propiciou a quebra da tradicional oposição entre sistemas fechados e sistemas abertos na medida em que, no paradoxo autopoiético da clausura auto-reprodutiva, os sistemas biológicos, psíquicos ou sociais estão "abertos" ao meio envolvente graças à clausura operativa do próprio sistema. ${ }^{82}$

sentido foram iniciadas por Luhmann, com os estudos de estrutura social e semântica (Gesellschaftstruktur und Semanitk), mas ele não conseguiu completá-las [até o fim de sua vida]". Nessa linha, os "processos sobrecomunicativos" são apontados na citada dissertação de mestrado como formas de inter-relações sistêmicas não expostas claramente na teoria luhmanniana. Tais processos poderiam, grosso modo, ser entendidos como situações de peculiar suspensão da clausura operativa do sistema que possibilitariam rápidas e reversíveis sujeições de parte de seu processo comunicativo a influências externas em situações muito específicas. (NEVES, 2005, p. 67).

${ }^{82}$ A esse respeito, Luhmann (1992) diferencia expressamente a teoria dos sistemas sociais da teoria dos sistemas abertos. Destaca, ainda, a inexistência de uma causalidade direta entre as relações do sistema social com seu ambiente o que só é factível a partir de um processo de seleção própria de um terceiro sistema observador que correlaciona a estrutura do sistema com determinadas interações. Situa-se, ao menos nesse ponto, na mesma linha de Humberto R. Maturana e Francisco J. Varela (2005, p. 150-151), posto que entendem que o meio não específica nem sequer instrui as mudanças estruturais do sistema, sendo a relação de causalidade dela decorrente criada pela seleção e dotação de sentido de uma observação externa: "The emergence of closed systems requires a specific form of relations between systems and environments; it presupposes such forms and is a condition of their possibility as well. The theory of 'open systems' describes the forms with the categories of input and output. This model postulates a causal chain in which the system itself serves as the connecting part linking inputs and outputs. The theory of autopoietic systems replaces the input/output model with the concept of structural coupling. It renounces the idea of an overarching causality (admitting it, of course, as a construct of an observer interested in causal attributions), but retains the idea of highly selective connections between systems and environments". (LUHMANN, 1992, p. 1431-1432). 
Em outras palavras, chega-se à conclusão de que a abertura e adaptação de um sistema autopoiético ao seu meio envolvente dependem, paradoxalmente, da capacidade que esse sistema tem de manter intacta a sua própria autoreferencialidade.

Em consequência, graças à visão autopoiética, é afastada da relação dos sistemas sociais com o meio em que estão inseridos, a visão até então dominante desses sistemas como realidades totalmente abertas — da qual resultou a crença na capacidade de se regular exogenamente tais sistemas, através de estímulos e respostas diretas (inputs-outputs), o que garantiria uma adaptação constante desses sistemas ao meio continuamente em mutação. (LUHMANN, 1998, p. 33).

À luz das ideias de autoreferencialidade de suas operações, de unidade e identidade dos sistemas, passa-se a considerar como fator de sua sobrevivência e estabilidade, frente às mudanças de seu meio envolvente, a sua própria capacidade de auto-observação e auto-organização. (ANTUNES, 1989, p. xvi).

Portanto, esse processo de diferenciação funcional interna e a própria natureza autoreferencial dos sistemas autopoiéticos denotam a impossibilidade de se compreender os problemas e as peculiaridades de um dado sistema, a partir de uma observação que lhe seja exterior. A teoria autopoiética repercute, assim, no campo da gnosiologia e epistemologia de modo a negar a separação entre a construção científica e seus objetos. (LUHMANN, 1998, p. 424).

\subsubsection{Inter-relações sistêmicas e a criação e generalização de expectativas sociais}

O relacionamento entre os sistemas sociais e destes com os elementos de seu ambiente ocorre, segundo a forma e grau de complexidade, através da formação de acoplamentos estruturais e as interpenetrações. ${ }^{83}$

\footnotetext{
${ }^{83}$ Os termos acoplamento estrutural e interpenetração decorrem de um aprimoramento teórico de Luhmann, não tendo sido criados simultaneamente. Sobre isso esclarece Rômulo Figueira Neves (2005, p. 49): "O conceito [de acoplamento estrutural] não existia no esboço inicial da teoria, apresentado em Soziale Systeme [em 1984]. Até então, Luhmann utilizava o termo interpenetração, originário da teoria parsoniana, para designar todas as relações inter-sistêmicas. A partir de Die Wissenschaft der Gesellschaft [obra de 1992], o conceito de acoplamento estrutural passa a ser utilizado para designar as relações inter-sistêmicas em geral e o termo interpenetração passa a designar um caso específico". Essa segunda hipótese, a ser restritamente denominada de interpenetração consiste na relação entre sistemas sociais e sistemas psíquicos, que já era tratada na primeira obra mencionada
} 
Por acoplamentos estruturais, em sentido amplo, denominam-se as relações entre os sistemas sociais e os elementos de seu ambiente, como outros sistemas sociais ou sistemas psíquicos. Correspondem ao aparato, simultaneamente sutil e complexo, com que um sistema se vale das estruturas de funcionamento de outro sistema a fim de viabilizar seus próprios processos comunicacionais. Segundo Niklas Luhmann (1992, p. 1.432):

O acoplamento estrutural entre sistema e ambiente não contribui com operações (ou quaisquer outros componentes) para a reprodução do sistema. É apenas a forma específica com que o sistema pressupõe estados específicos ou mudanças em seu ambiente e neles confia. A caminhada pressupõe forças gravitacionais da Terra com limites muito estreitos, mas a gravitação não contribui com quaisquer passos para o movimento dos corpos. A comunicação pressupõe estados atentos de sistemas de consciência, mas estados conscientes não podem se tornar sociais nem entram na sequência de operações comunicativas como parte destas; eles se mantém como estados ambientais para o sistema social. Acoplamentos estruturais são formas simultâneas (e, portanto, não causais) de relações. ${ }^{84}$

Em suas operações normais, os sistemas sociais não estariam sujeitos à observação das estruturas de seus acoplamentos. Contudo, em função das seleções realizadas nessa estruturação, o sistema tem que lidar com perturbações, irritações, surpresas e desapontamentos de modo a assimilar e acomodar tais ambiguidades. Essas perturbações se apresentam como construções internas, como divergências de expectativas relacionadas à própria estrutura sistêmica.

Cumpre, porém, destacar que, para Luhmann (1992, p. 1.432), o ambiente não contém em si perturbações nem quaisquer outras formas a isso assemelhadas. Portanto, não se pode falar em transmissão de perturbações do exterior para o interior do sistema.

inicialmente publicada em 1984, cuja versão espanhola - Sistemas Sociales: lineamientos para una teoría general, de 1998 - é utilizada nesse trabalho.

${ }^{84}$ Cf. original: "The structural coupling of system and environment does not contribute operations (or any other components) for the reproduction of the system. It is simply the specific form in which the system presupposes specific states or changes in its environment and relies on them. Waling presupposes the gravitational forces of the earth within very narrow limits, but gravitation does not contribute any steps to the movement of bodies. Communication presupposes awareness states of conscious systems, but conscious states cannot become social and do not enter the sequence of communicative operations as a part of them; they remain environmental states for the social system. Structural couplings are forms of simultaneous (and therefore, not casual) relations". (LUHMANN, 1992, p. 1.432). 
Isto porque, tanto o conceito de clausura operacional quanto o de acoplamento estrutural não são compatíveis com a ideia de trânsito ou troca de informações entre sistema e ambiente.

$\mathrm{O}$ mesmo se aplica às expectativas cognitivas. Assim como as seleções de informação são sempre construídas internamente, as expectativas cognitivas não passam de formas específicas do sistema se preparar para irritações (surpresas, imprevisibilidades) que ele antecipa da observação de outros sistemas e de seu ambiente. ${ }^{85}$

Enquanto condição de cognição, os acoplamentos estruturais são fundamentais para o processo comunicacional sistêmico, sem os quais não haveria a percepção de perturbação, retirando do sistema as "oportunidades de aprendizado e de transformação de suas estruturas". (LUHMANN, 1992, p. 1.433).

Dada à formação de alto grau de complexidade interna, tais acoplamentos apresentam-se como condição para a construção de regularidades, ordem e redundância necessárias para reduzir e ordenar a complexidade desorganizada frente a grande variedade de escolhas de sentido e de direcionamento de ações. (LUHMANN, 1998, p. 169-170).

A construção de regularidades internas do sistema depende, portanto, de acoplamentos estruturais. Nessa linha, esclarece Rômulo Figueira Neves (2005, p. 49):

Quando há um acoplamento estrutural, o processo comunicativo de um sistema aparece no outro não apenas como uma perturbação, mas também como uma ferramenta auxiliar de funcionamento das operações, seu significado, no entanto, vai ser construído apenas dentro do próprio sistema em que foi realizado o processo comunicativo, de forma independente do significado que tinha naquele sistema original. Apenas a complexidade

\footnotetext{
${ }^{85}$ De modo ilustrativo, pode ser citado o sintético exemplo proposto por Rômulo Figueira Neves (2005) em sua dissertação sobre o tema: "Outro modo de exemplificar o funcionamento do acoplamento estrutural é partindo da análise do acoplamento entre o sistema política e o sistema direito [sic] na elaboração das leis, no processo legislativo. Por um lado, a elaboração das leis é um processo político, que envolve as decisões de poder, a votação de determinações que vinculam toda a população que pertence àquela jurisdição política. Esse processo, no entanto, utiliza e obedece a certos parâmetros legais (que um dia já passaram pelo processo político) e pode ser questionado com base em códigos jurídicos que estão fora do escopo de atuação da política. Os legisladores não precisam ser bacharéis em direito para representar a população nas votações das leis, ou seja, o sistema político não precisa compreender a complexidade do sistema jurídico para realizar suas operações, no máximo precisa conhecer algumas limitações que podem gerar sanções e eliminar a comunicação do sistema político." (NEVES, 2005, p. 52).
} 
operacional de um sistema do ambiente é reproduzida dentro do sistema que realiza o processo comunicativo, não seus processos de cognição.

Por sua vez, as interpenetrações referem-se aos acoplamentos estruturais entre sistemas sociais e sistemas psíquicos.

Nesse sentido, para delimitar as especificidades dessa inter-relação sistêmica, é preciso retomar como tais sistemas psíquicos são entendidos no pensamento luhmanniano, em razão de sua oposição, já introduzida neste trabalho, às noções de ser humano e pessoa consolidadas pela tradição humanista.

A teoria dos sistemas sociais em questão distingue a expressão ser humano do termo pessoa. Em linhas gerais, ser humano refere-se tanto aos sistemas psíquicos quanto aos sistemas orgânicos do homem. Já a palavra pessoa, nessa específica teoria, é utilizada para designar uma unidade referenciada na comunicação, existindo tão somente na comunicação e para a comunicação, ou seja, como "a identificação social de um complexo de expectativas dirigidas a um homem individual”. (LUHMANN, 1998, p. 199).

A diferença central entre essa conceituação sistêmica e aquela empregada pela tradição humanista diz respeito à posição do ser humano e ao seu papel em relação à ordem social sendo que, para o referido humanismo clássico, o ser humano ocupa o centro da ordem social, estando dentro e não fora dela, como elemento da própria sociedade.

Já no que diz respeito à teoria luhmanniana, os sistemas psíquicos e consequentemente os seres humanos corporizados não constam dos sistemas sociais, ou seja, do interior da sociedade moderna, tida como um sistema global de comunicações, mas sim de seu exterior como importantes sistemas autopoiéticos presentes no ambiente da sociedade, cada qual com formação autônoma fundada em suas próprias operações elementares. (LUHMANN, 1998, p. 236).

Por sua vez, aos sistemas psíquicos aplicam-se os conceitos básicos de reprodução fechada e autorreferencial. Porém, diferentemente dos sistemas sociais, sua recursividade consiste na produção de consciência a partir de seus elementos internos de consciência. 
Dada a sua clausura operacional, os sistemas psíquicos não dependem, em tese, do ambiente e, por conseguinte, não recebem consciência do exterior nem podem lhe transferir tal elemento.

Destaca-se, contudo, que, para a mencionada teoria, por consciência deve-se entender tão somente o modo de operação peculiar dos sistemas psíquicos e não algo que exista substancialmente.

Nesse sentido e a partir dos estudos de Edmund Husserl sobre a consciência e seu papel nos sistemas psíquicos, segundo Luhmann (1998, p. 242):

Não há dúvida de que os sistemas psíquicos são sistemas autopoiéticos em virtude de sua situação frente ao ambiente (sobretudo porque são sistemas autopoiéticos constituídos sobre a base da consciência e não sobre a base da vida). Utilizam a consciência só no contexto de suas próprias operações e todos os contatos com o entorno (inclusive os que se estabelecem com o próprio corpo) estão mediados pelo sistema nervoso, ou seja, têm que utilizar outros níveis de realidade. O sistema nervoso mesmo é um sistema fechado e por esta razão o sistema psíquico que opera com a consciência tem que se edificar exclusivamente sobre elementos que se constituem a si mesmos. ${ }^{86}$

Os sistemas de consciência produzem em seu interior representações do mundo através de circuitos operativamente fechados com base em representações anteriores para, assim, ascender a novas representações.

Tal processo reiterado de reprodução de representações a partir de representações permitiria entender que a própria consciência consiste no reconhecimento da temporalidade da consciência, não restrita à sua dependência do tempo. Nesse contexto apresenta-se "a tese de que a consciência com todas as suas retenções e antecipações sempre opera no presente e que,

${ }^{86}$ Cf. o original: "No cabe duda de que los sistemas psíquicos son sistemas autopoiéticos en virtud de su situación ante el entorno (sobre todo porque son sistemas autopoiéticos constituidos sobre la base de la conciencia y no sobre la base de la vida). Utilizan la conciencia sólo en el contexto de sus propias operaciones y todos los contactos con el entorno (incluidos los que se establecen con el propio cuerpo) están mediados por el sistema nervioso, es decir, tienen que utilizar otros niveles de realidad. El sistema nervioso mismo es un sistema cerrado y por esta razón el sistema psíquico que opera con la conciencia tiene que edificarse exclusivamente sobre elementos que se constituyen a si mismos". (LUHMANN, 1998, p. 242). 
portanto, nela não pode haver temporalidade, continuamente tem que se sustentar e subsistir a si mesma (o que Derrida chamará de 'diferença' - différance)". (LUHMANN, 1998, p. 242). ${ }^{87}$

Em função dessas peculiaridades, ao contrário do senso comum, uma vez que os sistemas sociais de sistemas psíquicos apresentam-se de forma separada, a observação destes últimos não permite a observação em si de sua consciência.

Frente a essas limitações, a formação de expectativas é destacada como mecanismo autopoiético de redução da complexidade externa decorrente tanto das relações entre sistema psíquico e sistema social, quanto daquele com o seu ambiente.

Do ponto de vista dos sistemas psíquicos, a expectativa deve ser considerada como a forma com que esses sistemas podem se expor à contingência do mundo. Sobre essa questão Luhmann (1998) discorre de maneira comparativa:

[...] Então, se trata da mesma forma [de redução da complexidade] utilizada para a formação de estruturas sociais. Num dos casos está proposta como consciência; no outro, como comunicação. De acordo com isso, o conceito de expectativa tem que ser concebido muito amplamente para poder abarcar a sua aplicação no psíquico e no social, assim como nas interdependências correspondentes. [...] Relacionada aos sistemas psíquicos, entendemos por expectativa uma forma de orientação por meio da qual o sistema observa a contingência de seu entorno em relação consigo mesmo e a acolhe como incerteza própria no processo de reprodução autopoiética. (LUHMANN, 1998, p. 246). ${ }^{88}$

Assim, o ambiente enquanto complexidade desorganizada não tem nenhum tipo de participação direta no operar fechado da autopoiese psíquica. Sua complexidade é articulada e reprocessada pelo sistema psíquico apenas através das expectativas, possibilitando-lhe o seu

\footnotetext{
${ }^{87}$ Cf. o original: "[...] la tesis de que la conciencia con todas sus retenciones y anticipaciones siempre opera en el presente y que, por lo tanto, en ella no puede haber temporalidad, continuamente tiene que sustentarse y sustituirse a sí misma (lo que Derrida llamará la 'diferencia'-différance)”. (LUHMANN, 1998, p. 242).

${ }^{88}$ Cf. o original: "[...] Entonces, se trata de la misma forma que se utiliza para la formación de estructuras sociales. En uno de los casos está propuesta como conciencia; en el otro, como comunicación. De acuerdo con esto, el concepto de expectativa tiene que concebirse muy ampliamente para poder abarcar la aplicación a lo psíquico y a lo social, así como a las interdependencias correspondientes. [...] En cuanto a los sistemas psíquicos, entendemos por expectativa una forma de orientación por medio de la cual el sistema sondea la contingencia de su entorno en relación consigo mismo y la acoge como incertidumbre propia en el proceso de la reproducción autopoiética". (LUHMANN, 1998, p. 246).
} 
entendimento e utilização de modo operativo. Nas palavras do referido autor: "o sistema se projeta e logo registra se o esperado ocorre ou não". (LUHMANN, 1998, p. 247).

A formação de expectativas consiste, portanto, numa "técnica primitiva de antonomásia” que pode ser trabalhada quase sem condições prévias posto que não pressupõe uma descrição nem um conhecer a fundo do ambiente.

Daí porque, ainda segundo Luhmann (1998, p. 247): "se pode gerar uma expectativa sem conhecer o mundo", tendo como única condição necessária que tal expectativa seja autopoieticamente utilizável, ou seja, que pré-estruture o acesso às representações de enlace.

Tanto a realização de algumas expectativas quanto a formação de frustrações mediante o recursivo repertório de novas possibilidades de comportamento que surgem novamente pré-estruturadas seriam o resultado desse processo, de tal forma que:

[...] Depois de um determinado tempo de vida, e enriquecidas pelas experiências sociais, as expectativas perdem o caráter de arbitrárias. No avanço normal de uma representação em direção à outra não se cairá no inusitado. Um indivíduo se orienta inevitavelmente pela própria história de sua consciência, por mais singular que tenha sido seu desenvolvimento; a determinação da experiência atual assegura que não possam formar-se qualquer tipo de expectativas. Para isso estão à disposição tipos socialmente padronizados, com os quais um indivíduo pode orientar-se. (LUHMANN, 1998, p. 247). ${ }^{89}$

Não haveria, portanto, a possibilidade de comunicação no interior ou entre os sistemas psíquicos porque os processos psíquicos não seriam processos linguísticos. Tampouco o pensamento comportaria qualquer forma de "conversa interior" (hablar interior), como equivocadamente teria sido sempre sustentado, pois lhe falta o "destinatário interior". No sistema de consciência não haveria um "segundo eu", enquanto instância adicional que

${ }^{89}$ Cf. o original: “[...] Después de un determinado tiempo de vida, y enriquecidas por las experiencias sociales, las expectativas pierden el carácter de arbitrarias. En el avance normal de una representación hacia la otra no se caerá en lo inusitado. Uno se orienta inevitablemente por la propia historia de la conciencia, por más singular que haya sido su desarrollo; la determinación de la experiencia actual asegura que no puedan formarse cualquier tipo de expectativas. Para ello están a disposición tipos socialmente estandarizados con los cuales uno se puede orientar". (LUHMANN, 1998, p. 247). 
examinasse o pensamento linguisticamente formado, no sentido de aceitá-lo ou rechaçá-lo como decisão que trataria de antecipar. (LUHMANN, 1998, p. 249-250).

Em diferentes níveis autopoiéticos existiriam também no ser humano reproduções autorreferenciais fechadas, similares à autorreprodução do sistema social. Essas poderiam ser divididas em reprodução orgânica, cujo meio seria a forma de manifestação da vida, e reprodução psíquica, fundada na consciência.

Do ponto de vista da Teoria da Sociedade luhmanniana, os sistemas autopoiéticos, vida e consciência, seriam a condição da formação dos sistemas sociais de tal forma que "os sistemas sociais só podem se auto-reproduzir se a continuação da vida e da consciência estiver garantida". (LUHMANN, 1998, p. 206).

A interpenetração não pode, assim, ser entendida como a relação de duas coisas separadas, muito menos conforme a representação esquemática de círculos que se entrecruzam parcialmente.

Os limites de cada sistema podem ser adaptados no campo de operação do outro, ou seja, todo sistema que participa na interpenetração realiza em si mesmo o outro, como diferença entre sistema e ambiente sem com isso desintegrar-se.

Nesse sentido, cada sistema pode realizar então sua própria complexidade em relação ao outro, suas próprias descrições e reduções, e, com base nisso, pôr à disposição do outro sua própria complexidade.

Por essa razão, a comunicação dos sistemas sociais está obrigada a se orientar continuamente por aquilo que os sistemas psíquicos adotam ou não em sua consciência, porque os limites dos sistemas psíquicos não são, por sua vez, limites das possibilidades de comunicação. (LUHMANN, 1998, p. 205).

De maneira conclusiva, tem-se que as interpenetrações, enquanto formas especiais de acoplamentos estruturais, são necessárias para a própria existência dos sistemas, pois "a existência dos sistemas psíquicos são condição necessária para a existência dos sistemas sociais, assim como o sistema biológico é condição necessária para a existência dos sistemas psíquicos e vice-versa". (NEVES, 2005, p. 50). 


\subsubsection{As interações e organizações como sistemas parciais e a emergência de novos processos comunicacionais}

As interações e organizações apresentam-se como sistemas sociais parciais, formados por relações inter-sistêmicas, sociais e psíquicas, que constituem processos comunicacionais próprios, dos quais podem emergir novos sistemas sociais mais complexos.

As interações correspondem a formas específicas de relação entre sistemas psíquicos através de relações diretas e presenciais entre os seres humanos. A partir da percepção mútua, de tais interações decorrem processos comunicacionais, como modo rudimentar de informação.

Sociedade e interação representam processos distintos na medida em que esta se refere a uma espécie peculiar de sistema social que surge entre os presentes, enquanto que a sociedade representa o conjunto de todas as comunicações sociais possíveis. Nesse sentido, de acordo com Luhmann (1998, p. 373):

A sociedade e a interação são dois sistemas sociais distintos. A sociedade garante o fechamento pleno de sentido e a auto-referência de acontecimentos comunicacionais, isto é, garante a cada interação a capacidade de início e finalização, assim como o enlace de sua comunicação. Nos sistemas de interação se apresenta uma espécie de hidráulica da interpenetração. A atração e a pressão da presença atuam sobre os presentes e os motivam a renunciar à sua própria liberdade em favor de determinadas restrições. Por conseguinte, a sociedade não é possível sem interpenetração e vice-versa. Mas ambos os sistemas não se fundem; são indispensáveis um ao outro em sua diferença. ${ }^{90}$

Por sua vez, enquanto espécies de sistema social, às interações se aplicam as distinções entre exterior e interior e o fechamento sistêmico como modo operativo.

Destacam-se, porém, os processos de percepção decorrentes das relações entre sistemas psíquicos fisicamente presentes como importante característica dos sistemas de

\footnotetext{
${ }^{90}$ Cf. o original: "La sociedad y la interacción son dos sistemas distintos. La sociedad garantiza la cerradura plena de sentido y autorrefencial de acontecimientos comunicacionales; es decir a cada interacción le garantiza la capacidad de inicio y finalización, así como el enlace de su comunicación. En los sistemas de interacción se presenta una especie de hidráulica de la interpenetración. La atracción y la presión de la presencia actúan sobre los presentes y los motivan a renunciar a su propia libertad a favor de determinadas restricciones. Por consiguiente, la sociedad no es posible sin interpenetración y viceversa. Pero no se funden ambos sistema; son indispensables uno para el otro en su diferencia”. (LUHMANN, 1998, p. 373).
} 
interação. Isto porque é justamente através da presença física - em que se realizam essas específicas relações entre sistemas psíquicos — que se configuram processos de percepção necessários à constituição dos sistemas de interação. ${ }^{91}$

A presença dos sistemas psíquicos num dado tempo e espaço gera esse fenômeno de percepção reflexiva que, por sua vez, pode dar início aos processos comunicacionais de maneira quase inevitável, isto porque, segundo Luhmann (1998, p. 370):

[...] Se alter percebe que é percebido e que sua percepção de ser percebido é percebida, tem que partir de que seu comportamento é interpretado como um comportamento corretamente adaptado. $\mathrm{O}$ fato de que lhe convenha ou não, é também percebido como comunicação que lhe obriga, quase que inevitavelmente, a controlar seu comportamento como comunicação. Inclusive a comunicação de não querer se comunicar segue sendo uma comunicação. [...] Podemos afirmar que, praticamente, nos sistemas de interação é impossivel não comunicar, caso opte por evitar a comunicação, deve-se escolher a ausência. ${ }^{92}$

A dimensão social do sentido percebido desempenha funções de seleção, o que produz o próprio limite desses sistemas sociais de interação. Por essa razão, a presença é o princípio constitutivo e formador dos limites dos sistemas interacionais.

Essa reunião de pessoas - no sentido estrito de conjunto de expectativas socialmente identificadas - conduz a seleção de percepções e elege as perspectivas em função de sua relevância. (LUHMANN, 1998, p. 371).

A seleção dos temas de maneira concreta resulta da interação sendo, assim, contingente. Tal contingência represente sua própria sociabilidade, seja em relação ao ambiente da interação, ou a outras possibilidades de relacionamento que se apresentam aos participantes.

91 A percepção aqui tratada, ao contrário da comunicação, é um processo menos exigente de seleção de informação. Nesse contexto, pode ser entendida, em linhas gerais, como um ganho de informação psíquica que se transforma em fenômeno social através de uma articulação de dupla contingência marcada pela percepção recíproca e expectativas dela decorrente, isto é, a percepção que um indivíduo tem de ser percebido na presença de outro e vice-versa. (LUHMANN, 1998, p. 269).

${ }^{92}$ Cf. o original: "[...] Si alter percibe que es percibido y que su percepción de ser percibido es percibida, tiene que partir de que su comportamiento es interpretado como un comportamiento correctamente adaptado. El hecho de que le convenga o no, es también percibido como comunicación, lo que le obliga, casi inevitablemente, a controlar su comportamiento como comunicación. Incluso la comunicación de no querer comunicarse sigue siendo una comunicación. [...] Podemos afirmar que, prácticamente, en los sistemas de interacción es imposible no comunicar, si se quiere evitar la comunicación, ha que escoger la ausencia”. (LUHMANN, 1998, p. 370). 
Nesse processo de interação, selecionam-se entre possibilidades determinadas, ou pelo menos cada vez mais determináveis, aquelas situações que mantém abertas só uma quantidade limitada de variantes de desenvolvimento com que sua autopoiese pode lidar. (LUHMANN, 1998, p. 375).

No que diz respeito às ações decorrentes das interações, segundo Luhmann (1998, p. 377): "seria um erro pensar numa diferença sistema/ambiente ou ainda supor que a sociedade compreende [apenas] operações abstratas e a interação, de forma oposta, de operações concretas (comunicações, ações)" apenas porque a comunicação social se realiza em sua grande parte, embora não exclusivamente, como interação.

Não obstante essas considerações, "a sociedade não exclui, mas inclui a interação. Portanto, não se dá uma separação entre distintos tipos de ação: sociais e interacionais". (LUHMANN, 1998, p. 377).

Apesar do intrincando processo de comunicação que pode ser desenvolvido a partir dessa especial forma de inter-relação sistêmica que é a interação, nos limites do presente trabalho cumpre apenas relacionar essa sua contribuição para a redução da complexidade e para a operacionalização dos processos comunicacionais.

Isso se dá com a seleção de sentidos que constituem a diferenciação de cada um dos sistemas psíquicos envolvidos, bem como do próprio sistema social em que essas interações ocorrem, o que, por sua vez, pode levar à formação de outros sistemas sociais mais complexos.

Por fim, para que se possa compreender o direito como um sistema social autopoiético, deve-se, antes, destacar algumas considerações sobre os sistemas organizacionais e seu tratamento na teoria dos sistemas sociais de Luhmann $(1993,1998)$.

Nesse sentido, as organizações são tidas como espécies peculiares e parciais de sistemas sociais resultantes de acoplamentos estruturais entre sistemas sociais complexos.

Desenvolvem um código de comunicação próprio e diferenciado pela consideração de um critério especial: a ideia de pertencimento. Por essa razão, não seria possível a exata descrição de seus limites, posto que sua abrangência é expressa através de categorias como “membro e não-membro". (LUHMANN, 1993, p. 188). 
Os processos comunicacionais desses sistemas organizacionais, em sua autopoiese, não se restrinjem à seleção de sentidos através de códigos de pertencimento, sendo também possível sua diferenciação através de certas "vias de comunicação", formadas por meio de estruturas hierárquicas dentro da organização, as quais determinam as posições e a diferenciação interna do sistema organizacional. (NEVES, 2005, p. 60).

Destaca-se, ainda, nos sistemas organizacionais a existência de programas referentes aos seus objetivos, metas e condições em que tais objetivos devem ser alcançados. Estes programas determinam não só os limites de atuação dos membros das organizações, no sentido das decisões que lhes são atribuídas, como, também, o próprio modo de ascensão dentro da hierarquia da organização, dentre outros aspectos de seu funcionamento. ${ }^{93}$

Assim, como será tratado nos capítulos seguintes, partidos políticos, escolas, universidades e empresas midiáticas, dentre outras organizações sociais, desenvolvem processos comunicacionais que têm significado em mais de um sistema funcional consolidado, embora essas organizações em si estejam, em sua grande parte, reconhecidamente vinculadas a um determinado sistema funcional.

Tal vinculação não impede que as organizações enquanto sistemas parciais de comunicação tenham também relevância para outros sistemas consolidados. Isto decorre da dupla referência semântica de seus processos comunicacionais.

Os sistemas organizacionais moldam suas estruturas com as operações próprias daqueles outros sistemas, não sendo, portanto, compostos de processos comunicacionais de um único sistema social, mas o resultado do acoplamento estrutural entre sistemas sociais consolidados.

Os sistemas organizacionais, contudo, "não podem preencher todo potencial funcional de nenhum dos sistemas sociais - economia, ciência, política etc. — acoplados”, apesar de seu

93 Segundo Rômulo Figueira Neves (2005, p. 60): "Estas definições criam as vias por onde os processos comunicacionais podem ser canalizados - com a linguagem, essas vias constituem um meio para a ocorrência do processo comunicacional". 
importante papel para a redução da complexidade e mesmo para a administração e seleção de conflitos em relação a esses sistemas sociais. (NEVES, 2005, p. 59). ${ }^{94}$

Os sistemas interacionais e organizacionais são ainda fundamentais para o processamento comunicativo dos conflitos sociais, os quais, na teoria luhmanniana dos sistemas, devem ser entendidos como a comunicação de uma contradição no sentido de expectativas não aceitas. Tais conflitos referem-se a um procedimento de comunicação preciso e empiricamente concebido que comunica uma negação, um “não", por assim dizer, a uma comunicação anterior.

A expectativa social, segundo Luhmann (1998, p. 350), "não tem que referir-se necessariamente ao comportamento rechaçado, pode se referir também a terceiros ou constituir-se na descrição de uma realidade que não é crível para aquele a quem se comunica”.

Os conflitos, portanto, não se resumem à frustração ou negação de uma expectativa projetada por outro sistema desde que seja possível deduzir que a comunicação foi compreendida. No caso específico do conflito, para a sua configuração devem ocorrer duas comunicações contraditórias. (LUHMANN, 1998, p. 350).

Enquanto forma de sentido, essa contradição apresenta-se como a síntese de duas comunicações que, por sua vez, correspondem cada qual o produto de três etapas de seleção indissociáveis - informação, participação e compreensão. ${ }^{95}$

${ }^{94}$ Por outro lado, conforme disserta Rômulo Figueira Neves (2005, p. 61): "Paradoxalmente, as organizações podem ser as guardiãs de alguns processos comunicativos essenciais para o sistema ascendente, mesmo tendo esses processos comunicativos sentidos e relevância em outros sistemas por conta do acoplamento estrutural. É assim, por exemplo, com as organizações igrejas, para o sistema religião, universidade, para o sistema ciência, e partidos, para o sistema política: processos comunicativos essenciais dos sistemas ascendentes, o culto e a pregação, na igreja, a experiência e o exame de validade, na universidade, as convenções e as disputas, nos partidos, têm relevância não apenas no sistema ascendente, mas também em sistemas acoplados. O pastor bem articulado pode estar angariando poder político a ser transformado em um mandato no parlamento nas próximas eleições; o aluno aplicado pode estar angariando prestígio junto a um empregador potencial com os resultados de um experimento científico; e o candidato pode estar vislumbrando uma melhor remuneração do que a recebida em seu emprego ordinário. A relevância das realizações da organização, reconhecidas como parte dos sistemas sociais ascendentes, confere mais autonomia e legitimidade à autopoiese destes sistemas no conjunto da sociedade".

${ }^{95}$ Acerca do conceito de contradição utilizado por Niklas Luhmann (1998, p. 324 e ss.) na formulação de sua Teoria da Sociedade, é preciso destacar a profunda diferença de sentido e função por ele atribuídos a esse termo. $\mathrm{O}$ autor citado se opõe tanto a noção geral e valorativa que restringe as contradições a erros lógicos, ou infrações contra as regras da lógica que se deve evitar, quanto ao uso restrito de sua função "dialética". A despeito dessa tradicional construção teórica do campo da lógica e da própria sociologia, para a sua teoria dos sistemas a contradição deve ser entendida como "[...] uma indefinição do sistema e não uma indefinição de uma operação 
Sob essa perspectiva, seria um equívoco atribuir à ocorrência de um conflito "uma falta de comunicação (como se a comunicação fosse algo 'bom' suscetível de fracassar)”. De maneira oposta, para Luhmann (1998, p. 350):

[...] o conflito assume momentaneamente a autopoiese, a continuação da comunicação. [...] A comunicação é o processo autopoiético dos sistemas sociais que continua mais além de todos os episódios cooperativos ou antagônicos, sempre que continue. Os conflitos, portanto, servem, precisamente, para a continuação da comunicação por meio do emprego de uma das possibilidades que mantém abertas: a utilização do não.. ${ }^{96}$

$\mathrm{Na}$ teoria luhmanniana, os conflitos surgem corriqueiramente em quase todos os sistemas, como formações cotidianas, e em sua grande parte "constituem banalidades que se resolvem rapidamente".

Critica-se, por essa razão, "uma teoria dos conflitos" restrita a motivos estruturais ou que só considere os conflitos de "classe" ou de "dominação" como conflitos propriamente ditos. Dessa forma, perder-se-ia de vista "o caráter maciço deste fenômeno e a irrelevância das circunstâncias em que surgem (e em seu lugar introduzir-se-ia dados de fatos que todavia não chegam a um verdadeiro enfrentamento)". (LUHMANN, 1998, p. 352).

particular" (LUHMANN, 1998, p. 327). Distingue-se, portanto, a atribuição de contradições aos sistemas sociais daquela usualmente referida aos processos operativos dos sistemas psíquicos, posto que se desenvolvem com base em meios diversos: comunicação e consciência. Assim, “[...] Só nos sistemas psíquicos a unidade da contradição consiste em ter consciência de que o contraditório implica na impossibilidade de sua existência, e isso se reflete como 'mera' consciência. A consciência pode seguir adiante graças à contradição, ao atribuí-la a si mesma e ao controlar sua continuação e sua relação com a realidade, mas isso não é mais do que uma opção operativa". (LUHMANN, 1998, p. 329). Por sua vez, quanto aos sistemas sociais, em razão dos mesmos só existirem enquanto sistemas de comunicação, as contradições são produzidas mediante a comunicação de uma negação, tendo, nesse contexto, uma "existência exclusivamente comunicacional (que por sua vez, sem embargo, provoca mais ou menos consciência)". As contradições estariam "incluídas na auto-referência comunicacional dos sistemas sociais, se concebem como um momento dessa auto-referência e não como ataques ao exterior. A comunicação realiza a unidade (e com ela também a possibilidade de contradição), através de uma tríplice seleção. Informação, ato de comunicar e ato de entender são praticados como unidade, mesmo quando sejam distintos os respectivos conteúdos de consciência dos participantes e seus horizontes de seleção. [...] [Conclui-se, então, que:] Por meio dessa unidade de comunicação, o sistema social constitui as contradições válidas para ele". (LUHMANN, 1998, p. 330).

${ }^{96}$ Cf. o original: "[...] el conflicto asume momentáneamente la autopiesis, la continuación de la comunicación. [...] La comunicación es el proceso autopoiético de los sistemas sociales que continúa más allá de todos los episodios cooperativos o antagónicos, siempre que continúe. Los conflictos, por lo tanto, sirven, precisamente, para la continuación de la comunicación por medio del empleo de una de las posibilidades que mantiene abiertas: la utilización del no”. (LUHMANN, 1998, p. 350). 
Nesse contexto, os conflitos guardam estreita relação com os sistemas interacionais e organizacionais. Isto porque nos conflitos interacionais, que são também conflitos sociais, é possível identificar sinais de sua relevância social. Nesses específicos processos comunicacionais é maior a probabilidade de que um conflito "se estenda, se aprofunde e se perpetue”. (LUHMANN1998, p. 353).

Em razão do conflito podem emergir novos processos comunicacionais para além do sistema de interação, revelando interpenetrações entre os sistemas psíquicos nele presentes e outros sistemas sociais. Como exemplo dessa possibilidade, tem-se, a partir dos temas em conflito, a remissão a referências políticas, morais, científicas e de direito como formas de buscar apoio externo ao sistema de interação. Segundo Luhmann (1998, p. 353):

[...] Também a moral e o direito tendem a fomentar o conflito ao fazer crer a um dos rivais que sua posição é a correta e que é possível expor o adversário ao repúdio público ou ainda à sanção dos tribunais. Da mesma maneira, a argumentação científica pode garantir apoio aos conflitos. Assim, os médicos se arriscam nos conflitos (de fato, seus órgãos representativos são os mais combatíveis na política) porque sabem como curar as enfermidades e podem advertir ao rival que se trata de seu próprio enterro. Posto que, ninguém está em condição de obrigar que se faça a partilha da riqueza, o capital também é fonte do aumento de conflitos sociais. Parte das grandes conquistas da sociedade capitalista é, precisamente, haver dotado os donos do capital de uma grande capacidade de oposição e, em consequência, de atitude de conflito frente à política, a qual, não obstante, é tecnicamente soberana $\mathrm{e}$ aparentemente autônoma para escolher seus próprios meios. ${ }^{97}$

A partir de tais considerações não se pode, porém, concluir uma divisão de competências funcionais entre os sistemas de interação e a sociedade, como se coubesse aos primeiros enfrentar pequenos conflitos e, à sociedade, os grandes conflitos sociais.

\footnotetext{
${ }^{97}$ Cf. o original: "[...] También la moral y el derecho tienden a fomentar el conflicto al hacer creer a uno de los rivales que su posición es la correcta y que es posible exponer al adversario al rechazo público o aun a la sanción de los tribunales. De la misma manera, la argumentación científica puede garantizar o apoyo a los conflictos. Así, los médicos se arriesgan en los conflictos (en efecto, sus órganos representativos son los más combativos en la política) porque saben cómo curar las enfermedades y pueden advertirle al rival que se trata de su propio entierro. Puesto que, nadie está en condición de obligar a que se lleve a cabo la repartición de la riqueza, el capital también es fuente de incremento de conflictos sociales. Parte de las grandes conquistas de la sociedad capitalista es, precisamente, el haber dotado a los dueños del capital de una gran capacidad de rechazo y, en consecuencia, de la aptitud de conflicto frente a la política, la cual, no obstante, es técnicamente soberana y aparentemente autónoma para escoger sus propios medios. (LUHMANN, 1998, p. 353).
} 
Na presente Teoria da Sociedade, as seleções estruturais de conflitos passam a ser o resultado da própria "diferença entre o sistema de interação e o sistema social" na medida em que os sistemas de interação se reproduzem unicamente na sociedade. ${ }^{98}$

Em decorrência de seus limites, os sistemas de interação são capazes de reconhecer apenas "os sintomas" relacionados à capacidade e possibilidade de enlace de seus conflitos internos com o exterior. Como será delimitador adiante, para Luhmann (1998, p. 353): “A moral e o direito, sobretudo, servem para operacionalizar essa sintomatologia".

Em apertada síntese, as organizações exercem, quanto à operacionalização dos conflitos sociais, a tarefa de selecionar e, assim generalizar, os conflitos particulares socialmente importantes, sobretudo, nas hipóteses em que delas se constituem expectativas não atendidas adequadamente pelo direito e pela moral. De forma exemplificativa:

[...] Os sindicatos cumprem, com frequência, esta função. A semântica da "discriminação" tem assumido precisamente esta atividade de revalorização: quando o homossexual é despedido, o crítico da Constituição não é contratado no serviço público, a mulher foge do lar matrimonial, o negro não encontra alojamento, surgem rapidamente organizações e terminologias dispostas a dar ao conflito uma significância geral. (LUHMANN, 1998, p. 353$354)^{99}$

Portanto, a redução da complexidade social a condições estruturalmente possíveis e a operacionalização da comunicação através de sistemas sociais funcionalmente diferenciados que formam a sociedade global apresentam-se como condições necessárias à sua própria adaptação evolutiva. Perfazem uma série de relações sistêmicas internas e externas, revelando uma intrincada rede de seleção de sentidos, coordenação de ações, conflitos, organizações, acoplamentos estruturais e interações entre sistemas sociais e psíquicos, de modo circular, auto-reprodutivo e operacionalmente fechado.

\footnotetext{
${ }^{98}$ Assim, tal diferença revelaria a importância do conflito social não apenas para o sistema de interação, "como também fora dos limites de interação presente, em que tem capacidade de enlace para as relações sociais". (LUHMANN, 1998, p. 353).

${ }^{99}$ Cf. o original: "[...]. Los sindicatos cumplen, con frecuencia, esta función. La semántica de la 'discriminación' ha asumido precisamente esta actividad de revalorización: cuando el homosexual es despedido, el crítico de la Constitución no es contratado en el servicio público, la mujer huye del hogar matrimonial, el negro no encuentra alojamiento, surgen rápidamente organizaciones y terminologías dispuestas a dar al conflicto una significancia general". (LUHMANN, 1998, p. 353-354).
} 
A partir dessa introdutória identificação dos seus pressupostos e sua diferenciada base conceitual, torna-se possível discutir as potencialidades e os limites de tal teoria para a compreensão do direito e do sistema dos meios de comunicação e das organizações relacionadas, como sistemas sociais autopoiéticos, com especial atenção aos programas, conflitos e expectativas (normativas) que envolvem a comunicação e generalização de expectativas cognitivas e normativas acerca dos sentidos das políticas públicas de previdência, saúde e assistência social. 


\section{A VISÃO SISTÊMICA DO DIREITO E SUA RELAÇÃO COM A FORMAÇÃO DE CONFIANÇA SISTÊMICA}

A compreensão do direito e de suas consequências na "realidade social", segundo Luhmann (1989a), tem suscitado novas expectativas sobre as possíveis contribuições da sociologia para a administração da justiça.

Nesse sentido, a visão autopoiética do direito é apontada como alternativa para o impasse científico que tem dominado as teorias jurídicas, divididas entre a consideração do direito como sistema normativo fechado ou praticamente autônomo e a sua crítica sociológica como uma esfera decisória condicionada.

Ambas as correntes seriam insuficientes para explicar o direito na sociedade moderna e direcionar a sua interpretação frente aos novos limites e funções que lhe são colocados pelo alto grau de complexidade das relações sociais que deve regular. (LUHMANN, 1983; TEUBNER, 1989a; BÜLLESBACH, 2002; CAMPILONGO, 2002).

Dessa perspectiva, nas últimas décadas, teria resultado uma disputa entre algumas áreas do conhecimento que se dedicam ao estudo desse tema, como a jurisprudência e a sociologia clássica, além das abordagens intermediárias como a "Engenharia-social", o Pragmatismo e a Sociologia Jurídica, sem, contudo, chegar a uma "adequada sociologia da doutrina legal" ou “teoria legal”. (LUHMANN, 1989a, p. 136).

Para a surpresa dos acadêmicos dessas áreas, o tratamento de tais questões teria sido alterado radicalmente a partir de novos pontos de vista que têm atraído a atenção de juristas e sociólogos. 
Nesse contexto, inserem-se as descritas pesquisas sobre a teoria geral dos sistemas, a cibernética, a lógica multivalente, as teorias da automação e da informação, e, mais especialmente, a teoria dos sistemas autopoiéticos. (LUHMANN, 1989a, p. 137).

O próprio Niklas Luhmann (1989a) reconhece que a adoção da autopoiese para a compreensão dos sistemas sociais tem produzido mais confusões do que a esperada solução dos impasses que se propõe a superar. ${ }^{100}$

Apesar desses problemas, o que chama a atenção para o modelo autopoiético é sua peculiar forma de auto-organização e operação, sua estrutura recursiva, que no caso dos sistemas sociais é constituída de processos comunicacionais de seleção e dotação de sentido, e o decorrente reposicionamento teórico do sujeito nesse processo social. ${ }^{101}$

A abordagem dos limites dessa teoria para a compreensão do sistema jurídico não pode ignorar a observação feita inicialmente de que Luhmann (1998, p. 14), na construção de sua Teoria da Sociedade, buscou evitar a simples e direta transposição da autopoiese biológica à social, distinguindo sua teoria dos sistemas sociais, caracterizados como sistemas de comunicação, dos demais sistemas orgânicos, naturais e mecânicos que fazem parte do ambiente da sociedade. ${ }^{102}$

${ }^{100}$ Em sua visão, porém, esses mal-entendidos estariam relacionados ao fato da teoria autopoiética ter suas origens na matemática, na biologia e, mesmo na neurofisiologia, áreas científicas que, em princípio, não levam em conta aspectos sociais. (LUHMANN, 1989a).

101 Nesse sentido, destaca Luhmann (1989a, p. 137): "The new discovery is that biological systems, if not physical systems in general, are characterized by a circular, recursive, self-referential mode of operation. The mode of analysis that has emerged from this discovery has dethroned the 'subject' in its claim to be unique in its self-referentially".

${ }^{102}$ Em resposta às críticas dessa natureza que o acusam de uma "biologização" reducionista do fenômeno social e em defesa de uma teoria transdisciplinar da sociologia que a desloque da teoria da ação para constituir-se uma teoria da comunicação, cuja autopoiese social distingue-se claramente daquela biológica, posiciona-se o referido sociólogo alemão: "Esta orientación hacia la transdisciplinariedad no significa que el orden social sea reducido a hechos psicológicos, biológicos y fisiológicos mediante un procedimiento reduccionista. Y mucho menos que se argumente con analogías físicas, biológicas y psicológicas o echando mano de un recurso retórico con las metáforas correspondientes. Esta objeción es a menudo esgrimida por los sociólogos como un relejo condicionado contra conceptos utilizados por otras disciplinas - especialmente el concepto de autopoiesis. Sin embargo, la objeción muestra que no se ha entendido la teoría, ya que esta defiende, precisamente un relativismo radical sistémico y excluye cualquier continuum ontológico de la realidad que hubiera que presuponer en la propia conclusión analógica. Por eso no manejamos el argumento de que, puesto que existen reproducción autopoiética, 'cerradura operativa', evolución, etcétera, en el nivel de las células vivas, dichas estructuras deben 
Nesse sentido, para abordar a visão autopoiética do direito, deve-se, mais uma vez, ser retomada essa importante distinção para que sua teoria não seja interpretada como promotora de uma equivocada submissão da compreensão dos sistemas sociais à sua abordagem estritamente biológica. ${ }^{103}$

Devem ser afastados, portanto, a mera analogia entre biologia e sociologia, bem como o simples uso metafórico que transfere termos biológicos para a sociologia o que, em certa medida, teria ocorrido, inicialmente, pela ausência de uma teoria sistêmica geral capaz de evitar o recurso direto aos conceitos emprestados da matemática ou da biologia, sem uma adequada consideração da conveniência de sua transposição desses campos para o social. ${ }^{104}$

Frente a esses possíveis equívocos interpretativos, fora desenvolvido inicialmente neste trabalho, a reconstituição dos aspectos gerais da teoria luhmanniana dos sistemas sociais, com seus principais conceitos e mudanças paradigmáticas, fundamentais à compreensão de sua visão autopoiética do direito, cuja dimensão e pertinência jurídicas passam a ser discutidas neste seção.

A discutida teoria social introduz duas inovações conceituais próprias do paradigma sistêmico em vias de consolidação. A primeira inovação diz respeito à diferenciação do sistema, inspirada pela teoria geral sistêmica, que a concebe como o estabelecimento de diferenças e relações entre o sistema e o ambiente. A segunda consiste no

existir en los sistemas sociales. [...] Si se quiere aplicar al campo de estudio de la sociología el concepto general de autipoiesis y formularlo como una teoría de los sistemas sociales, se requiere de una indicación precisa respecto de la operación por medio de la cual el sistema se reproduce y luego se diferencia del entorno. Aquí es donde ha fracasado la actual teoría sociológica de la acción, pues el concepto de acción remite al hombre como ser viviente y como conciencia, es decir, no se refiere a un estado de cosas socialmente constituido. La teoría de los sistemas sociales, por ello, debe transformarse de teoría de la acción en teoría de la comunicación, si quiere aplicar el concepto de sistema que hemos delineado en los párrafos anteriores y hablar de sistemas sociales operativamente cerrados, autopoiéticos". (LUHMANN, 1998, p. 14-15).

103 Assim, o referido autor chega a ser enfático ao afirmar que a adesão à autopoiese "não significa que os sistemas físicos e sociais devam ser agora interpretados em termos de modelos de sistemas biológicos". (LUHMANN, 1989a, p. 137).

${ }^{104} \mathrm{Na}$ medida em que considera tais obstáculos à aplicação da teoria autopoiética dos sistemas em áreas sociais como o direito, Luhmann (1989a) acrescenta a esse problema terminológico a questão da coordenação dos múltiplos níveis envolvidos, que requer a consideração do direito e de toda a sociedade a partir da uma teoria geral dos sistemas sociais capaz de lidar não apenas com sua compreensão como um todo, mas, também, de suas interações e organizações em face dos demais subsistemas sociais. (LUHMANN, 1989a, p. 137-138). 
reconhecimento de que tal diferenciação só é possível em decorrência do fechamento operacional, autorreferencial, dos sistemas sociais, que lhes permite distinguir suas operações daquelas do ambiente.

Tais conceitos permitem a compreensão da função social do direito, de suas habilidades reflexivas que constituem e a própria autorreferencialidade do sistema jurídico.

Mesmo sob essa perspectiva, o direito não se encontra apartado ou fora da sociedade, mas no interior desse sistema global de comunicação.

É possível assim depreender um novo sentido para a autonomia do sistema jurídico em sua inter-relação com os demais subsistemas sociais que compõem a sociedade.

Se, de um lado, tais subsistemas sociais autorreferentes e diferenciados mantêm processos comunicacionais internos independentes, de outro, ao mesmo tempo conservam um elevado grau de dependência entre si e de seus respectivos ambientes, seja dos demais subsistemas sociais sob a ótica interna da sociedade, seja em relação ao ambiente que lhe é externo à sua dependência dos elementos e/ou sistemas de natureza física, biológica ou consciente, como os sistemas psíquicos. (LUHMANN, 1989a, p. 139).

Embora aparentemente paradoxal, tanto a independência quanto a dependência do direito não pode ser resumida à tradicional expressão "autonomia relativa do direito", na medida em que esta seria insuficiente para explicar as relações sistêmicas de independência e dependência citadas. Na melhor das hipóteses, o conceito de autonomia quando aplicado a essa teoria sistêmica, refere-se apenas ao fechamento ou clausura operacional do sistema como condição de sua própria abertura cognitiva.

O direito, enquanto subsistema social, se distingue em vários aspectos de seu ambiente, interno e externo à sociedade, ou seja, "o direito não é a política, nem economia, nem religião, muito menos educação, [...], embora não possa existir se todos esses demais não participarem também [do sistema social global]”. (LUHMANN, 1989a, p. 139). ${ }^{105}$

${ }^{105}$ Nesse mesmo sentido, ao discorrer sobre a inovação introduzida por essa concepção autopoiética do sistema jurídico, Campilongo (2000b) defende que, graças à abertura cognitiva e ao fechamento operacional, o Direito 
Embora se apresente diferenciado e operacionalmente autônomo, o sistema jurídico mantém uma estreita relação com os demais sistemas sociais. Sendo que, através de suas operações, não se exclui da sociedade, mas coopera para própria reprodução autopoiética do sistema social como um todo. ${ }^{106}$

Em outras palavras, enquanto subsistema de comunicação interno ao sistema de comunicação maior que seria a própria sociedade, o direito contribui, através de sua autopoiese, para a construção da própria realidade social. ${ }^{107}$

\subsection{A função do sistema jurídico frente às expectativas cognitivas e normativas}

Para Luhmann (1989a, p. 140), a operação interna do sistema jurídico consiste num peculiar "processamento de expectativas normativas que são capazes de se manter em situações de conflito".

Uma vez que a sociedade deva ser entendida como comunicação, caberia ao direito a função de estabilizar suas expectativas comunicacionais, contribuindo para a formação dos descritos meios de comunicação simbolicamente generalizados.

Moderno consegue estabelecer um elevado grau de interdependência com os demais sistemas sociais (v.g. política, economia, ciência, dentre outros), mantendo-se sensível às demandas dos mesmos (seu ambiente), sem contudo perder sua unidade e capacidade de diferenciação em seu interior para além da tradicional estrutura normativa hierárquica piramidal. A esse respeito sustenta: “[...] Dessa perspectiva, o sistema jurídico é um só, pouco importando se as cadeias normativas são múltiplas, não-hierarquizadas, informais ou produzidas em diferentes contextos. Essa unicidade decorre da função do direito e não da arquitetura do sistema normativo. A globalização demanda novas diferenciações no interior do sistema jurídico, mas não é capaz de corromper sua função. (CAMPILONGO, 2000b, p. 143)".

${ }^{106}$ Nesse sentido, esclarece Luhmann (1989a, p. 139): “[...] Thus, like every autopoietic system, it is and remains to a high degree dependent on its environment and the artificiality of the functional differentiation of the social system as a whole only increases this dependency. And yet, as a closed system, the law is completely autonomous at the level of its own operations. Only the law can say what is lawful and what is unlawful, and in deciding this question it must always refer to the results of its own operations and to consequences of the system's future operations". (LUHMANN, 1989a, p. 139).

${ }^{107}$ A respeito desse papel do Direito na construção da realidade social, esclarece Luhmann (1989a, p. 138-139): "[...] This means not only that the legal system fulfills a function for society - that it "serves" society - but also that the legal system participates in society's construction of reality, so that in the law, as everywhere in society ordinary meaning of words (of names, members, designations for objects and actions, etc.) can, and must, be presupposed". 
Essas expectativas, tratadas ao se discorrer sobre a arquitetura conceitual da Teoria dos Sistemas Sociais luhmanniana, são estruturas internas comuns aos sistemas de sentido, como os sistemas sociais e psíquicos. ${ }^{108}$

O sistema jurídico deve assegurar a manutenção de tais expectativas no sistema social como expectativas "mesmo no caso de sua frustração e de que alguém dela venha a saber e comunicá-la adiante", não sendo fundamental sua incapacidade em assegurar que tais expectativas em si não sejam, no caso concreto, eventualmente frustradas. (LUHMANN, 1989a, p. 140).

Antes mesmo de sua abordagem em termos declaradamente autopoiéticos, Luhmann (1983), ao discorrer sobre a sociologia do direito e sua função na sociedade, já antecipava, em linhas gerais, sua visão funcionalista do direito e as linhas interpretativas que formariam sua Teoria da Sociedade, destacando-se o papel das expectativas no processo de dotação de sentido e observação entre os sistemas tanto sociais quanto psíquicos. ${ }^{109}$

O conceito de expectativa já era assim trabalhado sob a perspectiva das relações entre os indivíduos, ou, em termos autopoiéticos, sob a abordagem das interações entre sistemas psíquicos, embora de forma ainda não acabada e tendente a um enfoque intersubjetivista. ${ }^{110}$

${ }^{108}$ Em apertada síntese, referem-se tanto a seus próprios processos internos de dotação de sentido quanto àqueles externos de outros sistemas, pressupostos a partir da auto-observação e das observações recíprocas decorrentes dos acoplamentos estruturais entre esses sistemas, que lhes permitem absorver e controlar o duplo problema da complexidade e contingência.

${ }^{109}$ Sobre a evolução do pensamento luhmanniano e a coerência de sua leitura do direito desde suas primeiras obras anteriores à fase declaradamente autopoiética, esclarece, em sua tese de doutoramento, Orlando Villas Bôas Filho (2006b, p. 145): “Conforme já observado anteriormente, a produção de Luhmann sobre o direito é bastante vasta e abrange um período longo, de modo que muitas de suas obras são anteriores à incorporação do conceito de autopoiesis em sua teoria. Não obstante, não há uma ruptura na obra de Luhmann que invalide seus escritos anteriores. Ao contrário, os desenvolvimentos posteriores de Luhmann acerca do direito não apenas estão em consonância com as análises mais antigas, como, inclusive, retomam uma série de problemáticas nelas constantes".

${ }^{110}$ A esse respeito, cumpre destacar a seguinte explicação de Luhmann (1983, p. 46): "Sobre essa situação existencial desenvolvem-se estruturas correspondentes de assimilação da experiência, que absorvem e controlam o duplo problema da complexidade e contingência. Certas premissas da experimentação e do comportamento, que possibilitam um bom resultado seletivo, são enfeixadas constituindo sistemas, estabilizando-se relativamente frente a desapontamentos. Elas garantem uma certa independência da experimentação com respeito a impressões momentâneas, impulsos instintivos, excitações e satisfações facilitando assim uma seleção continuada também ao longo do tempo, tendo em vista um horizonte de possibilidades ampliado e mais rico de alternativas. As 
Nessa fase inicial de sua teorização, a formação de estruturas gerais de expectativas apresenta-se como resposta à necessidade de segurança e previsibilidade, ainda que meramente consciente e sujeita a frustrações (“desapontamentos"), das quais o sistema psíquico depende não apenas para poder se "imunizar" parcialmente contra tais frustrações, mas, principalmente, para se integrar socialmente, avaliar o significado de suas ações a partir das expectativas que os outros tem dele mesmo e, dessa forma, amenizar o risco de que suas expectativas em relação aos demais venham a se revelar equivocadas. ${ }^{111}$

Como forma de acoplamento estrutural entre sistemas psíquicos, as descritas interações contribuem para a estruturação de expectativas através dos processos de atribuição de sentido no interior de cada consciência na medida em que o "comportamento do outro não pode ser tomando como fato determinado, ele tem que ser expectável em sua seletividade, como seleção entre outras possibilidades do outro". (LUHMANN, 1983, p. 47).

Haveria assim a necessidade de uma integração "confiável” para que as expectativas se constituam não só sobre seus comportamentos e operações, como,

comprovações e satisfações imediatas são em parte substituídas por técnicas de abstração de regras confirmadamente úteis, e de seleção de formas adequadas de experimentação e de auto-certificação. A esse nível do comportamento seletivo podem ser formadas e estabilizadas expectativas com relação ao mundo circundante. Seu efeito seletivo é ao mesmo tempo inevitável e vantajoso, motivando assim a retenção de tais estruturas, mesmo frente a desapontamentos [...] $\mathrm{Na}$ experimentação a complexidade e a contingência de outras possibilidades aparecem estruturalmente imobilizadas como "o mundo", e as formas comprovadas de seleção relativamente imune a desapontamentos aparecem como sentido, cuja identidade pode ser apreendida — por exemplo como coisas, homens, eventos, símbolos, palavras, conceitos, normas. Nelas se ancoram as expectativas."

${ }^{111}$ Essa estruturação de expectativas demandada, já no âmbito dos sistemas psíquicos, seria justificável segundo o referido sociólogo alemão, pois: "Neste mundo complexo, contingente, mas mesmo assim estruturalmente conjecturável existem, além dos demais sentidos possíveis, outros homens que se inserem no campo de minha visão como um 'alter ego', como fontes eu-idênticas da experimentação e da ação originais. A partir daí introduz-se no mundo um elemento de perturbação, e é tão-somente assim que se constitui plenamente a complexidade e a contingência. [...] O preço disso [ou seja de absorver as perspectivas dos outros] está na potencialização do risco: na elevação da contingência simples do campo de percepção, ao nível da dupla contingência do mundo social. Reconhecer e absorver as perspectivas de um outro como minhas próprias só é possível se reconheço o outro como um outro eu. [...] Com isso, porém, tenho que conceder (sic) que o outro possui igualmente a liberdade de variar seu comportamento, da mesma forma que eu. Também para ele o mundo é complexo e contingente. Ele pode errar, enganar-se, enganar-me. Sua intenção pode significar minha decepção. O preço da absorção de perspectivas estranhas é, formulado em termos extremados, sua inconfiabilidade. [...] Frente à dupla contingência necessita-se (sic) outras estruturas de expectativas, de construção muito mais complicada e condicionada as expectativas”. (LUHMANN, 1983, p. 46-47). 
principalmente, sobre as próprias expectativas desse outro sistema, em razão de tal seletividade basear-se na interpretação das estruturas de expectativas do outro.

A confiança é assim relacionada à redução da complexidade do mundo, enquanto realidade incomensurável de informações e possibilidades de decisões, e sua atuação no sentido de assegurar expectativas e direcionar decisões internas aos sistemas.

Niklas Luhmann (2005b) em seu trabalho Confianza (Verlagsgesellschaft), esboça suas questões referentes ao aumento da complexidade do mundo e o levantamento de como a confiança pode ser entendida como um mecanismo de redução de tal complexidade.

Embora ofereça uma segurança ilusória, a confiança não deixa por isso de ser relevante, pois possibilita a tomada de decisões de ação no presente e a de planejamento e orientação para o futuro mesmo em face da contingencialidade do mundo. Nesse sentido, distingue-se de simples esperança por, diferentemente desta, se relacionar a uma forma de racionalização de expectativas voltadas a decisões. ${ }^{12}$

No mais, para que essas interações sociais se realizem, não basta o aspecto presencial e que cada sistema "experimente" as possibilidades de sentido atribuídas pelos outros sistemas psíquicos, ou sociais como na hipótese de interpenetrações entre esses dois tipos de sistemas de sentido, sendo preciso possibilitar-lhes "ter uma expectativa sobre a expectativa que o outro tem dele".

Portanto o direito, como as demais estruturas e sistemas sociais normativos, desempenha a função de integrar o nível "das expectativas imediatas de comportamento, na satisfação ou no desapontamento daquilo que se espera do outro", em nível "de avaliação do significado do comportamento próprio em relação às expectativas do outro". (LUHMANN, 1983, p. 48).

\footnotetext{
112 Segundo Luhmann (2005b, p. 40-41): "La confianza solamente está implicada cuando la expectativa confiable hace una diferencia para una decisión; de otro modo, lo que tenemos es una simple esperanza. [...] Por lo tanto, la confianza siempre recae en una alternativa crítica, en la que el daño resultante de una ruptura de la confianza puede ser más grande que el beneficio que se gana de la prueba de confianza asegurada. De aquí que el que confía toma conocimiento de la posibilidad del daño excesivo provocado por la selectividad de las acciones de otros y adapta una posición hacia esa posibilidad. El que tiene esperanza simplemente tiene confianza a pesar de la incertidumbre. La confianza refleja la contingencia. La esperanza elimina la contingencia”.
} 
Cumpre, porém, destacar que as estruturas de expectativas, com as quais o direito trabalha, "não são capazes de garantir a plena determinação das seleções por ela realizadas, mas apenas torná-las mais prováveis, o que implica admitir que o problema da frustração das expectativas é imanente a qualquer estrutura desse tipo”. (VILLAS BÔAS FILLHO, 2006b, p. 148-149).

De modo contrário, apesar de sua função generalizante de expectativas, não raras vezes o direito contribui para a própria ampliação e generalização dos conflitos, como foi possível verificar na exposição inicial sobre o conceito luhmanniano de interação e da função desempenhada por certas organizações, como os sindicatos, na generalização e institucionalização de conflitos particulares, interacionais, não satisfeitos ou mesmo agravados pela frustração das expectativas a partir de seu inesperado tratamento inicial pelo próprio sistema jurídico. (LUHMANN, 1983, p. 48, 1998, p. 353).

Apesar dessas limitações, destaca-se que a função redutora da complexidade e estabilização de expectativas do sistema jurídico serve também de orientação para os sistemas psíquicos.

Tem-se, dessa forma, a estabilização de expectativas objetivas, buscando uma "simplificação através de uma redução generalizante". Nesse processo, tais expectativas "podem ser verbalizadas na forma do dever ser, mas também podem estar acopladas a determinações qualitativas, delimitações da ação, regras de cuidado, etc.” (LUHMANN, 1983, p. 52).

Esse aspecto simbólico da estabilização de expectativas empreendida pelos sistemas sociais, ou seja, sua função de "síntese regulativa de sentido" não seria, porém, compreendida pelas abordagens do direito centradas simplesmente em sua regulação de expectativas comportamentais e sua coercitividade, como forma de garantia de tais comportamentos. (LUHMANN, 1983, p. 52). ${ }^{113}$

\footnotetext{
${ }^{113}$ A esse respeito, o referido autor adverte: “[...] Essa função tem seu centro de gravidade no plano reflexivo da expectativa sobre expectativas, criando aqui segurança em termos de expectativas, à qual se segue, apenas secundariamente, a segurança sobre o comportamento próprio e a previsibilidade do comportamento alheio. É muito importante, para a compreensão do direito, ter uma visão clara dessa diferença. Isso porque a segurança na expectativa sobre expectativas, seja ela alcançada por meio de estratégias puramente psíquicas ou por normas
} 
Essa proeminência de sua função simbólica relaciona-se à peculiar generalização dessas expectativas de expectativas pelo direito a partir das três dimensões de sentido - a dimensão temporal, a dimensão social e a dimensão objetiva. $\mathrm{O}$ sistema jurídico deve produzir uma "congruência seletiva" entre elas de modo a garantir a manutenção contrafática de expectativas normativas. (LUHMANN, 1983. p. 114-115, 1998, p. 90).

Para a abordagem desse processo, é preciso, ainda que em linhas gerais, delimitar as distinções entre as expectativas normativas das demais expectativas cognitivas. Tal distinção, segundo Luhmann (1983, p. 56), "não é definida em termos semânticos ou pragmáticos, nem referenciada aos sistemas afirmativos que as fundamentam ou à contradição entre afirmações informativas e diretivas - mas sim em termos funcionais, tendo em vista a solução de um determinado problema". 114

Expectativas cognitivas e expectativas normativas diferem quanto ao tipo de antecipação que será produzida pelos sistemas de sentido para a absorção das frustrações, sendo, respectivamente, duas as possibilidades: (i) a adaptação da expectativa à situação que lhe é contrária ou (ii) a sua manutenção a despeito de sua frustração, em situações de conflito, daí porque a expressão "manutenção contrafática de expectativas normativas".

As expectativas cognitivas, uma vez não atendidas, caracterizam uma "nem sempre consciente disposição de assimilação em termos de aprendizado". De modo diverso, as expectativas normativas "caracterizam-se pela determinação em não assimilar os desapontamentos", ou seja, mantêm-se como expectativas apesar da situação que as contraria. (LUHMANN, 1998, p. 56).

sociais, é uma base imprescindível de todas as interações, e muito mais importante que a segurança na satisfação de expectativas. (LUHAMNN, 1983, p. 52-53).

114 O termo normativo ao ser relacionado à expectativa não diz respeito à dicotomia entre "dever ser" e "ser", própria do direito. Uma vez que qualifica expectativa, opõe-se não ao "ser", mas ao cognitivo em termos funcionais e não semânticos. Daí porque, segundo Luhmann (1983, p. 57): “Toda expectativa é fática, seja na sua satisfação ou no seu desapontamento o fático abrange o normativo. A contraposição convencional do fático ao normativo deve, portanto, ser abandonada. Ela é uma construção conceitual errônea, como no caso de se querer contrapor ser humano e mulheres; uma manobra conceitual que nesse caso é prejudicial às mulheres, e naquele ao dever ser. O oposto adequado ao normativo não é fático, mas sim o cognitivo. Só é possível optar-se coerentemente entre essas duas orientações com respeito ao tratamento de desapontamentos, e não entre o fático e o normativo". 
A normatização de expectativas através do direito opera inicialmente na dimensão temporal de sentido. ${ }^{115}$

A normatividade do direito pode então ser entendida, em linhas gerais, como uma espécie de estabilidade contrafática. ${ }^{116}$

Contudo, a generalização de expectativas pelo direito não se restringe à sua normatização na dimensão temporal, mas compreende, como foi possível introduzir acima, uma "congruência seletiva" entre esta e as demais dimensões de sentido, social e objetiva, a fim de garantir a sua referida manutenção contrafática.

Se na dimensão temporal essa generalização se dá através da fixação de normas, na dimensão social o direito envolve o mecanismo de institucionalização de expectativas comportamentais. (LUHMANN, 1983, p. 77).

A institucionalização surge da necessidade de direcionamento das expectativas normativas com o propósito de reduzir a sua exposição às frustrações ou mesmo ao conflito com outras expectativas normativas não limitadas a dois, mas a três ou mais sistemas de sentidos, que levem também às frustrações.

Tal necessidade relaciona-se à menor tolerância dos sistemas à frustração de expectativas normativas em comparação às cognitivas, devendo ser direcionadas de forma a poderem ser bem sucedidas. Cabe ao mecanismo de institucionalização de expectativas normativas, segundo Luhmann (1983, p. 77), “delinear o grau em que as expectativas podem estar apoiadas sobre expectativas de expectativas supostas em terceiros”.

\footnotetext{
${ }^{115}$ Segundo Orlando Villas Bôas Filho (2006b, p. 150), a norma "seria, assim, uma forma de estruturação temporal das expectativas, que consistiria em fixar uma dada expectativa como normativa e, mediante mecanismos de absorção das frustrações, neutralizá-la contra as condutas que dela se desviam”.

116 Nesse sentido, afirma Luhmann (1989a, p. 140): “In a way that no other system does, the law processes normative expectations that are capable of maintaining themselves in situations of conflict. The law cannot guarantee, of course, that these expectations will not be disappointed. But it can guarantee that they can be maintained, as expectations, even in case of disappointment, and that one can know this and communicate it in advance. From the sociological point of view, that normativity is nothing but counterfactual stability. To formulate this differently: in that it protects expectations, the law frees us from the demand that we learn from disappointments and adjust to them. It thereby holds out the prospect of resolving conflicts (and at the same time makes it possible to seek out and withstand conflicts), for it contains a preliminary decision (however unclear it may be in the individual case) about who has to learn from disappointment and who does not".
} 
Nesse sentido, a institucionalização envolveria a "função de terceiros no sentido neutralizante, objetivador, amenizador de disputas", os quais estariam presumivelmente dispostos a sustentar as expectativas institucionalizadas contra as condutas que as frustram. (LUHMANN, 1983, p. 78).

Insere-se, neste ponto, a delicada questão do "consenso pressuposto das expectativas institucionalizadas", sendo que tal institucionalização "não traria um fomento ao consenso. Ao contrário, ela antecipa ficcionalmente o consenso, de modo a fazer com que ele passe a ser pressuposto e não precise mais ser concretamente expresso". (VILLAS BÔAS FILHO, 2006b, p. 151).

Essa integração de expectativas no sentido realizado pela institucionalização remete normalmente ao consenso. Segundo Luhmann (1983, p. 79), desde "a derrocada do direito natural, afirma-se que a vigência do direito está fundamentada em convicções comuns". 117

Tal institucionalização de expectativas sobre outras expectativas só é possível como mecanismo de "aproveitamento de um mínimo em experiências simultâneas e sinônimas", que devem ser distribuídas de maneira igual entre os significados e os momentos socialmente relevantes, tornando o próprio consenso não apenas "expectável” e "ativável”, mas, sobretudo, expansível em suas predisposições. A esse respeito, conclui:

Dessa forma, a função das instituições reside menos na criação e mais na economia do consenso, que é atingida, principalmente, na medida em que o consenso é antecipado na expectativa sobre expectativas, ou seja, como pressuposto, não mais precisando, em geral, ser concretamente expresso. É essa institucionalização que permite uma comunicação rápida, precisa e seletiva entre pessoas. Pode-se trocar fluentemente de situações e parceiros, sem perder a base de entendimento e ter que reconstituí-la repetidamente. Quando a institucionalização envolve desconhecidos, até mesmo neles pode ser presumido um consenso, e suposto que mesmo sem um entendimento

\footnotetext{
${ }^{117}$ Ainda segundo o referido autor, o problema do consenso "tem que ser melhor refletido, e desenvolvido no sentido dos mecanismos que sustentam a interação", não sendo possível a sua apreensão apenas como uma variável empírica, dado o potencial muito limitado de concretização da experimentação e a diversidade de possíveis temas com que tem que lidar. Por considerar "o consenso fático como uma experimentação sincrônica no tempo e em seu sentido", além de muito raro, seria rico em determinações em um sentido concreto, não sendo possível "uma experimentação totalmente adequada, e muito menos um pleno consenso". (LUHMANN, 1983, p. 79).
} 
prévio explícito exista uma concordância genérica quanto a um conjunto mínimo de expectativas sobre expectativas. (LUHMANN, 1983, p. 80).

Dentre as diversas formas de institucionalização de expectativas podem ser citadas, no sistema jurídico, o contrato e o procedimento, embora não seja possível neste trabalho adentrar-se em suas especificidades. ${ }^{118}$

Portanto, ao se institucionalizar expectativas normativas na dimensão social de sentido, mais do que a ampliação do consenso, busca-se uma distribuição de riscos, de modo que as expectativas e condutas contrárias à instituição tenham contra si o peso de uma autoevidência presumida. (LUHMANN, 1983, p. 81). ${ }^{119}$

Assim, a função do sistema jurídico, mais do que garantir o consenso e fundamentar moralmente o ordenamento jurídico, seria "assegurar ao direito a capacidade de manter elevada a complexidade social e conferir às decisões judiciais uma adequada consistência em relação às expectativas normativas". (CAMPILONGO, 2002, p. 125-126). ${ }^{120}$

118 Para uma visão detalhada do papel desempenhado pelo procedimento e contrato na institucionalização de expectativas normativas deve-se recorrer aos seguintes estudos de Luhmann sobre Legitimação pelo procedimento (1980) e sua Sociologia do direito (1983, p. 88-93), devidamente citados nas referências deste trabalho.

${ }^{119}$ Com isso, o referido teórico alemão não pretende reduzir a institucionalização a um mecanismo restrito à compulsão social, de simples e impositiva determinação, antidemocrática, de comportamentos. Segundo Luhmann (1983, p. 81), embora surja obrigatoriamente, a institucionalização não atua como uma compulsão que exclui outras possibilidades, mas sim "mantém boa parte da variedade das projeções normativas, certas possibilidades de divergência e principalmente possibilidades de modificação na adaptação a condições alteradas". Mais do que uma pressuposição em sentido racional universal, trata-se de uma antecipação de consenso que pode ser questionado e resistido. Tal possibilidade é, inclusive, tratada pelo autor ao se referir aos desafios lançados àquele cujas expectativas sejam contrárias à instituição, este "precisa arriscar uma iniciativa, sem estar protegido por expectativas pré-estabelecidas.[...] [Nesse contexto] a crítica a expectativas institucionalizadas está acoplada a pretensões de liderança, as quais, independentemente de conteúdos, provocam resistências. [...] Para derrubá-la necessita-se a palavra. O atacante tem que encontrar as palavras certas, os argumentos que desestabilizam a instituição”. (LUHMANN, 1983, p. 82).

120 Segundo, Celso Fernandes Campilongo (2002, p. 124-125), essa função do direito denota a crítica luhmanniana ao consenso global e ao fundamento moral da democracia, o que por sua vez não quer dizer que a mesma seja antiliberal ou autoritária, pois, duvidar da "possibilidade do consenso — consenso no mínimo improvável nas sociedades altamente diferenciadas e complexas — significa reconhecer legitimidade ao dissenso. Até aqui, em termos bem sintéticos, não há nada de antidemocrático". Este autor contra-argumenta da seguinte forma em defesa da teoria sistêmica e de sua importância para compreensão da própria teoria democrática por ele desenvolvida: "Para a visão que a teoria dos sistemas tem da democracia não existe um futuro, mas sim vários futuros possíveis, contingentes e imprevisíveis para a sociedade e para a própria democracia. O que se descarta — e isso nada tem de antiliberal ou autoritário — é, definitivamente, o oposto: que se possa predeterminar o 
A dimensão social da generalização de expectativas pelo direito através da institucionalização constitui-se um mecanismo seletivo para além do sistema imediato de interação, para além dos presentes que se fundamenta

[...] não na concordância fática de determináveis manifestações de opiniões, mas sim no sucesso ao superestimá-las. Sua continuidade está garantida enquanto quase todos suponham que quase todos concordem; e possivelmente até mesmo enquanto quase todos suponham que quase todos concordem. Daí surge, comparativamente ao consenso fático, uma maior estabilidade uma mais apurada sensibilidade. Constituídas sobre a área movediça da experiência concreta através de mecanismos de seleção, as instituições podem tornar-se amplamente independentes da distribuição fática das experiências reais com respeito a temas e momentos, e também das entradas e saídas de seus participantes, passando então a moldar elas mesmas a estrutura de expectativas desses processos. (LUHMANN, 1983, p. 84-85).

Embora relacionada às operações internas do sistema jurídico, dada a sua peculiar função no sistema social global, essa generalização de expectativas na dimensão social, e objetiva como se verá a seguir, contribui para o desenvolvimento dos meios de comunicação simbolicamente generalizados de modo a permitir aos demais sistemas, em seus acoplamentos estruturais com os demais, facilitar suas operações de sentido e observação, conectando as expectativas comunicacionais generalizadas pelo sistema jurídico às suas operações internas pré-existentes e, assim, eventualmente reiterar suas mensagens, repetições e decodificações anteriores em seus processos autopoiéticos de dotação de sentido e de seleção das informações.

Deve ainda, ser considerada a generalização das expectativas na dimensão objetiva de sentido.

Enquanto que as dimensões temporal e social "atuam seletivamente sobre o que é possível [expectável] no sentido prático" (LUHMANN, 1983, p. 94), a generalização objetiva das expectativas consiste em fixar um ou alguns pontos de referência abstratos, entendidos inicialmente como "complexões de expectativas" a partir das quais as expectativas podem ser estabelecidas de forma concreta.

futuro. Perdem seu tempo aqueles que se ocupam em denunciar as supostas ligações do pensamento de Luhmann com o autoritarismo e com a apologia do 'status"”. (CAMPILONGO, 2002, p. 127). 
Tais complexões constituem-se como pontos de referência abstratos, pois através delas "as expectativas comportamentais podem transformar-se de cópia em modelo, podem ser 'seguidas' ou 'não seguidas', podem tornar-se objeto de entendimentos sociais ou opiniões de orientação a sanções ou ao escamoteamento de desvios". Quer com isso dizer que a generalização das expectativas normativas em sua dimensão social condensa expectativas comuns e reiteradas em manifestações simbolizáveis de sentidos. (LUHMANN, 1983, p. 95).

Dessa forma, a identificação de complexões de expectativas permite "a conservação e a reativação de expectativas, sedimentando-as como acervo cultural". Por conseguinte, operacionaliza os processos comunicacionais sistêmicos na medida em que reduz a necessidade de se recriar constantemente suas expectativas a cada caso, sendo possível "deduzi-las sempre que necessário, a partir de um dado contexto organizado em termos de seu sentido". (LUHMANN, 1983, p. 98).

Nesse sentido, as complexões de expectativas contribuem para o que Luhmann (1998), em sua fase autopoiética, identificou como a formação dos meios de comunicação simbolicamente generalizados.

No que diz respeito aos processos comunicacionais do sistema jurídico, tais complexões de expectativas, ou meios de comunicação simbolicamente generalizados, representam as bases sobre as quais “as normas assumem o caráter de algo que 'vige', que os direitos assumem o caráter de algo que se possa 'ter', que os institutos do direito tornam-se disponíveis como tipos que podem ser escolhidos através de decisões". (LUHMANN, 1983, p. 98).

A contribuição dessa dimensão para a compreensão da função social do direito, não restrita a um funcionalismo vazio, asséptico e distanciado da realidade, consiste na promoção da própria seleção do conteúdo das expectativas normativas.

Por essa razão, além de manter certa continuidade nas expectativas, essa dimensão mais abstrata de sentido serve de referência para expectativas aferíveis em casos concretos. Nesse sentido, utiliza quatro princípios de identificação de expectativas para a 
consecução dessas funções: (i) pessoas; (ii) papéis; (iii) programas; (iv) valores. (LUHMANN, 1983, p. 99). ${ }^{121}$

Para os fins desse trabalho, a atenção deve ser centrada na função atribuída aos programas e valores na referida teoria sistêmica.

A diferenciação da sociedade moderna requer do sistema jurídico um alto grau de abstração, fortemente variável, que só pode ser atendido através de uma complexão de expectativas não mais restrita à unidade de um ator dentro de um papel (mesmo que intercambiável e não identificado pessoalmente), "mas sim apenas em uma regra decisória verbalmente fixada, cuja aplicação seja garantida através da institucionalização". (LUHMANN, 1983, p. 102).

Para Luhmann (1983, p. 102), essas "regras" seriam os programas. Estes teriam condições de aplicabilidade específicas, relacionadas às expectativas de ações ou de determinadas consequências de ações que se é legitimo esperar. Dessa forma, "os programas exercem a dupla função de servir de apoio a decisões e expectativas". (LUHMANN, 1983, p. 102).

Como foi possível compreender no tópico referente à "relação entre dupla contingência, expectativas e programação sistêmicas e o desenvolvimento dos meios de comunicação simbolicamente generalizados", os programas surgem como mecanismo de controle interno das operações comunicacionais do sistema. Permitem-lhe estabelecer as condições sob as quais certos processos comunicacionais podem ocorrer e os processos que devem suceder à ocorrência de determinadas operações internas.

${ }^{121}$ A delimitação de cada um desses princípios extrapolaria os limites deste trabalho. Assim, cumpre apenas a transcrição de um excerto sintético em que os mesmos são relacionados entre si, permitindo uma introdutória explanação de seus sentidos e do enfoque dado aos programas pela abordagem sociológica luhmanniana do direito: "Dessa forma, as pessoas, os papéis, os programas e os valores representam diferentes momentos da generalização, através dos quais expectativas comportamentais podem ser enfeixadas por meio de um princípio objetivo de identificação, e assim, ancoradas no mundo exterior. Podemos partir da constatação de que as sociedades mais complexas necessitam crescentemente de premissas mais abstratas das expectativas, para poderem permitir e legitimar estruturalmente mais amplas possibilidades em termos de expectativa e comportamentos. Seria, porém, demasiadamente simples, e evidentemente incorreto, supor um desenvolvimento a partir da orientação individual, passando pela normalização através de papéis e programa, e finalmente desembocando em normas sedimentadas valorativamente (por exemplo como normas ideológicas). Aparentemente o que ocorre é que com a crescente complexidade da sociedade todos os planos da generalização são mais fortemente exigidos tendo então que ser mais nitidamente diferenciados". (LUHMANN, 1983, p. 104). 
Dessa maneira, reduzem uma parte da contingência sistêmica, direcionando suas operações apesar de sua evolução indeterminada e contingente.

A programação é, portanto, complementar à função desempenhada pelo código binário na evolução do sistema, sendo variável de acordo com o direcionamento que o sistema social assume ao longo de seu processo evolutivo.

Essa função programática não seria satisfeita ao se identificar a complexão de expectativas apenas ao nível mais abstrato da generalização, ou seja, aos valores.

Em julgamentos sobre a preferência de ações, os valores não especificariam quais ações têm preferência sobre outras, sendo, assim, entendidas como "referências muito indeterminadas para a formação e a integração de expectativas". Segundo Luhmann (1983, p. 103-104):

Ao contrário do campo dos programas, a esfera dos valores apresenta uma complexidade muito indeterminada com referência à ação permitida, oferecendo grandes possibilidades de consenso, sendo assim dificilmente modificável, além de conter uma série de contradições práticas - e tudo isso são indicadores de que os valores preenchem uma outra função que os programas. Por exemplo, podemos estar seguros de defender um valor considerável e não nos ridicularizamos ao propugnarmos pela saúde pública. Em termos grosseiros isso também delimita o campo de eventos e ações que podem ser observados da mesma forma; permanece porém em aberto quais são as ações que devem fomentar a saúde pública, e que por isso deveriam ser esperadas normativamente, quanto dinheiro (de outras pessoas) a saúde pública poderia custar, e também se ela seria preferencial no caso de conflito com outros valores, por exemplo econômicos, culturais, de liberdade e da dignidade individuais. Diferentemente dos programas, os valores são formulados tão abstratamente que a relação recíproca entre os diferentes valores não pode ser estabelecida em termos constantes. Podemos institucionalizar e generalizar abstratamente somente as próprias posições valorativas, mas não as relações entre elas.

Para o referido autor, o centro de gravidade da formação de estrutura sociais e sua consequente diferenciação sistêmica, dado o estágio de desenvolvimento atual da sociedade moderna, teriam se deslocado para os planos intermediários dos papéis e programas, nos quais a complexidade da sociedade pode ser reproduzida adequadamente. Neste processo 
comunicacional "as pessoas seriam identificações demasiadamente concretas, e os valores seriam demasiadamente abstratos". (LUHMANN, 1983, p. 107). ${ }^{122}$

Ademais, cumpre destacar que os programas mais encontrados nos sistemas sociais são de caráter finalístico ou condicional. (LUHMANN, 1998, p. 290).

Os programas finalísticos têm por função coordenar as operações sistêmicas para determinados resultados estipulados internamente e que, por esse motivo, constituem o objetivo da programação.

Embora o caráter condicional seja fortemente destacado no sistema jurídico, a sua evolução demonstra que o mesmo não se restringe a esse tipo de programação. Como se verá ao tratar da Constituição Federal brasileira de 1988 destaca-se o papel conferido aos programas finalísticos na própria atribuição de sentido aos seus códigos internos, ou seja, na interpretação do direito, o que a sua compreensão científica não pode mais ignorar.

Em conclusão parcial a esse levantamento teórico da visão autopoiética do direito, destaca-se que a generalização das expectativas normativas empreendida pelo sistema jurídico requer, na dimensão temporal de sentido, a sua normatização, a fim de garantir a manutenção de tais expectativas no futuro, mesmo em face de supervenientes fatos e condutas que lhes sejam contrários.

Por sua vez, a generalização empreendida pelo sistema jurídico depende da institucionalização das expectativas normativas na dimensão social de sentido, ainda que, para tanto, se valha de uma pressuposta antecipação do consenso de terceiros.

Por fim, em sua dimensão objetiva, essa seletividade do direito congruente de expectativas seria completada através da formação de meios de comunicação simbolicamente

\footnotetext{
${ }^{122}$ Nesse contexto, segundo Luhmann (1983, p. 108-109): “O direito adquire seu centro de gravidade em papéis específicos e programas específicos para o processo decisório jurídico. A diferenciação de papéis jurídicos, que trabalham segundo programas decisórios próprios, deve ser uma das condições históricas para uma mais forte separação dos diferentes planos das expectativas. Isso não significa que as pessoas e os valores perdem seu significado para o direito, mas sim que a identificação e a mutabilidade das complexões de expectativas no direito não mais estão vinculadas à unidade de uma pessoa ou à justificativa através de um valor. Separação não quer dizer isolamento, mas apenas invariância relativa e variabilidade independente".
} 
generalizados, nos quais as complexões de expectativas se autonomizam dos casos concretos permitindo a recursividade das operações seletivas de sentido, no interior dos sistemas sociais.

Nessa dimensão, destacam-se os programas que garantiriam um mínimo de coerência interna à autorreferencialidade do direito, exercendo o controle interno de suas operações comunicacionais, seu direcionamento e as condições sob as quais tais processos comunicacionais podem e devem ocorrer.

Destaca-se, por conseguinte, que essa atividade desempenhada pelo sistema jurídico, muito além das críticas correntes sobre seu suposto funcionalismo reducionista, tem certa finalidade relacionada ao campo dos valores e aos programas.

Nesse sentido, o próprio código binário — lícito/ilícito — utilizado pelo sistema jurídico para processar as referidas expectativas sociais contém em si valores positivos (justiça) e valores negativos (injustiça) que excluiriam, ademais, as contradições do sistema e outros valores que não lhes são próprios, contribuindo, em última instância, para a sua própria diferenciação sistêmica. ${ }^{123}$

\subsection{Desdobramentos teóricos da autopoiese do sistema jurídico e a tese referente à alopoiese do sistema jurídico brasileiro}

A partir da inicial concepção autopoiética biológica de Maturana e Varela (2005) e dos avanços teóricos da autopoiese do social luhmanniana, outros pesquisadores além do próprio Niklas Luhmann, como Gunther Teubner (1989a), Celso Fernandes Campilongo (2002), Germano Schwartz (2004), Orlando Villas Bôas Filho (2006b), procuraram demonstrar a existência de uma autopoiese específica do sistema jurídico, ou mesmo, em certos sistemas periféricos sua alopoiese (NEVES, 2007).

\footnotetext{
${ }^{123}$ A esse respeito, Luhmann (1989a) desenvolve o seguinte raciocínio: "Processing the expectations requires a binary code that contains a positive value (justice) and a negative value (injustice), and that artificially excludes both contradictions (justice is injustice, injustice is justice) and other values (utility, political expediency, and so forth). This coding is of decisive significance for the differentiation of the legal system, as it provides the system with its own internally constituted form of contingency. Everything that enters the law's sphere of relevance can be either lawful or unlawful, and anything that does not fit into this code is of legal significance only if it is important as a preliminary question in decisions about justice and injustice”. (LUHMANN, 1989a, p. 140).
} 
Teubner (1989a, p. 53) é enfático ao afirmar a autopoiese do direito que deve ser compreendido como um sistema social "de segundo grau, autonomizando-se em face da Sociedade, enquanto sistema autopoiético de primeiro grau, graças à constituição autorreferencial dos seus próprios componentes sistêmicos e à articulação destes num hiperciclo".

Visto como um subsistema funcionalmente diferenciado, de segundo grau, o direito pode se desenvolver à medida que for capaz de produzir seus próprios elementos de maneira exclusiva. Assim, através da repetição de um de seus elementos básicos, a decisão, o direito pode produzir e reiniciar sua própria autopoiese, num processo contínuo de autorreferencialidade, pois que ele próprio define suas premissas de validade por intermédio de uma norma jurídica e das decisões judiciais. (TEUBNER, 1988, p. 221).

Contudo, para o referido jurista, não se quer com isso afirmar um total isolamento do direito, nem que esta autorreferência se confunde com self-constitution. (TEUBNER, 1988, p. 222). ${ }^{124}$

Segundo Germano Schwartz (2004), a própria positividade do direito exige que o mesmo seja variável, no sentido de poder continuamente reprocessar através das decisões jurídicas as frustrações pelo próprio direito produzidas, e, dessa maneira, servir de base para a sua mudança. ${ }^{125}$

Tem-se, portanto, a recursividade hermética do sistema jurídico como pressuposto de sua autopoiese.

${ }^{124}$ Segundo enfatiza Gunther Teubner (1988. p. 222): “it is one thing when a system constitutes its components, i.e., when it defines self-referentially its elements, structures and processes as units and uses them operatively. Its is another thing if the system reproduces itself in the sense that elements produce structures and vice versa".

${ }^{125}$ A esse respeito complementa: "Assim, forma-se o sistema do direito de forma autopoiética. Fechado em seu interior, mas aberto ao entorno, Sua evolução reside na interação de sua parte endógena, absorvida pelo exógeno social”. (SCHWARTZ, 2004. p. 68). 
Para Teubner (1989a), a autorreprodução do direito ocorre sempre que as normas jurídicas se relacionam aos atos judiciais, às decisões jurisprudenciais, e vice-versa, ou quando se verifica a convergência entre as normas procedimentais e a doutrina. ${ }^{126}$

José Engrácia Antunes (1989), Após abordar a característica autorreferencial e autorreprodutiva do direito, faz a seguinte analogia entre o pensamento autopoiético e a teoria kelseniana, destacando a diferença de suas respectivas estruturações teóricas, aquela circular, esta piramidal:

Se Kelsen pensou poder encontrar numa fictícia Grundnorm a panaceia para o eterno problema do fundamento último da racionalidade jurídica, Teubner e os adeptos da teoria autopoiética eliminam o próprio problema ao salientar a circularidade e autorreferência do direito. (ANTUNES, 1989, p. xiii).

Assim, pode-se entender como o sistema jurídico, em tais visões sistêmicas, se apresenta, ao mesmo tempo, operativamente fechado e cognitivamente aberto ao ambiente, ou meio no qual se insere. ${ }^{127}$

Ademais, embora aberto cognitivamente à observação de seu ambiente, o sistema jurídico mantém sua autonomia a partir da atribuição de sentido aos estímulos percebidos através de seu próprio código comunicativo: lícito/ilícito.

Por sua vez, como destaca Germano Schwartz (2004, p. 70), o sistema jurídico possui também outros subcódigos que derivam daquele primeiro e que o auxiliam a continuar a

\footnotetext{
${ }^{126}$ A esse respeito, afirma o referido autor: "O direito torna-se autopoiético quando as suas auto-descrições permitem desenvolver e aplicar uma teoria de fontes jurídicas no contexto da qual as normas possam ser geradas através de precedentes jurisprudenciais ou outros processos de criação jurídica endógena. A normas jurídicas são então definidas por referência a operações jurídicas, isto é, componentes sistêmicos 'produzem' componentes sistêmicos. Este é, de resto, o caso do moderno direito 'positivo': as normas jurídicas podem apenas ser produzidas através de atos jurídicos especificamente definidos, consistam em leis, em decisões judiciais, ou em estatutos organizacionais, ou associativos, nos nossos dias, o próprio direito consuetudinário deve ser visto como um direito de criação jurisprudencial, já que a sua validade jurídico-positiva depende de um ato jurídico 'constitutivo' (e não meramente 'declaratório')”. (TEUBNER, 1989a, p. 85).

${ }^{127}$ Segundo André-Jean Arnaud e M. J. Farinas Dulce (2000, p.168): “Devemos considerar que a relação que o sistema jurídico mantém com o extrajurídico não é uma relação normativa, mas nesse caso, uma relação "cognitiva" ("abertura cognitiva do sistema"), porque se trata de um processo auto-regulado (regulado do interior). Isso significa que, na comunicação, a informação ou os 'estímulos' externos são transformados pelo sistema, ao longo do processo auto-referencial."
} 
produzir a unidade mediante a diferença, tais como: "legislação/jurisprudência", "normas jurídicas/normas positivas", jurídico/antijurídico" etc.

Como subsistema funcionalmente diferenciado, o direito somente terá sua autonomia afetada quando o seu código estiver em perigo, ou seja, quando começar a tomar decisões com base em códigos de outros subsistemas.

Tal é descrito como espécie de "assimetrização externa no plano da orientação normativa" capaz de negar a autorreferência operacional do direito, levando-o a uma forma de funcionamento alopoiético (NEVES, 2007, p. 142). ${ }^{128}$

Para Marcelo Neves (2007, p. 140), a partir da própria concepção sistêmica do funcionamento social, tal forma de determinação alopoiética do direito prevaleceria na maior parte da sociedade moderna mundial. Nesse sentido, o próprio direito positivo estatal, sobretudo, nos sistemas jurídicos periféricos, careceria mesmo de autonomia operacional.

Haveria, assim, segundo o referido autor, "a sobreposição de outros códigos de comunicação, especialmente do econômico (ter/não-ter) e do político (poder/não-poder), sobre o código 'lícito/ilícito', em detrimento da eficiência, funcionalidade e mesmo racionalidade do direito". (NEVES, 2007, p. 146). ${ }^{129}$

Ainda segundo Neves (2007), essa alopoiese jurídica poderia ser relacionada ao processo de constitucionalização simbólica do Estado de Direito Moderno, ocorrendo, em Constituições como a brasileira de 1988, “uma expansão da esfera do político em detrimento do desenvolvimento autônomo de um código específico de diferença entre lícito e ilícito". (NEVES, 2007, p. 148).

128 A esse respeito, discorre Marcelo Neves (2007, p. 142): "Derivada etimologicamente do grego állos ('um outro', 'diferente') + poíesis ('produção', 'criação'), a palavra [alopoiese] designa a (re)produção do sistema por critérios, programas e códigos do seu ambiente".

${ }^{129}$ Para Neves (2007), diferentemente de fenômenos localizados de "corrupção sistêmicas" previstos na teoria luhmanniana, essa perda de racionalidade não seria decorrente de bloqueios eventuais na reprodução autopoiética do direito positivo, mas decorreria, sim, do comprometimento generalizado e sua autonomia, diluindo-se, em suas palavras, "as próprias fronteiras entre sistema jurídico e ambiente". Tal restaria evidente, acrescenta ele, ao passo em que "os agentes do sistema jurídico estatal põem de lado o código-diferença 'lícito/ilícito' e os respectivos programas e critérios, conduzindo-se ou orientando-se primária e frequentemente com base em injunções diretas da economia, do poder, das relações familiares etc. [...].” (NEVES, 2007, p. 146-147). 
Tal discussão será retomada no último capítulo, sendo necessário, antes, fundamentar o entendimento adotado neste trabalho sobre a revisão a ser proposta na teoria luhmanniana acerca da própria função do direito e da compreensão específica da Constituição Federal brasileira de 1988, de modo diverso de sua pressuposição teórica geral que elenca as Constituições como acoplamentos estruturais de dois sistemas (político e jurídico), em vista do movimento social pela redemocratização do país que lhe precedeu.

\subsection{Contextualização e críticas referentes à visão funcional-estruturalista da sociedade e à inserção do pensamento sistêmico no direito}

Deve-se frisar, mais uma vez, que não é o objetivo deste trabalho defender a supremacia de um modelo em relação ao outro, mas, a partir do instrumental teórico fornecido pelo do pensamento sistêmico luhmanniano, defender a tese do conflito presente na comunicação produzida entre os sistemas jurídico e dos meios de comunicação de massa quanto aos sentidos das políticas públicas de seguridade social introduzidas pela Constituição Federal de 1988.

O desenvolvimento do presente tópico parte da recontextualização da visão autopoiética do direito no suposto estágio de transição científica para além do paradigma jurídico positivista, iniciada em estudos anteriores a este trabalho (CRUZ, 2007). Da mesma forma, requer a retomada da descrita epistemologia peculiar de sua visão sistêmica, sintetizadas no início desse capítulo.

Nesse sentido, as críticas dos defensores da visão autopoiética do direito ao referido impasse jurídico-científico destinam-se, de um lado, às teorias analítico-formalistas, como a Teoria Pura de Hans Kelsen (1998), centradas numa visão científica positivista do direito, alheia à sua relação com a sociedade, e, de outro, embora não se tratar do formalismo positivista citado rejeita-se o enfoque das teorias sociológicas do direito e de suas interações 
sociais como sistema aberto, compreendendo-o sob a ótica de um "sistema decisional socialmente condicionado" (ANTUNES, 1989, p. xix). ${ }^{130}$

No que diz respeito à Teoria Analítica do Direito, esta se insere no movimento positivista do século XIX e começo do século XX, sendo sua principal influência no campo jurídico exercida pela vertente lógico-analítica que, embora leve em conta fatos positivos - o direito como um algo existente na realidade social, dado positivamente, e por isso acessível a uma análise científica - , procura explicá-lo de modo formal como um sistema "conceitual", linguístico. ${ }^{131}$

O positivismo jurídico oriundo dessa orientação restringe a ciência do direito à "análise crítica de afirmações normativas e linguístico-conceptuais, deixando as investigações empíricas fundamentalmente para disciplinas da especialidade, como, por exemplo, a sociologia do direito". (MAZUREK, 2002a, p. 370).

Essa vertente lógico-analítica centra seu interesse nas proposições linguísticoconceituais e pressupõe, a partir da compreensão da estrutura das normas e de seus conceitos — da análise de determinadas palavras, por exemplo: direito, coação, moral etc. —, a

${ }^{130}$ Há que se distinguir claramente a crítica ao positivismo - enquanto modelo científico de análise do direito e das ciências sociais, sob o axioma da neutralidade valorativa e da busca de "leis naturais da vida social e de uma ciência da sociedade formada segundo o modelo das ciências da natureza" (LOWY, 2003, p. 18-19) — da consideração do Direito Moderno como Direito Positivo, no sentido da contingência de suas estruturas, relacionada à sua contínua adaptação às transformações da sociedade e de sua complexidade no contexto histórico, em oposição ao perene Direito Natural. (LUHMANN, 1983, p. 225; CANARIS, 1996, p. 27 e 30 ). Para uma visão abrangente e crítica da inadequação e das distorções ideológicas da aplicação do positivismo enquanto modelo científico no campo das ciências sociais recomenda-se a leitura da obra de Michael Löwy (2003) intitulada As aventuras de Karl Marx contra o Barão de Münchhausen: marxismo e positivismo na sociologia do conhecimento.

${ }^{131}$ Esse desenvolvimento histórico é tratado por Tercio Sampaio Ferraz Jr. (1994), como a consolidação da "Ciência Dogmática do Direito". A respeito da influência do positivismo e de seu caráter formalista, afirma o referido autor: "A primeira metade do século XX acentua as preocupações metodológicas já presentes no século anterior. $\mathrm{O}$ início do século é dominado por correntes que o levam às preocupações do pandectismo ao seu máximo aperfeiçoamento - por exemplo, na obra de Kelsen — ou insistem numa concepção renovada do saber jurídico ligando-o à realidade empírica. [...] O jurista aparece aí como o teórico do direito que procura uma ordenação dos fenômenos a partir de conceitos gerais obtidos, para uns, mediante processos de abstração lógica e, para outros, pelo reconhecimento de institutos historicamente moldados e tradicionalmente mantidos. [...] Neste quadro, a ciência dogmática do direito, na tradição que nos vem do século XIX, prevalecentemente liberal, na sua ideologia, e encarando, por consequência, o direito como regras dadas (pelo Estado, protetor e repressor) tende a assumir o papel de conservador daquelas regras, que, então, são por ela sistematizadas e interpretadas". (FERRAZ JR, 1994, p. 82-83). 
possibilidade de se "elucidar não só o seu significado, mas, para, além disso, os próprios fenômenos sociais nas suas relações uns com os outros". (MAZUREK, 2002a, p. 370).

Dessa forma, restringindo-se à análise de conceitos jurídicos básicos, espera desenvolver uma teoria sobre a estrutura geral do direito. (FERRAZ JR., 1994, p. 82).

Insere-se, segundo Claus-Wilhelm Canaris (1996, p. 27), numa visão sistêmica do direito restritiva pertencente aos "sistemas de puros conceitos fundamentais".

Embora o referido autor não ignore a importância do instrumental teórico da teoria kelseniana, de seus "sempre pré-elaborados conceitos fundamentais apriorísticos", entende que sistemas como este apresentam grandes limitações para a própria elaboração científica jurídica não sendo capazes de concretizar a unidade valorativa exigida pelo direito. Esta unidade "é sempre de tipo material e só pode realizar-se numa ordem jurídica historicamente determinada" o que estaria aquém das possibilidades daqueles sistemas analíticos, como o kelseniano, que tratam de "categorias puramente formais, que subjazem a qualquer ordem jurídica imaginável" (CANARIS, 1996, p. 27). ${ }^{132}$

Para essa criticada visão formalista-positivista, as normas jurídicas postas pelo Estado assumem a centralidade da análise científica do direito seja sob o prisma de Hans Kelsen (1998) e de sua Teoria Pura — em que tais normas são "o objeto da ciência jurídica, e a conduta humana só o é na medida em que é determinada nas normas jurídicas como pressuposto ou consequência, [...] em que constitui conteúdo de normas jurídicas" (KELSEN,

132 A mesma crítica é dirigida por Canaris (1996, p. 28) aos sistemas lógico-formais, como o da jurisprudência dos conceitos e do sistema axiomático-dedutivo, que, como os sistemas de puros conceitos formais, seriam inadequados para "exprimir a unidade interior e a adequação de determinada ordem jurídica positiva". Tais limitações decorreriam do conceito positivista de ciência fundado nos ideais metodológicos das ciências naturais, imprimindo à ciência jurídica um caráter estritamente lógico. Sua incongruência em relação à visão sistêmica da ciência jurídica, proposta pelo referido autor, que melhor se adequariam aos objetivos e à essência do direito é assim exposta: "Esta concepção [positivista] da essência e dos objetivos da Ciência do Direito pode-se hoje, sem reserva, considerar como ultrapassada. De fato, a tentativa de conceber o sistema de determinada ordem jurídica como lógico-formal ou axiomático-dedutivo está, de antemão, votada (sic) ao insucesso. Pois a unidade interna de sentido do direito, que opera para erguer o sistema, não corresponde a uma derivação da ideia de Justiça de tipo lógico, mas antes de tipo valorativo ou axiológico. Quem poderia seriamente pretender que a regra de tratar o igual por igual e o diferente de modo diferente, de acordo com a medida da diferença, pode ser acatada com os meios da lógica? Os valores estão, sem dúvida, fora do âmbito da lógica formal e, por consequência, a adequação de vários valores entre si e a sua conexão interna não se deixam exprimir logicamente, mas antes, apenas, axiológica ou teleologicamente". (CANARIS, 1996, p. 30-31). 
1998, p. 79) —, seja com uma maior abertura pela teoria estruturalista de Herbert Lionel Adolphus Hart (2001) e seu enfoque na diversificação das normas jurídicas em regras primárias e secundárias.

Enquanto que para a teoria kelseniana a condição de existência do sistema jurídico, restrito ao conjunto escalonado de normas jurídicas válidas, depende de um pressuposto lógico, com o estabelecimento lógico-fictício ("pressuposição lógicotranscendental") de uma norma fundamental (Grundnorm), para Hart (2001), o direito compreenderia um sistema de regras empírico sociais. ${ }^{133}$

Nesse sentido, nas regras primárias, a característica sociológica consistiria em sua manifestação exterior como regra de comportamento, consensual e que se repetiria regularmente, na maioria de um grupo social. O aspecto psicológico de sua existência se manifestaria quando certo comportamento é reconhecido pela maioria do grupo social como padrão geral.

As condições de existência das regras secundárias, de atribuição de competência, dependeriam da utilização de uma regra de reconhecimento por um tribunal ou por outras pessoas para a identificação das regras do sistema, sendo seu aspecto exterior um aplicar, enquanto prática complexa do sistema jurídico.

${ }^{133}$ Acerca dos limites dessa pressuposição, embora empregue o termo lógico-transcendental para se referir a esse processo cognitivo, Kelsen (1998) busca restringir o seu grau de abstração estipulando sua vinculação com uma dada ordem jurídica, ou seja, sua vinculação a uma Constituição sempre determinada e efetivamente estabelecida, portanto não condicionada a qualquer valor transcendente ao Direito Positivo, daí porque afirma: "[...] A norma fundamental não é, portanto, o produto de uma descoberta livre. A sua pressuposição não se opera arbitrariamente, no sentido de que temos a possibilidade de escolha entre diferentes normas fundamentais quando interpretamos o sentido subjetivo de um ato constituinte e dos atos postos de acordo com a Constituição por ele criada como o seu sentido objetivo, quer dizer: como normas jurídicas objetivamente válidas”. (KELSEN, 1998, p. 224-225). Não obstante a extensa argumentação por ele desenvolvida, o fato de propor uma fundamentação metafísica do direito em uma premissa maior que não pode ser posta em questão não deixa de ser abertamente reconhecida: "[...] Por outras palavras: se a norma fundamental não pode ser uma norma querida, mas a sua afirmação na premissa maior de um silogismo é logicamente indispensável para a fundamentação da validade objetiva das normas, ela apenas pode ser uma norma pensada. [...] Uma ciência jurídica positivista apenas pode constatar que esta norma é pressuposta como norma fundamental". Nesse sentido, conclui: “[...] e uma norma que é pensada como pressuposto quando uma ordem coercitiva globalmente eficaz é pensada como um sistema de normas jurídicas válidas". (KELSEN, 1998, p. 227). 
Segundo a síntese proposta por Per Mazurek (2002a,), essas regras secundárias de reconhecimento, diferentemente das demais, não encontrariam no interior desse sistema jurídico sua validade, não podendo, sequer, lhes ser atribuído um controle de validade no sentido habitual do termo. A solução para esse "equívoco linguístico" seria considerar que a regra de reconhecimento, por falta de um ponto de referência interno ao sistema, "não pode ter nem deixar de ter validade, sendo simplesmente aceita". (MAZUREK, 2002a, p. 375).

Percebe-se, então, o paradoxo normativo do direito em ambas as correntes analíticas quanto à sua fonte de validade, seja ela pressuposta numa norma fundamental ou num consenso geral e hipotético que se impõe como regra de reconhecimento. Daí porque, segundo Tercio Sampaio Ferraz Jr. (1994, p. 176): “para a dogmática analítica, ordenamento é um conceito operacional que permite a integração das normas num conjunto, dentro do qual é possível identificá-las como normas jurídicas válidas".

De qualquer forma, mais do que o seu encoberto caráter autorreferencial e paradoxal, que na teoria sistêmica é reconhecido como característica própria da diversificação dos sistemas sociais e de sua autopoiese, o ponto central da crítica a tais teorias analíticas relaciona-se ao isolamento do direito, não só no campo de sua "análise" científica, como em sua práxis, deixando de lado suas inter-relações com a sociedade, por ser considerado, enquanto sistema jurídico, sob uma perspectiva a-valorativa ou apenas descritiva. Nessa linha, Niklas Luhmann (1983) antes mesmo de sua completa adesão ao pensamento autopoiético, apontava a seguinte deficiência dessa visão estritamente normativista:

Não se pode negar que tal tipologia das normas é em princípio correta e fornece um certo grau de orientação. Mas ela não vai além de classificações incapazes de desvendar a interdependência funcional e a relação, em termos de desenvolvimento, entre os diferentes tipos, e muito menos sua relação com outras estruturas cognitivas, com a diferenciação funcional, etc. (LUHMANN, 1983, p. 42).

Um exemplo dessa tentativa de neutralização do direito pode ser extraído de sua distinção da moral. Para o positivismo jurídico, os valores, embora tenham sua existência objetiva reconhecida, estariam situados fora do direito, em uma ordem divina, ultrapositiva ou moral que apenas indiretamente, através de uma crítica moral do Direito Positivo, 
condicionaria a sua modificação ou legitimaria um direito de resistência a uma norma jurídica tão condenável que não mereça obediência. (MAZUREK, 2002a, p. 377).

O problema central da aplicação do direito na teoria analítica consiste na desconsideração de ideais sociais, éticos ou políticos, bem como de suas tensões com os demais sistemas sociais, que, quando muito, são deslocados para a esfera da argumentação jurídica.

Contudo, conforme a crítica de Fábio Konder Comparato (2006), essa separação do elemento axiológico do direito que a leva a se distinguir da moral, tornando dispensável a própria indagação se a ordem jurídica é justa ou injusta, é inaceitável e revela um sofisma evidente, o que leva referido autor à seguinte observação:

[...] A ordem jurídica não existe como uma finalidade em si mesma, mas sempre como meio institucional de se concretizarem certos fins sociais, tidos como valiosos. Que esses fins sociais sejam considerados justos para uma determinada comunidade e injustos para outra não significa que o direito deva reduzir-se a puras normas abstratas. (COMPARATO, 2006, p. 359). ${ }^{134}$

Assim, em determinadas situações limites de difícil decisão, em que não existe no sistema uma regra inequívoca para o caso jurídico em questão, também chamados hard cases, evidenciam-se algumas das críticas à compreensão estritamente positivista do direito como sistema fechado, hierárquico de regras válidas, uma vez que, por sua própria lógica interna, a decisão dos juízes nesses casos tende a aparecer como arbitrária ou política posto que não obedeça a uma regra específica. (MAZUREK, 2002a, p. 379).

De maneira contrária a essa arbitrária discricionariedade do juiz, poderia ainda ser citada a crítica de Ronald Dworkin (2002) ao positivismo jurídico e sua defesa do emprego dos princípios como normas de interpretação e de aplicação do direito.

\footnotetext{
${ }^{134}$ Nesse mesmo sentido, acerca da separação entre direito e moral decorrente dessa teorização jurídica analítica, acrescenta Comparato (2006, p. 360): "De qualquer modo, foi com base nessa concepção asséptica da ordem jurídica que Kelsen pretendeu separar o direito da moral. Para ele, esse discrime pode ser feito segundo o critério kantiano de que a moral rege apenas a conduta interior, enquanto o direito diz respeito ao foro externo das ações humanas. As intenções e motivos nem sempre ficam alheios à análise jurídica, ou ao exame judicial do caso concreto."
} 
Apesar dessa breve e superficial abordagem das teorias analíticas, em razão de sua natureza marcadamente positivista, criticada no âmbito das ciências sociais por diversos autores como Michael Löwy (2003) e, no meio jurídico, como Claus-Wilhelm Canaris (1996) dentre outros, resta evidente, conforme ressalta Per Mazurek (2002a, p. 380), que tais teorias formais em sua “[...] mera perspectiva neutral, apenas analítico-descritivo do direito, já tem efeitos prático-normativos na medida em que, nas suas análises de conceitos, revele ou oculte questões práticas de política jurídica”.

Por sua vez, quanto à visão oposta do direito, como sistema aberto, condicionado socialmente às relações de dominação e força, impostas pelas relações materiais presentes na sociedade capitalista, apresentam-se as concepções jurídicas marxianas (atribuídas ao próprio Marx) e marxistas (de seus seguidores).

Destacam-se aqui suas duras críticas ao "Direito Burguês" seja em seu viés "economicista" de sujeição às relações econômicas da infraestrutura, questionado por Eros Roberto Grau (2002, p. 50) como uma interpretação equivocada de Marx e Engels; seja como as empreendidas por Pasukanis (1989), em sua “teoria da circulação de mercadorias", a partir da qual desponta sua crítica à forma jurídica, cujo objetivo principal seria regular os vínculos entre dois agentes econômicos no mercado de modo a permitir e estimular a circulação de mercadorias, organizar a economia capitalista e, assim, garantir o nível de desenvolvimento de suas relações econômicas e sociais. (NAVES, 2000, p. 57).

Pasukanis (1989) ataca abertamente a teoria geral do direito positivista, sobretudo de escolas analíticas como a kelseniana, refutando o alto grau de abstração de seus conceitos jurídicos resultantes da elaboração lógica das normas de direito positivo. Nessa linha afirma o referido autor:

O direito enquanto fenômeno social objetivo não pode esgotar-se na norma, seja ela escrita ou não. A norma, como tal, isto é, o seu conteúdo lógico, ou é deduzida diretamente de relações preexistentes, ou, então, representa, quando promulgada como lei estatal, um sintoma que nos permite prever, com certa verossimilhança, o futuro nascimento de relações correspondentes. Para afirmar a existência objetiva do direito não é suficiente conhecer o seu conteúdo normativo, mas é necessário saber se este conteúdo normativo é realizado na vida pelas relações sociais. A fonte habitual de erros neste caso é o modo de pensar dogmático que confere, ao conceito de norma vigente, uma 
significação específica que não coincide com aquilo que o sociólogo ou historiador compreendem por existência objetiva do direito. (PASUKANIS, 1989, p. 57).

Nesse sentido, o direito só adquire significação se corresponde a determinadas relações entre sujeitos. Revela-se, assim, a posição teórica antinormativista de Pasukanis (1989), que, segundo Márcio Billarinho Naves (2000, p. 64), "recusa a prevalência da norma sobre a relação, isto é, que recusa a premissa de que é a norma que gera a relação jurídica".

Essa visão do direito e do próprio Estado como um aparelho garantidor e dependente de um "circuito de trocas mercantis que cria as condições básicas para que se opere a distinção entre o público e o privado" desvelaria "o segredo do Estado e das formas políticas burguesas" no sentido da dominação de classe por eles sustentada de modo indireto e mediato. (NAVES, 2000, p. 80).

A função do direito de encobrir e sustentar o desenvolvimento dos modos de produção capitalista dar-se-ia através das abstrações e ficções jurídicas tanto da impessoalidade do Estado quanto da forma jurídica em que se sustentam a liberdade e igualdade de partes nas relações de troca (PASUKANIS, 1989, p. 111-112). ${ }^{135}$

Ao tratar das relações entre a forma da mercadoria e o Estado, Mário Bilharinho Naves (2000) expõe a síntese dessa crítica marxista:

[...] Ora, o caráter público do Estado só pode se constituir em uma sociedade organizada sob o princípio da troca por equivalente, que pressupõe como condição necessária da circulação a presença de sujeitos proprietários que se

135 Dessa forma, segundo Pasukanis (1989, p. 113): “Qualquer teoria jurídica do Estado que queira alcançar todas as funções do Estado é, no presente, necessariamente inadequada. Não pode ser o reflexo fiel de todos os fatos da vida do Estado e apenas parece uma reprodução ideológica deformada da realidade. A dominação de classe, em sua forma organizada como em sua forma desorganizada, é muito mais ampla do que o domínio do poder estatal. A dominação da burguesia se exprime tanto na dependência do governo aos bancos e grupos capitalistas quanto na dependência de cada trabalhador particular em relação ao seu empregador, e no fato de que os funcionários do aparelho de Estado são intimamente vinculados à classe dominante. Todos estes fatos, cujo número poderíamos multiplicar até o infinito, não possuem qualquer expressão jurídica oficial mas concordam em sua significação, tal como a subordinação dos mesmos operários às leis do Estado burguês, às ordens e decretos de seus organismos, ao julgamento de seus tribunais, etc. Ao lado da dominação de classe direita e imediata constitui-se uma dominação mediata, refletida sob a forma do poder oficial do Estado enquanto poder particular destacado da sociedade. Assim surgiu o problema do Estado que oferece tanta dificuldade à análise quanto o problema da mercadoria". 
relacionam de modo voluntário e livre, sem a presença de uma autoridade coatora externa. O operário não é coagido a vender a sua força de trabalho para o capitalista, ele o faz por livre deliberação de sua vontade, por meio de um contrato. É o que acentua Pasukanis, ao dizer que "O poder político de classe pode assumir a forma de um poder público na medida em que a relação de exploração se realiza formalmente como relação entre dois possuidores de mercadoria independentes e iguais, um dos quais, o proletário, vende a sua força de trabalho e o outro, o capitalista, a compra". (NAVES, 2000, p. 80).

A despeito dessa bem articulada crítica às relações desiguais que a prática trabalhista e a luta hodierna do Direito do Trabalho tenderiam a confirmar, ao menos no campo das relações laborais, Eros Roberto Grau (2002, p. 50) posiciona-se de forma contrária à suposição "inteiramente equivocada [...] de que Marx e Engels teriam concebido o direito como mero reflexo da economia". 136

A partir de uma releitura funcionalista, que, embora não seja autopoiética, com ela guarda algumas semelhanças, o mencionado autor adere à tese de que o direito não possui apenas uma linguagem, "mas é uma linguagem, na medida em que instrumenta uma modalidade de comunicação entre os homens, seja para ordenar situações de conflito, seja para instrumentalizar políticas”. (GRAU, 2002, p. 56).

Por essa razão, o direito não poderia ser visto como uma simples "representação da realidade social, existente fora dela", devendo, contudo, ser entendido como um "nível do todo social”, em sentido funcional e não institucional, sendo a hierarquia entre infraestrutura e supraestrutura uma metáfora que só poderia ser interpretada como uma "hierarquia de funções, ou seja, [...] hierarquia entre as relações sociais segundo as funções que assumem no processo de produção e reprodução da vida social". (GRAU, 2002, p. 57).

Relativiza-se, dessa maneira, parte das críticas marxistas ao direito a partir da consideração das demais funções que exerce, não sendo apenas condicionado pela econômica,

\footnotetext{
${ }^{136}$ A partir de uma intrincada discussão interpretativa de diferentes trechos das principais obras de Karl Marx e Friedrich Engels, o referido jurista sustenta que: "Afirmar que o modo de produção da vida material (social) que é diverso do modo de produção dos bens materiais — determina o direito é algo inteiramente distinto da afirmação de que a estrutura econômica (uma das estruturas regionais integradas na estrutura global do modo de produção da vida social) determina o direito". (GRAU, 2002, p. 53).
} 
como também a condicionando, posto que ambos seriam interdependentes. Daí porque, com base numa releitura marxista, afirma Eros Roberto Grau (2002, p. 57): “A compreensão dessa realidade nos permite verificar que o direito é, sempre e também no modo de produção capitalista, um instrumento de mudança social, para ser dinamizado, nessa função, ao sabor de interesses bem definidos". 137

Luhmann (1983), por sua vez, ao tratar das abordagens clássicas da sociologia do direito refere-se à teoria da sociedade de Karl Marx como a reação a uma característica fundamental do desenvolvimento social moderno, qual seja, "a transição do primado sobre a determinação de sentido à sociedade, deslocando-o da política para a economia". ${ }^{138}$

Assim, desenvolveu-se uma teoria sociológica marxista do direito marcada por sua "uniteralidade" na medida em que lhe atribui o papel central de fixar as contradições sociais resultantes do modo de produção capitalista, através da atribuição individual de chances

${ }^{137}$ Conforme defende o referido autor: "A superação de leituras equivocadas deita por terra as concepções de que o direito é exclusivamente um produto, puro, das relações econômicas, relações, essas, às quais ele (o direito) seria alheio; de que o direito é somente ideologia, sob a qual as relações de produção dissimulam sua verdade que o direito é uma expressão da vontade de uma classe dominante ou simples meio de dominação, que instrumenta a repressão exercida por essa classe. O direito é mais do que isso. Há de ser visualizado, assim, como instância de um todo complexo, se manifesta no bojo de uma relação de causalidade estrutural (v. trechos das cartas de Engels, acima transcritos), resultante da interação dela - instância jurídica - com as demais instâncias desse todo complexo. [...] Se, por um lado, o direito interfere na constituição, no funcionamento e na reprodução das relações de produção, reproduzindo-as de maneira deformada, ideologicamente, é certo também, de outra parte, que a sociedade capitalista é essencialmente jurídica e nela o direito atua como mediação específica e necessária das relações de produção que lhe são próprias. Tais relações de produção não poderiam estabelecer-se, nem poderiam reproduzir-se, sem a forma do direito (Poulantzas 1967/160 e carta de Engels a Conrad Schmidt, de 27.10.1889, trecho acima transcrito). Em outros termos: a estrutura econômica do capitalismo não existiria se não existisse um direito que supusesse regras gerais e sujeitos abstratos, livres e iguais (Jeammaud, 1986/51). O que importa neste passo é a verificação de que o direito é, sempre, um instrumento de mudança social. O direito é produzido pela estrutura econômica mas, também interagindo em relação a ela, nela produz alterações. A economia condiciona o direito, mas o direito condiciona a economia. [...] Isso nos permite verifica que o direito não é mera representação da realidade social, existente fora dela, porém um nível do todo social. (GRAU, 2002, p. 57-59).

${ }^{138}$ Sobre a forma pela qual a teoria de Marx trabalha essa transição de sentido, explica Luhmann (1983, p. 23): "Ela interpreta o primado da economia, na medida em que este relaciona o econômico com a materialidade das necessidades humanas, como uma verdade antropológica e trans-histórica, formulando nesse contexto uma teoria natural-dialética do desenvolvimento social. A propulsão do desenvolvimento se dá a partir de alterações nas forças produtivas e nas condições de produção que intermedeiam a satisfação de necessidades materiais ou, em termos mais precisos: de contradições sociais que resultam no decorrer do desenvolvimento da produção e da satisfação de necessidades”. 
especiais e desiguais, sendo a "totalidade do direito moldada aos interesses dos proprietários", posto que concede e protege a propriedade. (LUHMANN, 1983, p. 23).

Nesse contexto, a visão marxista do direito poderia ser interpretada como "uma dissolução em entrelaçamentos, subjetivos e locais, entre a satisfação de necessidades e o processo decisório (se bem que esse raciocínio não transparece nas exposições oficiosas do marxismo nem na literatura secundária nelas inspiradas)”. (LUHMANN, 1983, p. 24).

Luhmann (1983) reconhece parcialmente a compatibilidade dessa visão estrutural jurídica com o aumento de complexidade da Sociedade Capitalista, no sentido de sua maior adequação à solução de problemas decisórios a partir um "grau máximo de variabilidade estrutural consentido" sustentado pelo direito. Contudo, segundo o referido sociólogo alemão:

A questão, porém, é se esse é o único sentido no qual o direito condiciona a complexidade sistêmica da sociedade. Certamente não. Aqui se localizam as limitações da ótica da sociologia marxista do direito, apresentando ao mesmo tempo um problema que só pode ser convenientemente articulado por meio de uma abordagem mais abstrata da teoria sociológica da sociedade. (LUHMANN, 1983, p. 24).

Embora não se possa chamar de estritamente marxista, cabe, ainda que superficialmente, introduzir neste tópico como a Teoria Crítica, sobretudo, através de Jürgen Habermas, posiciona-se frente a esse impasse teórico. ${ }^{139}$

Habermas (2001), em sua Teoria da Ação Comunicativa, em certa medida, afastase tanto da análise positivista da sociedade e do direito quanto de sua leitura estritamente marxista, como fora mencionado de modo incidental, ao tratar dos Aspectos gerais da Teoria

\footnotetext{
${ }^{139}$ Embora se reconheça a influência do pensamento marxista na obra de Jürgen Habermas, esse autor não adota de forma ordenada e direta alguns conceitos e interpretações formulados por Karl Marx, criticando, por exemplo, a redução do processo de constituição do gênero humano ao trabalho técnico-instrumental. (MAZUREK, 2002b, p. 451). No mesmo sentido, apresenta-se a sua conceitualização de sociedade civil e sua maior autonomia em relação à economia, na qual deixa claro a superação de alguns pressupostos marxistas: "[...] O atual significado da expressão 'sociedade civil' não coincide com o da 'sociedade burguesa' da tradição liberal, que Hegel chegara a tematizar como 'sistema das necessidades', isto é, como sistema do trabalho social e do comércio de mercadorias numa economia de mercado. Hoje em dia, o termo 'sociedade civil' não inclui mais a economia constituída através do direito privado e dirigida através do trabalho, do capital e dos mercados de bens, como ainda acontecia na época de Marx e do marxismo. O seu núcleo institucional é formado por associações e organizações livres, não estatais e não econômicas, as quais ancoram as estruturas de comunicação da esfera pública nos componentes sociais do mundo vida". (HABERMAS, 1997, v. 2, p. 99).
} 
dos Sistemas. Insere-se, ainda que à sua maneira intersubjetivista, na tentativa comum às teorias de Foucault (1979) e Luhmann (1998), apontada por Teubner (1989b, p. 729), de superação do realismo epistemológico e individualismo metodológico legados por Max Weber (2001).

$\mathrm{Na}$ construção das bases para o agir comunicativo, sua teoria, além de romper com o citado realismo epistemológico weberiano, distancia-se da concepção de razão prática aristotélica de modo a substituí-la pelo conceito de razão comunicativa, o que, segundo adverte o próprio Habermas (1997, v. 1, p. 19), "vai muito além de uma simples troca de etiqueta". Desta, depreende-se uma nova forma de compreensão da relação entre os indivíduos e destes com o Estado, própria da modernidade, em que os primeiros passam a estar essencialmente ligados à categoria de sujeitos privados, não sendo mais considerados apenas no conjunto que forma certa cultura ou ordem política.

Abandona-se, portanto, a visão de uma sociedade composta de indivíduos e centrada no Estado próprias da teoria normativista do Estado, direito racional, e da tradição filosófica empreendida pela razão prática. Contudo, o referido autor reconhece seus "vestígios filosófico-históricos no conceito de sociedade que se administra democraticamente a si mesma, na qual o poder burocrático do Estado deve fundir-se com a economia capitalista". (HABERMAS, 1997, v. 1, p. 18).

Para que essa fusão não resulte em uma opressora submissão das estruturas da sociedade civil e da esfera pública decorrentes de sua "contaminação pelos imperativos sistêmicos que emergem da administração e da economia", a teoria habermasiana precisa pressupor 'um 'mundo da vida' e uma 'esfera pública' não colonizados pela racionalidade teleológica que é própria dos sistemas”. (VILLAS BÔAS FILHO, 2006a, p. 215).

A saída para essa "contaminação", segundo Habermas (1997 v. 2, p. 310) consiste numa aposta no processo democrático fundado numa nova racionalidade e nova teoria do direito capazes de "assegurar simultaneamente a autonomia privada e pública dos sujeitos de direito". ${ }^{140}$

${ }^{140}$ Acerca do novo sentido atribuído à razão na sociedade moderna, explica Habermas (1997, v. 1, p. 20): “A razão comunicativa distingue-se da razão prática por não estar adstrita a nenhum ator singular a um macro-sujeito 
Daí resultaria o nexo conceitual interno entre Estado de direito e democracia, central à sua teoria intersubjetivista, fundada na racionalidade comunicativa, no discurso e numa visão procedimentalista do direito. Nessa linha, afirma:

Por conseguinte, a compreensão procedimentalista do direito tenta mostrar que os pressupostos comunicativos e as condições do processo de formação democrática da opinião e da vontade são a única fonte de legitimação. Tal compreensão é incompatível não somente com a ideia platônica, segundo a qual o direito positivo pode extrair sua legitimidade de um direito superior, mas também com a posição empirista que nega qualquer tipo de legitimidade que ultrapasse a contingência das decisões legisladoras. (HABERMAS, 1997, v. 2, p. 310).

A razão é, então, reposicionada como meio (medium) linguístico fundamental em toda a estrutura de seu pensamento, superando-se a tradicional redução da racionalidade ao seu aspecto cognitivo-instrumental, de que resultaria o seu déficit qualitativo, reabilitando-a através de uma mudança de paradigma capaz de superar o logocentrismo da filosofia da consciência criticado por Jacques Derrida, sem contudo, se recorrer a uma crítica radical da razão. (HABERMAS, 1998, p. 287-293). ${ }^{141}$

sociopolítico. O que torna a razão comunicativa possível é o medium linguístico, através do qual as interações se interligam e as formas de vida se estruturam. Tal racionalidade está inscrita no telos linguístico do entendimento, formando um ensemble de condições possibilitadoras e, ao mesmo tempo, limitadoras. Qualquer um que se utilize de uma linguagem natural, a fim de entender-se com um destinatário sobre algo no mundo, vê-se forçado a adotar um enfoque performativo e aceitar determinados pressupostos".

${ }^{141}$ A crítica da razão efetuada por Habermas é empreendida não no sentido de sua radical negação, mas de sua extensão. Dessa forma, ao invés de identificar o problema da racionalidade moderna como um excesso da razão que serviria para instrumentalizar a dominação social, para a teoria habermasiana, de forma contrária, sua crise resulta de uma deturpação de seus fins, que a transforma numa "ferramenta por excelência de supressão da liberdade". Isso decorreria de um déficit qualitativo de racionalidade que requer uma mudança de paradigma além de seu conceito unidimensional, cognitivo-instrumental, próprio da filosofia da ciência. Nesse sentido, disserta Orlando Villas Bôas Filho (2006a, p. 58): “[...] Não se trata de alargar essa dimensão teleológica da racionalidade, de modo a estender ainda mais a racionalidade cognitivo-instrumental. $\mathrm{O}$ déficit de razão apontado por Habermas não se relaciona com essa faceta da racionalidade. Trata-se antes de mostrar que a razão não se reduz ao seu aspecto cognitivo-instrumental, aspecto esse privilegiado por um paradigma que é o da 'consciência de si, da autorreferência de um sujeito que conhece e age isoladamente (...)"'. Ainda sobre esse assunto, acrescenta em sua dissertação de mestrado que: “[...] O projeto de Habermas pode ser entendido como uma mudança de paradigma justamente por negar essa coincidência da parte com o todo, no que concerne à racionalidade, de modo a negar esse paradigma centrado no sujeito, opondo-lhe outro que é o 'da relação intersubjetiva de indivíduos, que socializados através da comunicação se reconhecem mutuamente'. [...] Assim, a mudança de paradigma se dá com a negação do logocentrismo do pensamento ocidental e com a afirmação da compreensão intersubjetiva, o que implica uma negação da redução da razão ao seu aspecto cognitivoinstrumental". (VILLAS BÔAS FILHO, 2006a, p. 59). No que diz respeito ao termo logocentrismo, este remete à 
Nesse sentido, ao Direito Positivo moderno é atribuída a mediação social, como instrumento capaz de amenizar a tensão entre facticidade e validade, diminuindo de maneira segura o risco de dissenso, para, assim, possibilitar a integração social sem o apelo a fundamentações religiosas, metafísicas ou transcendentais, posto que, inserido no mundo da vida, contribuiria para a formação de "maciço pano de fundo consensual" para o agir comunicativo. (HABERMAS, 1997, v.1, p. 40).

Percebe-se, então, que nessa nova proposta interpretativa habermasiana, "as formas de comunicação da formação política da vontade no Estado de direito, da legislação e da jurisprudência, aparecem como partes de um processo mais amplo de racionalização dos mundos da vida de sociedades modernas pressionadas pelos imperativos sistêmicos". (HABERMAS, 1997, v. 1, p. 22). ${ }^{142}$

Diferentemente do que fora exposto sobre o conceito luhmanniano de comunicação e de sua função na redução da complexidade na sociedade, para Habermas (1997), o papel central da comunicação, através da "ação comunicativa", consiste em viabilizar o entendimento por meio da coordenação de ações.

Contudo, para isso, esse agir comunicativo deve partir de quatro "pretensões de validez" - verdade, correção, sinceridade e inteligibilidade —, que, segundo disserta Sidinei Cruz Sobrinho (2005), estariam garantidas por uma espécie de "argumentação transcendental". Esta, segundo o referido pesquisador, se justificaria ao passo em que "dada a 'impossibilidade de se recusar' determinados pressupostos, é que se concebe a razão comunicativa como aquela

filosofia pós-estruturalista de Jacques Derrida, filósofo francês, nascido na Argélia e de origem judaica, que em sua obra criticou a "centralidade do logos [razão] no pensamento ocidental [tendo-a como] questionável em decorrência de seu caráter metafísico, fruto de uma consciência interiorizada que se expressa essencialmente através de uma linguagem falada e empreende uma investigação ontológica da realidade". (HOUAISS, 2005).

142 O "mundo da vida" habermasiano seria formado por três componentes que precedem qualquer processo de entendimento, quais sejam: cultura, sociedade e personalidade. Segundo a síntese proposta por Sidinei Cruz Sobrinho (2005, p. 23), em sua dissertação de mestrado sobre Direito Humanos e Democracia em Jürgen Habermas, "a cultura apresenta-se [...] como aquele conjunto de crenças aceitas como verdadeiras em determinada sociedade e utilizadas para entender algo no mundo. Sociedade é, por sua vez, aquele conjunto de normas tidas como legítimas e que permitem uma identidade social e a solidariedade dos sujeitos. Por fim, a personalidade é dada pela própria interação e socialização dos sujeitos". 
capaz de produzir, ou melhor, de reproduzir um mundo de sujeitos autônomos e emancipados". (CRUZ SOBRINHO, 2005, p. 20).

A Teoria do Agir Comunicativo de Habermas, da mesma forma que a Teoria da Sociedade de Luhmann, apresenta um intrincado conjunto de pressupostos e conceitos próprios que fogem ao objeto deste trabalho acadêmico. Por essa razão, feita essa apertada síntese, devese centrar a atenção para o seu conceito de Direito Moderno e para a função a ele atribuída.

Nessa linha, Habermas (1997, v.1, p. 55-60) constrói sua teorização do direito e de sua fundamentação por meio da teoria do discurso, visando reestruturá-lo como sistema jurídico capaz de promover a citada integração social. Instrumentalizada pelo direito, como medium ou categoria de mediação social, sua teoria do discurso apresenta-se como a via capaz de promover a interação no espaço democrático das dimensões sociais, econômicas, políticas e de direito.

O direito, como medium de regulação da sociedade, trabalharia com as expectativas generalizadas de comportamento remetendo-se a uma forma de ação comunicativa carregada de sentido, a interação. Contudo, para que essa "determinação generalizante de expectativas" aconteça, faz-se necessário que o sentido dessa ação seja compreendido. Para tanto, as relações de ação devem ser analisadas também como relações de sentido.

Dessas expectativas de comportamento decorria uma natureza normativa, uma vez que, segundo Per Mazurek (2002b, p.452), “de uma série de ações e expectativas de ação, ela seleciona uma ação à custa da outra, a estabiliza como expectativa de comportamento geral, impondo-a mesmo com a ameaça de sanções, caso necessário".

Contudo, a legitimidade desse direito e a validade de suas normas, mesmo considerado como um sistema positivado, estão sujeitas à sua comprovação em face das objeções apresentadas contrafactualmente, prevalecendo na medida em que estiverem de acordo com as pretensões de validade do discurso e de seu núcleo de caráter moral. Portanto, sua positividade apresenta-se como uma simulação de parte da realidade social que apenas se 
sustenta "até segunda ordem, porque ela pode ser modificada ou colocada fora de ação em qualquer um de seus componentes singulares". (HABERMAS, 1997, v.1, p. 60). ${ }^{143}$

Por sua vez, por considerar que as sociedades modernas não se restringem a questões valorativas, as normas e os processos de entendimento necessários à integração habermasiana dependem também do mercado e do poder administrativo, por esse motivo, situa sua teoria do direito no contexto mais amplo de sua teoria da sociedade. ${ }^{144}$

Tem-se, dessa maneira, que o entendimento comunicativo garantido pelo direito pressupõe estruturas da intersubjetividade, até certo ponto, idealizadas, a partir das quais se formariam os mundos da vida e, de sua racionalização comunicativa, as esferas públicas. Daí resultariam a legitimidade e a própria função do direito conforme explica Orlando Villas Bôas Filho (2006a, p. 214):

[...] Trata-se da metáfora do direito enquanto correia de transmissão que levaria demandas normativas provenientes do "mundo da vida" para o âmbito dos sistemas que, em função de sua orientação codificada e da racionalidade que lhe é correlata, seriam indiferentes a tais demandas. Concebido nesses termos, o direito estará, portanto, fundado em última análise no princípio do discurso que, em termos bastante gerais, consiste na avaliação imparcial de questões normativas de qualquer espécie pelos possíveis envolvidos pelas decisões tomadas.

143 Dessa forma, embora reconheça o Direito Moderno como Direito Positivo, Habermas (1992) diverge claramente de sua interpretação em termos analíticos, lógico-formais, remetendo a questão de sua legitimidade não a observância estrita de uma legalidade sacralizada, mas a nova racionalidade democrática que engloba uma abordagem valorativa e moral dessas questões normativas: "Se, em sociedades do nosso tipo, a legitimidade deva ser possível através da legalidade, então, a crença na legalidade, que perdeu as certezas coletivas da religião e da metafísica, tem necessariamente, de se apoiar na 'racionalidade' direito, de uma forma qualquer. Porém, não se confirmou a suposição de Weber de que uma racionalidade independente, livre da moral, inerente como tal, ao direito, é a razão para a força legitimadora da legalidade. Legitimidade deve, sempre, a um poder político, exercido nas formas do direito positivo, cativo de fundamentação, um conteúdo moral implícito nas qualidades formais do direito". (HABERMAS, 1992, p. 54).

144 Nesse sentido, Habermas (1997, v.1, p. 61-62) entende que: “[...] Desta maneira, o direito está ligado às três fontes de integração social. Através de uma prática de autodeterminação, que exige dos cidadãos o exercício comum de suas liberdades comunicativas, o direito extrai sua força integradora, em última instância, de fontes da solidariedade social. As instituições do direito privado e público possibilitam, de outro lado, o estabelecimento de mercados e a organização e um poder do Estado, pois as operações do sistema administrativo e econômico, que se configura a partir do mundo da vida, que é parte da sociedade, completam-se em formas de direito.”. 
Essa mediação do direito e a passagem das expectativas sociais do "mundo da vida" para as esferas públicas partiriam da possibilidade de uma descrição compreensiva e representativa da sociedade como um todo, que segundo Luhmann e Fuchs (1988), não é mais alcançável em razão do estágio de diferenciação funcional alcançado pelos sistemas sociais. Assim, não seria mais possível conceber-se uma instância capaz de fornecer tal descrição em termos gerais de sociedade.

Habermas (1997, v. 1, p. 142), por sua vez, atribui a superação desse obstáculo à força normativa do entendimento comunicativo entre sujeitos que se pautam pela compreensão recíproca, a partir de uma racionalidade dialógica centrada não no agir estratégico weberiano, mas no agir comunicativo e na formação de uma vontade política racional.

Para que haja a institucionalização política, necessária para as formas de comunicações que viabilizam a formação discursiva da vontade política racional, requer-se a transformação do princípio do discurso em princípio da democracia. Da mesma forma, é preciso que o direito apresente-se como a expressão do processo racional de formação da opinião e da vontade. (HABERMAS, 1997, v.2, p. 99-119). ${ }^{145}$

Esse processo depende de que as estruturas da sociedade civil e a esfera pública política não se encontrem contaminadas pelos imperativos que emergem de outros sistemas, como da administração e da economia. Requer-se, assim, primeiramente, não apenas a formação de uma sociedade dinâmica de pessoas privadas no sentido de uma cultura política livre, "mas também de uma esfera privada intacta, o que equivale dizer que ela necessita de um mundo da vida já racionalizado”. (HABERMAS, 1997, v.2, p. 104).

145 A necessidade dessa institucionalização através de uma democracia racionalizada pelo direito se justifica, segundo Habermas (1997, v.2, p. 105), pois, "é preciso lembrar que, na esfera pública, ao menos na esfera pública liberal, os atores não podem exercer poder político, apenas influência. E a influência de uma opinião pública, mais ou menos discursiva, produzida através de controvérsias públicas, constitui certamente uma grandeza empírica, capaz de mover algo. Porém, essa influência pública e política tem que passar antes pelo filtro dos processos institucionalizados da formação democrática da opinião e da vontade, transformar-se em poder comunicativo e infiltrar-se numa legislação legítima, antes que a opinião pública, concretamente generalizada, possa se transformar numa convicção testada sob o ponto de vista da generalização de interesses e capaz de legitimar decisões políticas. Ora, a soberania do povo, diluída comunicativamente, não pode impor-se apenas através do poder dos discursos públicos informais - mesmo que eles tenham se originado de esferas públicas autônomas. Para gerar um poder político, sua influência tem que abranger também as deliberações de instituições democráticas da formação da opinião e da vontade, assumindo uma forma autorizada". 
Em outras palavras, conforme a síntese dessa questão exposta por Orlando Villas Bôas Filho (2006a, p. 215), "é preciso que se pressuponha um 'mundo da vida' e uma 'esfera pública' não colonizados pela racionalidade teleológica que é própria dos sistemas”.

Porém, o próprio Habermas (1997, v. 2, p. 106-107) reconhece a formação de "barreiras e estruturas de poder" o interior da esfera pública, sobretudo em sociedades complexas em que tal esfera forma uma estrutura intermediária de mediação entre, de um lado, os setores privados do mundo da vida e sistemas de ação especializados em termos de funções, e de outro lado o sistema político.

O poder da mídia, enquanto sistema de comunicação de massas, é destacado como um obstáculo à superação dessas barreiras ao passo em que as esferas públicas tradicionais das democracias ocidentais estariam por ele dominadas.

Dentre suas várias estratégias de elaboração da informação e influência na opinião pública, nucleares à teoria da indústria cultural, o referido sociólogo alemão destaca a “personalização das questões objetivas, a mistura entre informação e entretenimento, a elaboração episódica e a fragmentação de contextos formam uma síndrome que promove a despolitização da comunicação pública”. (HABERMAS, 1997, v. 2, p. 110). ${ }^{146}$

Apesar dessa constatação, a superação dessas barreiras seria possível a partir da iniciativa e mobilização dos atores da sociedade civil de modo a reivindicar modificações na esfera política e uma readequação de forças entre ela, os sistemas especializados e o sistema político. ${ }^{147}$

${ }^{146}$ Para uma visão mais aprofundada das críticas às relações de poder exercidas pelos meios de comunicação e seu papel na redução do espaço democrático a serviço de outras "racionalidades sistêmicas" no sentido da manipulação da opinião pública e controle dos poderes políticos, a despeito da vasta literatura nacional e internacional, destacam-se, como fonte para maiores referências sobre o assunto, os estudos de José Arbex Jr. sobre o Showrnalismo e a notícia como espetáculo (2001), O Jornalismo canalha (2003), bem como a vasta bibliografia de Noam Chomsky, em especial a seleção de suas de suas declarações, entrevistas e palestras realizada por Peter R. Mitchell e John Schoeffel (2005) em Para entender o Poder: o melhor de Noam Chomsky, sem contar as publicações do Project Censored News, coordenado por Carl Jensen (1997).

${ }^{147}$ Nesse sentido, afirma Habermas (1997, v. 2, p. 113): “Quando tomamos consciência da imagem difusa e da esfera pública veiculada pela sociologia da comunicação de massa, que aparece submetida ao poder e à dominação dos meios de comunicação de massa, cresce nosso ceticismo com relação às chances de a sociedade civil vir a exercer influência sobre o sistema político. Todavia, tal avaliação vale somente para uma esfera pública em repouso. Pois, a partir do momento em que acontece uma mobilização, as estruturas sobre as quais se 
Não obstante essa possibilidade tem-se claramente que tal depende da existência de mundo da vida racionalizado que favoreça "a formação de uma esfera pública liberal com forte apoio na sociedade civil", ou seja, de uma sociedade civil livre e racionalizada, capaz de identificar as controvérsias públicas. Ademais, é ainda preciso pressupor a disposição e capacidade de seus interlocutores em dialogar na busca do consenso comum e coordenar suas ações para tais mobilizações. ${ }^{148}$

Contudo, segundo Luhmann (1998, p. 147), essa pressuposta predisposição ao consenso, central à perspectiva habermasiana, não se sustentaria não sendo comprovado que as pessoas que participam desse tipo de comunicação estejam dispostas a ceder ao melhor argumento. Para o referido autor sistêmico, mesmo que se admita essa possibilidade, esses acordos racionalmente motivados graças ao agir comunicativo não seria ainda capaz de superar o déficit de racionalidade próprio da sociedade moderna, que em seu entender, estaria relacionado ao processo de diferenciação que leva a sociedade moderna a fragmentar-se em diversos sistemas funcionais.

Como foi exposta no tópico referente aos aspectos gerais da Teoria dos Sistemas Sociais, para Luhmann (1998, p. 395), tal racionalidade pode ser satisfeita apenas por meio da reflexividade, enquanto autorreferência processual sistêmica que viabiliza sua auto-observação e orientação a partir da unidade de sua distinção em relação ao ambiente.

apóia a autoridade de um público que toma posição começam a vibrar. E as relações de forças entre a sociedade civil e o sistema político podem sofrer modificações".

${ }^{148}$ Essas condições podem ser depreendidas do seguinte excerto: “[...] O certo é, no entanto, que nas esferas públicas políticas, mesmo nas que foram mais ou menos absorvidas pelo poder, as relações de forças modificamse tão logo a percepção dos problemas sociais relevantes suscita uma consciência de crise na periferia. E se nesse momento atores da sociedade civil se reunirem, formulando um tema correspondente e o propagarem na esfera púbica, sua iniciativa pode ter sucesso porque a mobilização endógena da esfera pública coloca em movimento uma lei, normalmente latente, inscrita na estrutura interna de qualquer esfera pública e sempre presente na autocompreensão normativa dos meios de comunicação de massa, segundo a qual os que estão jogando na arena devem sua influência ao assentimento da galeria. Pode-se dizer que, à medida que um mundo da vida racionalizado favorece a formação de uma esfera pública liberal com forte apoio na sociedade civil, a autoridade do público que toma posição se fortalece no decorrer das controvérsias públicas. Pois, em casos de mobilização devido a uma crise, a comunicação pública informal se movimenta, nessas condições, em trilhos que, de um lado, impedem a concentração de massas doutrinadas, seduzíveis populisticamente e, de outro lado, reconduzem os potenciais críticos dispersos de um público que não está mais unido a não ser pelos laços abstratos da mídia - e o auxiliam a exercer uma influência político-publicitária sobre a formação institucionalizada da opinião e da vontade". (HABERMAS, 1997, v. 2, p. 116). 
Frente a esses impasses e à necessidade de uma abordagem mais abstrata da teoria sociológica do direito e da própria sociedade que nem por isso deixe de lado seus conflitos, sua contingencialidade e complexidade históricas, a teoria dos sistemas autopoiéticos, no campo da ciência jurídica, seria de grande importância na medida em que representaria a "superação de uma concepção relativamente limitada das relações jurídicas" dadas às contínuas transformações estruturais da sociedade. (BÜLLESBACH, 2002, p. 409).

Há que se ressaltar, porém, que a "teoria sociológica como análise sistêmica", não se restringe à fragmentação, do sistema jurídico, mas pretende relacioná-lo à sua compreensão e da sociedade como um todo. Ademais, a sociedade, vista como um sistema social compõese, segundo Alfred Büllesbach (2002, p. 411), “de ações dirigidas por expectativas, sendo os sistemas vistos como molduras de orientação da ação incorporando muitas variáveis", dentre as quais estaria o próprio direito.

Tem-se, portanto, que a teoria sistêmica, enquanto teoria sociológica, não se confunde com as teorias fragmentárias que prescindem de um conceito de sociedade global, como as teorias da ação, dos grupos de referência, nem mesmo com a tradicional teoria funcionalista que, em razão da sintética apresentação de perspectivas individuais, perde a natureza de conjunto. (BÜLLESBACH, 2002, p. 412).

Por sua vez, no que diz respeito às criticas específicas à inserção do pensamento sistêmico no direito, Rolf Kühn (2001), em sua descrição dessa teoria, sugere certa superficialidade na redução de complexidade social empreendida tanto internamente quanto externamente pelos sistemas luhmannianos. ${ }^{149}$

Em que pese ser a função dos processos de seleção comunicacional de cada sistema de reduzir a complexidade desorganizada do ambiente, organizando-a a partir de suas

\footnotetext{
${ }^{149}$ Nesse sentido, afirma o referido autor: "[...] A diferença adicional entre estrutura e processo leva a perceber que todos os processos do sistema reduzem a complexidade tanto externa quanto interna. Esse abaixamento da complexidade produz, porém, sempre uma versão simplificada, que é a condição prévia para a adjunção de outros processos. A compreensão entre a complexidade menor e uma complexidade maior (por exemplo, o mundo) realiza-se de um modo interno por meio do equilíbrio restabelecido graças à seleção consertada das estruturas e dos processos." (KÜHN, 2001, p. 622).
} 
estruturas internas de sentido, essa simples descrição da teoria dos sistemas menospreza o seu potencial explicativo das relações intersistêmicas.

Contudo, se tal redução de complexidade for considerada sob o aspecto reativo, interno, no sentido de reprocessar e responder às demandas e expectativas projetadas pelo próprio sistema em relação aos demais, de modo a reafirmar a confiança em seu sistema - como no caso do direito, através de sua adequação aos seus fins (justiça, segurança, potencialização da dignidade da pessoa humana, previsibilidade etc.) - , sem contar o fato de que tal complexidade ao menos não é mais ignorada nos acoplamentos estruturais entre os sistemas e em seus processos comunicacionais e de enlace, é possível constatar que o processo de decisão do sistema jurídico não deixa de considerar tal complexidade embora objetive a sua redução.

Assim, tal processo de seleção de sentido e organização de níveis de complexidade operacionalizáveis pelo sistema jurídico implica, em certa medida, na própria decisão sob os riscos dessa redução de complexidade ou de sua simples negação, o que não tem sido observado no formalismo jurídico positivista, "asséptico" segundo Comparato (2006, p. 360), que tem provocado perda de legitimidade e eficácia jurídicas frente aos demais subsistemas sociais. Nesses termos, esse reducionismo parcial não seria apenas aceitável, senão também necessário para que o sistema jurídico cumpra sua função social.

Devem ser também consideradas outras críticas à teoria dos sistemas sociais autopoiéticos, como as de Ulrich Beck (1999, p. 188-189) que aponta para uma profunda mudança social decorrente da formação de uma "sociedade mundial transnacional" em que a própria diferenciação funcional estaria perdendo sentido, sendo que a globalização, nesse contexto, serviria apenas para facilitar o bloqueio dos demais sistemas pelo econômico. Em sua oposição, contra-argumenta Celso Fernandes Campilongo (2000b, p. 117):

Apenas uma visão incompleta da teoria dos sistemas pode levantar essas suspeitas. Não é razoável pensar que, num sistema social de complexidade espantosamente crescente, como é o caso da "sociedade global", seja possível a retomada de esquemas simplistas da organização da comunicação. Apesar da extraordinária força que as relações de mercado e a economia internacional ganharam com a globalização, nada indica que o Estado, as leis, a ciência ou, em linguagem técnica, os subsistemas funcionalmente diferenciados da política, do direito, da ciência, etc., estejam se tornando indiferenciados ou completamente submetidos a um único vértice, 
supostamente econômico. Melhor do que "indiferenciação funcional", como quer BECK, a globalização torna cada vez mais evidentes as intensas interdependências entre os subsistemas. Nessas situações, a sociedade diferenciada funcionalmente sempre reagiu propiciando estruturas que estabilizassem mecanismos de controle dessas interdependências. Foi assim com o contrato nas relações entre o sistema jurídico e o sistema econômico (a famosa passagem do "status" ao "contrato"). Foi assim, também, com as Constituições nas interdependências entre o sistema político e o sistema jurídico (com a passagem do "governo dos homens" para o "governo das leis"). Quanto maiores as interdependências do sistema com o ambiente, maiores as aquisições evolutivas que permitem a manutenção da integridade dos subsistemas.

Quanto às críticas à compreensão dos sistemas como uma "rede", segundo Campilongo (2000b, p. 145), o problema do sistema jurídico "reside menos na sua arquitetura formal ('pirâmide' ou 'teia de aranha') e muito mais na sua especificidade funcional (operar com base num código particular que permite produzir comunicação sobre o direito e o não-direito)".

Nessa linha, o referido autor não ignora as tensões e conflitos internos ao próprio sistema que, em princípio, a ideia de relações em rede, não hierarquizadas, aparentemente encobriria:

Ingênuo imaginar que, nas condições de alta complexidade impostas pela globalização, o direito emane como o fruto cristalino de consensos, acordos e concessões mútuas, pautadas pelo princípio da solidariedade e por comportamentos socialmente aceitos. O direito tende a ser, crescentemente, fruto de decisões, isto é, direito posto. Por isso, o direito da globalização com muita evidência, também é construção, artifício e contingência. Diante de escolhas assim difíceis, as regras da democracia, além de viabilizar as decisões são imprescindíveis. (CAMPILONGO, 2000b, p. 145-146).

Observa-se, nesse sentido, que se por um lado alguns ideólogos da teoria dos sistemas autopoiéticos luhmannianos, das relações em rede, não deixam de considerar as relações de força ou conflitos que impedem o completo consenso nessas relações comunicacionais, de outro lado, autores como Campilongo (2000b), embora respondam a esse impasse frisando o caráter decisório próprio da autopoiese jurídica, acabam, por sua vez, relegando a solução de tais "escolhas difíceis" à procedimentalização formal das "regras da democracia”, o que, partindo-se da boa-fé de seus defensores, não deixa de refletir uma similar e aparente ingenuidade acima refutada. 
O apelo a tais "regras da democracia" devem aqui ser entendidas como a recusa ou o temor da formação de uma arbitrária tecnocracia jurídica decorrente da hipótese de se permitir que as premissas de decisão do sistema jurídico fiquem relegadas a seus próprios "operadores".

Tal interpretação parece ignorar as recentes modificações do Direito Constitucional, ou para usar o termo técnico - em sua mais recente diferenciação que se depreende do Constitucionalismo Social e das novas teorias - práticas de interpretação constitucional (evolutiva, principiológica e finalística), que estabelecem toda uma nova e relativamente segura, ao menos não arbitrária, técnica decisória aos agentes do sistema jurídico (doutrinadores, juízes, advogados, dentre outros), incorporando à sua clausura operacional uma auto-organização orientada para a efetivação da própria democracia e demais valores constitucionalmente erigidos.

Depreendem-se tais observações da superficial crítica empreendida por essa corrente sistêmica às "velhas teorias do direito", sem, contudo, explicitar nesse julgamento a consideração das mudanças recentes na Teoria da Constituição e da própria modificação do sistema político como, por exemplo, a relativização da clássica e equivocada separação (total) dos poderes, ou seja, de seu silêncio sobre a nova complexidade social brasileira que exigiu a reorganização de seus subsistemas sociais e não apenas dos sistemas jurídico e político, a partir da Constituição Federal de 1988.

A despeito dessas transformações, equivocadamente se resumem a afirmar:

A teoria do direito não se encontra em condições de resolver essas questões de maneira definitiva. Não há evidências empíricas nem construções teóricas capazes de responder categoricamente a esses desafios. As velhas teorias do direito - que não são sequer capazes de levantar essas questões - são de pouca valia no presente. Entretanto, é possível formular algumas hipóteses sobre o direito da sociedade globalizada. Assim como o sistema político ou qualquer outro sistema parcial - é incapaz de controlar seu ambiente externo (não apenas em termos territoriais, mas, principalmente, em termos funcionais), também o sistema jurídico não está habilitado a substituir as operações do sistema político e econômico. Em outros termos: as funções operativas, estruturas, mecanismos seletivos, códigos e programas do sistema não são intercambiáveis. (CAMPILONGO, 2000b, p. 147). 
Em que pese tais considerações, não parece ser esse o entendimento das funções do sistema jurídico depreendidas constitucionalmente a partir dos processos sobrecomunicacionais da sociedade brasileira em 1988, quando do grande acoplamento estrutural entre os subsistemas sociais que resultou na Constituição Federal de 1988. ${ }^{150}$

Como será detalhado no item seguinte, mesmo em termos de teoria autopoiética social que identifica a sociedade como uma rede de processos comunicacionais, a Assembleia Constituinte de 1987, mais do que uma simples manifestação do sistema político, representou o acoplamento estrutural singular dos diversos subsistemas sociais que compõem a sociedade brasileira num processo democrático histórico que reordenou, a partir de seus próprios embates intersistêmicos os códigos e muitos processos comunicacionais comuns que servem de base recursiva para a operacionalidade interna desses vários sistemas.

A Constituição resultante expressa os novos meios de comunicação simbolicamente generalizados a partir dos quais os sistemas sociais, não apenas jurídico e político, mas também econômico, dentre outros, em seu processo comunicacional interno, redefinem suas novas fronteiras e autopoiese.

No que diz respeito ao tema desse trabalho, cumpre, desde já destacar que as competências, atribuições e finalidades (programas) do sistema jurídico apresentam uma maior complexidade interna, sobretudo em razão dos direitos sociais, que passam a integrar o nosso peculiar Estado Democrático (Social) de Direito, e do controle constitucional da efetivação de suas políticas públicas no sentido de se construir realmente uma sociedade livre, justa e solidária, que as atuais teorias sistêmicas parecem desconsiderar. . Esse tema será retomado neste trabalho no capítulo 4, após o levantamento da lógica sistêmica dos Meios de Comunicação de Massa e das tensões entre os sentidos das políticas públicas de Seguridade Social e a distorção comunicacional por eles promovidas.

\footnotetext{
${ }^{150}$ Os "processos sobrecomunicativos" dos sistemas autopoiéticos, segundo Neves (2005) podem ser entendidos como formas peculiares e raras de inter-relações sistêmicas não expostas claramente na teoria luhmanniana. Em linhas gerais, poderiam ser entendidos como situações de peculiar suspensão da clausura operativa do sistema que possibilitariam rápidas e reversíveis sujeições de parte de seu processo comunicativo a influências externas em situações muito específicas. (NEVES, 2005, p. 67).
} 


\subsection{A Constituição Federal de 1988 como acoplamento estrutural da sociedade brasileira não limitado aos sistemas jurídico e político nacionais}

A presente seção propugna a tese pela qual a Constituição da República Federativa do Brasil de 1988 deve ser entendida como o ponto de convergência dos processos comunicacionais da sociedade brasileira no sentido da mais abrangente forma de institucionalização de expectativas normativas.

Essa função constitucional é fundamental para a formação de meios de comunicação simbolicamente generalizados a partir dos quais as complexões de expectativas da sociedade, normatizadas em seus princípios e regras constitucionais, se autonomizam nos casos concretos permitindo a estabilidade e o funcionamento autopoiético dos sistemas sociais.

Dessa forma, será discutido como a Constituição, enquanto "unidade política de um povo" (BERCOVICI, 2005, p. 09), não se restringe, de forma alguma, a um "mecanismo de acoplamento estrutural [apenas] entre direito e política" (CAMPILONGO, 2002, p. 98).

Cumpre adiantar que essa subestimação de sua função sistêmica decorreria de um descompasso entre os sentidos atribuídos ao termo "política" e os equívocos interpretativos daí decorrentes, na medida em que, de um lado, em Direito Constitucional o mesmo é empregado numa dimensão mais ampla do todo social e, de outro, alguns teóricos sistêmicos interpretam equivocadamente o sentido político da Constituição a partir de uma acepção mais restrita em que o referido termo é utilizado na teoria luhmanniana para especificar o subsistema social em que seriam tomadas as decisões vinculantes, ou seja, o sistema político. (HESPANHA, 1999; LUHMANN, 2002).

Uma vez empreendida essa importante revisão teórica, será possível delinear a força normativa da constituição no direcionamento das políticas públicas de Seguridade Social a partir de sua interpretação constitucional e de seus processos autorreferenciais relacionados à dinâmica interna desse Sistema de Proteção Social. 


\subsubsection{A força normativa constitucional e a teoria dos sistemas}

Tendo em vista os limites e os objetivos deste trabalho, bem como sua continuidade em relação aos estudos que lhe precederam (CRUZ, 2007), faz-se necessário especificar que a problematização da Constituição será restrita ao enfoque sistêmico no sentido de sua controversa função em relação às inter-relações entre os sistemas sociais.

Dessa forma, não cabe aqui esmiuçar questões “jurídico-dogmáticas”, próprias do campo científico do Direito Constitucional e da Filosofia Política, centradas na discussão do "tipo de Constituição", por exemplo, se no Brasil vige uma Constituição-quadro, uma Constituição programa, dirigente ou uma Constituição-processo etc.

Nessa linha, poderia ainda ser citado o problema referente à natureza de suas normas, ou seja, se a Constituição de 1988 contém simplesmente regras ou também princípios, sendo ou não consagradora e garantidora de direitos fundamentais, ou, ainda, se está limitada a uma Constituição do poder, dentre tantos outros levantamentos possíveis nessa área (CANOTILHO, 1997, 2004).

De acordo com José Joaquim Gomes Canotilho (2004, p. 04), a pertinência de tais questionamentos não apresentaria em si grande relevância, ao menos em termos de sua alternatividade, pois, em seu entender, "em todas as Constituições há princípios, regras, programas, normas de direito, normas de organização e de competência”.

Sendo assim, a especificidade da Constituição Federal de 1988 quanto à preponderância de uma dessas características em detrimento de outras será tratada aqui apenas de maneira incidental.

A fim de situar a Constituição e sua força normativa em relação aos acoplamentos estruturais e processos comunicacionais que compõem a sociedade brasileira, deve ser retomada a discussão introduzida sobre dupla contingência e de como os sistemas sociais dependem do sistema jurídico para generalizar e reafirmar expectativas mínimas que cada sistema pode, em princípio, considerar em relação aos demais em seus processos internos de dotação de sentido. 
Como exposto inicialmente, os sistemas sociais são dotados de um fechamento operacional a partir do qual desenvolvem processos de criação e reprodução de seus elementos de funcionamento.

Daí decorre a impossibilidade de se alcançar sua total compreensão por meio de observações que lhes sejam externas tanto sob o ponto de vista do ambiente quanto do interior de outros sistemas de sentido, sociais ou psíquicos.

Insere-se, nesse contexto, a (dupla) contingência desses processos comunicacionais em face da dificuldade de se predeterminar com exatidão e segurança as condições de existência e as operações internas de tais sistemas, passíveis de mudança a qualquer tempo dada a ampla possibilidade de decisões e de escolhas de sentido que caracteriza a própria complexidade social. (LUHMANN, 1998, p. 113).

Reconhecida pelos sistemas, essa dupla contingência é enfrentada por seus mecanismos operacionais tornando-se parte de seu repertório sistêmico voltado à proteção frente à improbabilidade de comunicação decorrente dessa imprevisão.

Ainda assim, não se supera por completo os riscos a ela relacionados. Estes se mantêm, paradoxalmente, potencializados com a formação de expectativas operacionais em relação aos demais sistemas em suas inevitáveis inter-relações, seja nos acoplamentos estruturais entre sistemas sociais, nas interpenetrações entre sistemas sociais e psíquicos ou nas simples interações entre estes últimos. ${ }^{151}$

Destaca-se nesse ponto a função desempenhada por essas expectativas e confiança, decorrentes da mútua observação entre os sistemas, e o desenvolvimento dos meios de comunicação simbolicamente generalizados que permitem aos sistemas darem continuidade às

\footnotetext{
${ }^{151}$ Quanto à função dos acoplamentos estruturais, vale retomar, a sua importância como condição de cognição fundamental para o processo comunicacional sistêmico, sem os quais não seria percebida a perturbação decorrente da divergência de expectativas entre os sistemas levando à perda de "oportunidades de aprendizado e de transformação de suas estruturas". (LUHMANN, 1992, p. 1.433). Por essa razão é que esses acoplamentos apresentam-se como pré-condição para a construção de regularidades, ordem e redundância indispensáveis para a redução e ordenação da complexidade desorganizada do mundo. (LUHMANN, 1998, p. 169-170).
} 
suas operações de modo circular em seus processos de dotação de sentido e de seleção de informações.

Por sua vez, o sistema jurídico trabalha a redução de complexidade através da estabilização de expectativas, servindo de orientação para os demais sistemas sociais e psíquicos. Essa estabilização de expectativas objetivas tem por fim a sua "simplificação através de uma redução generalizante". (LUHMANN, 1983, p. 52). ${ }^{152}$

Nesse sentido, podem ser recontextualizados, inicialmente, o sistema jurídico e, logo a seguir, a própria Constituição. De acordo com Luhmann (1983, p. 227):

[...] Por tornarem-se potencialmente conflitantes, eles [os sistemas sociais] devem ser regulamentados detalhadamente. Em termos gerais, a diferenciação funcional acarreta um crescimento dos problemas e dos conflitos internos na sociedade e, dessa forma, um crescimento dos encargos decisórios em todos os planos da generalização. Os sistemas parciais da sociedade tornam-se cada vez mais reciprocamente dependentes: a economia depende das garantias políticas e de decisões parametrais; a política, do sucesso econômico; a ciência, de financiamentos e da capacidade de planejamento da política; a economia, da pesquisa científica; a família, do resultado econômico dos programas políticos de pleno emprego; a política, da socialização através da família; e assim por diante. Ao mesmo tempo os sistemas parciais, para poderem exercer sua função constante e confiavelmente, têm que ser protegidos contra flutuações em outras esferas por eles incontroláveis. As dependências e independências recíprocas dos sistemas parciais crescem simultaneamente. [...] Dessa forma, cresce a necessidade de disponibilidades e de seguranças, que tem que ser satisfeita se bem que a liberdade de um significa a insegurança do outro. [...] Os problemas em consequência da diferenciação funcional transparecem aqui, e também em outros casos, nos diversos institutos do direito, no fato de que noções já familiarizadas se tornam questionáveis e inseguras; surgem rachaduras nos sistemas dogmáticos.

Dessa forma, se de um lado o processo de diferenciação funcional do sistema social global implica no fato de nenhum dos sistemas emergentes poder reivindicar a supremacia sobre os demais, nem sequer pretender substituí-los em suas respectivas funções,

\footnotetext{
152 Vale lembrar o destaque feito por Luhmann (1983, p. 52) ao aspecto simbólico da estabilização de expectativas como forma de "síntese regulativa de sentido" pelos sistemas sociais, o que não seria plenamente compreendido a partir de uma visão restritiva à generalização de expectativas meramente comportamentais e à questão coercitiva da garantia do comportamento conforme essas expectativas.
} 
de outro lado, não se extinguiu a interdependência entre eles e, particularmente, a função sistêmica do direito. (LUHMANN, 1992, p. 1434-1435).

A generalização e institucionalização de expectativas normativas decorrem da necessidade de seu direcionamento com o propósito de reduzir a sua exposição às frustrações ou mesmo ao conflito com outras expectativas normativas não limitadas a dois, mas a três ou mais sistemas de sentidos.

Promove-se, assim, uma antecipação de expectativas que serão em parte produzidas pelos sistemas de sentido para a absorção dessas frustrações. ${ }^{153}$

Essa função de difusão e manutenção de expectativas mínimas (normativas) que cada sistema pode nutrir em relação aos demais, segundo Luhmann (1983) é exercida pelo sistema jurídico, daí porque afirmar:

Não é mero acaso que esse processo da positivação do direito se dê em paralelo ao pleno desenvolvimento da diferenciação funcional do sistema social. Seria possível comprovar o entrelaçamento de interdependências diretas e indiretas - basta pensar nos diversos motivos para a legislação que surgiram da insuficiente integração entre economia e família, entre economia e política. O decisivo é a convergência em princípio. A diferenciação funcional especifica e abstrai as perspectivas dos sistemas parciais da sociedade atribuindo-lhes funções e possibilidades desiguais. Já classificamos isso como superprodução de possibilidades estruturalmente condicionada. Essa mudança exige um direito que pode captar mais possibilidades e ordená-las em processos seletivos e cujo princípio satisfaça a riqueza de possibilidades e sua redução. A diferenciação funcional do sistema social e a positividade do direito convergem nesse traço básico de complexidade e contingência superdimensionadas - uma sobrecarga que a sociedade se auto-impõe e que desencadeia processos seletivos internos ao sistema (LUHMANN, 1983, p. 237).

Com a evolução da sociedade e do nível de diferenciação funcional de seus subsistemas sociais, a Constituição passa a assumir através de seus programas e princípios normativos o papel não mais restrito à positivação estritamente legal. ${ }^{154}$

${ }^{153}$ Cumpre acrescentar que a importância desse mecanismo relaciona-se à menor tolerância dos sistemas à frustração de expectativas normativas em comparação às cognitivas. Assim, através de sua institucionalização, segundo Luhmann (1983, p. 77), acaba-se por "delinear o grau em que as expectativas podem estar apoiadas sobre expectativas de expectativas supostas em terceiros". 


\subsubsection{Constituição, expectativas normativas e o papel desempenhado pela confiança na redução da complexidade social}

Em sua dimensão objetiva, os programas e princípios constitucionais, enquanto complexões de expectativas, permitem a formação de meios de comunicação simbolicamente generalizados, a partir dos quais essas complexões se autonomizam em casos concretos permitindo a recursividade das operações seletivas de sentido, no interior dos sistemas sociais.

Em relação ao sistema jurídico, esses programas finalísticos e os princípios interagem nos processos seletivos de informações em sua abertura cognitiva ao ambiente na medida em que delimitam os sentidos possíveis do código binário lícito/ilícito.

\footnotetext{
${ }^{154}$ Nesse sentido evolutivo do direito e da própria Constituição, Luis Roberto Barroso (2005), ao tratar da força normativa da Constituição, destaca a atribuição às normas constitucionais de status de normas jurídicas, sejam elas regras ou princípios, como uma das grandes mudanças paradigmáticas ocorridas ao longo do século XX. Por conseguinte, cumpre destacar, desde já, que a noção de princípios adotada neste trabalho e sua função no sistema jurídico não se restringem, de forma alguma, à concepção tradicional depreendida do art. $4^{\circ}$ da Lei de Introdução ao Código Civil (Decreto-lei 4.657, de 4 de setembro de 1942), que considera apenas os efeitos restritos do "princípios gerais de direito" em seu papel de complementação do sistema nas hipóteses em que a lei for omissa. Essa concepção supletiva dos princípios não mais se justifica em relação à diferenciação dos sistemas sociais. Sendo assim, segundo Robert Alexy (1993, p. 83): "tanto as regras como os princípios são normas porque ambos dizem o que deve ser. Ambos podem ser formulados com a ajuda das expressões deônticas básicas do mandamento, da permissão e da proibição. Os princípios, assim como as regras, são razões para juízos concretos do dever-ser, ainda quando sejam razões de um tipo muito diferente. A distinção entre regras e princípio é, portanto, uma distinção entre dois tipos de normas". Ademais, de acordo com o referido autor, além de serem considerados como verdadeiras normas jurídicas, os princípios exercem ainda uma função peculiar no sistema jurídico devendo ser entendidos como "mandamentos de otimização". Nesse sentido afirma: "o ponto decisivo para a distinção entre regras e princípios é que os princípios são normas que ordenam que algo seja realizado na maior medida possível, dentro das possibilidades jurídicas e reais existentes. Para tanto, os princípios são mandamentos de otimização, que estão caracterizados pelo fato de que podem ser cumpridos em diferentes graus e que a medida devida de seu cumprimento não só depende das possibilidades reais, senão também das jurídicas. [...] Por sua vez, as regras são normas que apenas podem ser cumpridas ou não. Se uma regra é válida, então há de fazer-se exatamente o que ela exige, nem mais nem menos. Para tanto, as regras contêm determinações no âmbito fático e juridicamente possível". Essa distinção entre regras e princípios é fundamental pois, enquanto que um "conflito entre regras só pode ser solucionado ou através da introdução numa das regras de uma cláusula de exceção que elimina o conflito ou declarando-se inválida, pelo menos, uma das regras", no que diz respeito aos princípios, quando estes "colidem", não se aplica o tudo ou nada do conflito citado entre regras, mas um equilíbrio entre eles que pode resultar em que, no caso concreto, um deles ceda ao outro. Porém, ainda conforme o renomado jurista mencionado, "isto não significa declarar inválido o princípio afastado nem que no princípio afastado tenha que se introduzir uma cláusula de exceção. O que sucede, mais exatamente, é que, sob certas circunstâncias, um dos princípios precede o outro. Sob outras circunstâncias, a questão de precedência pode ser solucionada de maneira inversa. É este o sentido que se quer dizer quando se afirma que, nos casos concretos, os princípios têm diferentes pesos e que prevalece o princípios com maior peso”. (ALEXY, 1993, p. 87-89).
} 
Conferem, dessa forma, um mínimo de coerência interna à autorreferencialidade do direito, exercendo o controle interno de suas operações comunicacionais, seu direcionamento e as condições sob as quais tais processos podem e devem ocorrer.

Nesse sentido, a interpretação constitucional dos princípios, a ser desenvolvida no último capítulo, permite a evolução do próprio direito na medida em que a produção legislativa se mostra incapaz de atender a essa generalização de expectativas e à uniformização parcial de sentidos atribuídos por sistemas sociais cada vez mais especializados, cujos meios de comunicação simbolicamente generalizados não seriam captados pelo processo legislativo tradicional.

Observa-se, contudo, certa subestimação dessa função constitucional e de sua força normativa em seu aspecto integrador na sociedade, mesmo sob o enfoque teórico sistêmico.

Como fora introduzido, esse equívoco, em termos luhmannianos, poderia ser entendido como um descompasso ou mesmo um conflito entre os diversos sentidos do termo "política" utilizados em diferentes sistemas comunicacionais ou mesmo psíquicos.

No que diz respeito ao tema em questão, a divergência interpretativa estaria relacionada ao emprego do termo política que pode se referir tanto ao sentido mais amplo do todo social no qual se insere a Constituição, quanto para especificar o subsistema social da política. A esse respeito, afirma Benedito Hespanha (1999, p. 60):

A amplitude da compreensão hermenêutica dos fenômenos políticos da ordem social poderá constituir óbice epistemológico para a comunicação normativa da realidade positiva constitucional; o político que se regula no texto Constitucional pode significar um minus, um plus ou um nihil do político que é regulado na experiência histórica.

Por essa razão, segundo o referido autor, apesar da "construção científica de um sistema constitucional [decorrer] da existência lógica de um sistema político", é preciso salientar que ambas as ciências, constitucional e política, são diferentes e autônomas entre si, de modo que o "político do Direito e do sistema constitucional não é idêntico ao político da ciência e do sistema político". (HESPANHA, 1999, 59). 
A esse respeito, deve-se transcrever a síntese desse desenvolvimento normativo constitucional sob a perspectiva evolutiva do direito e do papel dos Tribunais em sua interpretação e transformação feita pelo próprio Luhmann (1990a, p. 151-152):

A diferenciação de um sistema jurídico autoconstituinte encontra um respaldo organizacional na diferenciação de legislação e jurisdição. Isso acarreta numerosas consequências, que podemos sugerir aqui apenas em breves tópicos:

(1) - Torna-se possível incluir os fundamentos da vigência do Direito no próprio sistema jurídico na forma de uma lei constitucional, embora na forma de uma regulamentação especial, para a qual as regras jurídicas costumeiras (por exemplo, a regra da colisão, pela qual o Direito novo derroga em caso de contradição o Direito mais antigo), quando com este incompatível, não têm vigência. Ao mesmo tempo a legislação constitucional exige uma reorganização da referência externa, pois não podemos esperar que bons argumentos que Deus ou o monarca, que o representa, providenciem o texto no ano exato da revolução. Como é sabido, a solução chama-se "povo".

(2) - Os fundamentos da vigência podem ser ampliados. [...] No continente europeu o Direito Civil Romano, aperfeiçoado no decurso da história, é reconhecido como Direito vigente a partir da interpretação dos Tribunais e a partir da importância da experiência histórica - mas isso somente enquanto o processo de uma codificação legal ainda não está concluído.

(3) - A tradicional função administrativa local dos Tribunais como órgãos das instâncias centrais - podemos lembrar aqui que os Estados Unidos não conheciam nenhuma autoridade a nível local além dos Tribunais, na época em que a Constituição entrou em vigor sob o dogma da separação dos poderes - é limitada significativamente e finalmente delegada integralmente às autoridades administrativas especialmente criadas para tal fim. A jurisdição (Gerichtsbarkeit) é neutralizada politicamente como função nuclear do sistema jurídico. Mas isso não significa que ela estaria condenada à ineficácia em questões de transformação do Direito. $\mathrm{O}$ contrário é verdadeiro: justamente por não poderem ser responsabilizados politicamente pelas consequências das suas decisões, os Tribunais ficam excluídos da participação na ação política, mas são por isso mesmo favorecidos na sua participação na transformação do Direito, sobretudo em áreas nas quais o legislador demonstra ser relativamente inativo.

Portanto, não faz sentido reduzir a Constituição, de forma alguma, a um mero "mecanismo de acoplamento estrutural entre o sistema político e o jurídico" (CAMPILONGO, 2002, p. 98), muito menos afirmar que no "caso específico da Constituição os sistemas 
envolvidos são o político e o jurídico, os quais, embora possam ser observados como temas que não são reader friendly, permitem uma compreensão da Constituição como acoplamento estrutural entre eles, sistemas" (SILVA, 2006).

Hespanha (1999, p. 60) adverte, ainda, que a concepção "terminológica e axiológica das realidades políticas do sistema constitucional precisa ser bem interpretada no meio envolvente da comunicação social sob pena de intromissão indébita do objeto da ciência política no objeto da ciência constitucional".

A interpretação contrária a essa evolução do direito e da Constituição, parte de um pressuposto equivocado da função supostamente atribuída ao direito de empreender um controle totalizante dos processos internos dos demais sistemas com um grau de eficácia máxima.

Seja em termos positivistas clássicos ou sob o enfoque sistêmico, a condição de validade do direito, enquanto dever-ser ou expectativa normativa, independe do grau de eficácia de suas prescrições ou da garantia do comportamento conforme as expectativas. (KELSEN, 1998, p. 235-236; LUHMANN, 1983, p. 52).

Dentro de suas possibilidades, cabe ao direito exercer a referida generalização congruente de expectativas, influindo parcialmente nos processos comunicacionais dos demais sistemas que dependem das citadas expectativas normativas para a sua estabilização e funcionamento. A correção das externalidades decorrentes dos conflitos de sentido seria, portanto, complementar e apenas uma das formas de manutenção de tais expectativas normativas na sociedade.

Ao contrário dos ideólogos da autorregulação que fundamentam aquele controverso entendimento numa suposta interpretação da teoria dos sistemas luhmanniana, esses diversos excertos citados são elucidativos em reafirmar, pelas palavras do próprio Luhmann (1983, 1990a, 1992, 1998), a interdependência e a função desempenhada pelo direito, sobretudo a partir da Constituição, na manutenção contrafactual dessas expectativas normativas em relação a todos os sistemas sociais. 
Em outros termos, a regulação do direito não perde o seu sentido e funcionalidade no contexto de sistemas sociais autorreferenciais a despeito da impossibilidade de se direcionar totalmente os processos comunicacionais internos dos demais sistemas autopoiéticos.

Por conseguinte, a Constituição, sob uma perspectiva sistêmica, não seria pertencente a um determinado sistema, assumindo sim "o lugar por excelência de ocorrência do acoplamento estrutural entre o sistema jurídico e os demais subsistemas funcionalmente diferenciados da sociedade". (SCHWARTZ, 2004, p. 117).

No caso brasileiro, esse posicionamento é reforçado se for considerada a confluência histórica da sociedade que mobilizou os diversos sistemas sociais em torno da redemocratização do país no final da década de 1980, formando assim um singular acoplamento estrutural entre esses sistemas do qual é fruto a Constituição Federal de 1988.

Como foi possível esboçar no estudo anterior (CRUZ, 2007) sobre a conformação dos movimentos sociais em torno da saúde e de suas tensões com os beneficiários do sistema sanitário biomédico e privatista vigente até então, formou-se na sociedade brasileira uma rede de novos processos comunicacionais, não restritos à reforma sanitária, de modo que a Assembleia Constituinte de 1987, não pode ser reduzida, de modo algum, a uma simples manifestação do sistema político, ou de um exercício formal do Poder Constituinte Originário. ${ }^{155}$

${ }^{155} \mathrm{O}$ estudo da evolução do sistema jurídico sanitário em questão fora empreendido na dissertação de mestrado, intitulada "A teoria dos sistemas e a força normativa constitucional do sistema jurídico sanitário", apresentada em 2007 junto ao Departamento de Direito do Trabalho e Segurança Social da Universidade de São Paulo (CRUZ, 2007). No mais, esse aspecto conflituoso entre os diversos sistemas sociais não se reduziu às discussões do novo sistema sanitário sendo identificado em relação a outros temas, sobretudo, à ordem econômica. A despeito dos interesses e das desigualdades entre os atores envolvidos, a Constituição Federal de 1988 seria, ainda assim, representativa de diversos sistemas sociais. Nesse sentido, afirma Eros Roberto Grau (2003, p. 293-295): “Os conflitos entre elites, múltiplos, que a Constituinte registrou, são, seguramente, memoráveis. [...] Isso não significa não se possa identificar, com marcante atuação nela, facções articuladoras de interesses de classe. A heterogeneidade dos interesses representados, porém, não nos permite delinear plenamente o perfil de cada uma delas. [...] Pois essa heterogeneidade, superposta à coexistência de distintos modos de produção social que caracteriza a sociedade brasileira, é que, a um tempo só, confere complexidade e riqueza à ordem econômica na Constituição de 1988. Nela, o reflexo, correto, da realidade nacional. A Constituição de 1988 é, fidedignamente, a Constituição do Brasil, do Estado brasileiro e do povo brasileiro, conformado pela hegemonia dos grupos dominantes mas, concomitantemente, em potência capacitado - o povo - a projetar a sua própria hegemonia". Poderia ainda se citada, sob o aspecto político-partidário e seu impacto nos direitos sociais, o entendimento de Ivaneti Boschetti (2003, p. 70): “A Constituição Brasileira de 1988, como sabemos, foi o resultado de um longo e conflituoso debate político na Assembleia Constitucional que pôs, de um lado, os partidos de centro esquerda, e de 
Esse acoplamento estrutural singular dos diversos subsistemas sociais em relação à redefinição dos sentidos das políticas públicas, sobretudo da nova conformação da Seguridade Social, se deu num processo democrático histórico que confirma a tese segundo a qual, na Constituição Federal de 1988, reordenaram-se os processos comunicacionais comuns a diversos sistemas sociais, com a generalização de novas expectativas normativas, institucionalizadas no nível máximo constitucional. (CRUZ, 2007).

Daí decorre a força normativa da Constituição no sentido do caráter vinculante e obrigatório de suas disposições na medida em que representam essa máxima normatização das expectativas com as quais operam os diversos sistemas da sociedade. ${ }^{156}$

Nesse contexto, de acordo com Ivanette Boschetti $(2003,71)$, tem-se a Seguridade Social como o resultado desse processo. Sua institucionalização em 1988 representaria para o Brasil "o que significou a sécurité sociale para os franceses ou a social security para os ingleses na década de 1940: um movimento de reorganização de políticas já existentes sob novas bases e princípios, com ampliação, mas também introdução de novos direitos". (BOSCHETTI, 2003, p. 71-72).

outro, o chamado Centrão, formado por partidos de centro direita. A versão promulgada em 05 de outubro resulta de uma combinação de proposições conservadoras do Centrão e de reivindicações dos trabalhadores e dos partidos de esquerda: 'Não é uma Constituição de esquerda nem de uma Constituição socialista' afirmou o deputado federal Eduardo Jorge. Mas é uma Constituição que, inegavelmente, avançou na garantia dos direitos sociais”.

156 A expressão "força normativa da constituição" remonta à enfática oposição de Konrad Hesse (1991) à interpretação restritiva das questões constitucionais como questões políticas sem caráter jurídico. Tal forma de interpretação reduzia o seu poder prescritivo à simples reiteração da "Constituição real" e a "Constituição Jurídica" a um simples "pedaço de papel" (ein Stück Papier) conforme as palavras de Ferdinand Lassalle. (HESSE, 1991, p. 09). De acordo com Barroso (2005) teria sido superada essa visão, dominante até o fim do século XIX, da Constituição como um documento essencialmente político, condicionado "à liberdade de conformação do legislador ou à discricionariedade do administrador" de modo que ao Poder Judiciário "não se reconhecia qualquer papel relevante na realização do conteúdo da Constituição". No pós Segunda Guerra Mundial, com a reconstitucionalização de diversos países europeus como Alemanha, Itália, Portugal e Espanha, foi consolidado gradativamente, como premissa do estudo constitucional, o reconhecimento de sua força normativa. Essa nova característica da Constituição implica, segundo o referido autor, no reconhecimento de que suas "normas constitucionais são dotadas de imperatividade, que é atributo de todas as normas jurídicas, e sua inobservância há de deflagrar os mecanismos próprios de coação, de cumprimento forçado". (BARROSO, 2005). 
A Constituição Federal de 1988 expressa, portanto, os novos meios de comunicação simbolicamente generalizados em função dos quais, repita-se, os sistemas sociais - não apenas jurídico e político - desenvolvem seu funcionamento autorreferencial. 


\section{A LÓGICA SISTÊMICA DOS MEIOS DE COMUNICAÇÃO DE MASSA}

Neste terceiro capítulo serão discutidas as teorias explicativas do desenvolvimento dos meios de comunicação de massa, com destaque para os estudos de comunicação na América Latina e das organizações midiáticas brasileiras.

A partir de diferentes abordagens críticas dos meios de comunicação de massa, objetiva-se a consideração dos limites e potenciais explicativos do "modelo de propaganda" de Edward S. Herman e Noam Chomsky (2003) para a compreensão das funções desempenhadas pelo sistema dos meios de comunicação de massa no Brasil e sua relação com a definição das expectativas sociais em relação aos direitos fundamentais e às políticas públicas do Sistema de Seguridade nacional a partir de 1988, sendo esta específica relação objeto do capítulo seguinte.

Tendo por metodologia a revisão bibliográfica dos estudos de comunicação social, jornalismo, cultura e política nos Estados Unidos da América, no Brasil e na América Latina, pretende-se, nesta seção, contextualizar a tese proposta em vista da crescente influência dos meios de comunicação de massa no processo decisório dos rumos da sociedade em termos políticos, econômicos, sociais e culturais, apontadas por estes estudos.

Justifica-se, desse modo, o presente capítulo voltado à sistematização da lógica funcional-estruturalista, segundo a qual o sistema dos meios de comunicação de massa brasileiro e suas organizações têm se diferenciado histórica e funcionalmente, pressuposto para a discussão dos objetivos centrais da tese e sua defesa no capítulo seguinte.

\subsection{Desenvolvimento histórico e a teorização dos meios de comunicação de massa}

Cumpre, já de início, esclarecer que foge aos objetivos do presente trabalho tratar do desenvolvimento histórico dos meios de comunicação de massa de modo exaustivo e detalhado tal como o realizado por Asa Briggs e Peter Burke (2006), os quais propõem "uma história social da mídia", a partir de sua evolução no mundo ocidental moderno, 
já no século XV, com a suposta (re)invenção da impressão por Johann Gutenberg

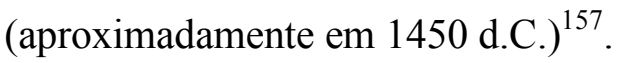

Assim como destacam os referidos autores, não se pode negligenciar que, embora a história da comunicação preceda ao próprio Gutenberg e ao século XV, o interesse acadêmico por seus meios tem como marco as décadas de 1920 e de 1950, a partir das quais, respectivamente, as pessoas teriam, enfim, começado a falar de "mídia" e a se preocupar com os impactos de uma "revolução da comunicação" então em curso (BRIGGS; BURKE, 2006, p. 11). ${ }^{158}$

Contudo, o presente capítulo destina-se, primordialmente, à discussão das teorias sociais explicativas do desenvolvimento dos meios de comunicação de massa, tal como estes são atualmente considerados, buscando, nesse contexto eminentemente teórico e comparativo, desenvolver a consideração dos limites e potenciais explicativos do "Modelo de Propaganda" de Edward S. Herman e Noam Chomsky (2003) para a compreensão das funções sistêmicas desempenhadas pelos meios de comunicação de massa e suas organizações midiáticas no Brasil.

Deste corte metodológico decorre outra fundamental limitação do presente trabalho o qual não desenvolverá de modo exaustivo a discussão sobre os efeitos dos meios de comunicação de massa sobre a cultura, a arte e nem sequer sobre seus polêmicos "poderes de manipulação", ao menos diretamente, sobre o comportamento social, embora se reconheça toda a gama de teorias voltadas à discussão destes supostos efeitos concretos.

Dentro dos pressupostos teóricos da teoria comunicacional inicialmente adotada, objetiva-se neste trabalho defender a tese do conflito em si existente entre, de um lado, as expectativas e os sentidos da comunicação disseminados pelos meios de

\footnotetext{
${ }^{157}$ Segundo Asa Briggs e Peter Burke (2006, p. 24): “Na China e no Japão, a impressão já era praticada há muito tempo - desde o século VIII, se não antes - mas o método geralmente utilizado era o chamado de 'impressão em bloco': usava-se um bloco de madeira entalhada para imprimir uma única página de um texto específico. O procedimento era apropriado para culturas que empregavam milhares de ideogramas, e não um alfabeto de 20 ou 30 letras. Provavelmente por essa razão teve poucas consequências a invenção de tipos móveis no século XI na China. No entanto, no início do século XV, os coreanos criaram uma forma de tipos móveis, descrita pelo académico Henri-Jean Martin como "de uma quase alucinatória similaridade àqueles de Gutenber'. A invenção ocidental pode ter sido estimulada pelas notícias do que havia acontecido no Oriente.”

${ }^{158}$ Por sua vez, em que pese esse corte metodológico, não se pretende ignorar ou reduzir a importância da retomada da retórica já nos séculos XVIII e XIX, em vista das revoluções industrial e burguesa então em curso, muito menos as tentativas de conceituação de "opinião pública", ao final do século, nem a atenção às "massas", a partir do século XIX (BRIGGS; BURKE, 2006, p. 80-110).
} 
comunicação de massa brasileiros, através de suas organizações e, de outro, os sentidos das expectativas normativas sobre os direitos sociais, cuja função precípua de generalização social pertenceria ao sistema jurídico.

Em outras palavras, foge aos objetivos e pressupostos sistêmicos comunicacionais desta tese discutir os efeitos concretos da comunicação produzida pelos meios de comunicação de massa, seja quanto a sua tão discutida capacidade manipuladora sobre os demais sistemas sociais e psíquicos na linha, por exemplo, defendida pela Teoria Crítica e seu conceito chave de "Indústria Cultural", seja quanto aos seus efeitos ideologizantes e de opressão simbólica amplamente rediscutidos pelo movimento estruturalista francês, seja, ainda, quanto às relações e intercâmbios entre a "cultural dominante" supostamente difundida por tais meios e os diferente grupos culturais existentes na sociedade, conforme os trabalhos interdisciplinares do Centro de Estudos Culturais de Birmingham, a partir da década de 1960. (MATTELART; MATTELART, 2000, p. 73-111; BRIGGS; BURKE, 2006, p; 243-250; HALL, 1999).

Feitas essas considerações e dados os objetivos acima delimitados, como fora inicialmente explicitado, cumpre salientar a primeira metade do século XX como marco do interesse acadêmico pelo estudo da propaganda, dos meios de comunicação conceituados, então, como "de massa" e sua relação com a suposta formação de "cultura(s) de massa" em oposição a sistemas culturais folclóricos e à “cultura superior”. (LIMA, 2000, p. 13-69). ${ }^{159}$

Nesse contexto, passadas as primeiras abordagens eminentemente especulativas frente à reviravolta provocada pelo rádio e cinema emergentes no início do século $\mathrm{XX}$, segundo Luiz Costa Lima (2000, p. 14), seguiram-se estudos de ordem estética sobre as possíveis e futuras repercussões da revolução tecnológica em curso, característica desses novos meios de comunicação da "sociedade burguesa", inicialmente sobre o campo da arte. $^{160}$

\footnotetext{
${ }^{159}$ A esse respeito, esclarecem Asa Briggs e Peter Burke (2006, p. 11): "De modo significativo, foi com a era do rádio que o mundo académico começou a reconhecer a importância da comunicação oral na Grécia antiga e na Idade Média. O início da idade da televisão, na década de 1950, deu surgimento à comunicação visual e estimulou a emergência de uma teoria interdisciplinar da mídia. Realizaram-se estudos nas áreas de economia, história, literatura, arte, ciência política, psicologia, sociologia e antropologia, o que levou à criação de departamentos académicos de comunicação e estudos culturais."

${ }^{160}$ Nesse sentido, foram como as "Reflexões para uma estética do cinema" de Lukács de 1913 e o ensaio de Walter Benjamin intitulado "A obra de arte na época de sua reprodutibilidade técnica" de 1936 (LIMA, 2000).
} 
Contudo, somente a partir de 1940, com os estudos empiristas norteamericanos, novas formulações eminentemente analíticas desses fenômenos passaram a ser empreendidas através de abordagens sociológicas. (LIMA, 2000).

Em sua "História das teorias da comunicação", Armand e Michèle Mattelart (2000, p. 10) sistematizam a pluralidade e dispersão dos estudos científicos sobre os processos de comunicação que têm suscitado o interesse de diversas áreas, sendo, porém marcados pela "tensão entre as redes físicas e imateriais, entre o biológico e o social, os dispositivos técnicos e o discurso, a economia e a cultura, as perspectivas micro e macro, o local e o global, o ator e o sistema, o indivíduo e a sociedade, o livre-arbítrio e os determinismos sociais".

Nessa síntese, os citados autores destacam como a embrionária noção de comunicação e as primeiras concepções ditas "científicas" da comunicação, já no final do século XIX, estiveram relacionadas ao pensamento da sociedade como organismo e à crença na possibilidade de gestão das multidões humanas. Sob essa ótica, teriam surgido as noções fundadoras de uma visão da comunicação como fator de integração das sociedades humanas. (MATTELART; MATTELART, 2000, 13-27).

No mais, a propaganda difundida por esses novos meios de comunicação despertou o interesse acadêmico por seu papel fundamental nas duas grandes guerras mundiais, a partir da primeira metade do século XX. Da mesma forma, a difusão da televisão e sua peculiar forma de comunicação visual alavancaram, nas décadas de 1950 e seguintes, estudos culturais e de comunicação a partir de diversas áreas como economia, história, ciência política, psicologia, sociologia e antropologia. (BRIGGS; BURKE, 2006, p; 243-250).

Desse modo, as teorias comunicacionais desenvolveram-se inicialmente a partir de diferentes perspectivas científicas tanto teóricas quanto empiristas.

Destacam-se, sob a perspectiva empirista, tanto a visão instrumental da comunicação de Harold Lasswell quanto o aperfeiçoamento técnico dos estudos funcionalistas norte-americanos da mídia empreendidos pelos sociólogos Robert K. Merton e, especialmente, por Paul F. Lazarsfeld. Enquanto que Lasswell defendera a tese segundo a qual os novos meios de difusão como o cinema, o rádio e a televisão seriam os instrumentos indispensáveis para a gestão governamental das opiniões, fora, porém, graças aos estudos quantitativos de Lazarsfeld sobre as audiências e o fluxo de comunicação que se desenvolveram os modelos das formas de comunicação "mais aptos" à mobilização do consumo, cuja importância prática lhe transformou no "guru" da indústria publicitária norte- 
americana a partir da segunda metade do século passado. (MATTELART; MATTELART, 2000, p. 36-51).

Assim desenvolveu-se, inicialmente, a sociologia funcionalista norte-americana no estudo das mídias, para a qual, os meios de comunicação proeminentes no século XX serviriam como ferramentas da democracia moderna e da expansão econômica capitalista, no sentido positivo que identificava a mídia como mecanismo decisivo da regulação social e reprodução dos valores da sociedade norte-americana em meio à bipolarização mundial, então em curso, entre capitalismo e comunismo.

Por sua vez, diversos estudos vieram a questionar tal análise meramente funcionalista e pragmática contrapondo-lhe abertamente suas críticas aos novos meios de comunicação - enquanto mecanismos negativos de instrumentalização do poder, da dominação e de violência simbólica - em clara oposição àquela primeira visão funcionalista e afirmativa dos meios de comunicação, defensora dos supostos benefícios sociais e democráticos de tais inovações tecnológicas sobre a sociedade contemporânea. (MATTELART; MATTELART, 2000, p. 73).

Nessa posição antagônica e de ruptura metodológica, ganharam proeminência os estudos filosóficos da Escola de Frankfurt. Dentre seus colaboradores, destacam-se, aqui, Walter Benjamin (2000) e seu trabalho sobre "A obra de arte na época de sua reprodutibilidade técnica” de 1933, bem como o trabalho de Max Horkheimer e Theodor W. Adorno (2000) intitulado "A Indústria Cultural. O iluminismo como mistificação das Massas", apresentado inicialmente como capítulo de sua obra "A dialética do esclarecimento" de 1947, sobre a produção industrial dos bens culturais, sem contar os não menos importantes estudos de Herbert Marcuse (1969), sobretudo, sua análise sobre " $O$ homem unidimensional” de 1964. (MATTELART; MATTELART, 2000, 74-84).

À exceção de Walter Benjamin, exilados nos Estados Unidos da América em função da ascensão nazista alemã e, de um modo geral, supostamente "inspirados num marxismo em ruptura com a ortodoxia”, os citados filósofos da escola frankfurtiana desenvolveram uma linha metodológica de análise da sociedade capitalista que veio a ser conhecida como Teoria Crítica, destacando-se aqui da referia escola apenas estes autores em função de suas análises mais diretas da comunicação de massa em questão.

$\mathrm{Na}$ nova epistemologia proposta pela Teoria Crítica, o "método marxista de interpretação da história é modificado por ferramentas emprestadas à filosofia da cultura, à 
ética, à psicossociologia e à "psicologia do profundo"”, cujo projeto central, consistiria, ademais, "em fazer a junção entre Marx e Freud". (MATTELART; MATTELART, 2000, 74).

Em que pese os riscos da síntese de tão bem estruturada crítica marxista da sociedade burguesa e sua relação com os meios de comunicação de massa, grosso modo, Horkheimer e Adorno (2000) criaram o citado conceito de "Indústria Cultural" a partir da análise da produção industrial dos bens culturais e sua interpretação enquanto parte do movimento global de produção da cultura como mercadoria.

Assim produzidos, os novos bens culturais frutos da revolução tecnológica e midiática como, por exemplo, os filmes, livros, a música, os programas de televisão etc., reverter-se-iam não apenas em novas formas de mercadoria como, também, numa importante estratégia de controle social capitalista.

Nesse sentido, os meios de comunicação de massa e sua imanente "Indústria Cultural" exacerbariam a perversão dos ideais iluministas do século XVIII, afastando-se cada vez mais do prometido progresso da razão e da tecnologia que, não menos idealizados por tais críticos, deveriam ser capazes de libertar o homem das crenças mitológicas e superstições, rumo a uma pressuposta e sempre futura sociedade mais livre, democrática e solidária. (ZIMA, 1974).

Ademais, ainda sob essa perspectiva "crítica", a tecnologia, a ciência e, por conseguinte, os meios de comunicação de massa submetidos ao poder econômico e político capitalistas seriam empregados para impedir que as pessoas tomassem consciência de suas condições de desigualdade e exploração.

Não se pode deixar de questionar não apenas a idealização como certo dirigismo social no sentido de que, sob esta perspectiva "crítica", pressupõe-se que um trabalhador, em seu horário de lazer, deva ler "bons" livros, ir ao teatro ou a concertos musicais não "comerciais", tornando-se uma pessoa mais "culta", "questionadora" e “engajada" politicamente, ao contrário de, simplesmente, ao voltar para sua casa, sentar-se em frente à televisão para supostamente se esquecer de seus problemas, absorvendo "passivamente" os mesmos valores que predominam em sua rotina "opressora" de trabalho. A "Indústria Cultural" reduziria, nestes termos, "cidadãos conscientes" a "consumidores passivos" contribuindo para o controle social das massas. 
Em que pese o pioneirismo do conceito de "Indústria Cultural" e sua aplicabilidade para a compreensão, por assim dizer, da "força motriz" de grande parte da produção midiática atual $^{161}$ - sua padronização, mercantilização, reprodutibilidade técnica e estratégias sensíveis -, não se pode deixar de questionar uma de suas principais teses segundo a qual os meios de comunicação de massa teriam a capacidade de promover a direta e passiva absorção de suas mensagens pela sociedade, no sentido comum da palavra.

Essa visão unidirecional da comunicação e sua capacidade manipuladora, em termos diretos, não apenas foram questionadas pela teoria sistêmica da qual parte este trabalho, como também por diferentes estudos de diversas áreas científicas. Ainda que sob diferentes perspectivas epistemológicas, tem-se demonstrado como as mensagens midiáticas tendem a serem "filtradas", "percebidas", "decodificadas" ou "reinterpretadas" pelas pessoas, grupos sociais, ou seja, pelos diversos sistemas de sentido. ${ }^{162}$

Portanto, sem ignorar a capacidade de influência social da mídia e seu papel crucial na apresentação de questões relevantes para a sociedade e sua contribuição para a compreensão do público sobre a realidade, ou seja, apesar de sua função generalizadora de sentido e de expectativas sociais, como se pretende reafirmar nesta tese, tal função não pode ter sua complexidade reduzida a simples modelos analíticos de "estímulo-reposta", nos quais o usuário ou "receptor" possa ser passiva e diretamente manipulado.

Contrapondo-se a essa visão totalizante da "Indústria Cultural" e à pressuposta e inevitável derrocada da cultura, cujo papel filosófico-existencial teria se perdido com sua redução à mercadoria, advertem Armand e Michèle Mattelart (2000) para a implícita sacrarlização da arte, a partir de certa visão europeia erudita a seu respeito, e superestimação de sua função revolucionária:

Por mais que tenha sido a clarividência de Adorno e Horkheimer na análise dos fenômenos culturais, eles parecem ter percebido apenas um aspecto - fundamental, sem dúvida - da conjunção entre arte e tecnologia, mas uma superestimação da arte como fermento revolucionário impediu-os de perceber muitos aspectos bastante diferentes dessa conjunção. Para se convencer disso, basta reler o texto de

161 A contextualização atual e revisão dos sentidos do descrito conceito de "Indústria Cultura" é objeto do estudo publicado em 2008, intitulado "A indústria cultural hoje”, organizado por Fabio Akcelrud Durão, Antônio Zuin e Alexandre Fernandes Vaz.

162 Neste sentido, embora, repita-se, sob diferentes metodologias, destacam-se Katz e Lazarsfeld (1970), Gerbner (1983), Barbero (2008), Zubieta (2004), Canclini (2001; 2008), Williams (1969), Cevasco (2001), Sarlo (2005), dentre outros. 
outro membro da escola de Frankfurt, Walter Benjamin (1892-1940), intitulado $A$ obra de arte na era de sua reprodutibilidade técnica, escrito em 1933, cerca de dez anos antes das análises de Horkheimer e Adorno. Está ali indicado, especialmente, como o próprio princípio da reprodução (e mostra muito bem em que medida uma arte como o cinema só tem razão de existir no estágio da reprodução, e não no da produção única) torna obsoleta uma velha concepção de arte que ele chama de "aurática". Ora, podemos nos perguntar em que medida a cultura de massa não é estigmatizada por Adorno e Horkheimer também porque seu processo de fabricação atenta contra certa sacralização da arte. Na verdade, é difícil não perceber em seu texto o eco de um vigoroso protesto erudito contra a intrusão da técnica no mundo da cultura. Sua pedra angular parece ser exatamente essa reprodutibilidade de um dado cultural por meios técnicos a que se refere Benjamin. Com certeza, o modo industrial de produção da cultura corre o risco de padronização com fins de rentabilidade econômica e controle social. Nem por isso a crítica legítima da indústria cultural deixa de estar estreitamente ligada à nostalgia de uma experiência cultural independente da técnica. (MATTELART; MATTELART, 2000, 78-79).

Reforça essa observação contrária aos pressupostos e efeitos totalizantes da "Indústria Cultural", os precursores estudos culturalistas de Raymond Williams (1969) apreendidos justamente a partir análise das mudanças de significado e amplitude da palavra "cultura" e da evolução histórica de seus sentidos (CEVASCO, 2001; SARLO, 2005). ${ }^{163}$

Da mesma forma, contrários à visão pessimista e reducionista frankfurtiana e à incapacidade de capatar as culturas marginais de tais perspectivas marxistas, são os estudos de Jesús Martín Barbero (2008), Ana Maria Zubieta (2004) e Néstor García Canclini (2001; 2008) sobre os processos em si de mediação entre cultura popular e a cultura de massas e seus hibridismos.

Para estes autores, de um modo geral, embora com certas distinções, a relação entre a cultura popular e a cultura de massas se daria por processos dinâmicos de mediação não limitados em termos passivos e de dominação como na citada concepção da "Indústria Cultural" e demais formas de leitura binária de manipulação dos meios de comunicação.

163 A influência de Raymond Willians sobre os estudos culturalistas, sobretudo, sobre o Centre of Contemporary Cultural Studies da Universidade de Birmingham, é sintetizada por Mattelart e Mattelart (2000, p. 105-106) nos seguintes e precisos termos: “A obra de R. Willians, The Long Revolution (1965), marca uma dupla ruptura. Em primeiro lugar, com a tradição literária que situa a cultura fora da sociedade, pondo em seu lugar uma definição antropológica: a cultura é o processo global por meio do qual as significações são social e historicamente construídas; a literatura e a arte são apenas uma parte da comunicação social. Ruptura, em segundo lugar, com um marxismo redutor: Willians posiciona-se em favor de marxismo complexo, que permite estudar a relação entre a cultura e as outras práticas sociais; ele debate o primado da base sobre a superestrutura, que reduz a cultura submetendo-a à determinação social e econômica.” 
Tem-se, assim, reforçada a justificativa da busca pelos sentidos em disputa no âmbito da definição dos direitos sociais, na medida em que, dos estudos culturais citados restou evidente que "o sentido das palavras acompanha as transformações sociais ao longo da história e conserva, em suas nuances e conotações, muito dessa história" e que os meios de comunicação de massa participam desse processo comunicacional. (CEVASCO, 2003, p. 11).

Por sua vez, sob a perspectiva sistêmica luhmanniana, a diferenciação social e emergência, por assim dizer de um sistema, em si, dos meios de comunicação se deve à "aquisição decisiva" de tecnologias de difusão, sem, contudo, com isso negar os aspectos sociais que levaram a essa diferenciação sistêmica. (LUHMANN, 2005a, p. 36).

Não obstante se reconheça essa condição, longe de qualquer determinismo tecnológico e de suas simplificações enganosas, isso não implica, repita-se, na aceitação de que as novas tecnologias sejam capazes de criar e desenvolver por si mesmas os meios de comunicação de massa, descontextualizadas dos demais sistemas sociais, pelo contrário. ${ }^{164}$

O que se destaca aqui, para a delimitação do quadro dentro do qual esse sistema poderá se autodiferenciar funcionalmente dos demais sistemas sociais, é justamente sua possibilidade de ampla difusão da comunicação a partir da qual "não apenas [se] poupa uma interação entre os presentes, mas a exclui eficazmente, no que se refere às próprias comunicações dos meios de comunicação." 165

Em outras palavras, embora o sistema dos meios de comunicação não exclua a importância e coexistência das comunicações sociais de tipo oral e escrito (seja por carta,

\footnotetext{
${ }^{164}$ Apesar da opção metodológica pela abordagem funcional-estruturalista sistêmica citada, a partir de sua revisão crítica e contextualização às peculiaridades dos sistemas sociais brasileiros, deve-se frisar desde já que este trabalho objetiva ultrapassar a visão dicotômica entre estrutura e organização que tem marcado os estudos midiáticos, no sentido a seguir descrito por Asa Briggs e Peter Burke (2006, p. 23): "Para historiadores e especialistas em estudos sociais, há uma divisão contínua entre os que enfatizam a estrutura e os que realçam a organização. De um lado, alguns reivindicam que não há consequências do uso do computador em si, pelo menos não mais do que há com o letramento (incluindo o visual e o computacional). Somente há consequências para indivíduos que usam essas ferramentas. De outro lado, outros sugerem que o uso de um novo meio de comunicação inevitavelmente muda a longo prazo, se não antes, a visão das pessoas sobre o mundo. Uma corrente acusa a outra de tratar pessoas comuns como passivas, objetos do impacto do letramento ou da computação. A acusação inversa é tratar a mídia, inclusive a imprensa, como passiva, espelho da cultura e da sociedade, e não como agência de comunicação transformando tanto uma quanto outra".

${ }^{165}$ Luhmann (2005a, p. 36) explica esse diferencial tecnológico e a finalidade alcançada socialmente, das formas tradicionais de comunicação da seguinte forma: "A escrita isoladamente não teve esse efeito, pois foi concebida no início apenas como apoio da memória para a comunicação primariamente oral. Somente com a impressão de livros multiplicou o bem literário de maneira bem acentuada, de forma que se tornou impossível uma interação oral efetiva de todos os participantes, assim como uma interação visual”.
} 
por telefone, seja mesmo através de mensagens eletrônicas) entre pessoas, "tais contatos não se realizam na forma específica como funcionam os meios de comunicação" (LUHMANN, 2005a, p. 37).

Sendo assim, os meios de comunicação, enquanto subsistema social, prescindem da mediação realizada pela interação entre os presentes, permitindo seu desenvolvimento em termos autorreferenciais e comunicacionais, a partir do código informação/não-informação ou, simplesmente, informativo/não-informativo, como o comumente adotado no meio jornalístico.

A relevância sistêmica dos meios de comunicação de massa se dá, portanto, por sua difusão e generalização de informações, sinalizando sua relevância social. Contribuem assim para a conformação de expectativas sociais, senão vejamos:

(...) Os meios de comunicação de massa, contudo, [diferentemente da comunicação privada] espalham a informação de forma tão ampla que as pessoas, no momento seguinte, já supõem que ela seja de conhecimento geral (ou que não a conhecendo significaria "ficar mal" e, por isso, não se reconhece que não se sabia). (...). Nesse sentido, os meios de comunicação produzem redundância social em ampla escala da sociedade, quer dizer, a necessidade diretamente vinculada a essa redundância de se ter informação nova. (LUHMANN, 2005a, p. 44).

Diferentemente do que é exteriorizado pelo próprio sistema para creditá-lo socialmente, observe-se, no entanto, que, sob essa peculiar perspectiva funcionalista tais informações generalizadas não correspondem necessariamente à verdade, enquanto descrição objetiva e unívoca da realidade, isto porque, diferentemente do sistema científico, como fora exposto acima, o sistema dos meios de comunicação não trabalha a partir do código verdade/não-verdade. ${ }^{166}$

No entanto, mais do que simplesmente expor o código binário informação/nãoinformação - a partir do qual o sistema dos meios de comunicação opera suas distinções e seleções de sentido -, destaca-se, como elemento primordial deste trabalho, a

\footnotetext{
${ }^{166}$ Para Luhmann (2005a, p. 70-71): “Embora a verdade ou a suposição de verdade seja indispensável para as notícias e as reportagens, os meios de comunicação não seguem o código verdade/não-verdade, mas mesmo em seu âmbito cognitivo de programação, o código informação/não-informação. Reconhece-se aí que o nãoverdadeiro não é utilizado como valor reflexivo. Para notícias e reportagens não é importante (ou, pelo menos, para informações de fundo que não são veiculadas) que se exclua aquilo que não é verdadeiro. Diferentemente da ciência, a informação não é refletida exaustivamente a ponto de poder ser constatado - de uma forma verdadeira - que antes que seja afirmada a verdade a inverdade já foi excluída. O problema das informações não está nesse ponto, mas na seleção, e isso tem consequências de grande alcance para aquilo que se poderia denominar 'criação de um clima' mediante os meios de comunicação".
} 
compreensão e discussão dos diferentes programas internos desse sistema, isto porque, segundo Luhmann (2005a, p. 39-40):

(...) No sistema tem que existir uma proposição de regras (possivelmente modificável) que resolva o paradoxo da informatividade da nãoinformação, aqueles programas com a ajuda dos quais se pode decidir se algo no sistema deve ser tratado como informativo ou não. (...) Por isso, toda informação depende de categorizações que demarcam espaços de possibilidades; nesses espaços é pré-estruturado o campo de escolhas para aquilo que pode ocorrer como comunicação. Isso é apenas uma outra formulação para a tese de que o código informação/não-informação não satisfaz, e, em vez disso, são necessários adicionalmente programas que classifiquem aquilo que pode ser esperado como informação e aquilo que permanece sem valor informativo em campos de seleção como esporte ou astrofísica, política ou arte moderna, acidentes ou catástrofes. A unidade ou invariância do código corresponde então a uma pluralidade de tais programas ou, dito de outra maneira, a uma seleção de dois níveis: o da área de seleção e o da informação concreta, que só se torna compreensível quando classificada sob um "a partir de onde?" de outras possibilidades.

Modelados pelo peculiar desenvolvimento histórico de cada subsistema social e seus acoplamentos estruturais, tais programas são essenciais ao funcionamento interno de cada subsistema em razão da restrição dos sentidos que conferem ao seu respectivo código binário, permitindo a seleção, no caso dos meios de comunicação, do que é informativo ou não frente à amplitude dos temas a se comunicar, propostos pelos demais sistemas sociais e psíquicos, que são o ambiente deste subsistema social de comunicação.

Em resumo, o sistema dos meios de comunicação determina seu valor positivo — informação - através de programas internos, reduzindo a complexidade da comunicação o que é essencial para suas operações sistêmicas.

O que fora acima descrito como desenvolvimento e diferenciação funcional dos sistemas dos meios de comunicação tem sido objeto de análise de diversos pesquisadores ${ }^{167}$ latino e norte-americanos, ainda que a partir de diferentes abordagens metodológicas e terminologias diversas.

Voltados ao estudo da teoria da comunicação, jornalismo, comunicação social, cultura e política na América Latina de um modo geral, nos Estados Unidos da América e

\footnotetext{
${ }^{167}$ Nesse sentido, nos referimos a Edward S. Herman e Noam Chomsky (2003), Maria Nazareth Ferreira (1995), Venício Arthur de Lima (2001, 2006, 2008), Dênis de Moraes (1998, 2001) e Dennis de Oliveira (2002a, 2002b, 2006), José Arbex Jr. (2002, 2003), Jesús Martín Barbero (2008), Nestor Garcia Canclini (2001; 2008) Beatriz Sarlo (2005), Sérgio Miceli (1994), Otávio Ianni (2003), Marilena Chauí (2006), Muniz Sodré (2005) dentre outros.
} 
no Brasil, os autores selecionados questionam, à sua maneira, o papel desempenhado pelos meios de comunicação de massa nestas sociedades ocidentais.

Como se pretende discutir a seguir, apesar de seus diferentes cortes epistemológicos e objetos centrais de análise, estes diferentes estudos confluem de certa forma para o forte questionamento dos meios de comunicação e de suas efetivas funções sociais, as quais seriam muito diversas de sua autodeclarada "missão" (in)formadora da sociedade enquanto instrumento de utilidade pública, cujas tarefas essenciais, exaustivamente propagandeadas, seriam de informar com isenção e comprometimento com a verdade e objetividade, bem como, supostamente, de fiscalizar os poderes estatais defendendo a democracia e as liberdades públicas, como se apresentam suas instituições em seu mais recente e diuturno discurso metalinguístico.

Essas diferentes abordagens e suas críticas dos meios de comunicação de massa nacionais confluem, de um modo geral, para o desenvolvimento da presente tese. São, igualmente, cruciais para a aferição dos limites e potenciais explicativos do "Modelo de Propaganda" - desenvolvido inicialmente por Edward S. Herman e Noam Chomsky (2003) para o estudo da mídia norte-americana - para a compreensão das funções desempenhadas pela mídia de massa no Brasil e sua relação com a definição das expectativas sociais acerca dos direitos sociais do Sistema de Seguridade nacional.

Do que fora exposto, decorre o caráter essencial para construção da presente tese justamente da compreensão do processo de desenvolvimento dos meios de comunicação de massa brasileiros, sobretudo, de seus programas internos na área de notícias e reportagens midiáticas, responsáveis, em última instância, pela seleção dos temas e direcionamento das informações relativas aos direitos fundamentais à saúde, previdência e assistência social no Brasil.

\subsection{O Modelo de Propaganda e sua aplicabilidade ao estudo da Mídia brasileira}

Desenvolvido por Noam Chomsky e Edward S. Hermam (2003), o Modelo de Proganda da mídia sintetiza o funcionamento dos meios de comunicação de massa nos Estudos Unidos da América.

Tal modelo aponta para a concentração das organizações midiáticas num pequeno número de empresas privadas orientadas para o lucro, tendo a propaganda como sua principal 
fonte de financiamento, o que permite sua extensão para a compreensão do funcionamento da mídia brasileira (HERMAN; CHOMSKY, 2003; ARBEX JR, 2002; LIMA, 2001, 2008).

Como enfatizam Herman e Chomsky (2003, p. 62):

Nos países em que as alavancas do poder estão nas mãos de uma burocracia estatal, o controle de monopólio que a mídia exerce, frequentemente complementado pela censura oficial, torna claro que a mídia é utilizada para os fins de uma elite dominante. É muito mais difícil ver um sistema de propaganda operando quando a mídia é privada e quando não existe censura formal. Isso acontece particularmente quando a mídia faz parte de um ambiente de competição acirrada, quando ela periodicamente ataca e expõe más condutas empresariais e governamentais e quando ela se apresenta agressivamente como portavoz da liberdade de expressão e do interesse geral da comunidade. O que não fica evidente (e permanece sem ser discutido na mídia) é a natureza limitada dessas críticas, assim, como a enorme desigualdade no domínio dos recursos, bem como seu efeito tanto no acesso ao sistema de mídia privado quanto em seu comportamento e desempenho. Um modelo de propaganda focaliza essas desigualdades de distribuição de renda e de poder [relacionados ao acesso ao sistema de mídia] e seus múltiplos efeitos sobre os interesses e opções da mídia de massa. Ele traça as rotas pelas quais o dinheiro e o poder são capazes de filtrar as notícias adequadas para serem impressas, marginaliza [sic] as opiniões contrárias e permite [sic] que o governo e os interesses privados dominantes transmitam suas mensagens ao público. (grifos nossos).

Elaborado inicialmente para a análise dos meios de comunicação norteamericanos, apreendido sob a presente visão sistêmica, o referido modelo permite uma compreensão mais aproximada dos atuais mecanismos internos de dotação de sentido e seleção de informações desse sistema social de comunicação, ainda que tais programas sistêmicos sejam apresentados sob a perspectiva de "filtros de notícias", a partir dos quais se estabeleceriam as premissas do discurso e da interpretação midiática.

Nesse sentido, segundo os referidos autores, tal modelo pode ser delimitado, em linhas gerais, a partir de cinco elementos ou "filtros":

(1) o porte, a concentração da propriedade, a fortuna dos proprietários e a orientação para o lucro das empresas que dominam a mídia de massa; (2) a propaganda como principal fonte de recursos da mídia de massa; (3) a dependência da mídia de informações fornecidas pelo governo, por empresas e por "especialistas" financiados e aprovados por essas fontes primárias e agentes do poder; (4) a bateria de reações negativas (em inglês flak) como forma de disciplinar a mídia, e (5) o "anticomunismo" como religião nacional [no caso norte-americano] e mecanismo de controle. (HERMAN; CHOMSKY, 2003, p. 62). 
Numa síntese introdutória, tem-se que o primeiro filtro relaciona-se ao fato de que as principais organizações midiáticas apresentam-se como grandes empresas não apenas voltadas para a obtenção de lucros como também com estreitas relações e parcerias econômicas com corporações de outros setores econômicos e dependência jurídica e econômica do próprio governo.

Diretamente relacionado a este primeiro, o segundo filtro/programa diz respeito basicamente ao fato da maior parte de seu financiamento decorrer não dos recursos de seu público, mas fundamentalmente de sua receita publicitária e de propaganda obtida junto a outras empresas e ao próprio governo. ${ }^{168}$

Sob essa perspectiva, destaca-se, desde já, que não apenas a notícia deve ser considerada como um produto da mídia, como, também e principalmente, que o seu próprio público passa a ser identificado como espécie de mercadoria. Este é "ofertado" aos seus anunciantes, ou seja, a outras empresas e ao governo, sendo que, nesse contexto, a notícia, o entretenimento e suas demais formas de informação funcionam como mecanismo de atração desse público, segundo o interesse específico dos anunciantes priorizados e a estratégia de mercado adotada.

Por essa razão, a própria seleção da informação/não-informação a ser apresentada para a atração desse público/produto passa a se submeter, em última instância, não diretamente aos interesses dos "consumidores" de sua informação, mas precipuamente às expectativas e aos interesses das empresas e do próprio governo anunciantes.

\footnotetext{
${ }^{168}$ Cumpre resaltar desde início que, embora tecnicamente distintas, as palavras propaganda e publicidade são usualmente empregadas como sinônimas. Ademais, não se observa na literatura sobre essa área em questão uma unidade de conceituação. Isto porque no entender de Isleide Arruda Fontenelle (2002, p. 141): “'propaganda' é o anúncio comercial pago, enquanto a "publicidade" seria a veiculação do nome de uma marca em notícias 'reais', aquelas que são transmitidas pela 'mídia-realidade', qual seja, a mídia de notícias, de informação.” Já para Pedrinho Arcides Guareschi; Lisie Polita Romanzini; Lúcia Biavaschi Grassi (2008, p. 571): "Nas sociedades capitalistas contemporâneas o termo publicidade passou a ser empregado, na maioria dos casos, como a prática de se oferecer e vender produtos comerciais, a tal ponto que em algumas línguas ele passou a ser substituído pelo termo "comerciais"' Deve-se, ainda reconhecer que, diferentemente de "publicidade", o termo "propaganda" tem uma acepção mais ampla não restrita à dimensão econômica ou comercial, a qual parece ser a seguida por Herman e Chomsky (2003), em que pese sua ênfase sobre seu papel econômico. Nesse sentido, segundo se aproximam os referidos autores da conceituação de "propaganda" proposta por Norberto Bobbio, Nicola Mateucci e Gianfranco Pasquino (2000), para os quais esta pode ser definida como a "difusão deliberada e sistemática de mensagens, (...) visando a criar uma imagem positiva ou negativa de determinados fenômenos (...) e estimular determinados comportamentos", sendo, assim, "um esforço consciente e sistemático destinado a influenciar as opiniões e ações de um certo público ou de uma sociedade total".
} 
Quanto ao terceiro filtro/programa de seleção de notícias, este sintetiza a relação de dependência das organizações dos meios de comunicação de massa em relação às empresas especializadas em informação e às próprias instituições governamentais, como fontes de informações para a grande parte de suas notícias. Este filtro será fundamental para o questionamento da reprodução parcial dos dados "oficiais" sobre o suposto déficit da previdência e falta de recursos para as políticas públicas de saúde no Brasil, em que pese sua contestação por organizações e estudiosos independentes sobre esse tema, marginalizados da discussão pública quando da veiculação de notícias sobre esses temas.

O quarto filtro, em síntese, reflete a tentativa de controle e disciplina exercida, sobretudo, por organizações políticas e econômicas sobre temas evidenciados pela mídia, no sentido de pressioná-la, através de suas reações negativas, a se adequarem quanto à forma de cobertura e linha editorial aos seus interesses parciais, não necessariamente coincidentes com as expectativas sociais generalizadas pelo direito sobre os temas questionados.

Por sua vez, o quinto filtro atuaria como programa de seleção de informações, de forma ideológica, no sentido de direcionar notícias para a generalização do anticomunismo como "religião nacional" norte-americana. Segundo Herman e Chomsky (2003 p. 88), essa “ideologia ajuda a mobilizar a população contra o inimigo comum, e como o conceito é obscuro pode ser utilizado contra qualquer um que defenda políticas que ameacem os interesses de proprietários ou apoie a acomodação com países comunistas e com o radicalismo".

É importante frisar desde já que o mecanismo da propaganda é descrito de modo sistemático e independente dos profissionais do setor, marginalizando os dissidentes na medida em que a seleção e o direcionamento da informação ocorrem "tão naturalmente que o pessoal da mídia de notícias, frequentemente atuando com completa integridade e boa vontade, é capaz de se convencer de que escolhe e interpreta 'objetivamente' as notícias com base nos valores profissionais dessas notícias". (HERMAN; CHOMSKY, 2003 , p. 62).

De modo similar ao que fora exposto neste trabalho acerca da autoreferência dos sistemas sociais e suas interações com os sistemas psíquicos, segundo o descrito modelo de propaganda, por mais que os profissionais da informação que interagem com esse sistema busquem conscientemente a objetvidade e imparcialidade em seu trabalho, a comunicação resultante seria direcionada em razão de suas restrições serem "tão poderosas 
e incutidas no sistema de uma forma tão fundamental, que bases alternativas de opções de notícias dificilmente são imagináveis” (HERMAN; CHOMSKY, 2003 , p. 63).

\subsubsection{O $1^{0}$ programa ou "filtro de notícias": porte, propriedade e orientação para o lucro da mídia de massa}

O primeiro filtro destacado por esse modelo - porte, propriedade e orientação para o lucro da mídia de massa - desenvolveu-se em função do aumento na escala de produção, primeiramente dos jornais, e da decorrente elevação de seus custos a partir da metade do século XIX na Inglaterra e, mais acentuadamente em suas últimas décadas, nos Estados Unidos da América.

Relaciona-se, portanto, à expansão do livre mercado e de seus reflexos na "industrialização da imprensa". Seu aperfeiçoamento tecnológico e o interesse dos proprietários em expandir cada vez mais seu público levaram, já ao final do século XIX, à concentração das primeiras organizações de comunicação e à falência dos pequenos jornais locais, sobretudo daqueles da classe operária inglesa, inviabilizando economicamente a imprensa alternativa. (HERMAN; CHOMSKY, 2003 , p. 64). ${ }^{169}$

Nesse mesmo sentido, Maria Nazareth Ferreira (1995), em sua pesquisa de campo sobre "a presença da América Latina nos media impressos", situa os meios de comunicação enquanto "instrumento privilegiado da expansão capitalista" e, a imprensa, como instituição suporte desse tipo de sociedade.

No que diz respeito diretamente ao tema das notícias e reportagens que perpassam boa parte da programação dos meios de comunicação em discussão, para a referida autora, o surgimento do jornalismo faz parte deste sistema de comunicação como um dado associado ao desenvolvimento do capitalismo comercial, no sentido de instrumento de divulgação de informações comerciais. ${ }^{170}$

Nessa linha, paralelamente aos desdobramentos do jornalismo no século XVIII como imprensa literária, política e mesmo partidária, o mesmo teria se transformado, tal

\footnotetext{
169 Este processo organizacional é também identificado nos estudos de Gabriel M. Niezen (1985), Ciro Marcondes Filho (1986) e Cremilda Medina (1988).

${ }^{170}$ Similar desenvolvimento histórico do “jornal comercial” é descrito por Denis McQuail (2003, p. 21-24).
} 
como hoje se apresenta em sua grande medida, já em 1830, em empresa, no sentido de atividade econômica organizada relacionada ao comércio de anúncios com fins lucrativos.

Daí porque, segundo Denis McQuail (2003, p. 23):

O jornal de massas tem sido chamado de ««omercial» por duas razões principais: é feito para o lucro por interesses monopolistas e é em grande medida dependente da publicidade (o que tornou possível e vantajoso desenvolver uma audiência de massas). Os objectivos comerciais e os alicerces dos jornais de massas exerceram influência considerável nos conteúdos, direccionados tanto para um populismo político como para suporte de negócios, consumos e empreendimentos de mercado.

Assim, ainda de acordo com Ferreira (1995), mais do que uma simples imprensa de opinião (pública), seria justamente esse modelo de imprensa empresarial o responsável pelas características da atividade jornalística da grande imprensa atual, quais sejam: a "busca de notícias, o furo, a aparência de neutralidade e de pluralismo". Contudo, dessa estrutura embrionária resultaria a mercantilização da notícia, isso porque:

Ao surgir como o instrumento que o capitalismo financeiro e comercial precisava para fazer fluir mais rapidamente as informações comerciais e as mercadorias, mas guardando as características dos jornais de opinião, o jornalismo empresarial criava um novo tipo de mercadoria: a notícia. Alicerçado nesta nova mercadoria, o moderno jornalismo passa a configurar-se atendendo ao mesmo tempo a dois mercados diferenciados: o da notícia e o dos produtos anunciados. (FERREIRA, 1995, p. 51).

Por sua vez, mais do que simplesmente enfatizar a informação, especialmente, sob a modalidade de notícia, como uma forma de mercadoria, o Modelo de Propaganda em tela destaca a lógica que perpassa a estruturação, o financiamento e, por conseguinte, o funcionamento dos meios de comunicação de massa de um modo geral e não apenas da imprensa como uma de suas organizações.

Permite, assim, compreender que esse acoplamento estrutural entre o sistema econômico e o dos meios de comunicação se dá não apenas no âmbito das notícias, as quais acabam mercantilizadas, em termos gerais, em razão da informação em si, enquanto forma de generalização de sentido sobre a realidade, desempenhar um papel de extrema relevância para o sistema econômico, seja como forma de insumo para o desenvolvimento 
de novos produtos, seja como mecanismo de conhecimento de mercado e exposição das empresas para a captação de recursos. ${ }^{171}$

Segundo Herman e Chomsky (2003, p. 65), essa vertente empresarial da imprensa levou à segmentação da mídia, no que diz respeito às suas principais organizações de produção e difusão das informações para a sociedade e demais sistemas de sentido.

Desse processo resultaria certo "segmento superior" reduzido a um pequeno número de empresas, nos Estados Unidos restrito a não mais do que 24 organizações, responsáveis por mais da metade da circulação dos jornais e pela grande parte do faturamento e do público de revistas, transmissões, livros e filmes, a despeito do grande número de jornais diários, revistas estações de rádio e televisão e editoras, existentes aos milhares naquele país.

De acordo com o levantamento histórico de Herman e Chomsky (2003, p. 65):

Há muito já se percebeu que a mídia está segmentada, com o segmento superior - como avaliado pelo prestígio, recursos e alcance abrangendo algo entre dez e 24 sistemas. É esse segmento superior, juntamente com o governo e as agências de notícias, que define a agenda de notícias e fornece a maior parte das notícias nacionais e internacionais aos segmentos inferiores da mídia, e daí ao público em geral. A centralização no segmento superior foi substancialmente aumentada com a evolução da televisão após a Segunda Guerra Mundial e com o surgimento das redes nacionais dessa importante mídia. Os mercados para as notícias antes da era da televisão eram locais, mesmo que pesadamente dependentes dos segmentos superiores e de um conjunto limitado de recursos para as fontes de notícias nacionais e internacionais; (...). ${ }^{172}$

Destaca-se, dessa forma, no descrito Modelo de Propaganda o impacto da concentração econômica tanto da propriedade quanto dos serviços relacionados aos meios de comunicação em poder de poucas organizações midiáticas.

\footnotetext{
${ }^{171}$ Nesse aspecto, a capacidade de uma empresa captar e absorver informação necessária e de forma rápida tem sido considerada determinante de suas possibilidades de inovação, aumento de lucratividade e de atendimento ao cliente em mercados competitivos. (BORGES; CARVALHO, 1998, p. 76).

${ }^{172}$ Nesse mesmo sentido, segundo o levantamento realizado por Filipe Reios Melo (2006, p. 2): “A tendência à oligopolização da economia tem recrudescido, atingindo, também, o setor dos meios de comunicação social e de entretenimento. Em 1980, 50 companhias respondiam por $90 \%$ do faturamento mundial com informação e entretenimento; em 1990, menos da metade delas ficava com os mesmos 90\%. (...), nos Estados Unidos, em 1999, 110 empresas partilhavam 60\% dos utilizadores de internet; em 2001, apenas 14 empresas detinham a mesma percentagem. Grupos empresariais das mais diversas áreas têm adquirido empresas da área de comunicação. Empresas como a Fiat, a Sony ou a General Electric controlam importantes empresas de comunicação e de entretenimento, entre as quais se destacam o jornal Corriere della Sera, a produtora cinematográfica Columbia Pictures e a rede de televisão NBC, respectivamente."
} 
Nesse mesmo sentido, ainda que sob uma diferente perspectiva teórica, em sua tese de doutoramento sobre regulação jurídica e concentração econômica dos serviços de comunicação social no Brasil, André de Godoy Fernandes (2009) distingue quatro modalidades de concentração do poder econômico na mídia brasileira: concentração horizontal, concentração vertical, conglomerados e concentração multimídia ou propriedade cruzada dos veículos (cross-media ownership). ${ }^{173}$

No que diz respeito à concentração vertical, esta pode ser entendida em termos gerais como aquela existente entre pessoas, sejam elas físicas ou jurídicas, situadas em diferentes níveis da cadeia de produção de um determinado produto ou serviço. (FERNANDES, 2009, p. 60).

Considerando-se, portanto, os serviços relacionados aos meios de comunicação de massa propriamente ditos, tal concentração vertical se daria pelo desempenho simultâneo de atividades tanto de produção de conteúdo, quanto de empacotamento ou programação, ou ainda de distribuição, como têm sido subdivida a cadeia produtiva desse setor (GIASANTE et al., 2004). ${ }^{174}$

$\mathrm{Na}$ rede mundial de computadores, Internet, seriam identificáveis mais facilmente quatro atividades econômicas: produção de conteúdo; hospedagem de sítio ou página na web, equiparável à tradicional atividade de empacotamento; provimento de acesso a tal meio eletrônico e infraestrutura de conexão. ${ }^{175}$

\footnotetext{
${ }^{173}$ Cumpre, porém, ressaltar que as três primeiras correspondem à classificação econômica tradicional das formas de concentração empresarial (SALOMÃO FILHO, 2002, p. 278), sendo a quarta, a propriedade cruzada dos veículos, considerada como uma forma específica de concentração das organizações dos meios de comunicação de massa.

${ }^{174}$ Considerando-se as peculiaridades internas de seus subsistemas, seria ainda possível destacar a distinção existente quanto ao desenvolvimento da produção de conteúdos entre jornais, revistas e televisão. De acordo com o levantamento realizado por Moacir Giasante et al. (2004), observa-se nos meios impressos que a produção de conteúdo jornalístico, por exemplo, distingue-se das atividades de edição de um jornal ou revista, consideradas como de "empacotamento". Estas últimas são, por sua vez, consideradas a parte da atividade de distribuição ou venda de tais publicações aos consumidores através de bancas de jornal e livrarias em geral. Já no que diz respeito à televisão, haveria ainda uma distinção entre as atividades de criação, produção de conteúdo audiovisual, organização de diversos programas dentro de uma grade de programação e sua final difusão ou distribuição (GIASANTE et al., 2004, p. 11-12).

${ }^{175}$ Como sintetiza André de Godoy Fernandes (2009, p. 62-63): "No tocante à Internet, a legislação brasileira distingue claramente entre infra-estrutura de telecomunicações e serviço de provimento de conexão à Internet, considerado um serviço de valor adicionado e não um serviço de telecomunicações. No entanto, não existe dispositivo legal que proíba uma empresa de telecomunicações, detentora de infra-estrutura de telecomunicações, de também prestar serviço de valor adicionado como o serviço de provimento de conexão à Internet. Pelo contrário, é muito comum as empresas de telefonia também oferecerem o serviço de provimento de conexão à Internet."
} 
O Código Brasileiro de Telecomunicações, instituído pela Lei ${ }^{\circ} 4.117$, de 27 de agosto de 1962, em seu art. 6 $6^{\circ}$, alínea "d", define os serviços de radiodifusão como aqueles destinados a serem recebidos direta e livremente pelo público em geral, compreendendo radiodifusão sonora e televisão. (BRASIL, 1962).

No Brasil, observa-se que estes serviços teriam suas as atividades de produção marcadas por sua concentração numa mesma organização empresarial sendo irrisória a participação de produtores independentes no total de programas veiculados pelos principais canais de televisão aberta do país. ${ }^{176}$

Porém, em que pese sua importância para a conformação do sistema dos meios de comunicação de massa, nesse primeiro aspecto pertinente à concentração vertical não haveria no sistema jurídico nacional brasileiro "qualquer dispositivo legal específico que impeça essa integração" vertical, segundo o citado levantamento jurídico de Fernandes (2009, p. 62).

Ainda em termos normativos, cabe ressaltar que a distinção entre serviços de produção, programação e difusão é delimitada de maneira expressa tão somente na legislação brasileira pertinente aos serviços de TV por assinatura. ${ }^{177}$

Por sua vez, no que diz respeito à concentração horizontal das atividades econômicas, esta é caracterizada pela concentração de da propriedade entre agentes econômicos que, ao menos em tese, deveriam ser concorrentes por situarem-se na mesma posição na cadeia produtiva. (FERNANDES, 2009, p. 60).

Diferentemente da forma vertical, a concentração horizontal da propriedade, ao menos dos veículos de radiodifusão, foi objeto de normatização através do Decreto-lei ${ }^{\circ}$

\footnotetext{
${ }^{176}$ O referido autor chama a atenção para o fato de que, a despeito da Constituição Federal de 1988, em seu art. 221, inciso II, determinar que a produção e a programação das emissoras de rádio e de televisão devam promover a cultura nacional e regional e estimular a produção independente que objetive a sua divulgação, "atualmente, a maioria da programação independente veiculada na TV aberta brasileira é formada por programas de proselitismo religioso, notadamente evangélicos, e programas de venda de produtos". (FERNANDES, 2009, p. 62).

177 Nesse aspecto, distinguem-se juridicamente pela Lei $\mathrm{n}^{\mathrm{o}} 8.977 / 1995$ as operadoras de TV a cabo enquanto pessoas jurídicas de direito privado que atuam mediante concessão, por meio de um conjunto de equipamentos e instalações que possibilitam a recepção, processamento e a geração de programação e de sinais próprios ou de terceiros, e sua distribuição por meio de redes de sua propriedade ou não, a assinantes localizados dentro de uma área determinada - das empresas programadoras, fornecedoras de conteúdo audiovisual.
} 
236, de 28 de fevereiro de 1967, o qual complementou o referido Código Brasileiro de Telecomunicações. ${ }^{178}$

Assim, por meio do art. 12 do citado Decreto-lei, foram limitadas juridicamente em todo país a concessão e permissão de serviços de radiodifusão, restringindo-se, ao menos juridicamente, o número de estações de radiodifusão por entidade concessionária ou permissionária segundo seu âmbito (local, regional ou nacional) e o comprimento de suas ondas (médias, tropicais ou frequencia modulada). ${ }^{179}$

Contudo, o mesmo dispositivo legal, em seu $\S 2^{\circ}$ acabou por reduzir sua amplitude ao acrescentar que não deveriam ser "computadas para os efeitos do presente artigo, as estações repetidoras e retransmissoras de televisão, pertencentes às estações geradoras" (BRASIL, 1967).

Nesse contexto, levando em conta a forma como essas determinações legais tem sido aplicadas pelo poder Executivo, Fernandes (2009) explica que

(...) a capacidade do art. 12 do Decreto-lei $\mathrm{n}^{\mathrm{0}} 236$, de 1967, para coibir a concentração da propriedade de emissoras de radiodifusão foi substancialmente reduzida por duas razões fundamentais. Em primeiro lugar, o Ministério das Comunicações, órgão fiscalizador do setor de radiodifusão, entende que o limite de concessões ou permissões de canais de radiodifusão é aplicável a cada pessoa física e não a um determinado grupo empresarial ou família. Assim, por meio de artifícios como o registro de concessões de canais em nome de outros membros da mesma família (pais, filhos, irmãos, cônjuges, cunhados) e até do uso de "testasde-ferro", as redes brasileiras de televisão conseguiram contornar os limites do Decreto-lei $\mathrm{n}^{\circ}$ 236, de 1967173. Embora formalmente em vigor, o art. 12 do Decreto-lei no 236, de 1967, praticamente a única regra legal que impõe limite à concentração de canais de radiodifusão, pode ser considerada letra-morta. (FERNANDES, 2009, p. 64-65).

A despeito de sustentar essa criticada interpretação ministerial, através da edição da Medida Provisória $n^{\circ} 70$, de $1^{\circ}$ de outubro de 2002, o próprio Poder Executivo Federal

\footnotetext{
${ }^{178}$ Ademais, cumpre ressaltar que, no que diz respeito à importância do mencionado Código, de acordo com César Ricardo Siqueira Bolaño (2007, p. 11), sua instituição foi o resultado de "um complexo processo de lutas e negociações, remontando aos embantes que, como em todo o mundo, separam os defensores de uma função eminentemente educativa e cultural, de um lado, ou comercial, de outro, para o rádio, nos anos 20".

${ }^{179}$ Nesse sentido, assim ficou limitada juridicamente o número de concessões e permissões por entidade: "I Estações radiodifusoras de som: (a) Locais: 4 em ondas médias e 6 em frequência modulada, (b) Regionais 3 em ondas médias e 3 em ondas tropicais, sendo ainda limitadas a 2 por Estado, e, em nível (c) Nacional: 2 em ondas médias e 2 em ondas curtas. Por sua vez, as estações radiodifusoras de som e imagem, ou seja, as redes de televisão aberta ficaram restritas a 10 em todo território nacional, sendo no máximo 5 em VHF e 2 por Estado. (BRASIL, 1967).
} 
brasileiro tentou ampliar a descrita limitação legal no número de concessões e permissões quanto a execução dos serviços de radiodifusão.

Fora, então, proposta através dessa nova forma de limitação, a consideração não apenas das entidades em sua totalidade como também dos sócios, acionistas ou cotistas que, direta ou indiretamente, detivessem percentual igual ou superior a vinte por cento das ações ou cotas representativas do capital social, total e votante, de outras concessionárias ou permissionárias de serviços de radiodifusão. Tal se daria com a alteração da redação do ainda em vigor do $\S 3^{\circ}$ do art. 12 do Decreto-lei no $236 / 1967 .{ }^{180}$

Porém, a Medida Provisória $\mathrm{n}^{\mathrm{o}}$ 70, de 2002 ao ser convertida na Lei $\mathrm{n}^{\mathrm{o}}$ 10.610, de 20 de dezembro de 2002, suprimiu do texto definitivo a descrita proposta de alteração. Dessa forma, ao contrário do que fora inicialmente formulado pelo Poder Executivo, na lei aprovada definiu-se, quanto ao controle da concentração da radiodifusão em matéria de capital societário, a aplicação dos mesmos critérios já expostos do art. 12 do Decreto-lei ${ }^{\circ}$ 236/1967 e, ainda, com a seguinte ressalva na nova lei em questão:

Art. $9^{\circ}$. Não se aplica a limitação estabelecida no caput do art. 12 do Decreto-Lei n 236, de 28 de fevereiro de 1967, aos investimentos de carteira de ações, desde que o seu titular não indique administrador em mais de uma empresa executante de serviço de radiodifusão, ou em suas respectivas controladoras, nem detenha mais de uma participação societária que configure controle ou coligação em tais empresas.

$\S 1^{\circ}$ Entende-se como coligação, para fins deste artigo, a participação, direta ou indireta, em pelo menos quinze por cento do capital de uma pessoa jurídica, ou se o capital de duas pessoas jurídicas for detido, em pelo menos quinze por cento, direta ou indiretamente, pelo mesmo titular de investimento financeiro.

$\S 2^{\underline{o}}$ Consideram-se investimentos de carteira de ações, para os fins do caput deste artigo, os recursos aplicados em ações de companhias abertas, por investidores individuais e institucionais, estes últimos entendidos como os investidores, com sede ou domicílio no Brasil ou no exterior, que apliquem, de forma diversificada, por força de disposição legal, regulamentar ou de seus atos constitutivos, recursos no mercado de valores mobiliários, devendo cada ação ser nominalmente identificada. (BRASIL, 2002).

\footnotetext{
180 A descrita proposta legal excluía dessa limitação apenas os "investimentos de carteira de ações das limitações à titularidade de empresas concessionárias ou permissionárias dos serviços de radiodifusão estabelecidas no art. 12 do Decreto-lei no 236, de 1967, desde que o seu titular não indicasse administrador em mais de uma empresa executante de serviço de radiodifusão, ou em suas respectivas controladas, nem detivesse mais de uma participação societária que configurasse controle ou coligação em tais empresas".
} 
Já em relação à participação de capital estrangeiro nas empresas do setor de radiodifusão, tal fora expressamente proibida, em nível constitucional, pela Constituição Federal dos Estados Unidos do Brasil de 18 de setembro 1946. ${ }^{181}$

Não obstante essa limitação, Sérgio Capparelli (1989), em sua análise acerca das influências que as ditaduras militares exerceram na indústria cultural do Brasil, Argentina, Chile e Uruguai, chama a atenção para a seguinte estratégia organizacional:

O grupo Globo, com uma estação de televisão em fase de implantação, aceitou finalmente os investimentos do conglomerado norte-americano, violando o artigo 160 da Constituição brasileira. Os signatários estabeleceram então uma série de artifícios para burlar a lei, através de um contrato de assistência técnica que incluía o setor de técnicas administrativas, assistência para a implantação de uma administração moderna e o fornecimento de informações. A organização Globo mascarou esses investimentos proibidos por lei através da venda ao TimeLife Inc. do edifício onde estava instalada e assinou um contrato de aluguel no valor de $45 \%$ do lucro líquido da empresa. A denúncia do acordo foi feita por grupos das indústrias culturais brasileiras, especialmente pelo representante dos Diários Associados, que era também presidente da Associação Brasileira de Emissoras de Rádio e Televisão (ABERT), e este acordo foi suspenso em 1967. (CAPARRELLI, 1989, p. 23-24).

Nessa mesma época, o referido Decreto-lei 236/1967 reiterou, em âmbito infraconstitucional, de maneira clara tal proibição quanto à participação de estrangeiros na propriedade ou direção dessas empresas de comunicação brasileiras. ${ }^{182}$

Tal proibição fora mantida inicialmente pela redação original do art. 222 da Constituição Federal da República Federativa do Brasil de 1988.

\footnotetext{
${ }^{181}$ Nesse sentido, prescrevia seu art. 160: "É vedada a propriedade de empresas jornalísticas, sejam políticas ou simplesmente noticiosas, assim como a de radiodifusão, a sociedades anônimas por ações ao portador e a estrangeiros. Nem esses, nem pessoas Jurídicas, excetuados os Partidos Políticos nacionais, poderão ser acionistas de sociedades anônimas proprietárias dessas empresas. A brasileiros (art. 129, $\mathrm{n}^{\mathrm{os}} \mathrm{I}$ e II) caberá, exclusivamente, a responsabilidade principal delas e a sua orientação intelectual e administrativa." (BRASIL, 1946).

${ }^{182}$ Ainda segundo Bolaño (2007, p. 13): “O rigor em relação ao capital estrangeiro se devia à experiência nefasta da entrada da TV Globo no mercado brasileiro, com o apoio do grupo norte-americano Time-Life, amplamente citado na bibliografia sobre a história da televisão brasileira". Nesse sentido, Geraldo Anhaia Mello (1994, p. 07-08) reproduz em seu livro as informações sobre a história da TV Globo, sobretudo de sua relação com o grupo Time-Life apresentadas no documentário de Simon Hartog - Brazil: Beyond Citizen Kane -, exibido inicialmente no Channel 4 da TV inglesa em 10 de maio de 1993, após uma disputa judicial de um ano. Nesse mesmo sentido, Daniel Herz (1991, p. 103-117), descreve detalhadamente a associação embrionária entre a sociedade limitada TV Globo e o grupo Time-Life, reproduzindo em sua obra depoimentos, inclusive do próprio Roberto Marinho, colhidos na Comissão Parlamentar de Inquérito criada pela Res. N. 185 de 1966 com o objetivo de apurar fatos relacionados às organizações de Radio e TV e ao Jornal "O Globo" e as empresas estrangeiras dirigidas pelo grupo Time-Life. Dominique Wolton (1996, p. 159) reitera a existência desses acordos entre as organizações Globo e o grupo norte-americano citado.
} 
Porém, constitucionalizando parcialmente essa forma ilícita de organização dos meios de comunicação de massa sustentada administrativamente, a Emenda Constitucional $\mathrm{n}^{\mathrm{o}} 36$, de 28 de maio de 2002, alterou por fim a redação do citado art. 222, pelo que passou a ser juridicamente admitida, ainda que com certas restrições, a participação de capital estrangeiro em empresas jornalísticas e de radiodifusão sonora e de sons e imagens. Segundo a nova redação do dispositivo constitucional em tela:

Art. 222. A propriedade de empresa jornalística e de radiodifusão sonora e de sons e imagens é privativa de brasileiros natos ou naturalizados há mais de dez anos, ou de pessoas jurídicas constituídas sob as leis brasileiras e que tenham sede no País.

$\S 1^{\circ}$ Em qualquer caso, pelo menos setenta por cento do capital total e do capital votante das empresas jornalísticas e de radiodifusão sonora e de sons e imagens deverá pertencer, direta ou indiretamente, a brasileiros natos ou naturalizados há mais de dez anos, que exercerão obrigatoriamente a gestão das atividades e estabelecerão o conteúdo da programação.

$\S 2^{\circ}$ A responsabilidade editorial e as atividades de seleção e direção da programação veiculada são privativas de brasileiros natos ou naturalizados há mais de dez anos, em qualquer meio de comunicação social.

$\S 3^{\circ}$ Os meios de comunicação social eletrônica, independentemente da tecnologia utilizada para a prestação do serviço, deverão observar os princípios enunciados no art. 221, na forma de lei específica, que também garantirá a prioridade de profissionais brasileiros na execução de produções nacionais.

$\S 4^{\circ}$ Lei disciplinará a participação de capital estrangeiro nas empresas de que trata o $\S 1^{\circ}$.

$\S 5^{\circ}$ As alterações de controle societário das empresas de que trata o $\S 1^{\circ}$ serão comunicadas ao Congresso Nacional. (BRASIL, 1988).

Destaca-se, ainda e de modo crucial, a peculiar concentração da propriedade das organizações de mídia em tempos de "propriedade cruzada", na qual uma única pessoa, física ou jurídica, detém o controle de diferentes veículos de comunicação - como jornal, Televisão, aberta e/ou por assinatura, rádio etc. - seja numa mesma localidade ou região. $^{183}$

${ }^{183}$ Conforme já fora exaustivamente denunciado por diversos autores (BOLAÑO, 2007; WOLTON, 1996; MELLO, 1994; HERZ, 1991), em consonância com Fernandes (2009, p. 69-70) deve-se ainda considerar que o "melhor exemplo de concentração multimídia ou propriedade cruzada de meios de comunicação social no Brasil é dado pelas Organizações Globo, da família Marinho, que atuam nos segmentos de televisão aberta, televisão por assinatura, rádio, jornais e revistas, e provedor de acesso à Internet". Nessa mesma linha, a 
Para Dênis de Moraes (1998, p. 70), nesta forma de concentração, poderia ainda ser observada a existência de "monopólio em cruz", identificado pela reprodução nos níveis local e regional, da situação oligopolista marcante da descrita propriedade cruzada.

A concentração multissetorial ou formação de conglomerados econômicos, por fim, consiste na forma de concentração empresarial em que uma pessoa, empresa ou grupo exerce atividades em setores econômicos distintos. (FERNANDES, 2009, p. 72).

Nesse sentido, tendo em vista ainda o favorecimento do controle dos canais por grupos familiares no Brasil, Fernandes (2009, p. 74) destaca a existência de "Controle oligárquico dos canais de radiodifusão como outro fenômeno específico do setor de comunicação social brasileiro".

Sendo assim, No Brasil, observa-se uma similar concetração das organizaões dos meios de comunicação tal como descrita pelo Modelo de Propaganda em questão.

A adequação, portanto, deste primeiro filtro/programa à realidade brasileira é ainda reforçada considerando-se os seguintes resultados do "Projeto Os Donos da Mídia", divulgados desde 2002 pelo Instituto de Estudos e Pesquisas de Comunicação - Epcom. Este estudo reforça a coexistência também no Brasil das diferentes formas de concentração apresentadas acima.

Em que pese as limitações normativas descritas, nesse estudo, foram identificadas seis grandes redes privadas de comunicação no país - Globo, SBT, Record, Bandeirantes, Rede TV! e CNT -, as quais controlavam no ano de 2002 cerca de 47 emissoras, interfirindo na atuação de aproximadamente 249 emissoras de televisão pertencetes às demais 138 empresas, que figuravam como suas afiliadas regionais. Além disso, identificou-se a vinculação daquelas seis grandes redes, através da propriedade cruzada, com outros 372 veículos de mídia como rádios, jornais e revistas. (EPCOM, 2002).

A partir desse levantamento, considerando ainda a Empresa Brasil de Comunicação - EBC, controlada pelo Governo Federal, o descrito projeto apresentou o quadro dos cinco maiores grupos de mídia brasileira em 2002, conforme tabela 1.

edição n. 42 da Revista da Associação dos Docentes da USP -Adusp, de janeiro de 2008 (disponível no sítio eletrônico: <http://www.adusp.org.br/revista/42/r42a02.pdf >) expõe de maneira detalhada a existência de propriedade cruzada e das demais formas de concentração tanto vertical quanto horizontal não apenas na referida "Organizações Globo", como também no "Grupo Sílvio Santos”, "Grupo Abril', "Grupo Folha”, “Grupo RBS”, "Grupo Estado", "Grupo Bandeirantes” e "Rede Record de Rádio e Televisão". 
Tabela 1 - Veículos das cinco maiores redes de TV e de seus grupos afiliados. Modificado de EPCOM (2002)

Siglas: TV - Geradora de serviço de radiodifusão de sons e imagens capaz de inserir conteúdo local ou distribuir programação de uma rede. Também chamada de emissora de TV. RTV - Retransmissora de televisão capaz de redistribuir sinais de geradoras ou captados por satélite. Em geral, não insere programação local. FM - Serviço de radiodifusão sonora em frequência modulada. OM - Serviço de radiodifusão sonora em ondas médias. Também conhecido como AM. OC - Serviço de radiodifusão sonora em ondas curtas. OT - Serviço de radiodifusão sonora em ondas tropicais. Radcom - Serviço de radiodifusão comunitária. Suas emissoras também são conhecidas como rádios de baixa potência. TVA - Serviço Especial de Televisão por Assinatura. Transmite programação não codificada até a definição de nova política para a regência desta modalidade de serviço

\begin{tabular}{|c|c|c|c|c|c|c|c|c|c|c|c|c|c|c|}
\hline Rede & TV & FM & OC & OM & OT & TVC & MMDS & DTH & TVA & Canal TVA & Jornal & Revista & Radcom & Total \\
\hline Globo & 105 & 76 & 11 & 52 & 4 & 9 & 2 & 1 & 2 & 17 & 33 & 27 & 1 & 340 \\
\hline SBT & 58 & 70 & 1 & 39 & 2 & 1 & 10 & 1 & & & 12 & & 1 & 195 \\
\hline Record & 46 & 51 & 2 & 31 & 3 & & & & & & 9 & & & 142 \\
\hline Band & 39 & 48 & 5 & 44 & 3 & 13 & 1 & & & 2 & 11 & & & 166 \\
\hline EBC & 18 & 32 & 10 & 27 & 7 & & & & & & 1 & & & 95 \\
\hline
\end{tabular}

No mais, para que se possa dimensionar a relevância econômica das organizações midiáticas e, por conseguinte, a aplicabilidade do Modelo de Propaganda em questão, tem-se que os serviços de informação geraram receita de $\mathrm{R} \$ 137,3$ bilhões, em 2006, contra R\$129,2 bilhões, em 2005, segundo o "Suplemento de Produtos e Serviços da Pesquisa Anual de Serviços - PAS 2006", elaborado pelo Instituto Brasileiro de Geografia e Estatística - IBGE a partir da análise de empresas do setor com 20 ou mais pessoas.

$\mathrm{Na}$ referida pesquisa do IBGE, os serviços de radiodifusão, bem como as agências de notícias e as demais atividades de jornalismo são enquadradas dentre os "Serviços Audiovisuais" ao lado das "Telecomunicações" e das "Atividades de Informática” no âmbito geral da atividade de Serviços de Informação.

Por sua vez, feito esse esclarecimento, de acordo com o citado levantamento econômico, tais "Serviços Audiovisuais" responderam por 13,7\% da receita dos Serviços de informação, em 2006, ou seja, por aproximadamente R \$ 18,820 bilhões, aumentando ligeiramente sua participação em relação a 2005 (13,0\%)”. (PAS, 2006 - Figura 2). 


\begin{tabular}{|c|c|c|c|c|c|c|c|c|}
\hline \multirow{3}{*}{ Produtos/serviços prestados } & \multicolumn{4}{|c|}{2005} & \multicolumn{4}{|c|}{2006} \\
\hline & \multirow{2}{*}{$\begin{array}{c}\text { Número } \\
\text { de infor- } \\
\text { mantes } \\
\text { (1) }\end{array}$} & \multicolumn{3}{|c|}{$\begin{array}{l}\text { Receita operacional } \\
\text { líquida e subvençōes }\end{array}$} & \multirow{2}{*}{$\begin{array}{c}\text { Número } \\
\text { de infor- } \\
\text { mantes } \\
\text { (1) }\end{array}$} & \multicolumn{3}{|c|}{$\begin{array}{l}\text { Receita operacional } \\
\text { liquida e subvençōes }\end{array}$} \\
\hline & & $\begin{array}{c}\text { Valor } \\
(1000 \mathrm{R} \$)\end{array}$ & $\begin{array}{l}\text { Total } \\
(\%)\end{array}$ & $\begin{array}{c}\text { Parcial } \\
(\%)\end{array}$ & & $\begin{array}{c}\text { Valor } \\
(1000 \mathrm{R} \$)\end{array}$ & $\begin{array}{l}\text { Total } \\
(\%)\end{array}$ & $\begin{array}{c}\text { Parcial } \\
(\%)\end{array}$ \\
\hline Total (2) & 989 & 16837226 & 100,0 & $\cdot$ & 999 & 18820289 & 100,0 & $\cdot$ \\
\hline Serviços de televisão (2) & 351 & 13807754 & 82,0 & 100,0 & 334 & 15529853 & 82,5 & 100,0 \\
\hline Operadoras de televisäo por assinatura (2) & 104 & 3974152 & 23,6 & 28,8 & 87 & 4580867 & 24,3 & 29,5 \\
\hline Pacotes básicos e especiais & 102 & 3484713 & 20,7 & 25,2 & 86 & 3851844 & 20,5 & 24,8 \\
\hline Serviços de pay-per-view & 34 & 59079 & 0,4 & 0,4 & 40 & 114727 & 0,6 & 0,7 \\
\hline Veiculaçäo de publicidade (3) & 12 & 29591 & 0,2 & 0,2 & 12 & 16898 & 0,1 & 0,1 \\
\hline Fornecimento de conexáo para acesso à Internet em banda larga & 32 & 382335 & 2,3 & 2,8 & 40 & 545712 & 2,9 & 3,5 \\
\hline Venda de revistas $\theta$ outros materiais impressos $(3)$ & 29 & 18425 & 0,1 & 0,1 & 34 & 21157 & 0,1 & 0,1 \\
\hline Aluguel de equipamento (3) & - & - & - & - & 16 & 30529 & 0,2 & 0,2 \\
\hline Programadoras de televisão por assinatura (2) & 20 & 874203 & 5,2 & 6,3 & 16 & 1114098 & 5,9 & 7,2 \\
\hline Serviços de programaçāo & 14 & 674034 & 4,0 & 4,9 & 12 & 809013 & 4,3 & 5,2 \\
\hline Veiculação de publicidade e merchandising & 14 & 200169 & 1,2 & 1,4 & 11 & (x) & (x) & (x) \\
\hline $\begin{array}{l}\text { Atividades de negociação de programaçăo contratadas pelas } \\
\text { operadoras - vide instruçōes (3) }\end{array}$ & - & - & - & - & 1 & $(\mathrm{x})$ & $(\mathrm{x})$ & $(\mathrm{x})$ \\
\hline Televisão aberta (programaçäo e broadcasting ) (2) & 233 & 8959400 & 53,2 & 64,9 & 233 & 9834888 & 52,3 & 63,3 \\
\hline $\begin{array}{l}\text { Serviços de televisăo aberta (produçăo, programação, veicula- } \\
\text { ção de publicidade e merchandising) }\end{array}$ & 229 & 8001218 & 47,5 & 57,9 & 230 & 8964760 & 47,6 & 57,7 \\
\hline Cessão de direitos de imagem para afiliadas & 15 & 116512 & 0,7 & 0,8 & 10 & 119998 & 0,6 & 0,8 \\
\hline Locação de espaço (horários) de televisão para terceiros & 29 & 59815 & 0,4 & 0,4 & 33 & 50667 & 0,3 & 0,3 \\
\hline Outros serviços de televisāo aberta & 9 & 781860 & 4,6 & 5,7 & 8 & 699464 & 3,7 & 4,5 \\
\hline Serviços de rádio (programação e broadcasting) (2) & 487 & 1084483 & 6,4 & 100,0 & 516 & 1197268 & 6,4 & 100,0 \\
\hline $\begin{array}{l}\text { Serviços de Produção e programação de rádio (veiculação de } \\
\text { publicidade e merchandising) }\end{array}$ & 482 & 1052063 & 6,2 & 97,0 & 510 & 1168119 & 6,2 & 97,6 \\
\hline Locaçäo de espaço (horários) derádio para terceiros & 83 & 21173 & 0,1 & 2,0 & 81 & 25563 & 0,1 & 2,1 \\
\hline Outros serviços de rádio & 16 & 11247 & 0,1 & 1,0 & 11 & 3581 & 0,0 & 0,3 \\
\hline Serviços de produção de filmes e vídeos (2) & 93 & 615172 & 3,7 & 100,0 & 93 & 701145 & 3,7 & 100,0 \\
\hline Produçăo de filmes cinematográficos (4) & 22 & 42948 & 0,3 & 7,0 & 19 & 78472 & 0,4 & 11,2 \\
\hline Produçāo de filmes/videos institucionais & 21 & 52255 & 0,3 & 8,5 & 19 & 63977 & 0,3 & 9,1 \\
\hline Produção de filmes/videos comerciais e publicitários & 55 & 392190 & 2,3 & 63,8 & 53 & 392148 & 2,1 & 55,9 \\
\hline Produção de filmes e programas para televisão & 13 & 22167 & 0,1 & 3,6 & 18 & 31957 & 0,2 & 4,6 \\
\hline Serviços de finalizaçăo da produçāo de filmes e videos (5) & 27 & 105611 & 0,6 & 17,2 & 27 & 134591 & 0,7 & 19,2 \\
\hline Comercialização e distribuição de filmes (2) & 17 & 391819 & 2,3 & 100,0 & 14 & 323059 & 1,7 & 100,0 \\
\hline Filmes cinematogrảficos nacionais & 11 & 48467 & 0,3 & 12,4 & 8 & 32762 & 0,2 & 10,1 \\
\hline Filmes cinematográficos estrangeiros & 15 & 343352 & 2,0 & 87,6 & 13 & 290298 & 1,5 & 89,9 \\
\hline Comercialização e distribuição de videos (2) & 9 & 110680 & 0,7 & 100,0 & 10 & 111383 & 0,6 & 100,0 \\
\hline Para locadoras de vídeo e DVD e lojas comerciais & 7 & 58895 & 0,3 & 53,2 & 6 & 50588 & 0,3 & 45,4 \\
\hline Para televisäo aberta & 3 & 24754 & 0,1 & 22,4 & 5 & 29647 & 0,2 & 26,6 \\
\hline Para televisão por assinatura & 3 & 27031 & 0,2 & 24,4 & 4 & 31146 & 0,2 & 28,0 \\
\hline Exibição de filmes e vídeos (2) & 92 & 665002 & 3,9 & 100,0 & 82 & 673871 & 3,6 & 100,0 \\
\hline No circuito exibidor (cinemas) & 88 & 613795 & 3,6 & 92,3 & 81 & 620563 & 3,3 & 92,1 \\
\hline Veiculaçăo de publicidade e merchandising em telas de cinema & 20 & 42901 & 0,3 & 6,5 & 25 & $(\mathrm{x})$ & (x) & $(\mathrm{x})$ \\
\hline Exibição ocasional de filmes e vídeos & 5 & 8309 & 0,0 & 1,2 & 1 & (x) & $(x)$ & $(x)$ \\
\hline Exploração de bombonieres, lanchonetes e cafeterias & 40 & 81735 & 0,5 & 100,0 & 37 & $(\mathbf{x})$ & $(\mathbf{x})$ & (x) \\
\hline Aluguel de estúdios de filmagem & - & - & - & - & 1 & (x) & $(\mathbf{x})$ & (x) \\
\hline Outros serviços prestados por empresas de áudio e vídeo & 26 & 80573 & 0,5 & 100,0 & 32 & 176166 & 0,9 & 100,0 \\
\hline
\end{tabular}

Fonte: IBGE, Diretoria de Pesquisas, Coordenação de Serviços e Comércio, Suplemento Serviços Audiovisuais da Pesquisa Anual de Serviços $2005-2006$. Nota: Empresas com 20 ou mais pessoas ocupadas săo as que compöem o estrato certo da Pesquisa Anual de Serviços. A definiçăo do estrato certo certo consta nas Notas Técnicas desta publicaçāo.

(1) Refere-se ao número de empresas que informaram cada produto, O número de informantes é maior ou igual ao número de empresas, uma vez que a empresa pode ser contada para cada produto informado. (2) Refere-se ao número de empresas pesquisadas na atividade. (3) Produtos e serviços nāo investigados em 2005. (4) Filmes de curta e longa metragens e documentários. (5) Revelaçāo, ediçāo, finalização sonora $\theta$ de imagem, dublagem e telecinagem.

Figura 2 - Receita operacional de serviços audiovisuais (PAS, 2006)

Ainda nesse contexto, cumpre frisar que as atividades de rádio e de televisão representaram, no ano de 2006, 89,9\% do valor de produção dos Serviços Audiovisuais, ou, aproximadamente, R\$ 16,919 bilhões. (FGV; ABERT, 2007, p. 20).

No que diz respeito aos serviços de televisão aberta (produção, programação, veiculação de publicidade e merchandising), estes alcançaram 47,6\% dos Serviços Audiovisuais em 2006, totalizando R \$ 8, 965 bilhões de receita, situando-os no $5^{\circ}$ lugar no 
ranking dos principais produtos/serviços das atividades de informação no Brasil. (PAS, 2006 - Figura 3).

\begin{tabular}{|c|c|c|c|c|}
\hline $\begin{array}{l}\text { Ranking } \\
2005\end{array}$ & $\begin{array}{l}\text { Ranking } \\
2006\end{array}$ & Produtos/serviços & $\begin{array}{c}\text { Receita } \\
\text { (1 } 000000 \mathrm{R} \$)\end{array}$ & $\begin{array}{l}\text { Percentual } \\
\quad(\%)\end{array}$ \\
\hline & & Total & 137311 & 100,0 \\
\hline 1 & 1 & $\begin{array}{l}\text { Serviços fixo-fixo de telecomunicaçöes por fio: chamadas } \\
\text { locais, interurbanas, internacionais e geradas em telefo- } \\
\text { nes públicos }\end{array}$ & 13652 & 9,9 \\
\hline 2 & 2 & $\begin{array}{l}\text { Serviços complementares de telecomunicaçöes por fio } \\
\text { (assinaturas, mudanças de titularidade, etc.) }\end{array}$ & 10965 & 8,0 \\
\hline 3 & 3 & Serviços de interconexão de telefonia móvel celular & 10520 & 7,7 \\
\hline 4 & 4 & $\begin{array}{l}\text { Chamadas locais, interurbanas e internacionais de servi- } \\
\text { ços móvel celular }\end{array}$ & 10350 & 7,5 \\
\hline 6 & 5 & Serviços de televisão aberta (programação e broadcasting) & 8965 & 6,5 \\
\hline 5 & 6 & Serviços fixo-móvel de telecomunicaçōes por fio & 8066 & 5,9 \\
\hline 8 & 7 & $\begin{array}{l}\text { Desenvolvimento de software sob encomenda ou especi- } \\
\text { fico para o cliente }\end{array}$ & 5349 & 3,9 \\
\hline 7 & 8 & Venda de telefones celulares & 5154 & 3,8 \\
\hline 9 & 9 & Serviços de telefonia celular pré-pago & 4443 & 3,2 \\
\hline 12 & 10 & $\begin{array}{l}\text { Serviços de consultoria em tecnologia da informação: espe- } \\
\text { cificaçăo de hardware e/ou software a partir das necessi- } \\
\text { dades dos clientes (soluçöes empresariais) }\end{array}$ & 4008 & 2,9 \\
\hline 11 & 11 & $\begin{array}{l}\text { Pacotes básicos e especiais de operadoras de televisāo por } \\
\text { assinatura }\end{array}$ & 3852 & 2,8 \\
\hline 10 & 12 & Serviços de processamento de dados para terceiros & 3700 & 2,7 \\
\hline 13 & 13 & Serviços complementares de telefonia móvel celular & 3201 & 2,3 \\
\hline 14 & 14 & $\begin{array}{l}\text { Outsourcing (locaçăo de mäo-de-obra de informática na } \\
\text { empresa do cliente) }\end{array}$ & 2635 & 1,9 \\
\hline 16 & 15 & $\begin{array}{l}\text { Revenda de softwares de prateleira, computadores, peças } \\
\text { e suprimentos de informática, năo produzidos pela em- } \\
\text { presa }\end{array}$ & 2563 & 1,9 \\
\hline 20 & 16 & $\begin{array}{l}\text { Fornecimento de conexāo para acesso à Internet em banda } \\
\text { larga (conexăo entre usuários e provedores de Internet) }\end{array}$ & 2527 & 1,8 \\
\hline 18 & 17 & $\begin{array}{l}\text { Serviços de telecomunicaçóos por fio: serviços de comuni- } \\
\text { cação multimídia }\end{array}$ & 2444 & 1,8 \\
\hline 17 & 18 & $\begin{array}{l}\text { Software prontos para uso: representaçäo e licenciamento } \\
\text { de softwares customizáveis }\end{array}$ & 2318 & 1,7 \\
\hline 15 & 19 & Serviços de interconexão de telecomunicaçōes por fio & 2017 & 1,5 \\
\hline 19 & 20 & $\begin{array}{l}\text { Serviços de manutenção e reparação de equipamentos } \\
\text { de computadores e equipamentos periféricos - inclusive } \\
\text { upgrades }\end{array}$ & 1392 & 1,0 \\
\hline & 21 & Outros serviços & 29190 & 21,3 \\
\hline
\end{tabular}

Fonte: IBGE, Diretoria de Pesquisas, Coordenaçāo de Serviços e Comércio, Suplementos Serviços de Informática, Serviços de Telecomunicaçōes e Serviços Audiovisuais da Pesquisa Anual de Serviços 2006.

Figura 3 - Principais produtos/serviços das atividades de informação - Brasil 2006

Frente a esse panorama dos meios de comunicação e de suas implicações econômicas não restrito à realidade brasileira e norte-americana, mas global, o "Relatório do Desenvolvimento Humano 2002: Aprofundar a democracia num mundo fragmentado", do 
Programa das Nações Unidas para o Desenvolvimento - PNUD, conclui que "as pressões comerciais e políticas ainda distorcem o mercado de ideias". De acordo com o seu atual levantamento internacional:

A liberalização, a privatização e a nova tecnologia tiraram os meios de comunicação das mãos do governo e puseram-nos em mãos privadas. A maioria dos meios de comunicação que se publicam no mundo é propriedade privada, embora o sector público ainda detenha $60 \%$ das estações de televisão de todo o mundo (...). Porém, a propriedade privada dos meios de comunicação está altamente concentrada, muitas vezes por famílias. No Reino Unido, quatro grupos são proprietários de $85 \%$ da imprensa diária (representando dois terços da circulação total). Nos Estados Unidos, seis empresas controlam a maioria dos meios de comunicação: AOL Time Warner, General Electric, Viacom, Disney, Bertelsmann e News Corporation. Na Austrália, o império de comunicação de Rupert Murdoch controla $60 \%$ da circulação de jornais diários. Nalguns países, famílias de políticos influentes são grandes proprietárias de meios de comunicação; o caso mais conhecido é o de Silvio Berlusconi e sua família, em Itália. A Televisa do México e a Globo do Brasil são dois dos maiores monopólios de comunicação do mundo, controlados por indivíduos e suas famílias, abrangendo todos os aspectos da produção e distribuição de televisão, rádio, filme, vídeo e grande parte das indústrias publicitárias dos respectivos países. $\mathrm{Na}$ Venezuela, duas grandes empresas familiares dominam o mercado: o Grupo Phelps e o Grupo Cisneros. (PNUD, 2002, p. 78).

O referido relatório internacional alerta para a concentração dos meios de comunicação em termos mundiais e seus riscos ao funcionamento das instituições democráticas, destacando a necessidade premente de reforma de tais meios sob o ideário de se "construir meios de comunicação diferentes e pluralistas, que sejam livres e independentes, que atinjam grande acesso e difusão, que apresentem informação precisa e não tendenciosa", na falta dos quais "os cidadãos e decisores [sic] ficam sem poder, carecendo dos instrumentos básicos para a participação e a representação informada" (PNUD, 2002, p. 77). ${ }^{184}$

Outro traço determinante do funcionamento desse primordial "filtro de notícias", consiste não apenas na demonstrada tendência oligopolista, mas, sobretudo, na exacerbação

\footnotetext{
${ }^{184}$ A partir do ideal que perpassa o descrito relatório do PNUD de 2002 e que, consequentemente, direciona suas propostas de reforma dos meios de comunicação, os "meios de comunicação livres" almejados devem desempenhar "três papéis cruciais na promoção da governação [sic] democrática: • Como um fórum cívico, dando voz a diferentes partes da sociedade e permitindo o debate de todos os pontos de vista; $\bullet$ Como agente mobilizador, facilitando o envolvimento cívico entre todos os sectores da sociedade e reforçando os canais de participação pública; •Como vigilantes, controlando abusos do poder, aumentando a transparência do governo e tornando os funcionários públicos responsáveis pelos seus actos no tribunal da opinião pública." (PNUD, 2002, P. 75).
} 
de seu caráter empresarial dado o estreitamento de suas relações com outros setores econômicos, na conceituada forma de concentração econômica em conglomerados, constituindo-se, tais empresas midiáticas, em grandes corporações que visam ao lucro.

A partir de seu extenso relatório sobre esse emergente mercado midiático e suas ramificações nos EUA ao final do século XX, sintetizam Herman e Chomsky (2003, p. 66):

Muitas das grandes empresas de mídia estão totalmente integradas ao mercado e, assim como para as outras, as pressões de acionistas, diretores e banqueiros para se focarem em lucro são fortíssimas. Essas pressões intensificaram-se nos últimos anos à medida que as ações das empresas de mídia se tornaram favoritas do mercado e os atuais ou potenciais donos de jornais e redes de televisão descobriram ser possível capitalizar maiores audiências e receitas de propaganda em valores multiplicados das franquias de mídia - e grandes fortunas. Isso incentivou a entrada de especuladores e aumentou a pressão e a tentação de o foco ser mais voltado à lucratividade. As famílias proprietárias de empresas de mídia têm ficado cada vez mais divididas entre as que querem aproveitar as novas oportunidades e aquelas que preferem manter o controle familiar, e suas divergências frequentemente precipitaram crises que levaram, por fim, à venda dos interesses da família no negócio.

No Brasil, segundo o levantamento mais recente de Antonio Biondi e Cristina Charão (2008, p. 07-08), "pelo menos seis dos oito grandes conglomerados de mídia do Brasil mantêm-se, também, entre os maiores grupos empresariais do país, por receita". ${ }^{185}$

\footnotetext{
${ }^{185}$ Baseados nos dados fornecidos por essas próprias organizações através de seus relatórios financeiros, os citados jornalistas reforçam o caráter empresarial da mídia brasileira e o estreitamento de suas relações com outros setores econômicos, nos mesmos moldes descritos pelo Modelo de Propaganda norte-americano, a partir do seguinte e preciso excerto: "A receita bruta da Globo Comunicação e Participações (Globopar), holding que controla a maior parte dos negócios das Organizações Globo (incluindo a TV, jornais, rádio e portais da internet) e tem participação em outros negócios (notadamente a TV por assinatura), somou R $\$ 6,8$ bilhões em 2006. Este valor colocaria o grupo na $36^{\mathrm{a}}$ posição do ranking dos maiores grupos empresariais do país. Já sobre o Grupo Folha, dono do jornal Folha de S. Paulo e do portal e provedor UOL, as informações são mais difusas. Quando anunciou, no início de 2005, a fusão de todas as suas operações em uma só empresa, a Folha-UOL S.A., a família Frias, dona do grupo, afirmava que estava consolidando o "segundo maior grupo de mídia do país”, com faturamento de R\$ 1,3 bilhão. Em 2006 o UOL faturou, sozinho, R\$ 634 milhões. Record e Bandeirantes acabam por não ser citados nos anuários dos "grandes" do empresariado. Porém, vale destacar que a própria Record admite ter alcançado um faturamento de R\$ 1 bilhão em 2006, estimando um acréscimo de $36 \%$ em 2007. A Bandeirantes teria obtido, em 2006, algo próximo de R\$250 milhões. Ser tão grande pode ser um problema. E até dois anos atrás, realmente foi. Neste período, praticamente todos os grandes grupos passaram por reestruturações forçadas pelo endividamento excessivo. Dívidas que vieram ora de aventuras no ramo da telefonia, como nos casos do Grupo Estado e da RBS; ora da confiança exagerada no crescimento dos mercados de TV por assinatura e Internet banda larga, casos da Globo e da Abril. E valores que se viram multiplicados quando a política cambial do governo FHC ruiu, desvalorizando o real frente ao dólar. Os conglomerados midiáticos encontraram saídas e os resultados que colhem são significativos. Em 2005 as Organizações Globo obtiveram um lucro liquido de R\$ 1,99 bilhão um dos 20 maiores da economia nacional nesse ano, não por acaso o mesmo em que o grupo apresentou a maior margem de lucro liquido dentre todas as empresas brasileiras: 92\%, segundo o anuário "Valor 1000", do jornal Valor Econômico, edição 2006. Em 2006, o lucro bruto da Globopar foi de R\$ 2,8bilhões." (BIONDI; CHARÃO, 2008, p. 07-08).
} 
Por fim, ainda sob esse primeiro programa sistêmico, ou "filtro de notícias", o Modelo de Propaganda destaca o papel determinante do relacionamento estrutural das empresas de mídia com o próprio governo e não apenas com outras empresas. Nas palavras de seus formuladores:

Todas as empresas e redes de rádio e televisão precisam de licenças e franquias do governo e, consequentemente, ficam sujeitas a serem controladas ou a sofrerem restrições por parte do governo. Essa dependência técnica e legal tem sido utilizada como um elemento disciplinador da mídia, e as políticas da mídia que se afastam com muita frequência de uma orientação oficial podem ativar essa ameaça. Para que isso não ocorra, a mídia protege-se por meio de lobbies e de outros expedientes políticos, cultivando relacionamentos e cuidando de suas políticas. (HERMAN; CHOMSKY, 2003, p. 72).

Nesse aspecto, como as demais empresas, a grande mídia guardaria interesses políticos gerais como em matéria de tributação; taxas de juros; direitos trabalhistas; relações diplomáticas com países cujos mercados são objeto de sua expansão empresarial; não aplicação de leis antitruste e regulação mínima das telecomunicações de um modo geral, bem como na obstrução de políticas públicas de aferição e promoção de sua real liberdade de expressão e através de limitações à sua autonomia privada em benefício da proteção de outros direitos fundamentais em conflito.

Aplicado à realidade brasileira, o aspecto político desse primeiro filtro/programa é ainda mais acentuado.

De início, é possível destacar que até o ínicio de 2008, no Brasil, 271 políticos apresentavam-se como sócios ou diretores de 324 veículos de mídia, sendo estes dados obtidos através do mapeamento da relação de prefeitos, governadores, deputados e senadores de todo o país com a propriedade dos veículos de comunicação então existentes, registrada Agência Nacional de Telecomunicações. ${ }^{186}$

Essa "relação política", no sentido usual da palavra, traduz-se, por suas extensões e peculiaridades, em linguagem sistêmica numa forma de acoplamento estrutural entre os sistemas dos meios de comunicação de massa e o sistema político.

\footnotetext{
186 Tais informações foram extraídas do estudo da Epcom (2002), atualizado em seu sítio eletrônico. Ademais, como parte de seu "Projeto Os Donos da Mídia", o referido Instituto disponibiliza em seu sítio eletrônico - <http://donosdamidia.com.br/levantamento/politicos/> - estatísticas detalhadas por Estado, partido, cargos e veículo midiáticos, bem como a citada relação entre comunicação e políticos, cujos gráficos e informações não são aqui reproduzidas por sua dispersão frente aos objetivos centrais do presente trabalho.
} 
Tal característica apontada pelo Modelo de Propaganda, no caso brasileiro é intensificada não apenas pelo descrito mapeamento, mas, sobretudo, em função das peculiaridades do desenvolvimento desses sistemas sociais no país. ${ }^{187}$

O estreitamento das relações entre a política e os emergentes meios de comunicação de massa no Brasil teria se desenvolvido, segundo Venício A. de Lima (2008), em função do modelo de outorga da exploração dos serviços públicos e rádio e televisão em benefício das empresas privadas, iniciado na década de 1930, pelo governo federal brasileiro.

Tal processo teria levado não apenas à progressiva concentração da propriedade desses meios, discutida cima, como também à formação de um novo coronelismo político, intitulado de “coronelismo eletrônico”, sobretudo a partir do regime militar.

Sob essa perspectiva, em linhas gerais, o "coronelismo eletrônico" poderia ser sintetizado como "fenômeno do Brasil urbano da segunda metade do século XX", no qual "as emissoras de rádio e televisão, mantidas em boa parte pela publicidade oficial e articuladas com as redes nacionais dominantes, dão origem a um tipo de poder agora não mais coercitivo, mas criador de consensos políticos". Tais consensos facilitariam, sem, contudo, garantir, tanto a eleição quanto a reeleição de representantes políticos nas diferentes instâncias e Poderes da Federação. (LIMA, 2008, p. 27).

Como defende o referido pesquisador do Núcleo de Estudos sobre Mídia e Política - NEMP da Universidade de Brasília - UnB:

Ao controlar as concessões, o novo coronel promove a si mesmo e aos seus aliados, hostiliza e cerceia a expressão dos adversários políticos e é fator importante na construção da opinião pública, cujo apoio é disputado tanto no plano estadual como no federal. No coronelismo eletrônico, portanto, a moeda de troca continua sendo o voto, como no velho coronelismo. Só que não mais com base na posse da terra, mas no controle da informação, vale dizer, na capacidade de influir na formação da opinião pública. A recompensa da União aos coronéis eletrônicos é de

\footnotetext{
${ }^{187} \mathrm{O}$ acoplamento estrutural entre a política e a mídia se reflete não apenas neste primeiro filtro/programa através do controle político da concessão da exploração dos serviços de comunicação, como também nos demais "filtros de notícias" desse modelo como se pretende demonstrar a seguir. Apenas de maneira introdutória, justifica-se tal assertiva levando em conta, por si só: o peso da propaganda das empresas públicas e da própria administração direta na receita das organizações midiática; a dependência de tais organizações das informações "oficiais" do governo reforça; bem como, considerando-se as reações negativas do sistema político, na tentativa de disciplinar o sistema dos meios de comunicação, através de ameaças veladas de cortes daquela propaganda e da propositura de projetos legais e políticas de maior controle supostamente sobre a "qualidade" de sua programação, vistas como atentatórias de sua sacralizada "liberdade de expressão".
} 
certa forma antecipada pela outorga e, depois, pela renovação das concessões do serviço de radiodifusão, que confere a eles poder na disputa dos recursos para os serviços públicos municipais, estaduais e federais. Por tudo isso, a continuidade da prática depende não só da existência de "brechas" legais que possibilitem o uso das concessões, mas também da exploração delas por políticos no exercício de mandato eletivo. Trata-se, portanto, de uma prática política de face dupla. (LIMA, 2008, p. 28).

Juridicamente, a Constituição Federal de 1988, em seu artigo 175, impõe à União, enquanto poder concedente de serviços públicos, a realização de procedimento licitatório para esse fim. A regulamentação infraconstitucional desse preceito foi realizada no que diz respeito aos serviços públicos de radiodifusão pelo Decreto n. 1.720 , de 28 de novembro de 1995. Impõe, dessa forma, em regra geral, que as outorgas de radiodifusão sejam “precedidas de processo seletivo, por meio de edital”. (BRASIL, 1988;1995).

No mais, os atos de outorga e renovação de concessões de radiodifusão, além do referido procedimento licitatório, devem ainda se submeter à apreciação do Congresso Nacional, nos termos do artigo $223, \S 1^{\circ}$ do citado texto constitucional. ${ }^{188}$

Embora o poder de concessão dos serviços de comunicação tenha, assim, passado a ser compartilhado entre os Poderes Executivo e Legislativo em nível federal, tal não teria sido capaz de extinguir a utilização das concessões de radiodifusão de caráter não apenas comercial, como também educativa e comunitária, como "moeda de barganha política".

Tais desvios seriam explicados, sobretudo, em função de "brechas legais" ainda existentes, denunciadas por Lima (2008, p. 29-31), as quais se relacionam, grosso

\footnotetext{
${ }^{188}$ Para esse fim, fora criado o Conselho de Comunicação Social - CCS, como órgão auxiliar do Senado Federal, nos termos previstos no art. 224 da Constituição Federal de 1988 e de sua regulamentação pela Lei $8.389 / 1991$. No entanto, tal órgão foi definitivamente instalado tão somente em maio de 2002 . O referido conselho tem formalmente por objetivo funcionar como fórum público com a participação da "sociedade civil" e dos representantes das organizações do setor voltado à discussão e elaboração de estudos e propostas normativas acerca da regulamentação do setor e dos demais assuntos relacionados à comunicação, como liberdade de expressão, outorga e renovação de concessões, programação da televisão e propaganda de cigarros e bebidas etc. Nos últimos anos, que tal fórum teria sido marcado por disputa entre as "lógicas de espaço público e de mercado" (BRITTOS, NAZÁRIO; SIMÕES, 2006) levando ao seu "esvaziamento" desde 2006 (COSTA, 2010). Interessante análise do referido conselho, de suas características e de sua dinâmica de funcionamento até 2006 foi realizada por Valério Cruz Brittos, Paola Madeira Nazário e Denis Gerson Simões (2006).
} 
modo, à dispensa de licitação para a concessão de radiodifusão formalmente "educativa" e à permissão para as retransmissoras mistas se transformarem em geradoras "educativas". ${ }^{189}$

Cabe ainda ressaltar que o descrito Código Brasileiro de Telecomunicações, em seu art. 38, parágrafo único, determina que as pessoas em gozo de imunidade parlamentar estão impedidas de exercer a função de diretor ou gerente de empresa concessionária de rádio ou televisão.

Tal restrição é reiterada pelo Regulamento dos Serviços de Radiodifusão, n. 2, alínea “d”, $\S 5^{\circ}$ do artigo 15 do Decreto $n^{\circ} 52.795$, de 31 de outubro de 1963, o qual impõe a declaração de que os dirigentes das entidades concorrentes "não estão no exercício de mandato eletivo", como um dos documentos necessários para habilitação ao procedimento licitatório. (BRASIL, 1963).

Tal restrição foi reafirmada em nível constitucional em 1988, sendo assim juridicamente recepcionada no atual sistema jurídico nacional, tendo em vista ser proibido aos deputados e senadores, desde a expedição do diploma, a manutenção de contrato ou exercício de cargo, função ou emprego remunerado em empresas concessionárias de serviço público, conforme as alíneas "a" e "b" do inciso I do art. 54 da Carta Magna.

No entanto, tais restrições normativas são diuturnamente violadas, como confirmam os dados acima citados acerca da inconstitucional vinculação direta de 271 representantes políticos a veículos de comunicação (EPCOM, 2002). Nesse aspecto, Lima $(2006,2008)$ destaca ainda o conflito de interesses não declarado por tais representantes populares quando da votação dessas questões no Congresso Nacional:

Mesmo assim, há registros da utilização de emissoras de rádio e televisão por políticos "no exercício de mandato eletivo" em seu benefício pessoal

\footnotetext{
189 Tais "brechas", segundo o minucioso levantamento normativo de Venício A. De Lima (2008, p. 29-33) decorrem, de um lado, do fato de o $\S 2^{\circ}$ do artigo 14 do Decreto-lei n. 236/1967 estabelecer que o artigo 34 do Código Brasileiro de Telecomunicações não se aplicar às TVs educativas, sendo essa "exceção" reafirmada para as TVs educativas pelo $\S 2^{\circ}$ do inciso XV do artigo 13, do Decreto n. 1720/1995. Por outro lado, esses desvios seriam viabilizados também pela criação das Retransmissoras de TV - RTV em Caráter Misto através da Portaria Interministerial $\mathrm{n}^{\circ}$ 236, elaborada pelo, então, Ministério da Infra-Estrutura , uma vez que o Ministério das Comunicações havia então sido extinto e suas atribuições absorvidas pelo Minfra. Segundo essa norma infralegal, tais serviços de RTV podiam ser explorados sem licitação por entidades com fins "exclusivamente educativos" abrindo a possibilidade de tais retransmissoras inserirem programação própria, de acordo com percentuais estabelecidos pela mesma Portaria. Contudo, como expõe Lima (2008, p. 31), acerca da definição realizada pelo governo, "as geradoras educativas nunca seguiram sua orientação. Uma prova disso é que, até hoje, existem inúmeras concessões de radiodifusão educativa controladas por diferentes igrejas — lideradas inclusive por políticos — que fazem proselitismo religioso permanente."
} 
e interesse privado, pelo menos desde o início da década de 80 do século passado. Além disso, pesquisas mais recentes revelam que deputados federais concessionários de radiodifusão chegam até mesmo a votar a favor da renovação das suas próprias concessões na Câmara dos Deputados. (LIMA, 2008, P. 28).

Em que pese sua manifesta inconstitucionalidade, tais questões são aqui apresentadas no sentido descritivo dos atuais acomplamentos estruturais entre a política e a mídia e, por conseguinte, da atualidade do Modelo de Proganda de Herman e Chomsky (2003), para a compreensão do funcionamento do sistema dos meios de comunicação no Brasil.

Sendo assim, foge aos objetivos do presente capítulo empreender a exaustiva discussão jurídica de tais violações normativas, por não tratar, ademais, esta tese fundalmentamente da regulação jurídica em si dos meios de comunicação de massa, mas sim do resultado funcional dessa forma de organização sistêmica e suas tensões com o sistema jurídico em matéria específica de direitos sociais de Seguridade Social. ${ }^{190}$

Feitas essas considerações acerca do primeiro filtro/programa dos meios de comunicação de massa, resta, por fim, abordar os aspectos principais dos demais filtros e de seu funcionamento sistemicamente integrado, na linha defendida de seleção parcial dos sentidos de seu código informação/não informação generalizadas socialmente em conflito com as expectativas normativas em matéria de direitos sociais de Seguridade Social, objeto deste trabalho.

\subsubsection{O $2^{\circ}$ programa ou "filtro de notícias": a propaganda como principal fonte de recursos da mídia de massa}

Ao situar a propaganda como filtro de notícias, Herman e Chomsky (2003, p. 73) destacam não apenas como esta forma de financiamento das organizações dos meios de comunicação de massa propiciou seu desenvolvimento e concentração, como também

\footnotetext{
${ }^{190}$ Não se ignora, portanto, a inconstitucionalidade dessa forma de organização das empresas midiáticas. Da mesma forma, o descrito corte metodológico não implica em renúncia ao caráter imperativo do Direito nem à sua força normativa constitucional. Isto porque, segundo os pressupostos teóricos adotados, a constatação de tais violações não afasta a função sistêmica precípua do Direito de generalizar expectativas normativas. Como fora exposto inicialmente, diferentemente das expectativas cognitivas, enquanto normas jurídicas, as expectativas generalizadas pelo Direito se mantêm contrafactual. A crítica jurídica a esta concentração dos meios de comunicação e a defesa dos meios jurídicos em favor da "promoção do pluralismo, direito de concorrência e regulação" dos meios de comunicação de massa no Brasil fora, por sua vez, o objeto central da tese de doutoramento de André de Godoy Fernandes (2009).
} 
"serviu como poderoso mecanismo para enfraquecer a imprensa da classe trabalhdora" já no início do século XIX.

Isto porque, levando em conta inicialmente os veículo de comunicação sob a forma impressa, se antes do desenvolvimento da propaganda o preço de um jornal, por exemplo, deveria cobrir os custos de sua produção, posteriormente, permitiu-se progressivamente sua oferta a preços abaixo desses custos à medida que o mesmo passou a atrair cada vez mais anunciantes.

Por sua vez, associadas à propanganda, as grandes organizações dos meios de comunicação de massa tendem a eliminar ou marginalizar as empresas e os tipos de mídia que dependem unicamente das receitas de vendas de seu produtos. Daí porque, afirmam os citados pesquisadores:

Com a propaganda, o livre mercado não gera um sistema neutro em que a escolha do comprador final é o fator decisivo. As opções dos anunciantes influenciam a prosperidade e a sobrevivência da mídia. As mídias baseadas em anúncios recebem um subsídio da propaganda que lhes dá vantagens de preço, marketing e qualidade, que lhes permite abusar de seus rivais que não utilizam propaganda (ou que ficam em desvantagem) e enfraquecê-los ainda mais. (...). Uma vantagem da participação de mercado e da propaganda por parte de um jornal ou estação de televisão dará a ele receitas adicionais para competir de forma mais eficaz - fazer promoções mais agressivas, comprar mais matérias especiais e programas vendáveis -, e o rival em desvantagem precisa fazer mais despesas que não pode se permitir para tentar frear o processo cumulativo da redução de sua participação de mercado (e no faturamento). Esse processo é muitas vezes fatal, e ajuda a explicar a "morte" de muitos jornais e revistas de grande circulação, e o atrito entre vários jornais. (HERMAN; CHOMSKY, 2003, p. 73-74).

Demonstra-se, dessa forma, a estreita relação entre notícia e seus patrocinadores, na medida em que, como no exemplificado caso dos jornais, seus anúncios dependem não apenas de seu volume de circulação como também, e por vezes inversamente proporcional, do perfil socioeconômico de seu público. ${ }^{191}$

Assim, como fora já introduzido sobre esse segundo filtro/programa sistêmico, o público, e não apenas a notícia, passa a ser considerado como um produto, ou mercadoria

191 A esse respeito sintetizam Herman e Chomsky (2003, p. 75): "Em resumo, a mídia de massa está interessada em atrair uma audiência com poder de compra, e não a audiência por si só; é a audiência com alto poder aquisitivo que atrai o interesse do anunciante hoje, assim como no século XIX. A ideia de que a corrida por grandes públicos torna a mídia de massa 'democrática' sofre da fraqueza inicial de que seu análogo político é um sistema de votação ponderado pela renda!’”. 
propriamente dita, das empresas midiáticas, o qual é "ofertado" aos seus anunciantes, ou seja, a outras empresas e ao próprio governo, como no caso brasileiro em que este último se apresenta, individualmente, como seu maior patrocinador.

Nesse contexto, a programação de entretenimento, as notícias e as informações a serem selecionadas para sua composição são orientadas internamente levando em conta a atração desse público segundo o interesse dos anunciantes, buscando, assim, atingir a estratégia de mercado de suas organizações midiáticas.

Essa estreita relação entre anunciantes e o desenvolvimento e a sustentação das organizações midiáticas é também destada por Leandro Marshall (2003, p. 108):

No século $\mathrm{XX}$, as estatísticas dão conta de que as propagandas pagas avançam rapidamente sobre os veículos de comunicação e passam a ocupar de $60 \%$ a $65 \%$, em média, das páginas dos jornais e das revistas. (...). Em muitos países, como o Brasil e os Estados Unidos, foram a publicidade e a força dos anunciantes que viabilizaram a gênese e o desenvolvimento das indústrias do rádio e da televisão, criações do século XX. Nos Estados Unidos, assim como no Brasil, grandes empresas bancavam o patrocínio integral dos pioneiros programas exibidos nos veículos eletrônicos. Muitas vezes, as agências de publicidade contratadas pelos anunciantes se encarregavam de pensar e produzir os próprios programas, exibidos nas emissoras comerciais.

Compreendido sob esse modelo, o funcionamento sistêmico dos meios de comunicação de massa, no que diz respeito não apenas sobre seus temas de entretenimento com também de notícias e reportagens, estaria sujeito a uma programação interna estritamente ligada a seus acoplamentos econômicos e políticos e não a sua autoconclamada função social informativa da realidade e fiscalizadora dos poderes públicos. ${ }^{192}$

Essa programação decorreria, portanto, do funcionamento de suas organizações centrais enquanto grandes empresas financiadas pela propaganda. Por conseguinte, seu código informação/não-informação orientado para a atração desse público/produto, passa a ser influenciado em grande medida por expectativas e interesses das empresas e do próprio governo, ou seja, de seus anunciantes.

À sua maneira, Herman e Chomsky (2003) enfatizam esse mesmo modo de funcionamento sistêmico não apenas em relação aos veículos impressos de comunicação

192 Quanto à influência da publicidade na televisão brasileira, no mesmo sentido discorre Sérgio Mattos (2010, p. 74-84). 
como também à televisão, empregando, porém, o termo "programação" não no sentido sistêmico exposto, mas como produto midiático. Em suas palavras:

$\mathrm{O}$ poder dos anunciantes sobre a programação da televisão deriva do simples fato de que eles compram e pagam pelos programas - são os "patronos" que fornecem o subsídio da mídia. Como tal, a mídia compete por seu patrono, desenvolvendo equipes especializadas para seduzir anunciantes e tendo necessariamente que explicar como seus programas atendem às suas necessidades. As opções desses patrocinadores afetam diretamente o desempenho da mídia, e eles se tornaram o que William Evan [1976, p. 123] denomina "organizações normativas de referência", a cujas exigências e requisitos a mídia tem que se acomodar se quiser ter sucesso. (HERMAN, CHOMSKY, 2003, p. 75).

Sendo assim, seus programas sistêmicos não se voltam primeiramente para a defesa e bem-estar do público destinatário nem mesmo no que diz respeito às suas notícias e reportagens. De maneira oposta, para atrair o público esperado por seus anunciantes, as grandes empresas do setor norteiam sua seletividade e difusão informativa com notícias e entretenimento, sem, porém, contrariar os interesses econômicos e políticos de tais patrocinadores.

Em razão do descrito filtro/programa, observa-se, ainda, que as "mídias radical e da classe operária também sofrem com a discriminação política dos anunciantes”. Isto porque, segundo Herman e Chomsky (2003, p. 75), não apenas os investimentos em propaganda são direcionados segundo a capacidade de consumo do público, com também pelo fato de que "muitas empresas, no entanto, sempre se recusarão a patrocinar tanto inimigos ideológicos quanto aqueles que acreditam oferecerem perigo a seus interesses (...)”.

Assim, a partir dos casos norte-americanos detidamente analisados com base neste Modelo de Propaganda, os referidos autores concluem:

Além de discriminação contra instituições de mídia não amigáveis, os anunciantes também selecionam os programas com base em seus próprios princípios. Com raras exceções, esses programas são cultural e politicamente conservadores. Grandes empresas anunciantes da televisão raramente patrocinarão programas que contenham críticas sérias às atividades empresariais, tais como problema de degradação ambiental, as engrenagens do complexo industrial-militar, ou o apoio corporativo e os benefícios às tiranias do Terceiro Mundo. (...). Os anunciantes desejarão, de forma mais genérica, evitar programas com sérias complexidades e 
controvérsias perturbadoras que possam prejudicar o "espírito de compra”. (HERMAN; CHOMSKY, 2003, p. 76). ${ }^{193}$

Seria justamente nesse movimento que ocorreria a mercantilização da informação em si. No que diz respeito à notícia, a partir de sua reelaboração com técnicas editoriais que reforçam seus apelos estéticos emocionais e sensacionais, expondo-a em manchetes e por outras técnicas de diagramação de forma atraente ao público. (FERREIRA, 1995, p. 52-53). ${ }^{194}$

Ademais, considerando especialmente o meio televisivo e seu desenvolvimento histórico enquanto meios de comunicação de massa em âmbito nacional, segundo Leandro Marshall (2003, p. 109):

No Brasil, desde o seu início, a televisão se caracterizou como um veículo de publicidade. Fazem parte da história da indústria cultural brasileira programas como Gincana Kibon, Sabatina Maizena, Teatrinho Trol, Telenotícias Panair, Repórter Esso, Telejornal Bendiz, Reportagem Ducal ou Telejornal Pirelli, produções integralmente subsidiadas por empresas anunciantes e formatadas por agências de publicidade. Os patrocinadores determinavam os programas que deveriam ser produzidos e veiculados, além de, inclusive, contratar diretamente os artistas e produtores. (MARSHALL, 2003, p. 109) ${ }^{195}$

${ }^{193}$ Embora a redação possa levar a simplificações e uma visão totalitária desse funcionamento, segundo os próprios autores esta forma de proceder corresponde a uma tendência geral, frente a qual se reconhece e justifica certas exceções. Nesse sentido, advertem: "Há casos excepcionais de empresas que desejam patrocinar programas sérios, algumas vezes fruto de recentes embaraços que exigem uma compensação na área de relações públicas. Mas, mesmo nestes casos, as empresas geralmente não desejarão patrocinar um exame minucioso de questões sensíveis e desagregadoras - preferem programas sobre antiguidade grega, balé e itens sobre história ou cultura nacional e nostalgia.” (HERMAN; CHOMSKY, 2003, p. 77).

${ }^{194}$ De acordo com Jeremy Rifkin (2001, p. 144-148) o poder na sociedade contemporânea estaria, assim, se deslocando para instituições e pessoas capazes de influir não apenas nas regras e condições de admissão como fundamentalmente no controle do acesso à informação. Existiriam, segundo o referido autor, "porteiros" como os meios de comunicação e seu setor editorial que, sob essa perspectiva, seriam os mediadores e árbitros do processo social sendo a que as informações fluiriam para dentro e fora da sala de notícias segundo as decisões de editoriais a partir de uma estreita relação entre mídia e publicidade.

${ }^{195}$ Cumpre destacar, como ponto de convergência entre os dois filtros/programas sistêmicos discutidos até aqui, a conceituação de Dominique Wolton (1996) acerca da televisão como "meio de massa". Ainda que sob uma base epistemológica própria, o autor em questão destaca quatro conotações que a identificação da televisão como meio de massa implica: “A primeira justificativa do termo é técnica, ou seja, a televisão é um meio de massa ligado a um efeito multiplicador propiciado pela difusão (hertziana-cabo-satélite) e pela recepção por muitos milhões de telespectadores no mundo [...]. A segunda é jurídica. Em todos os países, a atividade da televisão é estritamente regulada para permitir que todo mundo receba sua imagem. [...]. A terceira é política. Em todos os países, os poderes públicos desejaram que a televisão, ainda mais que o rádio, fosse objeto de um projeto global. Isso ia além da ideologia de serviço público e englobava o meio em seu conjunto, associando, talvez, aos projetos de televisão, a ideia de uma coesão social e cultura a ser reconstruída, principalmente depois da guerra: o controle político da televisão e seu derivado, a televisão politizada, são apenas a caricatura de um projeto que tinha, no início, tanta ambição quanto a escola um século antes. A quarta razão que faz a televisão um meio de massa é de ordem econômica. Tanto em relação aos equipamentos, quanto aos programas, pareceu indispensável produzir em grande escala para tornar rentáveis os altos investimentos. Por esse ponto de vista, a televisão entra diretamente numa econômica de 
Nesse contexto, Sérgio Mattos (2010) chama a atenção para o "pioneirismo" da Rede Globo de televisão no aprimoramento da descrita estratégia mercadológica, apontada pelo Modelo de Propaganda em tela:

No final dos anos de 1960, a Globo já possuía larga audiência, pois havia direcionado sua programação para as camadas socioeconômicas mais baixas da população. (...) Em 1971, a Rede Globo deu outro passo pioneiro e decisivo para o seu sucesso, criando um departamento de pesquisa e análise, através do qual planejou a publicidade e adaptou programas para diferentes gostos, adequando cada um deles aos resultados das pesquisas socioculturais. (...). A Globo também importou novas estratégias de comercialização que foram de fundamental importância para seu sucesso. Ela evoluiu da comercialização 'à moda do rádio' para técnicas bem mais avançadas, criando patrocínios, vinhetas de passagem, breaks e outras inovações (...), que continuam sendo utilizadas até os dias de hoje. (MATTOS, 2010, p. 102-103).

Observa-se, assim, o funcionamento desse segundo filtro/programa também no sistema midiático brasileiro, o que é ainda reforçado levando em conta a dimensão econômica e perfil de seus anunciantes.

Dessa forma, segundo os dados fornecidos pelas próprias organizações midiáticas nacionais, divulgados pela Associação Nacional dos Editores de Revista - ANER (2010a), o faturamento bruto dos meios de comunicação como um todo teria atingido, até o mês de agosto de 2010, certa de $\mathrm{R} \$ 16,6$ bilhões. (Tabela 2).

Tabela 2 - Publicidade - Faturamento Bruto dos Meios Fonte: Associação Nacional dos Editores de Revista - ANER (2010a)

\begin{tabular}{lcccc}
\hline \multicolumn{1}{c}{ Meio } & $\begin{array}{c}\text { Faturamento } \\
\text { Jan a agosto 09 }\end{array}$ & $\begin{array}{c}\text { Faturamento Jan } \\
\text { a agosto 10 }\end{array}$ & $\begin{array}{c}\text { Crescimento / } \\
\text { Decréscimo }\end{array}$ & $\begin{array}{c}\text { \% de } \\
\text { participação }\end{array}$ \\
\hline Televisão & $8.061 .872 .131,85$ & $10.558 .209 .634,22$ & 30,96 & 63,43 \\
Jornal & $1.990 .769 .628,74$ & $2.122 .367 .101,58$ & 6,61 & 12,76 \\
Revista & $978.974 .393,25$ & $1.160 .873 .013,27$ & 18,58 & 6,98 \\
Internet & $550.685 .776,97$ & $719.513 .251,66$ & 30,66 & 4,33 \\
Rádio & $604.996 .382,78$ & $702.676 .169,51$ & 16,15 & 4,23 \\
Tv assinatura & $464.740 .751,41$ & $611.024 .670,73$ & 31,48 & 3,67 \\
Mídia exterior & $407.415 .339,15$ & $482.405 .452,06$ & 18,41 & 2,90 \\
Guias e Listas & $238.147 .904,52$ & $218.325 .408,81$ & $-8,32$ & 1,31 \\
Cinema & $48.951 .633,27$ & $54.100 .081,18$ & 10,52 & 0,33 \\
\multicolumn{1}{c}{ Total } & $13.346 .553 .941,94$ & $16.629 .494 .780,02$ & 24,60 & 100,00 \\
\hline
\end{tabular}

massa. Existem economias de escala a serem realizadas nos dois extremos (equipamento e programas), em que a rentabilidade, como em toda atividade de espetáculo a fortiori nessa escala, é indispensável" (WOLTON, 1996, p. 74-75). 
Tal como fora introduzido ao tratar do acoplamento estrutural entre os sistemas econômico, político e midiático, deve-se ainda destacar o papel determinante da dependência das empresas de mídia do próprio governo também quanto a este segundo filtro/programa de notícias em discussão.

Nesse sentido, o referido acoplamento entre política e mídia no Brasil se apresenta não apenas no controle político da concessão dos serviços de comunicação e de suas externalidades expressas no discutido coronelismo eletrônico.

Isto porque é necessária consideração de um dado adicional quanto à diferenciação histórica e à atual configuração desses sistemas no país no que diz respeito a essa forma de controle exercido pelos financiadores de suas organizações. O sistema político, através de suas organizações governamentais em nível tanto municipal e estadual e não apenas federal, apresenta-se individualmente como principal anunciante das empresas midiáticas nacionais.

Essa assertiva é demonstrada na análise econômica intitulada "Pesquisa sobre televisão no Brasil” realizada pela Fundação Getúlio Vargas - FGV para a Associação Brasileira de Emissoras de Rádio e Televisão - ABERT de 2008, a partir dos dados fornecidos por 148 emissoras, num unverso de 351 emissoras contadas com base no cadastro de informações do Ministério das Comunicações, da Agência Nacional de Telecomunicações - ANATEL e da própria ABERT. (Figuras 4 e 5)

A figura 4, extraída do citado levantamento FGV-ABERT (2008), esquematiza de modo claro a dimensão e centralidade da propaganda, sob diferentes formas de publicidade, no financiamento das emissoras de rádio e televisão no Brasil, a qual é responsável por aproximadamente $95 \%$ do total das receitas desse setor: 


\section{Composição das Receitas - Brasil \\ Total das Emissoras}

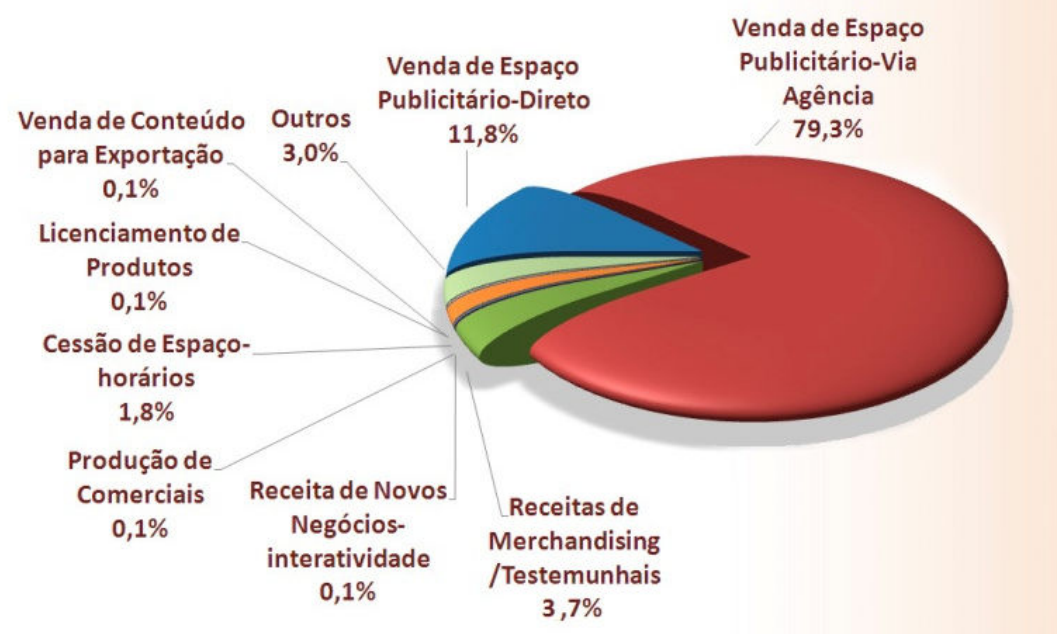

Figura 4 - Composição das Receitas no Brasil (FGV; ABERT 2008).

Por sua vez, o que fora exposto sobre o perfil dos anuciantes, sobretudo quanto ao papel da instituições governamentais, fica evidenciado na figura 5 acerca das origens de tais receitas, destacando-se que os governos federais $(4,6 \%)$, estaduais $(3,9 \%)$ e municipais $(5,1 \%)$ são os responsáveis por cerca de $13,6 \%$ desse financiamento.

\section{Origem das Receitas - Brasil \\ Total das Emissoras}

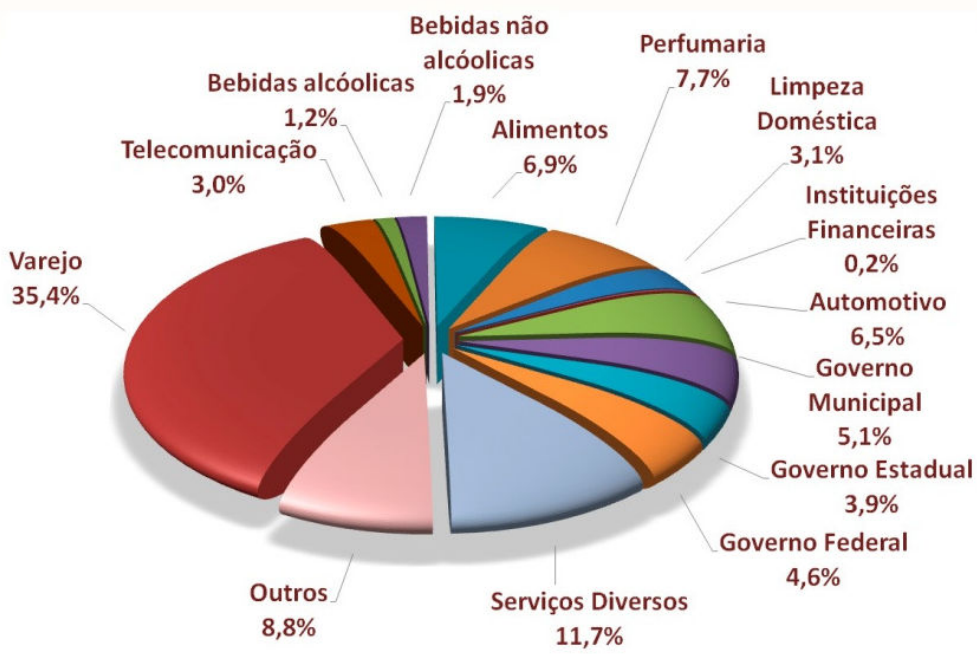

Figura 5 - Origem das Receitas (FGV; ABERT 2008). 
Nesse mesmo sentido, porém sobre a rubrica de "serviços públicos e sociais", são os dados acerca dos 10 maiores setores anunciantes em jornais, de acordo com o levantamento Ibope Monitor de 2008 publicado pela Associação Nacional dos Jornais ANJ. (Tabela 3).

Tabela 3-10 maiores setores econômicos anunciantes no Meio Jornal - 2008 Fonte: Ibope Monitor. Considerando tabela, sem descontos (ANJ; 2010)

\begin{tabular}{lcc}
\hline \multicolumn{1}{c}{ Setor econômico } & Investimento - R\$ & Investimento - US\$ \\
\hline Comercio Varejo & 5.706 .544 & 3.169 .041 \\
Mercado Imobiliário & 2.164 .132 & 1.227 .058 \\
Serviços ao Consumidor & 1.415 .031 & 783.012 \\
Cultura, Lazer, Esporte e Turismo & 1.235 .410 & 686.333 \\
Veículos, Peças e Acessórios & 1.019 .587 & 570.356 \\
Mídia & 838.097 & 462.940 \\
Mercado Financeiro e Seguros & 676.472 & 375.783 \\
Serviços Públicos e Sociais & 451.107 & 247.025 \\
Telecomunicações & 417.329 & 227.408 \\
Internet & 225.884 & 125.358 \\
$\quad$ Total de investimentos & $\mathbf{1 4 . 1 4 9 . 5 9 4}$ & $\mathbf{7 . 8 7 4 . 3 1 3}$ \\
\hline
\end{tabular}

Por sua vez, no que diz respeito aos anuncios em revistas, segundo a compilação do Ibope Monitor apresentada pela ANER (2010b), tem-se o seguinte ranking dos maiores anunciantes em jornais por número de páginas de anúncios veiculados em 2008 e 2009, de acordo com o levantamento Ibope Monitor. (Tabela 4). ${ }^{196}$

\footnotetext{
${ }^{196}$ Segundo explica a ANER (2010b): "Os dados do Ibope Monitor apontam os principais setores de revistas por páginas de publicidade no período de janeiro a dezembro de $09 \mathrm{x}$ janeiro a dezembro 08 . No período janeiro a dezembro/2009, o setor Comércio/Varejo manteve-se na $1^{\mathrm{a}}$. posição, com $16 \%$ de participação, Serviços ao Consumidor aparece na $2^{\mathrm{a}}$ posição com 10,5\% , Cultura Lazer Esporte e Turismo na $3^{\mathrm{a}}$ posição e participação de $10,2 \%$, na $4^{\text {a }}$ posição Higiene Pessoal e Beleza detém $8,2 \%$ de participação e na $5^{\text {a }}$ posição o setor Vestuário e Têxtil com 7,7\%. O total de inserções alcançou 98.021 páginas, registrando um decréscimo de 7,3\% em relação ao mesmo período do ano passado. Destaques positivos para os setores: Sorteios Loterias e Casas de Jogos - incremento de 123\% Petroleiro - incremento de 61,4\%. Apresentaram resultados negativos: Bens e Serviços Industriais : 41,83\% no número de páginas Eletroeletrônicos :42,18\% no número de páginas Os dados apresentados foram elaborados especialmente pelo Ibope para a ANER. O Estudo indica a quantidade equivalente à soma de espaços publicitários expresso em páginas. Critérios: A coleta de informação para a formatação do Estudo do Ibope obedece a uma série de padrões e critérios. Em Mídia Impressa não são considerados como investimento publicitário : encartes, publicidade legal, pequenos classificados, anúncios fúnebres, mídia interna e comerciais de partidos /candidatos políticos. Espaços cedidos gratuitamente são valorados nos mesmos critérios por serem considerados espaços ocupados. Os preços por inserção têm por base as tabelas vigentes de cada veículo, desconsiderando-se, portanto, os descontos negociados."
} 
Tabela 4 - Publicidade - páginas por setores econômicos. Modificado de ANER (2010b)

\begin{tabular}{|c|c|c|c|c|}
\hline RK & $\begin{array}{c}\text { Setor Econômico } \\
\text { Meio Revista } \\
\text { Dados de Páginas } \\
\end{array}$ & 2009 & 2008 & $\begin{array}{c}\text { Cresc. } \\
\text { Decresc. } \\
\% \\
\end{array}$ \\
\hline 1 & Comércio / Varejo & 15.646 & 16.437 & $-4,81 \%$ \\
\hline 2 & Serviços ao Consumidor & 10.254 & 10.101 & $1,51 \%$ \\
\hline 3 & Cultura Lazer Esporte Turismo & 9.956 & 10.715 & $-7,08 \%$ \\
\hline 4 & Higiene Pessoal e Beleza & 7.993 & 8.737 & $-8,52 \%$ \\
\hline 5 & Vestuário e têxtil & 7.521 & 8.311 & $-9,51 \%$ \\
\hline 6 & Mídia & 6.834 & 7.421 & $-7,91 \%$ \\
\hline 7 & Veículo Peça e Acessório & 5.826 & 6.869 & $-15,18 \%$ \\
\hline 8 & Mercado Financeiro e Seguro & 4.464 & 4.655 & $-4,10 \%$ \\
\hline 9 & Alimentação & 3.573 & 3.293 & $8,50 \%$ \\
\hline 10 & Serviços Públicos e Sociais & 3.420 & 2.604 & $31,34 \%$ \\
\hline 11 & Telecomunicações & 3.035 & 3.012 & $0,76 \%$ \\
\hline 12 & Produtos Uso Pessoal & 2.448 & 2.169 & $12,86 \%$ \\
\hline 13 & Bebidas & 2.211 & 3.286 & $-32,71 \%$ \\
\hline 14 & Mercado Imobiliário & 2.114 & 3.302 & $-35,98 \%$ \\
\hline 15 & Construção e Acabamento & 1.735 & 2.060 & $-15,78 \%$ \\
\hline 16 & Informática & 1.067 & 2.180 & $-26,28 \%$ \\
\hline 17 & Farmacêutica & 1.472 & 1.281 & $14,91 \%$ \\
\hline 18 & Internet & 1.348 & 1.347 & $0,07 \%$ \\
\hline 19 & Casa e Decoração & 1.254 & 1.643 & $-23,68 \%$ \\
\hline \multirow[t]{2}{*}{20} & Eletro Eletrônico & 1.017 & 1.759 & $-42,18 \%$ \\
\hline & Total & 93.188 & 101.182 & $-7,90 \%$ \\
\hline
\end{tabular}

Cumpre ressaltar, a partir dos dados listados acerca do perfil dos anunciantes nos meios jornal e revista (Tabelas 3 e 4), que nestes o peso das instituições governamentais e conseguinte influência do sistema política resta encoberto, não se restringindo aos investimentos publicitários descritos sob a rubrica "serviços públicos e sociais". Tal se afirma levando em conta os gastos de propaganda das empresas públicas e sociedades de economia mista cujo controle político se expressa pela indicação de seus dirigentes pelo próprio governo.

Nesse sentido, cumpre destacar a posição dessas empresas em especial no ranking dos 30 maiores anunciantes de 2009 da pesquisa Ibope Monitor, sistematizado por Alexandre Zaghi Lemos (2010) e publicado no sítio eletrônico Observatório da Imprensa. Nesta lista específica, figura a Caixa Econômica Federal na $4^{\mathrm{a}}$ posição, totalizando cerca de R\$ 847.500.000,00 em gastos com propaganda em 2009, bem como, em $11^{\circ}$ lugar, a Petrobras responsável, por sua vez por R\$ 546.736.000,00 do faturamento publicitário e, 
ainda dentre as 30 maiores empresas anunciantes, na $27^{\circ}$ posição, encontra-se o Banco do Brasil, com R\$333.711.000,00. (LEMOS, 2010).

Acrescente-se a esses dados, as informações oficiais e estarrecedoras da própria Secretaria de Comunicação Social da Presidência da República - SECOM (2009) acerca dos vultosos contratos de publicidade em vigência (Tabela 5).

No referido relatório oficial destacam-se não apenas os seguintes gastos anuais com propaganda em vigor, como o seu direcionamento prioritário para áreas de maior visibilidade política e econômica em detrimento dos investimentos em propaganda voltada à conscientização pública de direitos sociais e promoção de suas políticas públicas.

Nesse sentido, chama a atenção não apenas a destinação de aproximadamente R\$1 bilhão de reais do orçamento federal para propaganda oficial das empresas públicas e sociedades de economia mistas, mas, sobretudo, que os gastos individualmente da Petrobras (R\$ 375 milhões), Caixa Econômica Federal (R\$ 260 milhões) e Banco do Brasil (R\$ 150 milhões), bem como da Presidência da República (R\$ 150 milhões) e Ministério das Cidades (R \$ 125 milhões) superem em muito os investimentos em propaganda dos Ministérios da Saúde (R\$ 99,1 milhões), Educação, (R\$ 18,5 milhões), Trabalho e Emprego (R\$ 18 milhões) e da Cultura (R\$ 15 milhões), voltados, teoricamente, à promoção de direitos sociais fundamentais. (Tabela 5). 
Tabela 5 - Lista adaptada dos anunciantes do Poder Executivo Federal que atualmente mantêm contrato com agências de propaganda e seus gastos anuais. Adaptado a partir da "lista dos anunciantes do Poder Executivo Federal que atualmente mantêm contrato com agências de propaganda" (SECOM; 2009).

\begin{tabular}{|c|c|c|}
\hline lugar & Anunciantes do Poder Executivo Federal & RS \\
\hline $\mathbf{1}^{\mathbf{0}}$ & PETRÓLEO BRASILEIRO S/A - PETROBRAS & $375.000 .000,00$ \\
\hline $2^{\mathbf{o}}$ & CAIXA ECONÔMICA FEDERAL - CAIXA & $260.000 .000,00$ \\
\hline $3^{\circ}$ & BANCO DO BRASIL S/A - BB & $150.000 .000,00$ \\
\hline $4^{\circ}$ & PRESIDÊNCIA DA REPÚBLICA - PR & $150.000 .000,00$ \\
\hline $\mathbf{5}^{\mathbf{0}}$ & MINISTÉRIO DAS CIDADES - MCIDADES & $125.000 .000,00$ \\
\hline $6^{\mathbf{0}}$ & MINISTÉRIO DA SAÚDE - MS & $99.100 .000,00$ \\
\hline $7^{\mathbf{0}}$ & PETROBRAS DISTRIBUIDORA S/A - BR DISTRIBUIDORA & $60.000 .000,00$ \\
\hline $8^{\circ}$ & BANCO NACIONAL DE DESENVOLVIMENTO ECONÔMICO E SOCIAL - BNDES & $50.000 .000,00$ \\
\hline $9^{\circ}$ & EMPRESA BRASILEIRA DE CORREIOS E TELÉGRAFOS - ECT & $45.000 .000,00$ \\
\hline $10^{\circ}$ & MINISTÉRIO DO TURISMO - MTUR & $40.000 .000,00$ \\
\hline $11^{\circ}$ & INSTITUTO BRASILEIRO DE TURISMO - EMBRATUR & $38.000 .000,00$ \\
\hline $12^{\circ}$ & FUNDAÇÃO INSTITUTO BRASILEIRO DE GEOGRAFIA E ESTATÍSTICA - IBGE & $32.000 .000,00$ \\
\hline $13^{\circ}$ & CENTRAIS ELÉTRICAS BRASILEIRAS S/A - ELETROBRÁS & $27.000 .000,00$ \\
\hline $14^{\circ}$ & BANCO DO NORDESTE DO BRASIL S/A - BNB & $25.000 .000,00$ \\
\hline $15^{\circ}$ & FURNAS CENTRAIS ELÉTRICAS S/A - FURNAS & $20.000 .000,00$ \\
\hline $16^{\circ}$ & MINISTÉRIO DA EDUCAÇÃO - MEC & $18.500 .000,00$ \\
\hline $17^{\circ}$ & MINISTÉRIO DO TRABALHO E EMPREGO - MTE & $18.000 .000,00$ \\
\hline $18^{\circ}$ & EMPRESA BRASILEIRA DE INFRA-ESTRUTURA AEROPORTUÁRIA -INFRAERO & $15.000 .000,00$ \\
\hline $19^{\circ}$ & MINISTÉRIO DA CULTURA - MINC & $15.000 .000,00$ \\
\hline $20^{\circ}$ & MINISTÉRIO DA INTEGRAÇÃO NACIONAL - MIN & $15.000 .000,00$ \\
\hline $21^{\circ}$ & MINISTÉRIO DOS TRANSPORTES - MT & $14.000 .000,00$ \\
\hline $22^{\circ}$ & MINISTÉRIO DA AGRICULTURA, PECUÁRIA E ABASTECIMENTO - MAPA & $11.928 .965,00$ \\
\hline $23^{\circ}$ & BANCO CENTRAL DO BRASIL - BACEN & $11.160 .000,00$ \\
\hline $24^{\circ}$ & LIQUIGÁS DISTRIBUIDORA S/A - LIQUIGÁS & $10.000 .000,00$ \\
\hline $25^{\circ}$ & MINISTÉRIO DA JUSTIÇA - MJ & $10.000 .000,00$ \\
\hline $26^{\circ}$ & BANCO DA AMAZÔNIA S/A - BASA & $8.822 .481,00$ \\
\hline $27^{\circ}$ & COMPANHIA HIDRO ELÉTRICA DO SÃO FRANCISCO - CHESF & $8.258 .363,90$ \\
\hline $28^{\circ}$ & AGÊNCIA NACIONAL DO PETRÓLEO, GÁS NATURAL E BIOCOMBUSTÍVEIS & $7.700 .000,00$ \\
\hline $29^{\circ}$ & FINANCIADORA DE ESTUDOS E PROJETOS - FINEP & $7.000 .000,00$ \\
\hline $30^{\circ}$ & CENTRAIS ELÉTRICAS DO NORTE DO BRASIL S/A - ELETRONORTE & $6.000 .000,00$ \\
\hline $31^{\circ}$ & MINISTÉRIO DO DESENVOLVIMENTO AGRÁRIO - MDA & $6.000 .000,00$ \\
\hline $32^{\circ}$ & MINISTÉRIO DO PLANEJAMENTO, ORÇAMENTO E GESTÃO - MP & $6.000 .000,00$ \\
\hline $33^{\circ}$ & ELETROSUL CENTRAIS ELÉTRICAS DO SUL DO BRASIL S/A - ELETROSUL & $5.321 .640,00$ \\
\hline $34^{\circ}$ & MINISTÉRIO DA CIÊNCIA E TECNOLOGIA - MCT & $5.000 .000,00$ \\
\hline $35^{\circ}$ & AMAZONAS DISTRIBUIDORA DE ENERGIA S/A - AMENERGIA & $2.600 .000,00$ \\
\hline $36^{\circ}$ & EMPRESA DE TRENS URBANOS DE PORTO ALEGRE - TRENSURB & $2.520 .000,00$ \\
\hline $37^{\circ}$ & COMPANHIA DE GERAÇÃO TÉRMICA DE ENERGIA ELÉTRICA - CGTEE & $2.500 .000,00$ \\
\hline $38^{\circ}$ & AGÊNCIA NACIONAL DE SAÚDE SUPLEMENTAR - ANS & $2.095 .000,00$ \\
\hline $39^{\circ}$ & ELETROBRÁS TERMONUCLEAR S/A - ELETRONUCLEAR & $2.000 .000,00$ \\
\hline $40^{\circ}$ & CENTRAIS ELÉTRICAS DE RONDÔNIA S/A - CERON & $625.000,00$ \\
\hline $41^{\circ}$ & COMPANHIA DOCAS DO ESTADO DE SÃO PAULO - CODESP & $500.000,00$ \\
\hline $42^{\circ}$ & CENTRAIS DE ABASTECIMENTO DE MINAS GERAIS S/A - CEASA-MG & $461.660,00$ \\
\hline $43^{\circ}$ & BOA VISTA ENERGIA S/A - BVENERGIA & $400.000,00$ \\
\hline $44^{\circ}$ & UNIVERSIDADE FEDERAL DA GRANDE DOURADOS - UF/GD & $200.000,00$ \\
\hline
\end{tabular}


Dos dados até aqui expostos, cumpre, por fim, ressaltar a figura 6 de divisão de receitas segundo os meios de comunicação levando em conta a totalidade dos anunciantes, sendo o levantamento do Projeto Inter-Meios, divulgado pela ANER (2010c).

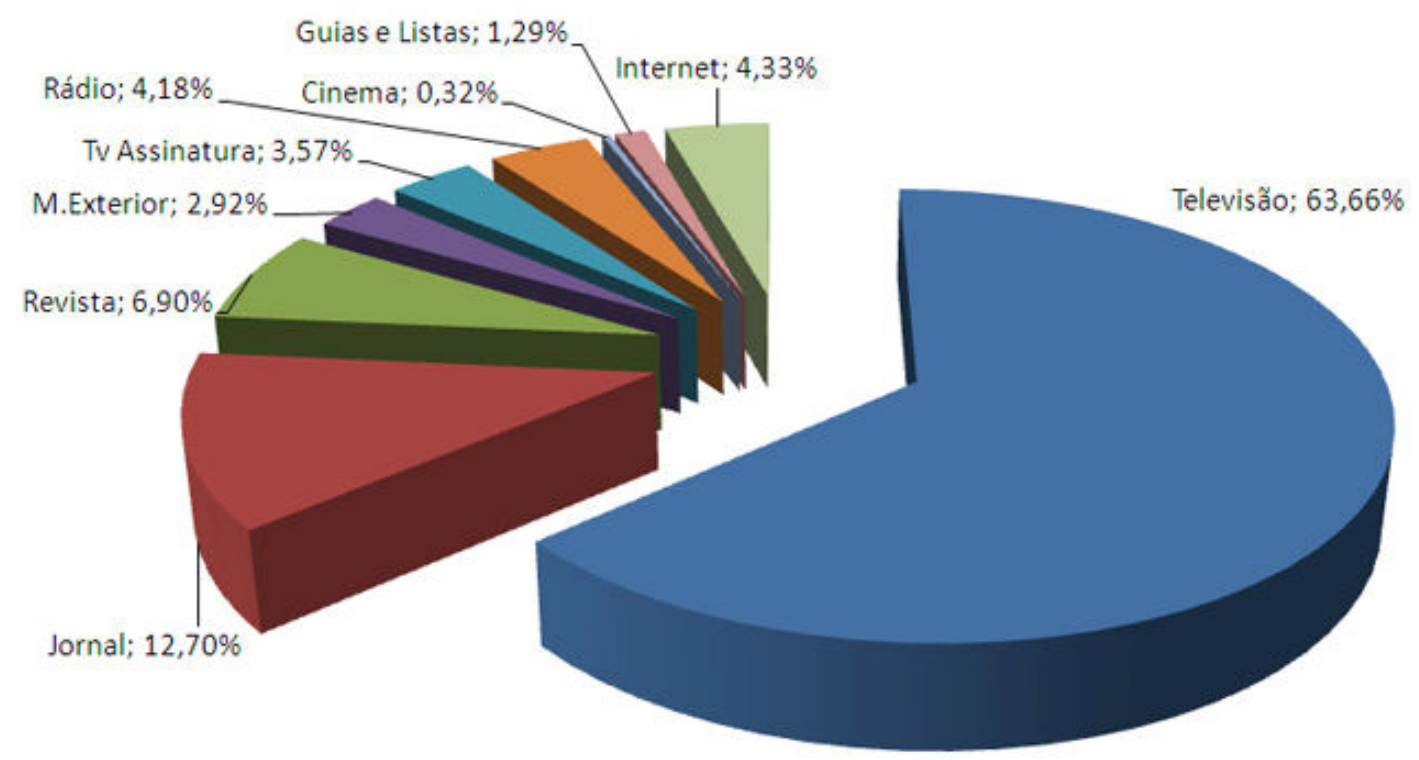

Figura 6 - Participação dos meios: janeiro a julho de 2010 (ANER, 2010c)

Através da propaganda das empresas públicas e da própria administração direta, o sistema político condiciona parcialmente o funcionamento sistêmico das organizações midiática nos moldes do que fora descrito acima acerca do segundo filtro/programa em tela.

Essa influência se dá de modo articulado com o terceiro filtro de notícias através da reprodução das informações "oficiais" sobre seu desempenho e adequação jurídica das políticas públicas em execução.

Por vezes, em momento de crise econômica e de legitimidade das próprias organizações midiáticas e políticas, os limites desse filtro são reordenados através de denúncias parciais de corrupção. Por sua vez, como delimita o quarto filtro/programa de notícias, o sistema político tenta, novamente, disciplinar o sistema dos meios de comunicação através de suas reações negativas que sinalizam ameaça de cortes da propaganda governamental e da prepositura de projetos legais e políticas de maior controle dos meios de comunicação.

Cumpre por fim destacar o arquivamento sumário pelo presidente da Câmara dos Deputados, Arlindo Chinaglia do Partido dos Trabalhadores, do Projeto de Lei no 362/2003, 
de autoria do deputado federal Feu Rosa do Partido Progressista. Se aprovado fosse, jornais e revistas com tiragem superior a 20 mil exemplares passariam a ser obrigados a divulgar a relação dos principais anunciantes e financiadores daquela edição, sob pena de multa no valor de R\$ 2 mil a R\$ 20 mil. Registre-se ainda, tal arquivamento decorre do acolhimento do pedido formulado pela Associação Nacional dos Editores de Revistas (Aner), sob o argumento de que o "projeto não preenchia os requisitos legais para continuar em andamento". (ANER, 2010d).

\subsubsection{3 $^{\circ}$ programa ou "filtro de notícias": a dependência da mídia de informações fornecidas pelo governo, por empresas e por "especialistas"}

O terceiro filtro/programa de notícias em discussão explicita a relação de dependência das organizações dos meios de comunicação de massa em relação às empresas especializadas em informação e às próprias instituições governamentais que atuam como a principal fonte de suas notícias e reportagens.

Dadas os acoplamentos estruturais entre mídia, economia e política apresentados pela conformação dos dois filtros anteriores, tem-se que as organizações desse sistema de comunicação de massa são levadas "a um relacionamento simbiótico com as poderosas fontes de informação pela necessidade econômica e pela reciprocidade de interesses”. (HERMAN; CHOMSKY, 2003, p. 77).

A compreensão deste filtro é de suma importância para a seguinte discussão da reprodução parcial dos dados "oficiais" sobre o suposto déficit da previdência e cobertura parcial das questões de saúde pública. As organizações e estudiosos sobre esse tema que não se adéquam às fontes oficiais e de "especialistas" alinhados com os interesses corporativos envolvidos têm sua contestação praticamente excluída da falseada discussão pública quando da cobertura midiática sobre esses assuntos.

De acordo com o Modelo de Propaganda, enquanto empreendimento empresarial, as organizações da mídia demandam um "fluxo constante e confiável de matérias-primas para notícias". Porém, dada sua orientação para o lucro e os custos dessa produção, não lhe é possível manter repórteres e câmeras em todas as partes em que acontecimentos relevantes possam ocorrer. 
Assim, aspectos econômicos de produção impõem que os tais veículos de comunicação de massa concentrem seus recursos nos lugares em que as notícias ocorrem com mais frequência, preferencialmente, através de coletivas de imprensa regulares.

Frente a essas limitações, grandes empresas e centros de pesquisa, por estas financiados, acabam por otimizar o trabalho da imprensa, reduzindo os descritos custos de exploração da realidade em busca de informações. Atuando, assim, como fornecedores regulares e "confiáveis" de matérias "geralmente interessantes", o próprio mercado e suas empresas especializadas em notícias e relações públicas acabam por gerar um "grande volume de matéria que atende às demandas das organizações de notícias por fluxos confiáveis e programados”. (HERMAN; CHOMSKY, 2003, p. 77).

De modo complementar a esse condicionamento econômico, Herman e Chomsky (2003, p. 78) acrescentam que esse recurso a fontes oficiais do governo e de agências especialistas servem ainda como mecanismo legitimador de sua suposta objetividade e isenção:

Uma outra razão para o alto peso dado a fontes oficiais é que a mídia de massa afirma ser distribuidora "objetiva" de notícias. Em parte, com o objetivo de manter a imagem da objetividade, mas também para se proteger de críticas quanto a tendenciosidades e de ameaças de ações cíveis, a mídia precisa de material que pode ser descrito como presumivelmente preciso. Trata-se em parte de uma questão de custo: tomar a informação de fontes que podem ser presumivelmente confiáveis reduz as despesas de investigação, ao passo que o material de fontes que à primeira vista não são confiáveis, ou que darão margem a críticas e ameaças, exige uma cuidadosa verificação e uma pesquisa dispendiosa.

Essa necessidade é identificada, por sua vez, como uma grande oportunidade de abertura sistêmica por grandes grupos econômicos e organizações políticas como o governo tentem generalizar, através da mídia, suas expectativas sociais parciais sobre si e a respeito dos demais sistemas sociais e psíquicos objeto das notícias e reportagens em questão. ${ }^{197}$

197 De modo direto, essa forma de funcionamento é criticada por Herman e Chomsky (2003, p. 81) nos seguintes termos: "Na realidade, as grandes burocracias dos poderosos subsidiam a mídia de massa, e ganham acesso especial por sua contribuição para redução dos custos de aquisição de novas matérias-primas e da produção de notícias para a mídia. As grandes entidades que fornecem esse subsídio tornam-se fontes 'rotineiras' de notícias e têm acesso privilegiado aos portões. Fontes não-rotineiras têm que lutar pelo acesso, e podem ser ignoradas pela decisão arbitrária dos guardas dos portões. Deve ser também observado que no caso da grandeza do Pentágono e do Escritório de Diplomacia Pública de Estado, o subsídio acontece às expensas dos contribuintes, de modo que, na realidade, os cidadãos pagam para receber propaganda de interesse de grupos poderosos como, por exemplo, fabricantes de material bélico e outros patrocinadores do terrorismo estatal." 
Justifica-se, dessa forma, o grande investimento de organizações tanto privadas quanto públicas e em serviços de relações públicas e na formação de especialistas reprodutores de sua lógica e interesses sistêmicos, buscando, assim, com o fornecimento de informações previamente selecionadas e, por vezes, das próprias notícias prontamente disponibilizadas, influir na comunicação difundida pela imprensa.

No que diz respeito ao trabalho e formação de um corpo de especialistas fornecedores de informações tendenciosas para as empresas midiáticas, esclarecem Herman e Chomsky (2003, p. 82):

A relação entre o poder e a necessidade de fontes se estende além do fornecimento diário de notícias pelo governo e por empresas, indo até a formação de "especialistas". A dominação das fontes oficiais é enfraquecida pela existência de fontes extra-oficiais altamente respeitáveis que fornecem visões dissidentes com grande autoridade. Esse problema é aliviado pela "cooptação dos especialistas" - ou seja, sua inclusão na folha de pagamento como consultores, o financiamento de suas pesquisas e a organização de think tank que os contratarão direta ou indiretamente e os ajudarão a disseminar suas mensagens. ${ }^{198}$

A operação desse terceiro filtro/programa é também identificada no funcionamento sistêmico das grandes organizações midiáticas em âmbito nacional.

Perseu Abramo (2003), ao discorrer sobre o significado político da manipulação na grande imprensa em texto original de 1988, critica as técnicas de manipulação da informação, cujo principal efeito seria sua constatação de que assim operando "os órgãos de imprensa não refletem a realidade".

Os padrões de manipulação da notícia por ele analisado serão detidamente apresentados no capítulo seguinte quando da discussão das principais notícias sobre a cobertura dos direitos sociais de Seguridade.

Sendo assim, no que diz respeito diretamente ao filtro/programa em tela, ou seja, à dependência da mídia de informações fornecidas pelo governo, por empresas e por

\footnotetext{
${ }^{198}$ Os referidos autores assim contextualizam a partir de sua experiência norte-americana esse processo de formação e cooptação de especialistas que usualmente são chamados a assessorar as empresas midiáticas, legitimando os sentidos escolhidos de suas notícias e reportagens: "Durante os anos 197 e no início dos anos 1980, de acordo com essa fórmula, foi criada uma séria de instituições, e outras mais antigas reativadas, com o objetivo de divulgar o ponto de vista empresarial. Centenas de intelectuais foram trazidos para essas instituições, onde seu trabalho foi financiado e seus resultados disseminados para a mídia por um sofisticado esforço de propaganda. Os recursos corporativos e o claro propósito ideológico no esforço global não tiveram efeito discernível na credibilidade dos intelectuais assim mobilizados; pelo contrário, o financiamento e a disseminação de suas ideias os lançaram para a imprensa". (HERMAN; CHOMSKY, 2003, p. 82-83).
} 
especialistas, destaca-se desde já o funcionamento do "padrão de inversão" dos fatos e sua fragmentação para a composição da noticia, identificado por Abramo (2003).

Segundo o renomado jornalista e sociólogo, tal padrão promove a "destruição da realidade original e a criação artificial de outra realidade", operando "tanto no planejamento como na coleta e na transcrição das informações”. (ABRAMO, 2003, p. 28).

No funcionamento de tal padrão de manipulação de notícias em sua vertente de "inversão da versão pelo fato", resta evidenciado o que Herman e Chomsky (2003) desenvolvem como terceiro filtro de notícias. Nesse aspecto operacional, de acordo com Abramo (2003, p. 29):

Não é o fato em si que passa a importar, mas a versão que dele tem o órgão de imprensa, seja essa versão originada no próprio órgão de imprensa, seja adotada ou aceita de alguém - da fonte das declarações e opiniões. O órgão de imprensa praticamente renuncia a observar e expor os fatos mais triviais do mundo natural ou social e prefere, em lugar dessa simples operação, apresentar as declarações, suas ou alheias, sobre esses fatos.

Nesse padrão de funcionamento encontra-se o oficialismo, como outro "extremo da inversão do fato pela versão". Tal expressão indica a predileção das organizações midiáticas pelo recurso às fontes "oficiais" ou "mais oficiais" da sociedade e "não apenas as autoridades do Estado ou do governo". (ABRAMO, 2003, p. 30).

Sobre a proeminência desse modo de funcionamento em boa parte das organizações dos meios de comunicação de massa na elaboração de suas notícias e reportagens, discorre o referido autor:

No lugar dos fatos uma versão, sim, mas de preferência a versão oficial. A melhor versão oficial é a da autoridade, e a melhor autoridade, a do próprio órgão de imprensa. À sua falta, a versão oficial da autoridade cujo pensamento é o que mais corresponda ao do órgão de imprensa, quando se trata de apresentar uma realidade de forma "positiva", isto é, de maneira que o leitor não apenas acredite nela mas aceite e adote. A autoridade pode ser o presidente da República, o governador do estado, o reitor da universidade, o presidente do centro acadêmico, do sindicato, do partido político ou de uma sociedade de amigos de bairro. Ela sempre vale mais do que as versões de autoridades subalternas, sempre muito mais do que a dos personagens que não detêm qualquer forma de autoridade e, evidentemente, sempre infinitamente mais do que a realidade. Assim, o oficialismo se transforma em autoritarismo. (ABRAMO, 2003, p. 30-31). 
Nesse mesmo sentido, Hamilton Octavio Souza (2003, p 18) explicita como, desde o final da década de 1980, tal oficialismo tem se transformado numa prática constante da imprensa brasileira.

Segundo este jornalista, sobretudo, a partir do final do século XX no Brasil, as organizações midiáticas teriam praticamente substituído a representação parlamentar, as organizações sociais e as entidades de classe na intermediação com a sociedade na medida em que teriam se funcionado como reprodutores do discurso oficial do governo. Sobre esse aspecto, discorre ainda no seguinte sentido:

O oficialismo que tomou conta dos meios de comunicação de 1994 para cá reduziu o jornalismo ao procedimento declaratório de um número bemcomportado de fontes "oficiais" e previsíveis, todas naturalmente engajadas no projeto entreguista do governo FHC e na economia de mercado, de tal forma que a relação com o autoritarismo não pudesse mais ser ignorada. $\grave{E}$ claro que o discurso permanente continuou sendo o da liberdade de expressão, o da "isenção" da imprensa e o da "objetividade jornalística", mas sem espaço para que veículos destoassem da lógica de pensamento único. (SOUZA, 2003, p. 18-19). ${ }^{199}$

Esse panorama permite uma compreensão aproximada do funcionamento deste terceiro programa sistêmico no sentido da influência exercida pelas grandes empresas e organizações políticas, através de seus pareceres especializados e de suas informações oficiais sobre a seleção internas de informações a serem reproduzidas pelos meios de comunicação de massa em questão.

\footnotetext{
${ }^{199}$ A esse respeito, o referido autor cita como exemplo a edição do jornal O Estado de S. Paulo de 30 de junho de 1998, o qual, suspotamente empenhado na reeleição de Fernando Henrique Cardoso, "apresentou na capa cinco chamadas (a manchete principal e quatro submanchetes) baseadas em previsões de futuro, em provessas vagas, do tipo 'privatização das teles criará 2 milhoões de empregos', 'governo abrirá financiamento da casa própria', 'balança comercial terá superávit' e coisas parecidas.” Porém, acrescenta ainda como tais "chamadas do jornal jamais se concretizaram na época, no prazo e nas condições apontadas pelas matérias, as quais, na verdade, não guardavam nenhuma relação com fatos reais, mas apenas com intenções e declarações de pessoas do governo devidamente comprometidas com a reeleição de FHC". (SOUZA, 2003, p. 21).
} 


\subsection{4 $O 4^{0}$ programa ou "filtro de notícias": a bateria de reações negativas como forma de disciplinar a mídia}

O quarto filtro/programa do Modelo de Propaganda em discussão reflete a tentativa de controle e disciplina exercida por organizações políticas e econômicas sobre temas evidenciados pela mídia. Suas reações negativas funcionam, assim, como mecanismo de pressão no sentido de fomentar a adequação da cobertura midiática e de sua linha editorial aos seus interesses parciais propostos por tais organizações, em que pese sua adequação às expectativas sociais dos demais sistemas sociais e psíquicos sobre os temas reportados.

Suas formas de expressão são as mais variadas compreendendo cartas, telegramas, telefonemas, petições, ações judiciais, discursos e projetos de lei, dentre outros meios de queixa e ameaças punitivas. Porém, como destacam Herman e Chomsky (2003, p. 84):

Se a bateria de reações negativas for produzida em grande escala, por pessoas físicas ou grupos com recursos substanciais, pode ser tanto desconfortável quanto dispendioso para a mídia. Posições têm que ser defendidas dentro e fora da organização, algumas vezes perante legisladores e possivelmente até em tribunais de justiça. Os anunciantes podem retirar seu patrocínio. A propaganda na televisão é basicamente voltada para bens de consumo, que são produtos facilmente sujeitos a um boicote organizado.

Nesse aspecto, a intensidade de tais reações seria diretamente relacionada aos centros de decisão, tanto político quanto econômico, tendo, nos Estados Unidos, "aumentado em íntimo paralelo com a crescente indignação das empresas com as críticas da mídia e com a ofensiva das corporações nos anos 1970 e 1980". (HERMAN; CHOMSKY, 2003, p. 85). ${ }^{200}$

Ademais, tais reações podem ocorrer tanto direta, quanto indiretamente, seja, por exemplo, pelo telefonema de membros do governo e outras autoridades públicas para as empresas midiáticas solicitando documentos utilizados na formulação das notícias e

\footnotetext{
${ }^{200}$ Dentre os diversos casos reportados acerca da aplicabilidade desse filtro ao funcionamento da mídia norteamericana, Herman e Chomsky (2003, p. 85) destacam, por exemplo, como "A comunidade corporativa patrocinou, juntamente com seus outros investimentos políticos nos anos 1970 e 1980, o crescimento de instituições como a American Legal Foundation, a Capital Legal Foundation, o Media Institute, o Center for Media and Public Affairs e a Accuracy in Media (AIM), que podem ser vistas como instituições organizadas par ao propósito específico de produção de reações negativas. Uma outra máquina produtora de reações negativas, mais antiga e de concepção mais ampla, é a Freedom House. A American Legal Foundation, organizada em 1980, especializou-se em queixas relativas à Doutrina da Justiça e ações cíveis para ajudar "vítimas da mídia"”.
} 
reportagens, seja indiretamente, reportando-se aos seus eleitores, acionistas, empregados sobre a atuação questionada da mídia.

Atuando de maneira integrada aos demais filtros/programas expostos até aqui, é possível compreender como essas reações negativas podem influenciar em maior ou menor grau no funcionamento sistêmico das organizações midiáticas.

De qualquer forma, em que peses os limites da dupla contingência e impossibilidade de total antecipação da reação dos demais sistemas à comunicação realizada, tal filtro reforça a existência de uma tendência no funcionamento dos meios de comunicação de massa, a partir de suas organizações centrais de informação, orientada para seleção de sentidos, sobretudo, de suas notícias e reportagens a serem divulgadas de modo, adequando-as na busca de reduzir tais externalidades e possíveis ameaças de rompimentos de seus acoplamentos econômicos e políticos, como a perda da concessão de tais serviços, restrições à sua liberdade de expressão, perda de receita com propaganda ou com indenizações judiciais vultosas.

\subsection{5 $05^{\circ}$ programa ou "filtro de notícias": o "anticomunismo" como religião nacional e mecanismo de controle}

Por sua vez, o quinto filtro ou programa sistêmico esboça o mecanismo de seleção de informações no sentido claramente ideológico.

Tal direcionamento de notícias seria voltado especialmente para a generalização do anticomunismo como "religião nacional" norte-americana. Isto porque, segundo Herman e Chomsky (2003 p. 88), essa “ideologia ajuda a mobilizar a população contra o inimigo comum, e como o conceito é obscuro pode ser utilizado contra qualquer um que defenda políticas que ameacem os interesses de proprietários ou apoie a acomodação com países comunistas e com o radicalismo".

Assim, a partir do descrito crescimento da participação de grandes corporações transnacionais no controle das empresas de mídia, os referidos autores demostram como essa sinergia entre as grandes organizações em acoplamento estrutural econômico midiático e político estabelecem, sob sua perspecetiva analítica, um poderoso instrumento de criação de consensos políticos tido como hegemônicos. 
José Arbex Jr. (2002, p. 141-172) descreve com detalhes e de maneira fundamentada, a partir de sua experiência profissional no jornal Folha de S. Paulo, a implantação acelerada no Brasil, ao longo da década de 1980, dessa lógica empresarial e ideologia (neo)liberal que "a moderna imprensa capitalista construiu ao longo de várias décadas nos Estados Unidos e na Europa". Segundo o referido autor:

O Projeto Folha, sinteticamente, significou a adoção do discurso-para-omercado como estratégia empresarial e editorial. Não se deveu a uma mera coincidência o fato de sua implantação ter acontecido ao longo dos anos 80 , embora ele já estivesse em gestação desde os anos 70 . Foi a década da expansão do neoliberalismo, no cenário internacional, e de profundas transformações políticas no Brasil (...). Nem foi um acaso a nomeação, em 24 de maio de 1984, de Otavio Frias Filho como diretor de redação: apesar da retórica e dos métodos supostamente "modernizadores" adotados pela FSP, a empresa preservava seus traços fortemente marcados por uma estrutura familiar de poder. Desde o início, o Projeto Folha caracterizava a notícia como mercadoria, destinada a gerar lucros. Essa perspectiva exigia, obviamente, o fim da "politização" da redação, uma das características mais fortes do jornalismo até então praticado no Brasil. Os jornalistas, em geral, tinham uma certa formação marxista ou de esquerda, até como reação ao autoritarismo da direita, traço marcante da história nacional. A adoção do Projeto Folha impunha, portanto um 'saneamento ideológico' da redação. (ARBEX JR, 2002 p. 141,142).

Mas do que simplesmente filtrar notícias numa perspectiva anticomunista, observa-se o desenvolvimento funcional desse programa em termos da reprodução do ideário de consumo e de organização político-econômico neoliberal, especialmente a partir da década de 1980. Nesse mesmo sentido, sistematiza Dennis de Oliveira (2009, p. 02-03):

A desregulamentação e privatização do conjunto da economia nacional, feita com mais intensidade na última década do século passado, gerou não apenas um debate ideológico em que os grupos midiáticos claramente apoiaram o lado conservador, mas também uma participação direta destas empresas no próprio "negócio neoliberal". Exemplos: a participação ostensiva da Globo no processo de privatização da telefonia em associação com grandes grupos privados nacionais e multinacionais, a vinculação negocista de setores da mídia com o Grupo Oportunitty, um dos principais players da privatização da telefonia, etc.

Esse filtro de notícia será detalhado na discussão da cobertura midiática das reformas do Estado brasileiro a partir da década de 1980 com especial atenção para a difusão do ideário não apenas de desregulamentação das atividades econômicas fortemente controladas, senão, exercícidas pelo Estado brasileiro, como fundamentalmente pela reversão de suas políticas públicas em matéria de Seguridade Social no sentido de sua sistemática e inconstitucional redução a medidas assistenciais e focalizadas, fomentando a 
exploração de tais serviços sociais pelas empresas privadas de saúde e previdência complementar. $^{201}$

Nesse contexto e a partir das mudanças na socialibilidade enfatizadas por Zygmunt Bauman (2001) em sua obra acerca da "Modernidade Líquida", Dennis de Oliveira (2009) conclui que:

Toda essa situação coloca a indústria da mídia como um elemento fundamental na construção de cenários favoráveis a interesses particulares, retirando qualquer vestígio que ainda exista de uma esfera pública, ainda que hegemonizada pela ideologia capitalista. A batalha na esfera pública tende a caminhar de uma disputa por hegemonia para uma batalha de interesses negocistas que, inclusive, contamina o próprio ethos de alguns profissionais de comunicação, que se vêem colocados muito mais como estrategistas de mercado do que como operadores simbólicos. A colonização da esfera pública pelo aparelho midiático traz para esse locus todo o emaranhado de esquemas, lobbies, interesses escusos que marcam a cultura política brasileira. Daí que o papel de fiscalizador do jornalismo se transfigura para um lugar de produção de discursos destinados a defender interesses particulares de corporações e pessoas, uma vez que estes se transformaram em players do jogo políticoinstitucional-econômico, principalmente após a onda de privatizações. Esse contexto da indústria midiática tem uma afetação profunda na socialidade. Isto porque destrói completamente a idéia da ambiência política do espaço público, uma das características que inovaram a tipologia humana pós-iluminismo. (OLIVEIRA, 2009, p. 03).

Sendo assim, aplicado à realidade brasileira, o citado "modelo de propaganda" permite a compreensão do favorecimento e disseminação, por parte da mídia nacional, dos interesses dos sistemas sociais parciais que financiam suas organizações, fazendo com que sua comunicação de mensagens e símbolos não se restrinja apenas a uma forma de divertir, informar e entreter o público, como também numa tentativa de incutir nos indivíduos valores, credos e códigos de comportamento através de um minucioso processo de seleção de expectativas cognitivas parciais acerca da realidade a serem generalizadas socialmente por esses meios de comunicação.

A partir do que fora até aqui exposto, será possível defender a tese em questão no derradeiro capítulo seguinte com a aplicação do modelo de propaganda adaptado à perspectiva sistêmica na discussão de como essa forma atual de financiamento e estruturação empresarial dos meios de comunicação de massa também no Brasil

${ }^{201}$ Maria Eduarda da Mota Rocha (2007) discorre sobre o desenvolvimento durante a década de 1990 do discurso neoliberal na publicidade tal qual o "canto da séria" de Ulisses, demonstrando assim o desenvolvimento dessa função ideológica para além da simples opsição ao comunismo em ruptura. 
condicionam de tal forma o processo de seleção das informações que compõem suas notícias, reportagens, formas de entretenimento e publicidades, acerca das questões relacionadas à saúde, previdência e assistencial sociais nacionais, de modo que tais informações sejam veiculadas, em sua grande parte, no sentido de reduzir a esfera da opinião pública (CHAUI, 2006; CANCLINI, 2001; IANNI, 2000) e instrumentalizar, através da banalização das injustiças sociais (DEJOURS, 2010), a quebra de confiança (LUHMANN, 2005b) no próprio Sistema de Seguridade Social, solapando, dessa forma, a solidariedade essencial para a construção desse sistema de proteção social e para o sucesso de suas políticas públicas. 


\section{AS TENSÕES ENTRE OS SENTIDOS DAS POLÍTICAS PÚBLICAS DE SEGURIDADE SOCIAL E A DISTORÇÃO COMUNICACIONAL DOS MEIOS DE COMUNICAÇÃO DE MASSA NO BRASIL}

O desenvolvimento nesta última seção da tese proposta requer a prévia discussão acerca dos modelos explicativos do Estado de Bem-Estar Social, sua pressuposta e propagandeada crise, para, a partir dessas visões, serem questionados os sentidos e as expectativas acerca de suas políticas públicas em matéria de Seguridade Social difundidos pelos meios de comunicação de massa no Brasil tendo em vista seu conflito com aqueles normatizados constitucionalmente.

Embora sejam consideradas diferentes interpretações sociológicas, sobretudo do campo da Ciência Política, dessa forma de organização do Estado e do conceito em si de políticas públicas adotadas para sua consecução, cumpre desde já destacar a opção desse estudo pela perspectiva jurídica, ou seja, pelos sentidos normativos sobre o Estado de BemEstar Social e pela definição mais geral das políticas públicas para sua concretização expressos na própria Constituição da República Federativa do Brasil de $1988 .{ }^{202}$

A partir dessa perspectiva discursiva, se desenvolverá, na segunda e derradeira parte deste capítulo, a comprovação da tese inicialmente apresentada, confrontando-se tais sentidos normativos com aqueles, diametralmente opostos, generalizados pelos meios de comunicação de massa em função da descrita conformação de seus programas/filtros de seleção de notícias e sua repercussão na confiança e solidariedade social em matéria de Seguridade Social.

\footnotetext{
${ }^{202} \mathrm{O}$ conceito em si de política pública varia conforme a perspectiva teórica adotada, conforme se pretende demonstrar nesta seção. Ainda assim, cabe desde já demarcar que para os fins da presente tese será adotado o conceito utilizado em direito, proposto por Maria Paula Dallari Bucci (2006) a partir de sua interpretação constitucional, segundo a qual as políticas públicas seriam definidas como "programas de ação governamental visando coordenar os meios à disposição do Estado e as atividades privadas, para a realização de objetivos socialmente relevantes e politicamente determinados.” (BUCCI, 2006, p. 38).
} 


\subsection{Sistema político, políticas públicas e a conformação jurídica das expectativas sociais acerca do Estado de Bem-Estar Social}

O sistema político e as políticas públicas podem ser compreendidos levando-se em conta os diferentes modelos analíticos desenvolvidos pela Ciência Política contemporânea. ${ }^{203}$

De acordo com March e Olsen (1984) tais modelos teriam se caracterizado, em linhas gerais, desde 1950, por diferentes abordagens de cunho (a) contextualista; (b) reducionista; (c) utilitarista; (d) funcionalista, e/ou (e) instrumentalista.

Essas abordagens analíticas acabariam por enfatizar, cada qual ao seu modo e com diferentes correntes internas, a subordinação do "jogo político" (politics) ${ }^{204}$ e da produção de políticas públicas (policy-making) a diferentes causas, as quais poderiam ser, respectivamente, assim resumidas:

(a') sob a perspectiva contextualista, estariam assim relacionadas ao resultado das forças e determinantes exógenos à própria política - como à estrutura de classes sociais e às questões culturais, demográficas, tecnológicas, religiosas, étnicas ou ideológicas;

(b’) já numa abordagem reducionista, enquanto "fenômeno político", tanto a politics (ação política) quanto a policy (política pública) seriam macro resultantes de comportamentos individuais dos atores sociais envolvidos;

(c') por sua vez, nas abordagens de cunho utilitarista prevaleceriam como caráter determinante as decisões calculadas racionalmente para a

\footnotetext{
${ }^{203}$ Nesse sentido, sistematiza Giselle de Amaro e França (2010, p. 15): “A expressão políticas públicas é um termo polissêmico que, por si só, já denota seu vasto campo de abrangência. Envolve questões políticas, questões de interesse público, gestão da coisa pública, em suma, abarca as principais discussões acerca das opções políticas realizadas para a satisfação dos interesses gerais da coletividade, mediante utilização dos recursos públicos."

${ }^{204}$ Nos trabalhos publicados na área de Ciência Política, os termos policy, politics e polity se distinguem, sendo entendido por policy as políticas públicas em si, ou seja, as ações governamentais. Por sua vez, o termo politics diz respeito às ações políticas ou às estratégias políticas desenvolvidas nos processos políticos; e polity seriam as estruturas formais, as instituições políticas formais. Nesse sentido, Klaus Frey (2000) sintetiza as seguintes dimensões da política nas policy analysis: "• a dimensão institucional 'polity' se refere à ordem do sistema político, delineada pelo sistema jurídico, e à estrutura institucional do sistema político-administrativo; • no quadro da dimensão processual 'politics' tem-se em vista o processo político, frequentemente de caráter conflituoso, no que diz respeito à imposição de objetivos, aos conteúdos e às decisões de distribuição; • a dimensão material 'policy' refere-se aos conteúdos concretos, isto é, à configuração dos programas políticos, aos problemas técnicos e ao conteúdo material das decisões políticas.” (FREY, 2000, p. 216-217).
} 
maximização dos interesses pessoais e a antecipação de escolhas ao passo em que, assim, as ações dependeriam dos valores dos principais atores decisórios e não dos arranjos institucionais ou menos da conformação das esferas de veto e de decisão nos quais tais atores influiriam;

(d') no que diz respeito às abordagens funcionalistas, haveria a ênfase na ideia de progresso e desenvolvimento histórico no sentido de que os comportamentos e instituições seriam guiados por um processo progressivo de maximização de sua eficiência e pela resposta às necessidades sociais e sistêmicas;

(e') de modo instrumentalista, haveria, por fim, a redução da esfera política e de seus resultados como artifícios simbólicos e instrumentais da real política desempenhada por grupos de poder a fim de legitimar suas relações de dominação. (MARCH; OLSEN, 1984, p. 735-738).

Essas diferentes formas de abordar os fenômenos sociais e de buscar a relação causal de seus processos constitutivos levaram, por exemplo, a formulação de diversas teorias explicativas para a emergência e o desenvolvimento do Welfare State ou Estado de Bem-Estar Social.

Essas explicações variam ainda segundo a ênfase na suposta subordinação do Estado de Bem-Estar Social a (i) determinantes fundamentalmente de ordem econômica que teriam levado ao aumento dos "gastos sociais"; ou como (ii) "resposta às necessidades de acumulação e legitimação do sistema capitalista"; passando pela identificação de condicionantes de ordem política das mais variadas, desde a sua consideração como (iii) um simples processo de ampliação progressiva de direitos fundamentais — de civis a políticos e destes últimos até os direitos sociais propriamente ditos no conceito tradicional de Thomas Humphrey Marshall (1964) — ou (iv) por sua identificação como fruto de um arranjo político entre capital e trabalho organizado, para, apenas mais recentemente, com o neo-institucionalismo, sobretudo histórico, passar-se a (v) considerar como possíveis "causas determinantes" do Estado de Bem-Estar, ou em termos mais precisos - como uma de suas "variáveis independentes" — as "configurações históricas particulares de estruturas estatais e instituições políticas”. (ARRETCHE, 1995; BÉLAND; HACKER, 2004).

Esses diversos modelos analíticos dos sistemas de Welfare State servem para compreender como diferentes abordagens e pressupostos relacionados ao suposto 
mecanismo causal de fenômenos sociais aparentemente semelhantes podem levar a diferentes explicações, cada qual com pressupostos, pontos polêmicos e críticas insuperáveis segundo a ótica dos adeptos das correntes rivais.

Nesse sentido, por exemplo, tem-se que Béland e Hacker (2004, p. 43-44), ao analisarem o caráter "excepcional" do modelo de Welfare State norte-americano, dividem, de modo geral, as teorias explicativas tradicionais de seu desenvolvimento entre "teorias societais" e "institucionais".

As primeiras, na linha desenvolvida acima, estariam centradas em fatores considerados independentes em relação às instituições políticas, tais como tendências e processos econômicos, valores culturais e o poder de grupos sociais existentes nos Estados Unidos da América - EUA.

Por sua vez, para explicar esse mesmo fenômeno social - ou seja, a conformação de um sistema de proteção social parcial e não sistematizado completamente nos EUA - as correntes, por assim dizer, "institucionalistas" destacariam as características próprias das instituições políticas norte-americanas como o grau de centralização/descentralização da autoridade política, a capacidade decisória de tais organizações e a estruturação de suas regras eleitorais, ou mesmo, como propõem Béland e Hacker (2004), a influência decisiva das próprias "políticas sociais privadas" nas políticas públicas dos EUA. ${ }^{205}$

Depreende-se, portanto, das considerações até aqui realizadas, a tentativa de ruptura e recontextualização tanto teórica quanto metodológica das novas explicações institucionalistas frente aos diferentes modelos explicativos vigentes na ciência social positiva no final do século XX e início deste século.

No entanto, mesmo este neo-institucionalismo "não constitui uma corrente de pensamento unificada", podendo ser subdividido em aos menos três vertentes analíticas: institucionalismo da escolha racional, institucionalismo sociológico e institucionalismo histórico. (HALL; TAYLOR, 2003, p. 193).

\footnotetext{
205 Ainda segundo os referidos autores, a insuficiência das explicações societais para a compreensão do particular caso norte-americano poderia ser atribuída ao fato de que tais modelos foram inicialmente formulados para analisar grandes diferenças entre nações do norte da Europa não sendo, contudo, aplicáveis para a compreensão interna dos diferentes arranjos institucionais em torno da provisão de benefícios sociais entre os diferentes estados que compõem o federalismo norte-americano. (BÉLAND; HACKER, 2004, p. 44).
} 
No mais, essas teorias institucionais contrapõem-se às teorias sistêmicas em ciências sociais e à sua busca de formular explicações gerais da vida social. Sendo, assim, tais correntes neo-institucionalistas teriam em comum o reconhecimento de certos limites ao estágio atual da ciência política positiva, concentrando-se na produção de conhecimentos de natureza causal e de médio alcance, ou seja, na delimitação das probabilidades de determinação de certas relações causais explicativas de um conjunto restrito de fenômenos sociais. (ARRETCHE, 2007a, p. 148).

O principal aspecto em comum entre essas correntes neo-institucionalistas consiste no fato de "encarar o estudo dos processos políticos, tendo como variável independente as instituições" (FERNANDES, 2002, p. 80).

Porém, cumpre ainda apontar a abrangência conceitual da própria noção de “instituição” por elas empregada. Nesse sentido, afirma Limongi (2002, p.109):

Em que pese a importância conferida às instituições no interior de seu
arcabouço explicativo, e por paradoxal que possa parecer, os Novos
Institucionalistas não apresentam, ou mesmo se preocupam em
apresentar, uma definição precisa do que se deve entender por
instituições. O que esta literatura sugere é que regras, leis, procedimentos,
normas, arranjos institucionais e organizacionais implicam a existência de
constrangimentos e limites ao comportamento. Em última análise, estes
constrangimentos e limites acabam por explicar os próprios resultados do
comportamento. Na literatura, o termo instituição tende a ser empregado
com este significado genérico.

Por sua vez, como será detalhado no tópico seguinte, sob a perspectiva funcional-estruturalista, segundo Luhmann (2002, p. 31), o Estado de Bem-Estar Social que se desenvolveu nas áreas mais industrializadas do mundo não pode mais ser suficientemente compreendido como mero Estado Social, ou seja, como um Estado simplesmente reativo frente às consequências da industrialização com medidas de assistência e compensação de desvantagens sociais, não se sujeitando, assim, a "causas determinantes" de ordem meramente econômica.

Em que pese sua possível caracterização como provedor de "extensas prestações sociais a determinadas camadas da população", ainda segundo o referido autor, essa perspectiva tradicional e sua pressuposta e alardeada tendência ao fracasso frente às demandas e custos crescentes que este modelo implicaria, seriam apenas seus sintomas não refletindo a profunda estrutura social desse fenômeno. (LUHMANN, 2002, p. 47). 
Partindo, pois, dos conceitos tradicionais de cidadania e de Estado de Bem-Estar Social formulados por T. H. Marshall (1964) - relacionado ao surgimento e evolução de direitos civis, políticos e sociais -, Luhmann (2002, p. 47-48) busca redefinir essa forma de Estado a partir do conceito sociológico de inclusão enquanto "incorporação da população global nas prestações dos diferentes sistemas funcionais da sociedade”.

Esse movimento sistêmico implicaria não apenas o acesso das pessoas a estas prestações como, também, relações de interdependência entre estes sistemas e os distintos modos de vida individual. ${ }^{206}$

Nesse sentido, se de um lado os sistemas funcionais incorporam toda a população, de outro, porém, tal ocorre apenas nos aspectos em que seu modo de vida possua a respectiva relevância funcional. Assim, em princípio, todos gozariam de capacidade jurídica e proteção legal, todos receberiam educação escolar e todos poderiam adquirir e gastar dinheiro etc.

Contudo, sob essa perspectiva de inclusão e normatividade assumidas por essa nova forma de Estado, a desigualdade efetiva de possibilidades se torna um problema na medida em que a própria diferenciação da sociedade se reproduz de modo não funcional para a superação dessas desigualdades. (LUHMANN, 2002, p. 49).

O desenvolvimento do Estado de Bem-Estar Social seria, então, melhor compreendido como forma de realização do princípio da inclusão no âmbito funcional do sistema político. Isto porque, muito além da mera garantia de condições mínimas de bemestar para cada individuo, a principal consequência dessa diferenciação funcional do Estado seria a incorporação sistêmica e crescente de problemas de natureza cada vez mais distintas, não restritos à melhoria dos níveis mínimos de proteção existentes.

\footnotetext{
${ }^{206}$ Sobre o desenvolvimento histórico desse processo de inclusão/diferenciação funcional, explica Luhmann (2002, p. 48-49): "Este fenómeno que se designa como inclusión tiene también su propio carácter histórico. Sólo hace su aparición una vez disuelta la sociedad estratificada estamentalmente de la antigua Europa. Esta sociedad asignaba a cada persona (mejor: a cada familia) únicamente a un solo estamento. La persona era definida por su estamento de pertenencia, era asi localizada e integrada socialmente. En consecuencia, mediante este esquema de diferenciación de la sociedad, el hombre como entidad social era, a la vez, diferenciado y determinado socialmente. Con el tránsito hacia una diferenciación orientada primariamente a partir del criterio funcional, este orden tuvo que ser abandonado. Pues es obviamente imposible atribuir a las personas al sistema de la religión, la economía, la ciencia, la educación y la política, de forma que cada individuo habite únicamente en uno de ellos. El lugar del antiguo orden lo ocupan las reglas de acceso. El hombre, en tanto que individuo, vive fuera de los sistemas funcionales, pero cada uno debe tener acceso a cada sistema funcional siempre y en tanto que su modo de vida le exija el recurso a las funciones sociales."
} 
Mais do que simplesmente criticar essa conformação social, Luhmann (2002) destaca que o maior problema dessa diferenciação funcional do sistema político diz respeito não aos aspectos intervencionistas e econômicos - a seguir discutidos necessários para a implementação de suas políticas sociais de prestação de serviços públicos e benefícios pecuniários à população, mas sim, aos riscos de sobrecarga funcional do sistema político que tal desenvolvimento implicaria.

Este sistema, na incorporação crescente de problemas e expectativas sociais, restaria ameaçado pela incapacidade de exercer sua função sistêmica essencial de tomar decisões coletivamente vinculantes em razão da crescente complexidade dos temas a serem por ele resolvidos. Trata-se, portanto, de uma crítica funcional à capacidade decisória e vinculante do sistema político expandido através da incorporação crescente de demandas sociais das mais diversas.

Paulo Thadeu Gomes da Silva (2005, p. 111) ressalta a existência no centro do sistema político - no Estado - de uma "abundância de exigências inconsistentes de decisão", o que se constitui como efeito principal da própria diferenciação funcional desse sistema.

Contudo, diferentemente do sistema jurídico, o non liquet não constitui uma de suas cláusulas operativas, sendo possível ao sistema político simplesmente não decidir certas questões que lhe são postas. Sobre essas questões, preleciona o referido professor:

LUHMANN argumenta que a diferenciação interna do sistema político é caracterizada por uma diferenciação de sistemas organizacionais, onde o Estado ocupa o centro e a periferia é ocupada por organizações políticas, tais como partidos políticos e organizações de interesses: o Estado, portanto, é uma organização política. [...]. A função do sistema político, que é a de produzir decisões coletivas vinculantes, não pode ser desempenhada pela ação de cada uma das organizações políticas: a responsabilidade dela é da organização central do Estado, pois que ela deve ocorrer no interior do sistema político. Na periferia não são tomadas as decisões coletivas vinculantes. Ela serve de campo de jogo para as representações dos desejos e dramatização das orientações dos clientes. Por isso o sistema político tem que trabalhar com a possibilidade de não decidir: a bifurcação decisão/não-decisão é, portanto, a transformação e dissolução do paradoxo da unidade da complexidade. Vale dizer, o sistema político, ao contrário do jurídico, pode dar-se ao luxo de não decidir, e por isso mesmo, se no sistema jurídico se impõe a dupla negativa da proibição do não-decidir, no sistema político se manifesta a tripla negativa representada pela não-proibição do não-decidir, o que, paradoxalmente, produz uma margem maior de liberdade àqueles que tomam decisões políticas. (SILVA, 2005, p. 110-111). 
Essa contínua incorporação de demandas sociais pelo sistema político no Estado de Bem-Estar Social é explicada por Luhmann (2002, p.62) através de sua peculiar e tridimensional forma de estruturação comunicacional interna.

A comunicação do sistema político estaria fundada na tríplice diferenciação de seus subsistemas política, administração e público, em razão do que esse sistema social pode superar historicamente sua anterior forma organizacional de ordem estratificada, fundada na relação entre súdito e autoridade, para se constituir, modernamente, num sistema funcionalmente diferenciado de comunicação incorporando hierarquia, divisão de competências e mandatos em sua vertente administrativa. Nesse sentido, explica o autor citado:

A reestruturação se produziu gradualmente. Partindo do fato, organizacional e institucionalmente constituído, do "Estado" (government) e de sua diferenciação interna segundo o esquema da divisão de poderes, a democratização do sistema político conduziu inicialmente à diferenciação de um público politicamente relevante, que em todas as ações políticas participa de modo decisivo (não só em suas atuações "próprias", as eleições). Ademais, como consequência essencialmente da diferenciação dos partidos políticos como organizações permanentes ao longo do século XIX, aparece um âmbito separado de comunicação especificamente política, que se estabelece entre o público e o Estado e serve de canal de mediação entre eles. Com tal estrutura, a política não pode ser concebida já como preparação de atos de domínio, nem como influência sobre o detentor de poder político; constitui um sistema diferenciado para a política dentro do sistema político, portanto, um sistema social complexo, autônomo, que opera e sofre limitações estruturais próprias. Esta diferenciação de público e política (genuína) necessariamente transforma aquilo que anteriormente se entendia como "Estado" e se havia identificado o sistema político. A partir destes dados, no que se segue falaremos apenas de administração (no sentido mais amplo que inclui governo e legislação), para nos referirmos à totalidade das instituições que, apoiando-se em mandatos ou pontos de vista políticos, criam decisões vinculantes. (LUHMANN, 2002, p. 63).

Essa diferenciação interna do sistema político de modo tridimensional redefiniu, assim, os destinatários de que tal sistema dispõe para organizar sua comunicação interna. Tal distinção permitiu uma considerável expansão do tipo de comunicação e também uma maior interdependência em sua dimensão interna a partir da qual o sistema político pode perceber e se relacionar com o seu ambiente externo, filtrando e, por conseguinte, simplificando seus processos comunicativos. (LUHMANN, 2002, p. 62-63).

Nesse contexto comunicacional, se explica a incorporação de demandas sociais pelo sistema político no Estado de Bem-Estar Social porque com essa reestruturação funcional o sistema político se direciona de modo crescente rumo às fronteiras de seu sistema. 
A administração, enquanto governo e seu aparato burocrático institucional, se orienta, de um lado, a partir das premissas colocadas pela política e, de outro, pelo controle da acessibilidade do público, filtrando rigorosamente as possibilidades de perceber os problemas que são relevantes para a sociedade como um todo, bem como os problemas específicos dos demais sistemas sociais.

Restaria, dessa maneira, superado o tradicional caráter hierárquico e assimétrico do poder político na medida em que este deveria se reconduzir, em geral, segundo a seguinte circularidade dinâmica: o público influenciaria a política através das eleições. A política estabeleceria os limites e as prioridades das decisões da administração, inclusive de natureza legislativa. A administração, por sua vez, se vincularia a si mesma e ao público por decisões e este último seguiria reagindo às decisões através das eleições ou mediante outras expressões de opinião apoiadas nestas. (LUHMANN, 2002, p. 64).

Haveria, assim, uma circularidade oficial da comunicação interna desse sistema de modo a equilibrar suas relações de poder a partir da ordem jurídica imposta, sendo essa circularidade comunicacional expressa da seguinte forma:

[...] Uma vez que os grupos funcionais da política, administração e público foram identificados inicialmente com os "órgãos do Estado", parlamento, governo/administração e eleitorado, o modelo hierárquico tradicional pode ser traduzido à imagem de uma circularidade de poder que se move em uma direção. O parlamento dita as leis e atribui os meios para chegar aos fins; o executivo põe em marcha os programas decididos politicamente; o público se submete às decisões e elege, por sua vez, o parlamento. O poder dispõe, ainda que seja em forma circular, de si mesmo, e se desenvolve numa única direção (LUHMANN, 2002, p. 64).

Porém, em que pese essa arquitetura teórica imposta como forma de limitação do poder, segundo reconhece o próprio autor citado, na prática, mal esta fora implantada e se pôde observar que a efetiva circularidade do poder se desvirtuou num movimento circular contrário de sua inicial programação comunicação sistêmica.

Nesse sentido, como buscam descrever as correntes de ciência política de cunho neo-institucionalistas citadas, a própria administração tende na prática a produzir os projetos para a política, se fazendo prevalecer nos comitês parlamentares e institucionais similares. A política, por sua vez, acaba por sugerir ao público, com o auxílio das organizações partidárias, e, acrescente-se, através dos meios de comunicação de massa, o que deve eleger e a razão. Dessa forma, resta ao público tentar influenciar a administração 
valendo-se de canais, os mais diversos, desde as organizações de interesse até o recurso a procedimentos administrativos e judiciais de controle.

Tal "contracircularidade" da comunicação interna do sistema político decorreria da sobrecarga de complexidade das questões sociais impondo-se não apenas em casos excepcionais, mas com certa regularidade no funcionamento do Estado de Bem-Estar Social.

A despeito da importância dessas questões, foge aos objetivos desta tese esgotar a discussão dessas tensões internas ao sistema político, que ficam abertas na própria discussão proposta por Luhmann (2002) para a reformulação da teoria política no Estado de Bem-Estar Social.

Tendo em vista os objetivos desse trabalho, cumpre, contudo, esclarecer que, segundo o referido autor, seria função própria do direito justamente manter contrafactualmente a circularidade oficial desse fluxo de comunicação, através das competências reguladas juridicamente para a superação dos conflitos internos a este sistema. (LUHMANN, 2002, p. 65).

Essa função normativa não implica na submissão do sistema político ao jurídico nem na perda de sua autopoiese. A esse respeito, discorre Paulo Thadeu Gomes da Silva (2005) em sua tese sobre as relações sistêmicas entre Constituição, sistema jurídico e questão política:

\begin{abstract}
A decisão política - quer assuma forma de programa do sistema jurídico quer se constitua em critério auto-imunizador do sistema político - que engendra uma questão política e que é objeto de análise judicial, uma vez não sendo convertida em questão jurídica, permanecendo como nãojurídica, é observada pelo sistema político como a garantia e a confirmação de sua auto-imunização à análise de outro poder. $\mathrm{O}$ fato de existir o controle jurídico do poder e ser aplicado ao caso jurídico não exclui a possibilidade, conforme já escrito, de que o próprio sistema político, v.g., o Estado, lance mão de controles políticos de poder autocontrole e controle pelo Legislativo. Exercitar o controle jurídico do poder, o que é feito pelo Judiciário, não implica em relação de hierarquia ainda que, conforme escreve LUHMANN, o espaço de liberdade concedido para as political questions tenha que ser juridicamente permitido. (SILVA, 2005, p. 113).
\end{abstract}

Depreende-se, portanto, como as políticas públicas acabam condicionadas juridicamente. Nesse mesmo sentido, Maria Paula Dallari Bucci (2008, 2006) define políticas públicas, de um modo geral, como “arranjos institucionais complexos, expressos 
em estratégias ou programas de ação governamental, que resultam de processos juridicamente regulados, visando adequar meios e fins". (BUCCI, 2008, p. 251).

Tem-se assim, a regulação jurídica do processo de formulação e implementação de políticas públicas, a partir das disposições constitucionais. Sob essa perspectiva processual, a referida autora complementa seu conceito jurídico de política pública, situando-a como

[...] o programa de ação governamental que resulta de um processo ou conjunto de processos juridicamente regulados - processo eleitoral, processo de planejamento, processo de governo, processo orçamentário, processo legislativo, processo administrativo, processo judicial - visando coordenar os meios à disposição do Estado e as atividades privadas, para a realização de objetivos socialmente relevantes e politicamente determinados. Como tipo ideal, a política pública deve visar a realização de objetivos definidos, expressando a seleção de prioridades, a reserva de meios necessários à sua consecução e o intervalo de tempo em que se espera o atingimento dos resultados. (BUCCI, 2006, p. 39).

No que diz respeito aos direitos sociais, como será retomado a seguir em matéria de Seguridade Social, Paulo Thadeu Gomes da Silva (2010, p. 69) explica que estes direitos "são positivados nas normas constitucionais sob o formato de políticas públicas a serem criadas e implementadas pelos Poderes Executivo e Legislativo e a serem controladas pelo Poder Judiciário". 207

Nessa mesma linha, em sua dissertação acerca do Poder Judiciário e as políticas públicas de previdência social, conclui Giselle de França e Amaro (2010, p. 157):

É importante ressaltar que o Judiciário não cria políticas públicas, mesmo quando fornece uma solução no caso de omissão do poder competente. Trata-se de uma regra específica a resolver apenas e tão somente aquela hipótese. [...]. Em qualquer caso, quer quando o Judiciário se manifesta sobre uma política pública já existente, quer quando é instado a se pronunciar nos casos de omissão, não há formulação de política pública, mas apenas adequação dos atos praticados pelos demais Poderes (ou que deveriam ter sido) à ordem jurídica. E assim deve ser efetivamente, já que a medida da intervenção judicial está estritamente relacionada à questão

${ }^{207}$ Em relação aos limites à atuação do Poder Judiciário no citado controle de políticas públicas, assim preleciona o jurista citado: "De acordo com a compreensão jurisprudencial que vem sendo construída pelos Tribunais no país e, em geral, pelo Supremo Tribunal Federal, o Poder Judiciário se limita, em regra, a controlar a constitucionalidade da política pública, vale dizer, não a cria, pois a criação é de competência do Poder Legislativo e do Poder Executivo. A exceção fica por conta daquelas situações que representem um limite entre a sobrevivência digna e a indignidade, conforme se percebe dos julgados que se referem ao direito à saúde e à educação quando implicarem o mínimo existencial." (SILVA, 2010, p. 69). 
democrática, não sendo dado ao Poder Judiciário desbordar das suas atribuições constitucionais e exercer as funções típicas dos outros Poderes.

Ademais, no Brasil, a descrita contracircularidade comunicacional, mais do que amplificar as questões políticas de seu Estado de Bem-Estar Social, acabou por impulsionar todo um movimento de sua desconstrução normativa através de reformas políticas e da sistemática adoção de normas inconstitucionais de redução de seus sistemas de proteção social. (FRANÇA, 2010; PAULANI, 2008; SAVARIS, 2008; TAVARES, 2005; BUCCI, 1995).

Contra essa distorção comunicacional, cabe ao direito manter os sentidos e expectativas sociais normatizados constitucionalmente acerca das políticas públicas do projetado Estado de Bem-Estar Social brasileiro, fazendo-os prevalecer na programação comunicacional interna do sistema político, através da imposição jurídica à administração da simples execução das medidas necessárias para a implementação das políticas já delimitadas na própria Constituição Federal para a efetivação desses direitos sociais.

\subsubsection{Direito da Seguridade Social e sua função sistêmica no direcionamento das políticas públicas de saúde, previdência e assistência social no Brasil}

Cumpre, assim, contextualizar essa ampla abordagem sociológica sobre políticas públicas e Estado de Bem-Estar Social na realidade brasileira. Tal contextualização requer a consideração da diferenciação sistêmica própria dos sentidos e das expectativas normativas acerca da Seguridade Social, retomando, para tanto, o que fora delimitado sobre a conformação desse subsistema jurídico em âmbito nacional no trabalho de mestrado (CRUZ, 2007, p 267-282) que precede e, em parte, fundamenta teoricamente a presente tese.

Nesse aspecto, restou demonstrado na referida dissertação que o sentido do termo Seguridade Social resiste a uma definição simples e inequívoca.

A dificuldade na delimitação do sentido do termo Seguridade Social, segundo Marcus Orione Gonçalves Correia e Érica Paula Barcha Correia (2008, p. 15), decorre “do próprio conceito jurídico, mutável pela evolução das circunstâncias e dos sistemas de organização social e, sobretudo, pela diferente perspectiva política e jurídica adotada pelos Estados que a institucionalizam". 
Por sua vez e de certa forma restrita à sua inicial identificação como Estado Social, Moacyr Velloso Cardoso de Oliveira (1987) propõe uma definição voltada para a ideia de seguro social garantido pelo Estado, para quem a Seguridade Social representa o

[...] conjunto de medidas adotadas pelo Estado, por meio de organizações próprias ou subvencionadas, destinadas a prover as necessidades vitais da população do país, nos eventos básicos previsíveis e em outras eventualidades, variáveis segundo as condições nacionais, que podem verificar-se na vida de cada um, por meio de um sistema integrado de seguro social e de prestação de serviços sociais. (OLIVEIRA, 1987, p. 21).

Assim, tal qual a crítica de Luhmann (2002), já citada, se depreende desse primeiro conceito que Oliveira (1987) restringe tal definição basicamente à noção de Estado Social e ao aspecto da relação direta e prestacional entre este e os beneficiários desse sistema de proteção social.

Por sua vez, Ilídio das Neves (1996) defende a abrangência desse sistema jurídico de proteção social em sentido próximo ao de inclusão e interdependência sistêmica apontada por Luhmann (2002).

Não obstante se reconheça a sua variabilidade em diferentes sistemas sociais, ainda assim, para Neves (1996) haveria certo consenso, ao menos na Europa, em torno da existência e natureza imprescindível da Seguridade Social, referida por esse jurista português através da expressão "Segurança Social”, daí porque afirma:

Um pouco por toda a Europa a Segurança Social constitui uma realidade coletivamente assumida que, nos seus aspectos essenciais, permanece indiscutível, para além de todas as controvérsias. Se é certo que ela se apresenta com formas e funções muito variadas, permanece solidamente um denominador comum de grande latitude que exprime a sua missão fundamental: assegurar de forma organizada a proteção dos cidadãos contra determinados riscos da existência, pois se considera que os seus efeitos danosos não interessam apenas individualmente às pessoas, mas também à sociedade como um todo. Daí a particular responsabilidade reconhecida ao Estado no conjunto das diferentes políticas sociais. (NEVES, 1996, p. 19). ${ }^{208}$

\footnotetext{
${ }^{208}$ Essa assertiva do referido autor baseia-se não apenas em sondagens de opinião elaboradas pela Comissão Europeia como no próprio reconhecimento da necessidade de sistema de proteção social pelos próprios críticos da segurança social. Nesse sentido afirma: "Na realidade, verifica-se que, em geral, mesmo os mais energicamente críticos da segurança social e, desse modo, mais convictamente propugnadores de iniciativas privadas de proteção, não negam a necessidade ou, pelo menos, não recusam a conveniência de haver um conjunto de modalidades de proteção social da iniciativa e da responsabilidade do Estado, ou seja, garantidas por ele. Pode assim afirmar-se que há hoje um amplo consenso neste domínio fulcral, embora apareçam
} 
Portanto, sob essa perspectiva de proteção social, destaca-se desde já a importância da Seguridade Social para os diversos sistemas sociais, na medida em que a “segurança social mergulha as suas raízes profundamente na sociedade”. (NEVES, 1996, p. 20).

Em termos sistêmicos, a Seguridade Social integra os processos comunicacionais de diversos sistemas sociais, não apenas do jurídico como parte de "um sistema de garantia de direitos sociais", como, por exemplo, do próprio sistema econômico, uma vez considerada "no plano das pessoas enquanto agentes econômicos, caso em que falamos de segurança social como um sistema de garantia de rendimentos ou de transferências". (NEVES, 1996, p. 20).

Ademais, essa "grande interdisciplinaridade da Segurança Social que apresenta uma considerável variedade de articulações interativas com outras realidades e outros sistemas" decorre, segundo Neves (1996, p. 21), da diversidade de modelos a partir dos quais pode ser implementado esse sistema de proteção social. Em suas palavras:

A concretização dos objetivos da proteção, que constitui a missão
fundamental da Segurança Social, apresenta um quadro muito
diversificado de soluções, em natural adequação às características das
sociedades concretas, aliás, sujeitas a mudanças, em que se insere. Esta
circunstância condiciona a concepção do próprio Direito da Segurança
Social, dos regimes jurídicos das prestações, das técnicas de
financiamento e das formas de gestão. (NEVES, 1996, p. 21).

Sendo assim, seria possível demonstrar essas inter-relações entre diversos sistemas em torno da Segurança Social através de pelo menos quatro "razões" para a existência de sistemas organizados de Seguridade Social de iniciativa estatal, quais sejam:

(i) razão econômica: relaciona-se aos "efeitos materiais negativos (perda de rendimentos) que os vários riscos da existência (incapacidade para o trabalho, desemprego, família, velhice, invalidez, morte, bem como a doença)" apresentam na sociedade moderna, não se restringindo a um questão meramente individual de responsabilidade de cada cidadão, "mas dizem respeito a toda a sociedade, no seu conjunto". 209

como extremamente diversificadas os pontos de vista sobre a dimensão que essas iniciativas públicas devem apresentar". (NEVES, 1996, p. 21).

${ }^{209}$ Em função dessa dimensão coletiva, esses "riscos de existência" devem ser considerados como riscos sociais. Sendo assim, de acordo com o referido autor, a "superação dos efeitos danosos dos riscos sociais exprime, desse modo, um interesse coletivo, atinente ao bem comum, ao equilíbrio da atividade produtiva e à repartição dos rendimentos assim gerados, a que o Estado, cuja dimensão é servir a sociedade, com justiça e 
(ii) razão social: justifica a existência do sistema de proteção social público e coletivo na incapacidade previdencial dos cidadãos de "tomarem pessoalmente medidas de autoproteção contra as consequências dos riscos sociais". Na medida em que o Estado dispõe de informações mais completas sobre os riscos e sua incidência, os poderes públicos devem suprir essa omissão ou incapacidade de agir das pessoas em face do interesse coletivo de que tais riscos não as afetem excessivamente, comprometendo a própria sociedade.

(iii) razão jurídica: diz respeito à incorporação dos "princípios orientadores do direito pessoal dos cidadãos a determinada forma de proteção pela segurança social" ao sistema jurídico em seus diversos níveis, tanto nacional (constitucional, legal e administrativo regulamentar), quanto internacionais (tratados, convenções, direito comunitário etc.). ${ }^{210}$

(iv) razão politica: a implementação do sistema de proteção social, do qual faz parte a Segurança Social, através da atuação dos órgãos do poder político apresenta-se como uma espécie de diferenciação funcional desse sistema que "na garantia de direitos sociais aos cidadãos deu origem a compromissos e a expectativas, que atravessam transversalmente as sociedades modernas". (NEVES, 1996, p. 20-24).

Essa atuação do Estado torna-se o centro das discussões sobre a Seguridade Social, uma vez que esta compreende os direitos sociais à saúde, à assistência social e à previdência social, os quais por sua própria natureza demandam a ação estatal.

Acerca dessa estreita relação entre direitos sociais e políticas públicas, afirma Maria Paula Dallari Bucci (1995, p. 17):

A "compensação" das condições sociais dos mais favorecidos e dos pobres, pela mediação do Estado, é o que define o Welfare State. Esse modo de atuação do Estado, não mais limitado ao "governo das leis", mas transcendendo-o com um "governo de políticas", as quais se realizam pela efetividade dos chamados direitos sociais, é o diferencial jurídico do século XX. Os direitos sociais, cuja existência justifica a formulação das políticas públicas de educação, saúde, previdência e assistência como processos de eliminação de desigualdades, estariam num plano diferente

equidade, deve dar resposta adequada, como noutras situações (segurança, educação, justiça, etc.). Por isso mesmo, muitos dos riscos da existência passaram a se considerados riscos sociais, cuja ultrapassagem deve ser feita de forma coletiva e mediante organismos públicos adequados”. (NEVES, 1996, p. 22).

210 Portanto, restringir a segurança social à sua razão econômica é um equivoco interpretativo da complexidade assumida por esse sistema. De acordo com Neves (1996, p. 23): "Constitui um erro de análise, porque distorce a realidade objetiva dos fatos, a perspectiva puramente economicista da segurança social que faz tabua rasa do patrimônio jurídico existente em matéria de proteção social". 
dos direitos individuais. Enquanto os últimos, direitos de liberdade, asseguram a igualdade de todos perante o Estado, os primeiros consagrariam certa forma de equiparação, em nome da promoção da igualdade de oportunidades sociais.

Nesse mesmo sentido, preleciona Fábio Konder Comparato (2001, p. 200):

Os direitos sociais, ao contrário [das clássicas liberdades individuais], têm por objetivo não uma abstenção, mas uma atividade positiva do Estado, pois o direito à educação, à saúde, ao trabalho, à previdência social e outros do mesmo gênero só se realizam por meio de políticas públicas, isto é, programas de ação governamental. Aqui, são os grupos sociais inteiros, e não apenas indivíduos, que passam a exigir dos Poderes Públicos uma orientação determinada na política de investimentos e de distribuição de bens; o que implica uma intervenção estatal no livre jogo do mercado e uma redistribuição de renda pela via tributária.

Ainda sob essa dimensão nuclear, Correia e Correia (2008) propõem a compreensão da Seguridade Social a partir de três perspectivas:

a) Perspectiva politica - Sob essa perspectiva a Seguridade Social tem em primeiro plano e como finalidade a proteção da necessidade social, ou seja, estende-se a toda a sociedade e tem como prestador o Estado, em missão fundamental.

b) Perspectiva jurídica - Quanto à perspectiva jurídica, refere-se ao meio ou instrumento com que se pretende almejar a finalidade de proteção às necessidades sociais, por meio de uma organização normativa instrumental e das relações jurídicas decorrentes.

c) Em face da sociedade atual - Destarte, pode-se, hoje, afirmar que o conceito de Seguridade Social equivalente à Previdência Social (destinada, apenas, à prestação dos chamados seguros sociais) está ultrapassado, cedendo lugar a uma noção assistencial, que supera todas as deficiências contidas na estrutura da Previdência Social, inclusive o mecanismo clássico de seguro privado. (CORREIA; CORREIA, 2008, p. 15-16).

Cumpre ressaltar, no entanto, que essa nova "noção assistencial", da qual se extrai o sentido mais amplo de Seguridade Social, não está restrita à organização e execução de serviços sociais, mas decorre diretamente da ampliação das atribuições do Estado Democrático de Direito.

Nesse aspecto, Ivanete Boschetti (2003), destaca o redimensionamento da atuação do Estado e a ampliação das políticas públicas relacionadas a essa matéria:

A Constituição de 1988 institucionalizou o conceito de Seguridade Social para designar uma forma nova e ampliada de implementar e articular políticas já existentes no Brasil desde o início do século XX. Esta Constituição tem o mérito de introduzir um novo conceito e propor uma reestruturação e reorganização inovadoras das políticas que passam a 
compor esta área: previdência, saúde e assistência. Mas não é a Carta Magna que decreta o surgimento da Seguridade Social. Inexistente em língua portuguesa, este termos é utilizado desde 1935 nos Estados Unidos e desde a década de 1940 nos países capitalistas da Europa para designar um conjunto variável de programas e serviços sociais.

Em face das transformações dos sistemas sociais e do consequente aumento da complexidade do sistema de Seguridade Social, suas citadas finalidades de "proteção da necessidade social" e de "organização normativa instrumental" não podem mais ser interpretadas de forma restrita às prestações do Estado no sentido tradicional do Estado Providência ou Estado Social, embora se reconheça a persistência e a importância de seu papel na efetivação dos direitos fundamentais e na garantia da dignidade da pessoa humana.

Foram, assim, acrescidas outras funções essenciais ao Estado no que diz respeito não apenas à Ordem Social, na qual se insere a Seguridade, como à própria Ordem Econômica (Títulos VII e VIII da Constituição Federal de 1988).

Nessa linha, destaca-se a atuação estatal nas atividades de caráter social e econômico, seja esta última em sentido estrito ou amplo, que tenham implicações diretas ou indiretas na efetivação e manutenção dos direitos fundamentais. (GRAU, 2003, p. 82-83).

Ressalte-se, contudo, o cuidado em não se restringir essas transformações funcionais do Estado a um juízo superficial que possa, por ventura, sugerir a adoção de um modelo interpretativo simplista e equivocado de substituição ou negação do Estado Providência por um "Estado Regulador". A esse respeito, afirma Denise Cristina Vasques (2004, p. 153):

Acredita-se que esta nova maneira de agir [como controlador e fiscalizador das atividades empreendidas pela iniciativa privada] possibilita o enxugamento do Estado. Este se torna diminuído se comparado à máquina do Estado Provedor. No entanto, o que se vê é que aquela postura não leva, necessariamente, a uma diminuição do aparelho do Estado. O que ocorre é que, ao deixar a iniciativa privada preencher [alguns] espaços que antes eram estatais, o poder público viu-se compelido a intervir na atuação privada para possibilitar a realização de suas políticas públicas. Ou seja, o Estado pretende realizar políticas públicas por meio de agentes privados. Para isso, deve controlar suas atividades. Houve uma mudança da atuação do Estado, mas não necessariamente uma diminuição de suas tarefas e de seu aparato.

É justamente a partir dessa "mudança da atuação do Estado" que o conceito de Seguridade Social e a nova "noção assistencial" nele introduzida devem ser reinterpretados. 
Portanto, ao lado de toda a estrutura pública de serviços sociais que continuam sim a serem prestados diretamente pelo Estado através do Regime Geral de Previdência Social, do Sistema Único de Saúde e de sua rede de assistência social, acrescenta-se às suas atribuições um rígido controle das atividades complementares (não substitutivas!) a esses serviços públicos, como as iniciativas privadas de previdência e assistência à saúde.

Nesse sentido, ao tratar da "Concretização Constitucional do Princípio da Democracia Econômica e Social”, em relação às novas funções do Estado, afirma José Joaquim Gomes Canotilho (1997, p. 326-327):

\begin{abstract}
A Constituição, ao impor aos órgãos do Estado a criação de pressupostos materiais para a realização da democracia social e econômica, atribuiu também ao Estado funções de Estado de terceira ordem. Isto significa que o quadro das funções do Estado não se reduz à manutenção da segurança interna e externa do Estado, à manutenção de uma ordemquadro para o exercício da liberdade política e econômica (funções de Estado de primeira ordem). Também as funções do Estado não se reconduzem a uma política de $<<$ intervenção $>>$ e $<<$ estímulos $>>$ com o fim de criar instrumentos de <<integração $>>$ necessários à organização capitalista da economia (funções de Estado de segunda ordem). Avançouse para funções de Estado de terceira ordem que pressupõem intervenções qualitativas na ordem econômica existente. Estas intervenções não se limitam a uma função de direção (Steuerung durch Recht, Lenkungrescht) ou de <<coordenação $>>$ de uma $<<$ economia de mercado $>>$. São instrumentos de transformação e modernização das estruturas econômicas e sociais [...].
\end{abstract}

Ademais, Eliane Romeiro Costa (2003, p. 38) compreende que "a Seguridade pode representar tanto política de prevenção quanto política de proteção dos riscos", sendo assim, acrescenta tratar-se "de um conjunto de medidas gerais para a melhoria econômica do conjunto social e [não apenas] de políticas de atendimento prestacional individual".

Concebida como "um instrumento protetor, garantindo o bem-estar material, moral e espiritual de todos os indivíduos da população" (ALMANSA PASTOR, 1977, p. 60), a Seguridade Social estende seus princípios, sua lógica interpretativa, enfim, sua autopoiese, aos subsistemas previdenciário, assistencial e sanitário tanto em sua perspectiva política (de proteção das necessidades sociais) quanto em sua perspectiva jurídica (enquanto organização normativa instrumental).

Tem-se, nesse contexto, que tal sistema de proteção social ocupa uma posição de destaque na Constituição Federal brasileira de 1988 entre os direitos e garantias fundamentais da República, especificados em seu Título II. No artigo $6^{\circ}$ são reafirmados 
os direitos sociais, dentre os quais, em linhas gerais, encontram-se "[ [...] a saúde, [...] a segurança, a previdência social, a proteção à maternidade e à infância, [e] a assistência aos desamparados". (BRASIL, 1988).

Por sua vez, ao ser tratada no contexto da Ordem Social no Título VIII, delineou-se a sua abrangência, sendo a Seguridade Social definida no artigo 194 como "o conjunto integrado de ações e iniciativas dos Poderes Públicos e da sociedade, destinadas a assegurar os direitos relativos à saúde, à previdência e à assistência” (BRASIL, 1988).

Observa-se, portanto, a inserção da Seguridade no Constitucionalismo Social enquanto “processo de 'socialização' de algumas liberdades públicas". (CORREIA, 2003, p. 10).

A compreensão da dimensão e da importância do Constitucionalismo Social na conformação do sistema de Seguridade Social brasileiro requer uma sintética digressão histórica relativa à ruptura proposta por esse movimento e os novos processos comunicacionais dela decorrentes que vieram a se estabelecer entre o direito, a política, a econômica e os demais sistemas sociais.

Lucyla Tellez Merino (2006, p. 89) situa o desenvolvimento do Constitucionalismo Social como forma de resistência e objeção ao movimento de 1789 que dera origem um Estado não intervencionista e liberal.

Nesse sentido, ao analisar a passagem do Estado Liberal para o Estado Social, Ronaldo Lima dos Santos (2003, p. 255), destaca que:

[...] o crescimento da intervenção estatal na vida da sociedade e a busca de igualdade material, trouxe à baila a necessidade de salvaguarda dos hipossuficientes e de suprir as carências dos menos favorecidos nas áreas de saúde, da cultura, da educação, da participação política e do acesso à justiça. O modelo de igualdade meramente formal é, gradativamente, substituído por um novo modelo que vai buscar a igualdade material.

A partir do desgaste desse modelo liberal e da crise do individualismo que o fundamentava, buscou-se a redefinição da atuação estatal na sociedade daí advindo o Estado Social de Direito. Essa nova forma de organização social, embora "tivesse seu princípio no Liberalismo", buscou "promover um Estado de Direito privilegiando o seu cunho social, como forma de fomentar um Estado de Bem-Estar Social”. (MERINO, 2006, p. 89).

No que diz respeito ao sistema jurídico nacional, segundo Paulo Thadeu Gomes da Silva (2010, p. 23): 
O constitucionalismo social, no Brasil, teve início com a Constituição de 1934, esta que trouxe em seu texto, além dos clássicos direitos individuais, uma ordem social protetora dos direitos trabalhistas. Essa mudança de enfoque ocorre pela urbanização do país como um todo e pela mudança da estrutura social do poder, que sai das mãos da oligarquia agrária e vai parar sob o manto de uma burguesia da cidade, o que coincide com o fim da República Velha.

O Constitucionalismo Social refere-se, portanto, à evolução da sociedade no sentido de novos processos comunicacionais que, do ponto de vista histórico, tem como marco as Constituições mexicana de 1917 e alemã de Weimar de 1919. (CORREIA, 2003, p. 10).

A importância da Carta Política mexicana de 1917, segundo Comparato (2001), reside no fato de ter sido "a primeira a atribuir aos direitos trabalhistas a qualidade de direitos fundamentais, juntamente com as liberdades individuais e os direitos políticos (arts. $5^{\circ}$ e 123 )", precedendo, inclusive, a consciência europeia de direitos humanos, cuja "dimensão social só veio a se afirmar após a grande guerra de 1914-1918”. (COMPARATO, 2001, p. 184).

A Constituição mexicana de 1917 representou já no início do século XX uma "reação ao sistema capitalista" na medida em que estabeleceu a "desmercantilização do trabalho" deslegitimando, por conseguinte, "as práticas de exploração mercantil do trabalho, e, portanto da pessoa humana, cuja justificativa se procurava fazer, abusivamente, sob a invocação da liberdade de contratar”. Os seus avanços em relação à proteção da pessoa humana estenderam-se sob a propriedade privada, posto que “aboliu [...] o caráter absoluto e 'sagrado' da propriedade privada, submetendo-se o seu uso, incondicionalmente, ao bem público, isto é, ao interesse de todo o povo". (COMPARATO, 2001, p. 187-188).

Por sua vez, a Constituição de Weimar de 1919, instituidora da Primeira República alemã, apesar de posterior à mexicana de 1917, teve grande impacto sobre o Constitucionalismo Social.

Teria, assim, influenciado decisivamente a própria "evolução das instituições políticas em todo o Ocidente". Em sua declaração de direitos e deveres fundamentais, essa histórica Constituição não se limitou às clássicas liberdades individuais sendo a elas somadas os “novos direitos de conteúdo social”. (COMPARATO, 2001, p. 199). 
Destaca-se, ainda segundo Comparato (2001, p. 201), que "[tanto na Constituição de Weimar de 1919], como na Constituição mexicana de 1917, os direitos trabalhistas e previdenciários são elevados ao nível constitucional de direitos fundamentais".

A partir desses novos processos comunicacionais, inicia-se uma ruptura epistemológica com a inserção dos direitos sociais entre os direitos e garantias fundamentais do Estado Democrático de Direito.

Por conseguinte, é possível observar uma modificação do próprio conceito de liberdade que, se antes podia ser visto "sob a lógica do indivíduo de forma isolada, hoje [entende-se que] somente há liberdade onde ela possa crescer de forma a propiciar o engrandecimento de todos os indivíduos" (CORREIA, 2003, p. 10). ${ }^{211}$

A esse respeito, afirma Paulo Thadeu Gomes da Silva (2010, p. 32-32):

[...] as fronteiras existentes entre os conceitos de direito individual e direito social se dissipam cada vez mais. Vale dizer, cada vez mais direito de liberdade e direito à prestação se confundem num único todo, fazendo cair por terra a surrada distinção dos direitos fundamentais por gerações [...]. Portanto, e agora num raciocínio próprio, é de se destacar que a igualdade não anda separada da liberdade e que esta não pode ser exercitada sem o oferecimento de condições fáticas, sejam estas referentes à inexistência de censura prévia, sejam relacionadas à existência de condições materiais minimamente adequadas à fruição do direito de liberdade, raciocínio esse que produz consequências diretas na tese aqui apresentada e defendida, pois que, tomado como correto, a liberdade vai exigir um juízo de comparação para ser compreendida como direito. Traduzindo: pode-se afirmar que há liberdade em uma sociedade na qual não são ofertadas prestações sociais mínimas aos cidadãos, vale dizer, sem educação pública de qualidade, sem saneamento básico, sem acesso à saúde pública? A negativa parece se impor.

A importância dessas considerações é estabelecer as relações auto-referenciais próprias entre os processos de dotação de sentido e operacionalização dos subsistemas previdenciário, assistencial e sanitário e o nível sistêmico mais abrangente da Seguridade Social relacionado ao campo constitucional dos direitos sociais fundamentais.

211 A esse respeito, embora não em termos estritamente sistêmicos, conclui Dallari (1998, p. 305): "Com efeito, as doutrinas individualistas exaltaram a liberdade individual, mas concebendo cada indivíduo isoladamente. Ora, se todos reconhecem que o homem é por natureza um ser social, é evidente que se deve conceber sua liberdade tendo em vista o homem social, o homem situado, que não existe isolado da sociedade. A liberdade humana, portanto, é uma liberdade social, liberdade situada, que deve ser concebida tendo em conta o relacionamento de cada indivíduo com todos os demais, o que implica deveres e responsabilidades". 
Outro fator relevante dessa diferenciação funcional da sociedade moderna e por consequência do próprio sistema jurídico refere-se ao impacto que a redefinição do conceito e da abrangência dos direitos fundamentais exerce sobre a eficácia das garantias constitucionais, inclusive nas relações privadas que devem ser permeadas pela atuação do Estado, fenômeno ao qual não está imune, por exemplo, os setores privados referentes à previdência e saúde complementares ao sistema público.

A repercussão prática dessas considerações acerca da evolução dos direitos fundamentais, de sua interpretação e aplicação sobre o sistema jurídico inclusive sobre os sistemas privados de previdência, assistência e saúde, integrantes da Seguridade Social, em que pese seu caráter "complementar", pode ser depreendida das seguintes considerações de Gilmar Ferreira Mendes (1998, p. 237-238):

Os direitos fundamentais são concebidos, originariamente, como direitos subjetivos públicos, isto é, como direitos do cidadão em face do Estado. Se considerar que os direitos fundamentais são prima facie direitos contra o Estado, então parece correto concluir que todos os Poderes exercentes de funções públicas estão diretamente vinculados aos preceitos consagrados pelos direitos e garantias fundamentais. [Razão pela qual] [...] os direitos fundamentais obrigam todos os Poderes do Estado, seja o Legislativo, Executivo ou o Judiciário, nos planos federal, estadual e municipal. Nesse contexto, assume relevo questão relativa ao grau dessa vinculação, especialmente à aplicação desses direitos e garantias fundamentais nas relações privadas.

A partir desse pressuposto, o atual ministro do Supremo Tribunal Federal acrescenta o dever de proteção atribuído ao Estado em face dessas relações privadas:

A concepção que identifica os direitos fundamentais como princípios objetivos legitima a ideia de que o Estado se obriga não apenas a observar os direitos de qualquer indivíduo em face das investidas do Poder Publico (direito fundamental enquanto direito de proteção ou de defesa Abwehrrecht), mas também a garantir os direitos fundamentais contra agressão propiciada por terceiros (Schutzpflicht des Staats). [...] Essa interpretação do Bundesverfassungsgericht empresta sem dúvida uma nova dimensão aos direitos fundamentais, fazendo com que o Estado evolua da posição de 'adversário' (Gegner) para uma função de guardião desses direitos (Grundrechtsfreund oder Grundrechtgarant). (MENDES, 1998, p. 242-243).

Some-se a essa positivação gradativa em nível constitucional dos sistemas jurídicos nacionais, o desenvolvimento no plano internacional da teoria dos direitos humanos no sentido de sua universalidade e indivisibilidade. 
Segundo Flávia Piovesan (2004, p. 14), se inicialmente os direitos humanos nascem como direitos naturais universais, estes passaram gradativamente a se desenvolver como direitos positivos particulares, direitos fundamentais positivados em cada Constituição, fruto do processo de incorporação das declarações internacionais de direitos humanos, ou em termos autopoiéticos, dos acoplamentos estruturais entre os diversos sistemas sociais que compõe a sociedade global, atingindo "sua plena realização como direitos positivos universais". ${ }^{212}$

Tais considerações acerca da indivisibilidade e interdependência entre os direitos individuais, civis e políticos, e os direitos sociais - dentre os quais se encontram os relativos à Seguridade Social - apresentam-se como fundamentais para a defesa destes direitos sociais enquanto direitos fundamentais e a compreensão de sua influência nos processos de seleção de sentido do sistema jurídico como um todo.

Nessa mesma linha, afirma Marcus Orione Gonçalves Correia (2004, p. 28):

Diga-se, ainda, que não há qualquer novidade neste reposicionamento dos direitos sociais, já que se trata de uma natural evolução do status conferido a estes. A verdade é que os direitos fundamentais deixaram de ser concebidos apenas a partir da perspectiva das liberdades públicas - em que se buscava do Estado apenas uma postura passiva. Os direitos fundamentais da pessoa humana devem ser concebidos, portanto, não apenas a partir da perspectiva individual, mas também à luz dos direitos sociais. Aliás, não há como se conceber a consolidação destes direitos fundamentais apenas da perspectiva do indivíduo isoladamente considerado, mas também a partir de sua inserção na coletividade. Aliás, temos constantemente afirmado que esta nova visão dos direitos fundamentais, com uma perspectiva mais social, é sentida de forma mais comum a partir da ideia de que o próprio constitucionalismo teria sofrido profundo impacto das Constituições mexicana de 1917 e de Weimar de $1919 .{ }^{213}$

${ }^{212}$ A citada autora destaca ainda o caráter indivisível dos direitos humanos, sendo, para a compreensão do desenvolvimento do Constitucionalismo Social, oportuno transcrever a contextualização internacional e história por ela sintetizada: “Além do alcance universal dos direitos humanos, a Declaração Universal [de 1948] também inova ao consagrar que os direitos humanos compõem uma unidade indivisível, interdependente e inter-relacionada, na qual os direitos civis e políticos hão de ser conjugados com os direitos econômicos, sociais e culturais. Vale dizer, a Declaração rompe com as concepções anteriores decorrentes das modernas Declarações de Direitos que apenas ressaltavam ora o discurso liberal da cidadania (Declarações francesa e americana do final do século XVIII) ora o discurso social (Declaração do povo trabalhador e explorado da então República Soviética Russa do início do século XX). Até então os valores liberdade e igualdade vinham divorciados. A Declaração de 1948 vem a inovar prevendo, de forma inédita, que não há liberdade sem igualdade, e não há igualdade sem liberdade. (PIOVESAN, 2004, p. 15).”

${ }^{213}$ Nesse mesmo sentido, poderia ainda ser citado Hector Gros Espiell (1986) e sua importante contribuição nesse tema, transcrita por Flávia Piovesan (2002) ao tratar da indivisibilidade e interdependência 
A partir do posicionamento estratégico dos direitos sociais no contexto constitucional (no Título II do texto constitucional, que trata justamente dos "direitos e garantias fundamentais") e em razão da própria teoria dos direitos humanos, concebida a partir da inovação introduzida pela Declaração Universal de 1948, conclui-se que a Seguridade Social deve ser interpretada e concretizada sob a ótica constitucional dos direitos e garantias fundamentais, da solidariedade social e da primazia da dignidade da pessoa humana, fundamento de nosso Estado Democrático de Direito, conforme o art. $1^{\circ}$, inciso III, da Constituição Federal brasileira de 1988.

Sob essa ótica constitucional torna-se possível, ademais, a discussão desses mecanismos autorreferenciais do sistema jurídico, indispensáveis para se alcançar o sentido e o funcionamento desse amplo sistema de Segurança Social (CORREIA, 2005, p. 252.) e para a própria delimitação da dinâmica dos processos de seleção e dotação de sentido de seus subsistemas previdenciário, assistencial e sanitário.

Isto porque, de acordo com Eros Roberto Grau (2002, p. 207), “interpretar não é apenas compreender [...], consubstancia operação de mediação que consiste em transformar uma expressão em uma outra coisa". ${ }^{214}$

Dessa forma, conforme Marcus Orione Gonçalves Correia (2005, p. 253): “o sistema de Segurança Social é um sistema que se encontra, a partir de 1988, originariamente em sede constitucional", sendo assim, acrescenta o referido autor, "passou a ser segurança normativa e, mais, segurança normativa-constitucional”.

Em decorrência de tais considerações, a seleção dos sentidos e a operacionalização de questões relacionadas à Seguridade Social, como aquelas pertinentes

características dos direitos humanos: "Só o reconhecimento integral de todos estes direitos pode assegurar a existência real de cada um deles, já que sem a efetividade de gozo dos direitos econômicos, sociais e culturais, os direitos civis e políticos se reduzem a meras categorias formais. Inversamente, sem a realidade dos direitos civis e políticos, sem a efetividade da liberdade entendida em seu mais amplo sentido, os direitos econômicos, sociais e culturais carecem, por sua vez, de verdadeira significação. Esta ideia da necessária integralidade, interdependência e indivisibilidade quanto ao conceito e à realidade do conteúdo dos direitos humanos, que de certa forma está implícita na Carta das Nações Unidas, se compila, se amplia e se sistematiza em 1948, na Declaração Universal de Direitos Humanos, e se reafirma definitivamente nos Pactos Universais de Direitos Humanos, aprovados pela Assembleia-Geral de 1966, e em vigência desde 1976, na Proclamação de Teerã de 1968 e na Resolução da Assembleia-Geral, adotada em 16.12.1977, sobre os critérios e meios para melhorar o gozo efetivo dos direitos e das liberdades fundamentais (Resolução n. 32/130)”. (ESPIELL, 1986, p. 16-17 apud PIOVESAN, 2002, p. 41).

${ }^{214}$ No que diz respeito à interpretação do direito, tem-se que a "interpretação é atividade que se presta a transformar disposições (textos, enunciados) em normas; é meio de expressão dos conteúdos normativos das disposições, meio através do qual o juiz desvenda as normas contidas nas disposições”. (GRAU, 2002, p. 39). 
à previdência, assistência social e saúde, sejam elas de ordem pública ou privada, devem ser feitas "a partir da Constituição e não a partir dos atos administrativos que, aparentemente, possuem efeito normativo". (CORREIA, 2005, p. 252).

Tratando-se, pois, da interpretação constitucional faz-se necessário considerar a função elementar dos princípios.

Segundo Eros Grau (2003), a interpretação constitucional é marcada pela ponderação dos valores da sociedade que através da Constituição passam a fazer parte do sistema jurídico na forma de princípios explícitos e implícitos. Em função dessa conformação do sistema jurídico, tais princípios devem ser considerados "como conformadores da interpretação das regras constitucionais". (GRAU, 2003, 143). ${ }^{215}$

Por essa razão, o referido autor afirma que "todo intérprete estará sempre vinculado pelos textos de direito, em especial pelos que veiculam princípios". (GRAU, 2002, p. 209).

215 Deve-se ainda ressaltar a classificação utilizada por Grau (2003, p. 136), para o qual "o sistema que o direito é compõe-se de: [i] princípios explícitos, recolhidos no texto da Constituição ou da lei; [ii] princípios implícitos, inferidos como resultado da análise de um ou mais preceitos constitucionais ou de uma lei ou conjunto de textos normativos da legislação infraconstitucional (exemplos: o princípio da motivação do ato administrativo, art. 93, X, da Constituição; o princípio da imparcialidade do juiz, arts. 95, parágrafo único, e $5^{\circ}$, XXXVII da Constituição); e [iii] princípios gerais de direito, também implícitos, coletados no direito pressuposto, qual o da vedação do enriquecimento sem causa". Outra importante classificação dos princípios a ser considerada é proposta por Canotilho (1983) para quem os princípios jurídicos constitucionais se dividem em: “a) princípios jurídicos fundamentais, assim entendidos os 'princípios historicamente objetivados e progressivamente introduzidos na consciência jurídica geral e que encontram uma recepção expressa ou implícita no texto constitucional' (aí os princípios da publicidade dos atos jurídicos; da proibição do excesso - o que importa exigibilidade, adequação e proporcionalidade dos atos dos poderes públicos; o princípio do acesso ao direito e aos tribunais; o princípio da imparcialidade da Administração); b) princípios políticos constitucionalmente conformadores, entendidos como tais os 'princípios constitucionais que explicitam as valorações políticas fundamentais do legislador constituinte' (aí os princípios definidores da forma de Estado - onde os princípios da organização econômico-social; os princípios definidores da estrutura do Estado - unitário ou federal, com descentralização local ou autonomia local; os princípios estruturantes do regime político - princípio do Estado de Direito, princípio democrático, princípio republicano, princípio pluralista etc.; e os princípios caracterizadores da forma de governo e da organização política em geral separação e interdependência dos poderes, princípios eleitorais etc.); c) princípios constitucionais impositivos, entendidos assim os princípios constitucionais nos quais 'subsumem-se todos os princípios que no âmbito da constituição dirigente impõem aos órgãos do Estado, sobretudo ao legislador, a realização de fins e a execução de tarefas'; tais princípios [...] são muitas vezes designados por 'preceitos definidores dos fins do Estado', 'princípios diretivos fundamentais' ou 'normas programáticas, definidores de fins ou tarefas' (aí o princípio socialista, o princípio da socialização dos meios de produção etc.); d) princípios-garantia, nos quais incluídos 'outros princípios que visam instituir direta e imediatamente uma garantia dos cidadãos'; a eles é 'atribuída a densidade de autêntica norma jurídica e uma força determinante positiva e negativa'; por se traduzirem no estabelecimento direto de garantias para os cidadãos, são chamados de 'princípios em forma de norma jurídica' (aí o princípio do nullum crime sine lege e de nulla poena sine lege, o princípio do juiz natural, os princípios de non bis in idem e in dúbio pro reo)" (CANOTILHO, 1983, p. 200-203). 
Essa vinculação aos princípios estará sempre presente na operacionalização e nos processos de seleção de sentido com os quais interage o intérprete do direito em sua interpenetração com esse sistema social na concretização da norma em cada caso concreto.

Ademais, a atribuição dessa função aos princípios é possível graças ao seu sentido deontológico que obriga seu destinatário "igualmente, sem exceção, a cumprir as expectativas generalizadas de comportamento". (GRAU, 2002, p. 112). ${ }^{216}$

Nessa linha, ao tratar da interpretação constitucional da Seguridade Social, conclui Marcus Orione Gonçalves Correia (2005, p. 268):

[...] que a interpretação no sistema de Segurança Social é uma interpretação essencialmente de princípios e que os princípios relevam os conceitos constitucionais dentro de um patamar de unidade político-constitucional. Obtido o conceito, a partir dos princípios, tem-se que todo subsistema infraconstitucional, e também a atuação da administração pública, deve se submeter a esse conceito constitucional. A interpretação deve se fazer à luz desta perspectiva e daquela segundo a qual os direitos sociais são direitos fundamentais: portanto, ao lado dos direitos fundamentais individuais, existem os direitos fundamentais sociais, e a estes segundos se aplica toda a metodologia de interpretação e de dicção do direito que é aplicável aos primeiros, no sentido de maximização dos resultados.

A Seguridade Social como um todo deve ser interpretada essencialmente a partir dos princípios normatizados, implícita ou explicitamente, nos arts. 1º, $3^{\text {o }}, 194$ e seguintes da Constituição Federal de 1988, com especial destaque para a solidariedade social e a maximização da dignidade da pessoa humana. (VILLELA, 2004, p. 41).

Ademais, como restou discutido a partir do extenso levantamento histórico realizado na dissertação de mestrado que precede este trabalho, tais expectativas generalizadas pela Constituição Federal de 1988 resultam dos acoplamentos estruturais entre os diversos sistemas sociais que participaram do amplo movimento comunicacional da formação desse sistema maior de proteção social. (CRUZ, 2007).

\footnotetext{
216 Ao tratar da função essencial dos princípios na conformação do novo direito, frente ao processo de “desestruturação do direito formal/moderno" decorrente da "crise do Estado Moderno", afirma Grau (2002, p. 109-110): "De seu renovar-se [a ideia de direito em seu processo de contínua evolução] vamos tomando consciência, paulatinamente. A teoria jurídica volta-se aos princípios jurídicos, salientando a sua importância, seja porque o modo formal de aplicação do direito (direito formal) não satisfaz socialmente, seja porque o direito moderno (direito posto pelo Estado) não viabiliza, por si só, a fluência das relações sociais e o dinamismo da circulação mercantil, carente de formas renovadas de legitimação. E a verificação de que os princípios são normas jurídicas, ao lado das regras - o que converte norma jurídica em gênero, do qual são espécies os princípios e as regras jurídicas - abre novas vias de indagação, riquíssimas, para os que se dedicam à teoria do direito".
} 
A força normativa desse sistema jurídico diz respeito, portanto, à manutenção pelo direito, como verdadeiras normas jurídicas cogentes e autoaplicáveis, de tais expectativas normativas em relação à Seguridade Social.

\subsubsection{Os sentidos da solidariedade social e a manutenção da confiança no Sistema de Seguridade frente às propostas de desconstrução de suas políticas públicas}

Para a consideração dos efeitos da cobertura midiática sobre os sentidos das políticas públicas de seguridade social, cumpre a delimitação inicial do que se entende por solidariedade social. Esta, em linhas gerais, pode ser entendida como a relação de interdependência entre os indivíduos, caracterizada pela cooperação, pela igualdade de oportunidades e pela busca do bem-estar de todos. (PONTES, 2006, p. 05).

Uma vez positivada pela direito, a solidariedade passa a ser considerada por este sistema social sob a perspectiva dos princípios jurídicos, inseridos no ordenamento jurídico brasileiro.

Como fora introduzido acima, tal princípio jurídico produz efeitos sobre toda a Seguridade Social, sendo fundamental na manutenção da dignidade da pessoa humana e no respeito dos direitos sociais, através de políticas públicas de proteção das pessoas que se encontrem em situações de necessidade decorrentes de contingências sociais. ${ }^{217}$

Alan Oliveira Pontes (2006, p. 81-118), em sua dissertação de mestrado acerca do "princípio da solidariedade social na interpretação do Direito da Seguridade Social”, realiza um extenso levantamento histórico e sociológico acerca da evolução do conceito de solidariedade.

O referido pesquisador desenvolve seu trabalho a partir da sistematização do pensamento de Emile Durkheim (1989), Pitirim Alexandrovich Sorokin (1951; 1968), Léon Duguit (1927; 2003), John Rawls (2002; 2003) e Pedro Demo (2001; 2002), bem como da doutrina social da Igreja Católica sobre os fundamentos da solidariedade, esta última

\footnotetext{
${ }^{217}$ Por essas razões, é possível destacar como exemplo de seus efeitos sobre esse subsistema jurídico que, em decorrência do princípio da solidariedade social, na interpretação das normas relacionados ao custeio da Seguridade Social deve prevalecer o interesse da coletividade em detrimento do interesse individual. Da mesma forma, sob a ótica da concessão de benefícios deve ser dada maior importância à manutenção da dignidade humana e à proteção social, do que aos aspectos econômico, financeiro e atuarial do sistema.
} 
centrada na ideia de justiça social e no atendimento das necessidades básicas por meio de obras de misericórdia motivadas pela caridade fundada no amor cristão pelo próximo. ${ }^{218}$

José Carlos de Castro Farias (1998, p. 190), destaca, porém, para o fato de que, somente no final do século XIX, a solidariedade passou a não mais se confundir com caridade ou com filantropia, tendo Emile Durkheim (1989) como um dos contribuintes da sistematização desta diferenciação. ${ }^{219}$

Para Pitirim Alexandrovich Sorokin (1968, p. 146-180), seria possível a identificação de três tipos de relações sociais: (i) aquelas de natureza predominantemente solidárias, (ii) as predominantemente antagônicas, e (iii) as relações sociais mistas. ${ }^{220}$

Ainda segundo o referido autor, na maioria dos grupos organizados normalmente se observaria a existência de coerção e de sanção através do sistema jurídico. Sendo assim, caso não existisse antagonismos entre as aspirações dos membros e as normas jurídicas, e tudo estivesse em perfeita harmonia, não haveria necessidade da sanção ou da coerção. (SOROKIN, 1968, p. 146).

Por sua vez, segundo a síntese de Alan Oliveira Pontes (2006, p. 98-101), para Léon Duguit (2003), apesar de compreendido como um ser autônomo, o homem seria essencialmente social, vivendo em comunidade através de laços de solidariedade social inerentes às suas relações sociais. Viveria, ademais, consciente de sua interdependência para com o grupo social, e por esta razão permaneceria ligado às outras pessoas.

Partindo de tais pressupostos, a solidariedade social seria entendida como a força de coesão da sociedade, de modo que, quanto mais estreitos forem os laços de solidariedade, mais forte será a sociedade. Desse modo, todas as pessoas estariam

\footnotetext{
${ }^{218}$ Em que pese a seguinte síntese de seus sentidos generalizados socialmente, cumpre, porém, desde já destacar que a solidariedade social, enquanto princípio jurídico, não pode ser compreendido como simples promotor de ações eventuais, de cunho ético, moral ou caritativo, mas sim como um princípio dotado de completa força normativa e capaz de tutelar o respeito devido a cada pessoa. (MORAES, 2003, p. 141).

219 Para Emile Durkheim (1989), a solidariedade estaria associada à sociabilidade inerente ao ser humano. Nesse sentido, existiriam dois tipos de solidariedade social: (i) a solidariedade "mecânica ou por semelhanças", resultante das semelhanças entre as pessoas e da prevalência de certa "consciência coletiva" sobre a consciência individual; e, como segundo tipo, a (ii) solidariedade "orgânica". Esta última seria decorrente da divisão do trabalho e da diferenciação entre os indivíduos.

${ }^{220}$ Porém, segundo Sorokin (1968, p. 146), os grupos puramente solidários, como a "família perfeita" ou a interação entre amigos íntimos seriam raros, prevalecendo relações mistas com certas nuances na maioria dos grupos organizados. Dessa forma, relacionando solidariedade ao direito, seria possível compreender a existência de solidariedade forçada, por meio da coerção estatal para unir as partes e impedir a dissolução onde prevalecem relações sociais de ordem antagônica.
} 
obrigadas a cooperar na solidariedade social, impondo-se a cada uma delas obrigações diferentes e impedindo a realização de qualquer ato atentatório à solidariedade social. $\mathrm{O}$ sentimento de solidariedade social ainda que em diferentes graus, existiria em todos os seres humanos. (DUGUIT, 1927, p. 86).

Quanto à noção de solidariedade no pensamento de John Rawls (2002; 2003), para este autor a sociedade democrática estaria fundada na ideia de cooperação social e de uma concepção pública de justiça. Tal cooperação social estaria estritamente relacionada às ideias de reciprocidade, mutualidade e à busca de bem-estar para cada um. (RAWLS, 2003, p. 20-21).

Assim, todos os cidadãos seriam considerados iguais, sendo, por sua vez, as desigualdades sociais aceitas tão somente se estas resultarem no máximo de benefícios e vantagens aos menos favorecidos. A vida social restaria, portanto, baseada numa cooperação social justa em que todos trabalhariam e desempenhariam suas funções na distribuição de responsabilidades, desde que isto se desenvolva de forma equitativa, restando, o bem-estar de cada pessoa diretamente ligado ao modelo de cooperação social. (PONTES, 2006, 101-106).

Por fim, de acordo com Pedro Demo (2002, p. 62), as ações de solidariedade não devem ser reduzidas a "efeito de poder", em função do que resultariam em medidas meramente assistencialistas. Tais ações precisariam superar seu caráter assistencialista e promover a emancipação das pessoas que se encontrem em situações de necessidade ou em situações de pobreza. (DEMO, 2002, p. 209).

Sob essa última perspectiva, os homens estariam dispostos a cooperar uns com os outros dentro de um grupo social tanto por motivos egoísticos quanto por motivos benevolentes, mas sempre perseguindo seus interesses, o que só seria possível em sociedade. Desse modo, a construção de relações solidárias dependeria da efetiva redistribuição do trabalho coletivo de maneira mais igualitária entre as pessoas, através do Estado e de suas políticas públicas.

Voltadas essencialmente às questões sociais, tais políticas de cunho emancipatório deveriam, assim, ter por finalidade a libertação da pobreza. Isto porque, à medida que tais políticas forem capazes de promover a redistribuição não apenas da renda, mas também do poder, a qualidade de vida de cada indivíduo passará a ser vinculada à qualidade de vida de todos, tornando o grupo social mais apto a sobreviver do que grupos não-solidários. (PONTES, 2006, p. 210). 
A partir dessas diferentes perspectivas, tem-se em comum que a solidariedade social aponta para a ideia de responsabilidade social "na qual cada pessoa se responsabiliza por todo o grupo e todo o grupo se responsabiliza por todas as pessoas". (PONTES, 2006, p. 211).

Dessa forma, a ideia de solidariedade se contrapõe aos valores liberais burgueses, na busca do equilíbrio social e do reconhecimento da importância única de cada indivíduo. Daí porque, afirma Fábio Konder Comparato (1999):

Foi justamente para corrigir e superar o individualismo próprio da civilização burguesa, fundado nas liberdades privadas e na isonomia, que o movimento socialista fez atuar, a partir do século XIX, o princípio da solidariedade como dever jurídico, ainda que inexistente no meio social a fraternidade Como virtude cívica. A solidariedade prende-se à ideia de responsabilidade de todos pelas carências ou necessidades de qualquer indivíduo ou grupo social. E a transposição, no plano da sociedade política, da obligatio in solidum do direito privado romano (D. 45, 2, 11). $\mathrm{O}$ fundamento ético desse princípio encontra-se na ideia de justiça distributiva, entendida corno a necessária compensação de bens e vantagens entre as classes sociais, com a socialização dos riscos normais da existência humana. [...]. Com base no princípio da solidariedade, passaram a ser reconhecidos corno direitos humanos os chamados direitos sociais, que se realizam pela execução de políticas públicas, destinadas a garantir amparo e proteção social aos mais fracos e mais pobres, ou seja, aqueles que não dispõem dos recursos indispensáveis para viver dignamente.

No que diz respeito ao direito, propriamente dito, tem-se que a solidariedade social apresenta-se como um dos princípios fundamentais da Seguridade Social brasileira e de todo sistema social acoplado constitucionalmente. ${ }^{221}$

Ademais, para José Fernando de Castro Farias (1998) o direito de solidariedade é inerente à própria democracia, sendo que, no Estado Democrático de Direito, por seu discurso solidarista, o direito de solidariedade estaria sobreposto ao individualismo em matéria de organização social e política.

221 Apenas de maneira complementar, cumpre ressaltar que em matéria de direito civil, a solidariedade relaciona-se às medidas acautelatórias do direito das obrigações, como garantia que reforça o direito do credor disponibilizando-lhe certa facilidade para realização do crédito na medida em que lhe permite exigir o montante total da dívida de todos os credores solidários. Ao lado desta forma passiva de solidariedade há a previsão legal da solidariedade ativa relacionada à pluralidade de credores e à faculdade conferida a qualquer um destes de exigir toda a dívida. Seria possível, mesmo a partir dessa perspectiva civilista, identificar na solidariedade a coincidência de interesses juridicamente tutelados e a ideia de um fim comum tutelado cuja unidade seria imprescindível, uma vez que a própria noção de solidariedade estaria relacionada da ideia de algo sólido. (PONTES, 2006, p. 81-82). 
Para o referido autor, não há liberdade sem solidariedade, nem solidariedade sem liberdade, da mesma forma que não seria possível democracia sem que as pessoas se conscientizassem de suas liberdades e de suas responsabilidades, pois não se alcança a democracia onde prevalecem desigualdades sociais. (FARIAS, 1998, p. 276-285).

Enquanto princípio jurídico, a solidariedade social impõe a mobilização de parte da população em favor das pessoas em situação maior de risco ou em efetiva contingência social.

Dessa forma, estariam obrigados os jovens em favor dos idosos, os trabalhadores empregados em benefício dos desempregados involuntariamente, os vivos em favor das famílias dos segurados falecidos, os que recebem mais renda em favor daqueles que pouco ou nada recebem. Haveria, portanto, justamente em função do princípio da solidariedade social, a obrigação de todos em "contribuírem na medida de sua possibilidade e usufruem das prestações na medida de sua necessidade”. (PONTES, 2006, p. 211).

Nesse mesmo sentido, Antonio Rodrigues de Freitas Junior (1993, p. 34) compreende o Estado de Bem-Estar Social como um mecanismo complexo de acumulação de capital para, a partir daí, promover o bem-estar social, a partir de certa solidariedade coercitiva.

O princípio da solidariedade social restaria, por conseguinte, intimamente relacionado ao princípio da dignidade da pessoa humana, sendo que as políticas de solidariedade social devem ter por fim garantir uma vida digna para todas as pessoas que dela dependerem. Isto porque, segundo Ingo Wolfgang Sarlet (2008, p. 63):

[...] temos por dignidade da pessoa humana a qualidade intrínseca e distintiva de cada ser humano que o faz merecedor do mesmo respeito e consideração por parte do Estado e da comunidade, implicando, neste sentido, um complexo de direitos e deveres fundamentais que assegurem a pessoa tanto contra todo e qualquer ato de cunho degradante e desumano, como venham a lhe garantir as condições existenciais mínimas para uma vida saudável, além de propiciar e promover sua participação ativa e corresponsável nos destinos da própria existência e da vida em comunhão com os demais seres humanos.

Nesse aspecto, destaca-se a pobreza como principal causa do desrespeito ao princípio da dignidade humana, na medida em que impede que as pessoas atinjam a defendida condição digna. (VILLELA, 2006).

Assim, como preleciona Lucyla Tellez Merino (2006, p. 215): 
Solidariedade é a visão do reflexo de nossa condição humana no outro, o que nos faz agir com consciência da preservação da dignidade da pessoa, da própria vida como valor de fundo a ser protegido. Não é o agir pelo impulso da comiseração, ou do afastamento do incômodo, ou de modo paliativo.

Ainda de acordo com Antonio Rodrigues Freitas Junior (1993, p. 67), a erradicação da miséria absoluta e uma melhor distribuição de riqueza, instrumentalizadas pela solidariedade social em questão, constituem-se como objetivos da justiça social e, assim, como condição de democracia para a solução de desigualdade material.

Portanto, em função do princípio jurídico da solidariedade social, impõe-se normativamente que as políticas públicas sejam implementadas no sentido de melhor distribuir a renda socialmente produzida, reduzindo as desigualdades sociais e garantindo o mínimo existencial a todas as pessoas, o que se apresenta como condição essencial à superação da marginalização social rumo a descrita emancipação social. (PONTES, 2006, p. 211).

Por sua vez, como será discutido a seguir, não se compatibiliza com esse sentido normativo, a comunicação difundida pelas principais organizações midiáticas brasileiras, quando repercutem a visão parcial dos sistemas político e econômico relacionadas às reformas do sistema de proteção social brasileiro em busca de uma suposta eficiência econômica e não do aumento do nível de bem-estar social, analisadas por Maria Paula Dallari Bucci (1995, p. 117).

Enquanto princípio jurídico, a solidariedade social está presente no direito brasileiro sendo previsto na Constituição Federal de 1988 - CF/88 tanto em seu Preâmbulo, quanto de maneira tanto explícita como implícita em seus artigos $1^{\circ}$, inciso III; $3^{\circ}$, incisos I, III e IV , 4 , inciso IV, 170, 193, 194, parágrafo único e incisos I ao IV caput do artigo 195.

Nesse sentido, o referido princípio jurídico tem como finalidades promover uma redistribuição de renda em sociedade que permita uma redução das desigualdades sociais, realizar a cooperação mútua entre todos os seus membros, promover a liberdade real e contribuir para a manutenção de um Estado Democrático no qual todos tenham iguais oportunidades de participação.

No que diz respeito diretamente à Seguridade Social, tem-se que do princípio da solidariedade social deveriam os seguintes princípios: a) universalidade da cobertura e do atendimento (artigo 194, I, CF/88); b) uniformidade e equivalência dos benefícios e serviços às populações urbanas e rurais (artigo 194, II, CF/88); c) seletividade e 
distributividade na prestação dos benefícios e serviços (artigo 194, III, CF/88); d) equidade na forma de participação no custeio (artigo 194, V, CF/88); e) diversidade na base de financiamento (artigo 195, caput, CF/88); f) compulsoriedade da contribuição (artigo 149, $\mathrm{CF} / 88$ ); g) filiação obrigatória (artigo 201, caput, CF); h) caráter contributivo (artigo 201, caput, $\mathrm{CF} / 88$ ); i) garantia do benefício mínimo (artigo 201, $\left.\S 2^{\circ}, \mathrm{CF} / 88\right){ }^{222}$

No mais, enquanto espécie normativa, o princípio da solidariedade social se impõe tanto nas relações particulares quanto públicas.

No âmbito do poder público, tem-se que todas as funções estatais - normativa, administrativa e jurisdicional - devem se pautar pelo descrito princípio. Daí porque, o Poder Legislativo não tem competência para editar normas infraconstitucionais e mesmo reformas à Constituição Federal que contrariem os postulados da solidariedade social. Do mesmo modo, cabe ao Poder Executivo atender na implementação das políticas públicas ao comando de solidariedade social e, ao Poder Judiciário, decidir buscando otimizar a cooperação social que fundamenta o sistema jurídico. (PONTES, 2006, p. 211-212).

Maria Celina Bodin de Moraes (2003, p. 138) e Wladimir Novaes Martinez (2001, p. 132) defendem que o princípio da solidariedade social deve nortear a elaboração da legislação ordinária, a execução de políticas públicas, a interpretação e a aplicação do direito.

Quanto aos efeitos deste princípio sobre a atuação do poder executivo bem como sobre a interpretação judicial, destaca ainda Marcus Orione Gonçalves Correia (1996, p. 88) que na relação processual entre Instituto Nacional do Seguro Social - INSS e a pessoa que requer a concessão de direitos sociais, o INSS deve defender o "interesse público que congrega tanto a necessidade daquele segurado contra o qual litiga, como a dos demais."

Sendo assim, no caso de dúvida, a partir da análise no caso concreto, segundo o referido jurista, deve-se buscar a partir da maximização tanto do princípio da solidariedade social quanto do princípio da dignidade da pessoa humana e bem-estar social. (CORREIA, 1996, p. 96).

\footnotetext{
${ }^{222}$ No que diz respeito ao custeio desse sistema de proteção social, segundo Alan Oliveira Pontes (2006, p. 195): "Considerando a existência do comando constitucional de se construir uma sociedade solidária, a atuação do Estado na captação de recursos financeiros deve estar em sintonia com os objetivos de solidariedade e não apenas como mero meio de se obter recursos." Nesse mesmo sentido, para Ricardo Lobo Torres (2005, p. 200), a contribuição social está norteada pelo princípio da solidariedade social, de modo que se a finalidade de redistribuição de renda não for buscada, a contribuição será inconstitucional.
} 
Isto porque, como fora exposto, a Seguridade Social tem como objetivo a proteção dos indivíduos em situação de necessidade, também entendida como hipossuficiência de status tanto do ponto de vista material, como do ponto de vista psicológico e sociológico, visando, em última instância, propiciar o bem-estar social de todos e uma consequente melhor distribuição de renda, de acordo com o descrito modelo de solidariedade social.

Porém, como destaca José Fernando de Castro Farias (1998), o fenômeno da globalização, fundado no modelo neoliberal, tem gerado resultados desastrosos nos campos econômico e social, atentando contra o descrito princípio da solidariedade social:

[...] desmantelamento das relações sociais, enfraquecimento dos laços de solidariedade, esvaziamento das organizações da sociedade civil, profundas desigualdades sociais, problemas cotidianos relacionados à fome, saúde, educação e ao desemprego. E não há mais ordem no centro do que na periferia, pois mesmo os sistemas dominantes, ou seja, mesmo os países que detêm as riquezas e as tecnologias avançadas não escapam aos problemas de gestão do espaço urbano, de desigualdades, de desemprego e de relação com o outro. Em todo lugar podemos facilmente perceber a escalada da intolerância, do egoísmo e da exclusão social. (FARIAS, 1998, p. 02).

Estudos como os de Mariza Velloso Fernandez Conde (1996), Eduardo Navarro Stotz e José Wellington Gomes Araújo (2004) alertam para uma importante mudança no eixo das políticas sociais no sentido do desmantelamento do aparato de proteção social, frontalmente contra os direitos fundamentais declarados $\mathrm{e}$ a responsabilidade assumida pelo Estado brasileiro em 1988. ${ }^{223}$

Tais mudanças têm por objetivo propiciar ajustes estruturais e macroeconômicos inseridos na agenda neoliberal dos anos 1990 que propiciem aos setores privados explorar parte dos serviços de saúde, previdência e assistência rentáveis sob a ótica econômica, sem qualquer compromisso com os princípios e finalidades desse sistema social.

Essas "políticas" de reestruturação têm sido exigidas dos países em desenvolvimento, incluindo o Brasil, pelas agências internacionais de financiamento, como

${ }^{223}$ Diversos autores abordam as origens e consequências do ideário neoliberal nas reformas da Seguridade Social na América Latina Nesse sentido, são os trabalhos de Savaris (2008), Stotz e Araújo (2004), EspingAndersen (2003) Mesa-Lago (2003) e desta última com Müller (2003), bem como de Costa (2001), Farias (1998), Conde (1996) e Bucci (1995), dentre outros. 
o Banco Mundial, conforme se depreende de seu Relatório sobre o Desenvolvimento Mundial, já em 1993. (CONDE, 1996, p. 03). ${ }^{224}$

Esses sentidos são difundidos socialmente pela comunicação produzida tanto pelos sistemas econômico quanto midiático - sob a perspectiva neoliberal de Estado mínimo e do descrito $5^{\circ}$ filtro/programa de seleção de notícias - generalizando a expectativa de que solução para todos os problemas da sociedade somente seria alcançada através do mercado.

Em contrapartida, Maria Celina Bodin de Moraes (2003, p. 136) destaca que, segundo a própria noção contemporânea sobre direito à liberdade, este significa poder efetivamente realizar as próprias escolhas individuais. Por essa razão o próprio princípio da liberdade deve ser interpretado em meio às relações entre pessoas, e, assim, sopesado com o princípio da solidariedade social.

Como alerta José Fernando de Castro Farias (1998, p. 03-05), em função da proeminência ideológica do neoliberalismo, as discussões públicas sobre o Estado e suas políticas sociais teriam se "esquecido" do discurso solidarista, essencial à consolidação da própria democracia através de suas políticas públicas, de um Estado socialmente ativo e do pluralismo da vida social, como fora até aqui exposto.

Nesse contexto, de acordo com Paulo Thadeu Gomes da Silva (2010, p.135), a "superação" da crise do Estado de Bem-Estar Social brasileiro teria sido direcionada para a "privatização de direitos” e o consequente declínio da distinção público/privado.

Para o referido autor, a dificuldade de adjudicação dos direitos sociais relacionados a este modelo de Estado, bem como o apontado movimento de privatização

\footnotetext{
${ }^{224}$ Nesse sentido, Peter Orszag e Joseph E. Stiglitz (2001) questionam os pressupostos econômicos e fáticos do texto paradigmático do Banco Mundial - Adverting the Old Age Crisis, de 1994 a respeito da necessidade de adaptar os sistemas previdenciários delineados nos anos de ouro do capitalismo (pós-segunda guerra mundial até a década de 1970, quando o crescimento econômico garantia as necessidades orçamentárias crescentes do Estado de Bem-Estar Social. Os referidos autores apontam as limitações desse estudo ao tratar o mundo de uma maneira idealizada e homogênea insensível as diferenças entre modelos de Estado de BemEstar e dos países que os implementaram. Demonstram, assim, que a maioria dos argumentos em favor de uma reforma previdenciária que substitua, mesmo que parcialmente, os regimes previdenciários públicos de repartição simples por privados de capitalização individual de contribuição definida, tem se mostrado um conjunto de mitos sem respaldo na teoria ou na prática. E no que concerne particularmente a questão dos riscos, as análises mostram que na maioria dos casos, essas reformas não beneficiariam a maioria dos segurados. Marcelo Alves de Oliveira (2008) demonstra esses mesmos problemas no caso brasileiro, em sua análise do risco nos sistema de previdência complementar nacional.
} 
decorreriam "tanto do conteúdo do texto constitucional, quanto da ação, muitas vezes irresponsável, do sistema político”. (SILVA, 2010, p. 136). ${ }^{225}$

De modo contrário às expectativas normativas referentes ao funcionamento do sistema político e à circularidade oficial de seu fluxo de comunicação, as reformas da Seguridade Social têm sido impulsionadas pelo governo/administração, sendo, assim, impostas ao subsistema da política em sua dimensão partidária e legislativa e ao seu público eleitoral.

Dentre essas reformas, no período recente após a promulgação da Constituição Federal Brasileira de 1988, destacam-se as Emendas Constitucionais - EC n. 20, 41 e 47, referentes aos sistemas de previdência e assistência social, bem como as EC no .29 e 51 referentes ao sistema sanitário. ${ }^{226}$

No plano, infraconstitucional, podem ser citadas as alterações à Lei de Benefícios da Previdência Social (n. 8.213/1991), especialmente a realizada pela lei n. 9.876/1999 que instituiu o fator previdenciário, bem como a implementação das Normas Operacionais Básicas - NOBs responsáveis pela regulamentação da Lei n. 8.080/1990 e implementação do Sistema Único de Saúde - SUS. (BRASIL, 1990; 1991; 1999).

No que diz respeito às NOBs, estas em sua maior parte seriam contrárias ao princípio da universalidade e gestão pública desse sistema sendo apontadas como inconstitucionais por Gilson Carvalho (2001).

Observa-se, desse modo, a existência de uma política sistemática de retração das políticas sociais. Tal processo, de acordo com José Antônio Savaris (2008; p. 52),

[...] se verifica não apenas como uma questão de diminuição de orçamento, mas também como o emprego de um novo modelo dos programas de bem-estar, no qual a noção de provisão social é substituída por uma direção de atuação estatal mais residual. [...]. Governos interessados no encurtamento dos programas sociais podem decretar políticas que diminuam despesas imediatamente, como podem ordenar mudanças cujos efeitos não serão sentidos senão após muitos anos, mesmo porque os defensores das políticas reducionistas buscam estratégias que escondem a magnitude dos custos, minimizando

\footnotetext{
${ }^{225}$ Nesse sentido, afirma Paulo Thadeu Gomes da Silva (2010, p.136): “A diferenciação funcional, contudo, teima em se manifestar, e isso mesmo num país como o Brasil, onde a Constituição é tomada na conta de mero instrumento para a ação política, e não como estrutura para essa mesma ação, o que leva os processos de reforma constitucional a desafiarem os mais complexos conceitos de reflexividade existentes na teoria sociológica contemporânea."

226 As principais alterações normativas realizadas por essas Emendas Constitucionais são detidamente analisadas por Giselle de Amaro e França (2010, p. 50-58).
} 
consequências negativas de curto prazo e, por conseguinte, diminuindo a visibilidade dos impopulares programas de redução.

Em matéria de Seguridade Social, o referido autor destaca ainda como as seguintes alterações em seu subsistema previdenciário atentaram contra o princípio jurídico da solidariedade social, fundamental à efetivação das políticas públicas de proteção social positivadas na Constituição Federal de 1988. Em suas palavras:

[...]. É possível perceber-se que, no período de pouco mais de quinze anos, dá-se restrição não apenas no campo de proteção previdenciária, com a extinção de prestações previdenciárias, inclusive, como igualmente há uma diminuição do conteúdo dos benefícios, especialmente no caso das aposentadorias por tempo de contribuição. Também se pode identificar uma substituição da lógica que determinava a contrapartida previdenciária às contribuições vertidas pelos trabalhadores, fundada na inconstitucionalidade da exigência de contribuição sem causa eficiente, pela lógica que autoriza a exigência de contribuições para a seguridade social dos trabalhadores sem repercussão no nível de seu benefício, fundada em uma perspectiva de solidariedade que impõe ao obreiro aposentado o dever de contribuir para a seguridade social sem qualquer perspectiva de ampliação de cobertura previdenciária. (SAVARIS, 2008; p. 52).

Quanto às políticas sanitárias, por sua vez, Eduardo Navarro Stotz e José Wellington Gomes Araújo (2004) destacam as tensões em torno dos sentidos de promoção da saúde a partir da divergência entre as distintas concepções desse termo e sua definição em diferentes documentos internacionais da Organização Mundial da Saúde - OMS.

Tal conflito é identificado a partir da existência de dois sentidos de promoção em saúde: um generalizado para o centro do capitalismo e outro, para os países que compõem a sua periferia.

Nesse aspecto, enquanto que em documentos europeus, como na Carta de Ottawa de 1986, a promoção é vista como um programa de "redução das diferenças no estado de saúde da população sob o enfoque da equidade em saúde”, por sua vez, para os países pobres ou "em desenvolvimento" como o Brasil passa-se cada vez mais a se propugnar, no que diz respeito a essa mesma promoção em saúde, uma "responsabilização das pessoas pelas suas condições sanitárias".

Esta responsabilização procura "impulsionar a cultura da saúde modificando valores, atitudes e relações" e não as condições estruturais de vida a que essas pessoas são submetidas, como se depreende da Carta de Bogotá de 1992 promovida pela Organização 
Pan-Americana de Saúde - OPAS e das políticas de ajustes estruturais impostas aos países devedores pelo Banco Mundial a partir de 1990. (STOTZ; ARAÚJO, 2004).

A esse respeito, explicam os referidos autores:

De fato, consideramos que uma das mudanças relevantes na prática da saúde pública no Brasil, desde o advento da promoção, tenha sido a sofisticação das estratégias de culpabilização das próprias vítimas da incúria sanitária, além da creditação oficial do condicionamento comportamental (behaviorismo), absolutamente avessas a qualquer pedagogia da problematização. (STOTZ; ARAÚJO, 2004, p. 13).

Por sua vez, como será exemplificado a seguir, os meios de comunicação de massa, em função de seus descritos acoplamentos estruturais políticos e econômicos, generalizam socialmente essa distorção política e econômica dos sentidos normativos da Seguridade Social.

Nesse contexto, a mídia acaba por impulsionar o movimento de sua desconstrução através da cobertura parcial das citadas reformas constitucionais e da edição de normas legais e regulamentares de redução de suas políticas públicas. ${ }^{227}$

Promove-se, assim, a quebra da confiança social no sistema público de proteção social e o impulso comunicacional em favor da desconstrução de políticas públicas voltadas à efetivação dos direitos sociais delineados na Constituição Federal de 1988.

Como fora exposto no segundo capítulo, a confiança sistêmica no direito e em sua capacidade de generalizar expectativas normativas é essencial para a construção da solidariedade social e o funcionamento em si da sociedade, tendo em vista à dinâmica decisória

${ }^{227}$ Esse movimento de desconstrução pela via infraconstitucional e regulamentar foi descrito por Antônio Rodrigues de Freitas Júnior (1993) em sua análise acerca da repercussão na nova conformação dos direitos sociais na Constituição Federal de 1988: "Mesmo sem esconder uma certa amargura e desapontamento com o resultado das votações constituintes, a maioria dos analistas liberais pareceu orientar-se por atitudes de indulgência, procurando secundarizar o que, segundo seu argumento, constituíra uma renovação do pecado original de Weimar. É certo que não faltaram lamentações quanto ao desprezo dos representantes constituintes pelas soluções 'ótimas' de síntese por eles propostas. De modo algum, porém, voltaram progressivamente suas atenções para o segundo round da competição política que se anunciava com o início do debate regulamentar. Na conformidade com os objetivos preconizados por esses setores, a etapa regulamentar seria decisiva na medida em que muitos dos 'direitos' previstos no Texto Constitucional dependiam de complementações legislativas para que pudessem alcançar um patamar mínimo de explicitação e, consequentemente, de eficácia. Nesta direção, a tática recomendada seria naturalmente a que a efetivação dos 'direitos' reconhecidos pelo Texto ocasionaria o aprofundamento da crise da 'governabilidade', tendendo a por em risco a própria ordem constitucional. Na certeza de que o emprego iterativo do recurso à hipótese de retrocesso tenderia ao desgaste - ou mesmo, na medida em que verossímil, comportaria efeitos perversos - a ênfase do discurso liberal recai a partir de então na formulação de argumentos pretensamente técnicos e autorreferidos, ordenados de modo a justificar a inconveniência e/ou a inadequação dos estímulos regulamentares.” (FREITAS JÚNIOR., 1993, p. 07-08). 
dos sistemas sociais e psíquicos frente à crescente complexidade social e à contingência decorrente de sua ampla possibilidade de relações e sentidos. (LUHMANN, 2005b).

A generalização do sentido neoliberal e a tentativa de legitimação políticoeconômica dessas propostas de desconstrução das políticas públicas de Seguridade Social, bem como seu consequente impacto na confiança e solidariedade social podem ser relacionados, portanto, à cobertura midiática parcial e à ausência de efetivo debate público e democrático acerca de tais questões.

\subsection{Os meios de comunicação de massa e a desconstrução das políticas públicas de proteção social}

A discussão pública da pressuposta crise do Estado de Bem-Estar Social brasileiro nos meios de comunicação de massa, quando proposta, na maior parte das vezes acaba sendo falseada pelos descritos filtros/programas sistêmicos de seleção de notícias, sobretudo no que diz respeito à cobertura jornalista do suposto "déficit" previdenciário, como se pretende demonstrar no tópico seguinte a partir das notícias selecionadas.

Apresenta-se, nestes termos, o conflito crescente entre boa parte da comunicação produzida pelas organizações midiáticas e o sistema jurídico nacional acerca delimitação e interpretação dos direitos sociais garantidos constitucionalmente, alvos constantes de propostas políticas e econômicas de reforma, às quais tem se sujeitado esse sistema público de proteção social.

Tal processo comunicacional de desconstrução e de enfraquecimento da confiança e solidariedade social em relação às políticas públicas de proteção social se desenvolve através da redução da esfera pública empreendida pelos meios de comunicação de massa a na tentativa de transformar cidadãos em consumidores dos produtos e ideais de seus patrocinadores. (CHAUI, 2006; CANCLINI, 2001; IANNI, 2000).

Marilena Chauí (2006), ao tratar da anulação das categorias de verdade e falsidade das informações difundidas pela mídia, relaciona o esvaziamento da opinião pública, enquanto questão relativa à vida política, e sua substituição, ao funcionamento dos meios de comunicação de massa. 
Segundo a referida autora, tais efeitos midiáticos resultariam de seu recurso à intimidade, à personalidade e à vida privada como suporte e garantia da ordem pública. Sobre essas questões, afirma:

[...] os códigos da vida pública passam a ser determinados e definidos pelos códigos da vida privada, abolindo-se a diferença entre espaço público e espaço privado. As relações interpessoais, as relações intersubjetivas e as relações grupais [priorizadas pela cobertura midiática da realidade] aparecem com a função de ocultar ou de dissimular relações sociais enquanto sociais e relações políticas enquanto políticas, uma vez que a marca das relações sociais e políticas é serem determinadas por instituições sociais e políticas, ou seja, são relações mediatas [...]. As relações sociais e políticas, que são mediações referentes a interesses e a direitos regulados pelas instituições, pela divisão social das classes e pela separação entre o social e o poder político, perdem sua especificidade e passam a operar sob a aparência da vida privada, portanto referidas a preferências, sentimentos, emoções e gostos, agrado e aversão. (CHAUI, 2006, p. 09).

Esses últimos fatores, subjetivos seriam enaltecidos e disseminados pelos meios de comunicação de massa na medida em que se situam na esfera sensível e não racional, decorrendo daí, o suposto poder midiático do príncipe eletrônico, no entender de Octavio Ianni (2000).

Tal poder estaria relacionado à construção em si da "fortuna" e "virtu" situadas, desde Maquiavel, na esfera privada, promovendo-se, em última instância, uma espécie de deslocamento sutil das decisões políticas para a economia, bem como da arena democrática para o mercado e a transfiguração dos cidadãos em meros consumidores, e das ideologias em mercadorias. (IANNI, 2000, p. 141-166).

Essa colonização do público pelo privado, com o apoio dos meios de comunicação de massa, e o desvirtuamento de seu papel essencial de informar o cidadão, e não de reduzi-los a meros consumidores, no Brasil, podem ser explicados pelos interesses e acoplamentos estruturais envolvendo os grandes grupos de mídia, como se depreende do $1^{\circ}$ filtro/programa de notícias das organizações midiáticas nacionais.

Em decorrência da centralização dos meios de comunicação de massa em grandes organizações empresariais e de sua descrita programação interna, a informação que tem valor central para a construção da esfera pública, deixa de ser constituída pela cidadania e passa, assim como a esfera pública, a ser expropriada pelo mercado para reforçar a assimetria da informação e privatização das informações que deveriam ser públicas. 
De maneira não restrita à Seguridade Social, essa distorção comunicacional é identificada em matéria de direitos sociais trabalhistas, segundo Nilton Hernandes (2004), e sua análise da revista Veja no período de 04/12/1996 a 27/01/1999, intitulada Revista VEJA e o discurso do emprego na globalização.

No referido estudo são analisadas cinco capas do referido periódico, nas quais, a questão trabalhista é abordada sob os seguintes títulos: "O desafio do emprego", na edição de 04/12/1996; “Onde estão os empregos”, na edição de 10/02/1997; "Profissões as mais promissoras - as congestionadas - como escolher a sua", na edição de 20/08/1997; "Você tem medo de perder o emprego?”, na edição de 11/02/1998; e, por fim, “A chave do emprego", na edição de 23/07/1998. ${ }^{228}$

Note-se que, inicialmente, a revista, até aproximadamente a década de 1980, tinha como mote principal a política, em seus mais diversos aspectos econômicos e sociais. Porém, quando a mesma atingiu um número extremamente significativo de tiragens semanais, por volta de um milhão de exemplares, em meados de 1995, uma nova postura editorial foi traçada, tendo em vista as concessões mercadológicas e o direcionamento de seu conteúdo para o que o seu público alvo supostamente "quer ler". Esse público seria formado por leitores de classe média, gente "incorporada à sociedade de consumo" que teria passado a ler a referida revista. (HERNANDES, 2004, p. 23).

Suas pautas de notícias seriam ainda guiadas, segundo Hernandes (2004, p. 23), por meio de "outras publicações, sobretudo, internacionais, como a Times e Newsweek".

Nesse aspecto, o referido autor descreve, ainda, como a pauta desta revista semanal era definida às segundas-feiras, em uma reunião de sua direção editorial. Chama, assim, a atenção para o fato de que o número de editores da revista VEJA ser superior ao seu número de repórteres, conforme se depreendeu da redação apresentada na edição 1533 de 11/02/1998. (HERNANDES, 2004, p. 27).

Tal fato explicita como é menor o número de profissionais - jornalistas - em busca de informações sobre determinado tema e de sua efetiva apuração, se comparado àqueles que vão manipular o decorrente texto informativo produzido, transformando-

\footnotetext{
228 Neste trabalho, Hernandes (2004) pôde ainda observar que a revista em questão se apropriou desta temática trabalhista, inclusive, para sua própria campanha publicitária na edição comemorativa de trinta anos da revista, com o seguinte slogan: "Veja. Não é curriculum, mas é vitae."
} 
o/filtrando-o em "notícia" a ser efetivamente publicada, através de um explícito exercício de controle da informação, do modo e da entonação com que esta será veiculada.

A partir dessa lógica funcional, segundo relata Hernandes (2004), na cobertura “jornalística" da questão trabalhista relativa ao aumento do desemprego em 1997, na edição 1533 da revista Veja, destaca-se a generalização de dois sentidos contrapostos do termo emprego, usualmente difundidos pela referida revista, bem como por outras mídias:

[...]. Em comum, todos têm como meta a manutenção da relação desejável com seu objeto "emprego". O texto, porém, cria dois sentidos diferentes para a palavra. Há uma relação entre o "velho" emprego versus o "novo" emprego, construída de maneira bastante sutil. O primeiro, ligado principalmente à indústria, está desaparecendo. E envolve o ferramenteiro, o gerente de almoxarifado, e até quem não é do setor industrial, como o caixa de supermercado. Mas há os "novos" empregos, como o de operador de telemarketing, relacionados aos setores de serviços. (HERNANDES, 2004, p. 108).

A partir da análise do conteúdo noticiado, o referido trabalho aponta a tendência midiática de "condenação" do pleno emprego. Este estaria fadado a desaparecer, restando destinado o "velho" emprego e sua precarização às pessoas incapazes de se inserirem num mercado competitivo e dinâmico. (HERNANDES, 2004).

Isto porque, da mesma forma que outras organizações empresariais midiáticas, a revista Veja em sua comunicação tende a generalizar um modelo perfeccionista de trabalhador do futuro. Ao mesmo tempo, banaliza-se como consequência natural dessa "evolução" social que as pessoas que não se enquadram nesse padrão sejam empurradas para os empregos precarizados e para o trabalho informal, cada vez mais distantes da manutenção de sua dignidade no exercício do trabalho. ${ }^{229}$

\footnotetext{
${ }^{229} \mathrm{O}$ referido autor sintetiza, assim, o tratamento que a citada revista dispensa ao emprego: "O 'velho' emprego, afirma o texto, está condenado. E já na primeira página da matéria começam a ser apresentados os antisujeitos. Os primeiros são o desenvolvimento tecnológico e a informática. Ambos fazem parte de um sistema de valores que VEJA expõe como o 'novo padrão econômico mundial': a alta eficiência, o baixo custo, e a "tremenda competição". A Revista, ainda na primeira página da matéria, mostra a globalização como a fonte dos valores dos anti-sujeitos. E esclarece que 'o Brasil mergulhou de cabeça nessa nova era, a da globalização ou da internacionalização da economia' devido ao Plano Real, em julho de 1994. O plano aparece nesse momento como um anti-sujeito operador, que dá competência, o poder fazer ao anti-sujeito desenvolvimento tecnológico e informática para realizar a ação de espoliar o emprego dos trabalhadores". (HERNANDES, 2004, p. 108).
} 
O problema do desemprego é assim apresentado e generalizado socialmente como questão a ser enfrentada individualmente, já que a solução oferecida é particularizada, depende apenas da "força de vontade e garra" do trabalhador para se moldar à necessidade contemporânea da atividade econômica. Em outras palavras, a revista Veja está "informando" que a perda do emprego seria decorrente de deficiências do próprio trabalhador. (HERNANDES, 2004).

Reproduz, assim, como comunicação socialmente generalizada a banalização da injustiça social descrita por Christophe Dejours (2010) em sua análise sobre as reais causas do sofrimento no trabalho, relacionadas à sua forma de organização e aos mecanismos sociais de sua negação e não simplesmente à capacidade individual para se adaptar ao "novo" emprego.

Em sua análise da psicodinâmica do trabalho, Dejours (2010) recontextualiza a banalização do mal inicialmente descrita por Hannah Arendt (2007). Nesse aspecto, tal processo não seria restrito aos sistemas totalitaristas sendo também identificado, com certas peculiaridades, no sistema neoliberal. Sob a ótica, o referido autor entende por

[...] banalização do mal não somente a atenuação da indignação contra a injustiça e o mal, mas, além disso, o processo que, por um lado, desdramatiza o mal (quando este jamais deveria ser desdramatizado) e, por outro, mobiliza progressivamente um número crescente de pessoas a serviço da execução do mal, fazendo delas 'colaboradores'. [...]. Tentamos dar a essa questão uma resposta que não se apoia na análise do totalitarismo nem do nazismo, mas do neoliberalismo. Este último também gera injustiça e sofrimento [...]. (DEJOURS, 2010, p. 138).

Com base no estudo do sofrimento nas situações comuns de trabalho, em sua análise da banalização da injustiça social, Dejours (2010, p. 139) demonstra os processos a partir dos quais "tantas pessoas de bem aceitam prestar sua colaboração num novo sistema de gestão empresarial que vai constantemente ganhando terreno nos serviços, na administração do Estado, nos hospitais etc., do mesmo modo que no setor privado.”

A comunicação é destacada por seu papel crucial nesses processos simbólicos de naturalização das contingências sociais e de negação do sofrimento gerados pela ausência ou redução dos mecanismos de proteção social. Daí, porque afirma Dejours (2010, p. 138-139):

Novo sistema que se baseia na utilização metódica da ameaça e numa estratégia eficaz de distorção da comunicação. Sistema que gera adversidade, miséria e pobreza para uma parcela crescente da população, enquanto o país não pára de crescer. Sistema que tem, portanto, papel 
importante nas formas concretas que assume o desenvolvimento da sociedade neoliberal.

Assim, de acordo com o referido pesquisador da psicodinâmica do trabalho moderno, a cada dia se aprimoram os meios de comunicação interna e externa às organizações em que o trabalho se desenvolve de modo a sustentar práticas discursivas falaciosas. Nesse sentido, explica:

O discurso oficial sobre o trabalho e sua organização é pois construído sobretudo para servir a uma propaganda visando ao exterior da empresa: o mercado, a clientela etc. Na verdade, contudo, atualmente ele é também construído para servir a objetivos "internos", da "cultura da empresa", que preconizam o rigoroso ajustamento da produção e da organização do trabalho às exigências do mercado e da clientela, devendo, além disso, atestar a satisfação e a felicidade dos empregados que trabalham na empresa. No todo, a descrição ganha o lisonjeiro título de "valorização", noção que teve um desenvolvimento considerável no discurso modernizado das organizações. A eufemização do real do trabalho e do sofrimento de quem produz não tem nada de novo em si. Também a mentira comercial é bastante antiga. A novidade é a organização das práticas discursivas de "valorização" para dentro da empresa, visando aos atores da organização. (DEJOURS, 2010, p. 65).

Em que pese esses sentidos da comunicação em relação à desconstrução das políticas públicas de Bem-Estar Social, seja em matéria de Seguridade Social, seja quanto aos direitos sociais fundamentais trabalhistas, o princípio da solidariedade social mantémse enquanto norma jurídica constitucionalmente positivada sendo, do ponto de vista sociológico, relacionada à interdependência dos indivíduos em função da divisão do trabalho e da cooperação social para o bem de todos. (PONTES, 2006, p. 16).

Como fora exposto, ao lado da dignidade da pessoa humana, a solidariedade social apresenta-se como princípio fundamental da Seguridade Social. Em decorrência disso, cabe ao direito generalizá-lo enquanto expectativa normativa fundamental ao funcionamento desse sistema de proteção social.

Sem ignorar esses desafios comunicacionais, a Seguridade, a partir de tais princípios, deve se impor contrafactualmente garantindo a seus direitos sociais àqueles que dele necessitem. Para tanto, requer-se a efetivação de políticas públicas voltadas não apenas à sua finalidade última no sentido da promoção de uma melhor distribuição de renda, bem como do aprimoramento e estímulo da cooperação social por meio da manutenção de um Estado que garanta a cada pessoa o mínimo existencial para uma vida 
digna e do combate à descrita distorção comunicação, essencial para se desbanalizar o mal e a injustiça social segundo Dejours (2010, p. 133-135).

\subsubsection{Cobertura midiática e a simulação do consenso acerca das reformas neoliberais de redução dos direitos sociais previstos constitucionalmente}

Cumpre neste último tópico demonstrar como o descrito conflito
comunicacional se apresenta na cobertura realizada pelas grandes organizações empresariais que compõem o sistema dos meios de comunicação de massa no Brasil no que diz respeito a questões significativas de previdência, assistência e saúde, de modo que a confiança e solidariedade sociais acabam reduzidas pelos sentidos e expectativas cognitivas assim generalizados.

Para tanto, foram selecionadas algumas notícias e reportagens representativas da presente tese, veiculadas na mídia impressa dos principais jornais e revistas nacionais, reproduzidas em seus sítios eletrônicos na rede mundial de computadores. Pode-se, assim, observar a disseminação pelos meios de comunição de massa das expectativas dos sistemas sociais político e econômico que financiam suas organizações no sentido da redução das políticas públicas de Seguridade Social e do fomento do mercado privado de serviços de saúde, previdência e assistência.

Quanto à previdência, destaca-se a reprodução maciça de aparentes notícias acerca do pressuposto déficit previdenciário, que, embora questionável, tem sua existência generalizada como um dado objetivo e não como versão governamental, construída a partir da manipulação contábil dos dados orçamentários oficiais, tal como efetivamente se apresenta.

Dessa forma, as medidas políticas de retração desse subsistema de proteção social são banalizadas, fomentando, em contrapartida, o consumo dos serviços privados de previdência e saúde. Nesse sentido, destaca Denise Lobato Gentil (2007a, p. 02):
A imprensa noticia dados trágicos acompanhados de linguagem dramática sobre a situação da previdência social. Um dos argumentos mais repetidos periodicamente pela mídia é de que os déficits crescentes da previdência engessam a administração das contas públicas, restringindo cada vez mais o espaço para investimento pelo Estado.

Ainda segundo a referida professora de economia, os "números utilizados para avaliar a situação financeira da Previdência são normalmente enganosos e alarmistas", isto 
porque, o que tem sido chamado de déficit da Previdência é, entretanto, o saldo previdenciário negativo quando considerada, apenas, a soma de receitas das contribuições ao Instituto Nacional do Seguro Social - INSS dos segurados e daquela incidente sobre a "folha de salários e demais rendimentos do trabalho", deduzidos os benefícios previdenciários. (GENTIL, 2007b, p. 30).

Contudo, não é noticiado que esses cálculos “oficiais” divulgados pelo governo federal e amplamente difundidos pela mídia sem qualquer questionamento

[...] não levam em consideração todas as receitas que devem ser alocadas para a Previdência Social, conforme estabelece o artigo 195 da Constituição Federal de 1988, que versa sobre o orçamento próprio e exclusivo da seguridade social. Deixam-se de computar recursos significativos provenientes da Cofins, CPMF, CSLL e receita de concursos de prognóstico. Essas receitas financiam a saúde, assistência social e também a Previdência. Sem incluí-las no cálculo, o resultado fere os princípios constitucionais e resulta num déficit irreal. Se computada a totalidade das fontes de recurso que cabem à Previdência, conforme disposto na Carta Magna, e deduzida a despesa total inclusive com pessoal, custeio, dívida do setor e gastos não previdenciários, o resultado apurado será um superávit de $\mathrm{R} \$ 921$ milhões em 2005 e $\mathrm{R} \$ 1,2$ bilhão em 2006 (...). Houve superávit em todos os últimos sete anos, com exceção de 2003. Esse superávit, denominado superávit operacional, uma informação favorável ao sistema público de previdência, não é, entretanto, divulgado para a população como sendo o resultado da Previdência Social. (GENTIL, 2007b, p. 30).

Essa manipulação persiste como pode ser observado no "relatório de avaliação orçamentário até o terceiro bimestre de 2010", divulgado pela Secretaria de Orçamento Federal - SOF. (BRASIL, 2010b).

No citado relatório, destaca-se como déficit do Regime Geral de Previdência Social - RGPS o valor de R\$ 45,694 bilhões, excluindo-se, porém, desse cálculo aproximadamente $\mathrm{R} \$ 231$ bilhões em receitas provenientes das demais contribuições sociais que compõe o sistema geral de seguridade, as quais são descontextualizadas neste documento sendo divulgadas dentre as "receitas administradas pela Receita Federal do Brasil e Ministério da Fazenda -RFB/MF”. (Figura 7). 


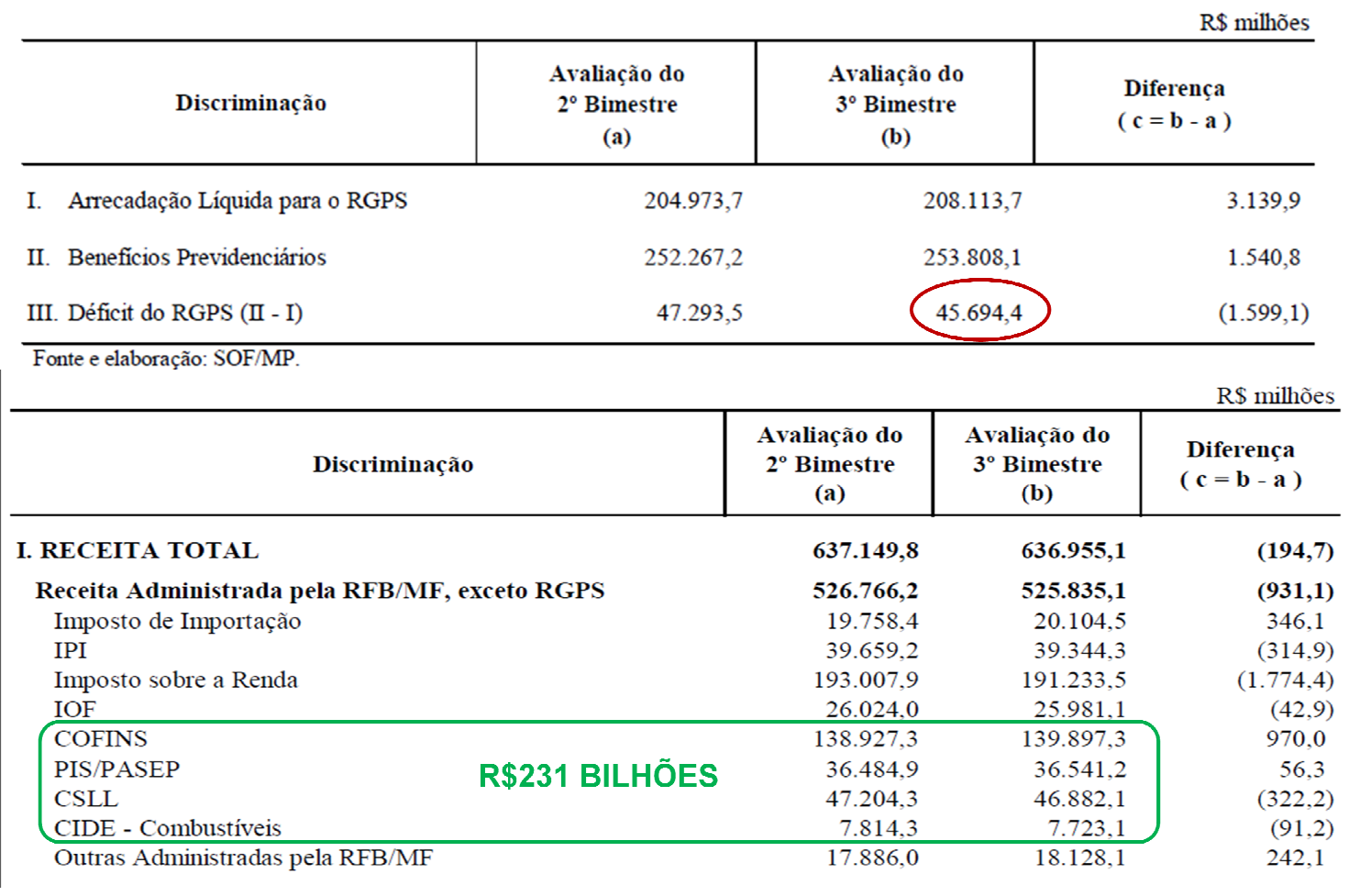

Figura 7: Distorção na apresentação dos dados oficiais do orçamento. (Brasil, 2010b)

Não obstante essa segunda possibilidade interpretativa dos referidos relatórios oficiais do governo, em geral, ao invés de noticiar, tem-se não apenas a reprodução das informações sobre a Previdência Social brasileira pré-fabricadas pelo governo e por "especialistas", como, também, a tendência de se editar a notícia com expressões aterrorizantes e valorativas como "rombo", "problema de envelhecimento", "sangria", "vespeiro" e o delineamento unívoco de um futuro "inquietante".

Esse sentido alarmista e redutor das questões sanitárias e previdenciárias a seus aspectos meramente econômicos, e ainda assim distorcidos, sobressai-se nas notícias a seguir comentadas. Embora veiculados como jornalísticos, estes textos, em função da examinada programação sistêmica ("filtros da notícia”) de suas organizações midiáticas, disseminam expectativas sobre a Seguridade Social de maneira oposta àquelas delimitadas normativamente a partir dos programas e princípios constitucionais desse sistema de proteção social.

Em que pese essa possível interpretação jurídica e as descritas divergências da própria análise econômica do orçamento social, o funcionamento do código informação/nãoinformação, pelas razões expostas no terceiro capítulo, acabada sendo direcionado pelos descritos filtros/programas de notícia que compõe esse sistema midiático. 
Nessa linha, sobretudo em função do $3^{\circ}$ programa ou "filtro de notícias" dependência da mídia de informações fornecidas pelo governo, por empresas e por especialistas -, desenvolve-se uma estrutura encadeada e aparentemente "jornalística" dos “problemas" financeiros e demográficos da previdência, com a reprodução sistemática dos dados oficiais do governo e das opiniões de supostos especialistas.

No mais, sequer chega a ser questionado o conflito de interesses do governo e dos especialistas consultados, como se observa nas seguintes notícias comentadas, bem como no "moderno" jornalismo de um modo geral. (BARROS FILHO; BARTOLOZZI, 1995, p. 63; BUCCI, 2008, p. 56).

Tem-se como primeiro exemplo dessa forma de comunicação a notícia 1 , na qual aparece claramente a inversão do fato pela versão na manipulação da notícia, como fora explicado quando da discussão do $3^{\circ}$ filtro/programa de seleção de notícias. Recorrese, ainda, à dramatização da informação objetivando afastar qualquer forma de discussão pública e racional destas questões através do recurso à intimidação e ao medo, nos moldes descritos por Abramo (2003), Chauí (2006) e Dejours (2010).

\section{Notícia 1-Reformas são urgentes}

TRIBUNA DO NORTE - Negócios e finanças (19/12/2010)

O analista da S\&P Marko Mrsnik, diz que o Brasil deveria aproveitar sua situação econômica relativamente tranquila para fazer as reformas da previdência. A Ucrânia, Rússia, Brasil e Romênia, segundo o estudo, deverão ter os maiores gastos com pagamento de pensões em 40 anos, devido ao fato de não terem reformado seus sistemas. A estimativa é que o Brasil hoje gaste 13,6\% do PIB com pagamento de pensões. Em 2050, essa fatia poderá abocanhar $15,8 \%$ do crescimento, acima da média geral de 49 países (10,3\%), das economias avançadas (12,2\%) e dos países da América Latina $(8,6 \%)$, só para exemplificar. "É sempre pior fazer reformas em momentos de crise, como a Grécia e Portugal estão fazendo agora. Mas países como Itália, por exemplo, já vinham implementando mudanças graduais e agora enfrentam a crise com maior facilidade", diz.

\section{Ameaca}

Autor do livro "Demografia, a ameaça invisível", o economista Paulo Tafner diz que o Brasil precisa elevar a idade mínima da aposentadoria para 65 anos, e aumentar o período de contribuição. Ele defende ainda o fim do reajuste das aposentadorias pelo salário mínimo e o acúmulo de benefícios. As mudanças valeriam para novos 
entrantes, com regras de transição para quem já contribui para a previdência. [...]. (TRIBUNA DO NORTE, 2010 - sublinhado).

Como fora sublinhado, em vista da inquestionável "ameaça" demográfica, nesta primeira notícia, dissemina-se, como fato, a opinião do citado "especialista" de que a única e indiscutível solução para esse "alarmante" quadro seria a responsabilização individual dos beneficiários do sistema de previdência, em que pese, ao menos juridicamente, tratar-se de um sistema de proteção social.

Apesar de extensa, a seguinte "notícia" é elucidativa dessas questões, especialmente em seus trechos sublinhados, tendo sido veiculada como notícia, e não como propaganda, na seção de economia no sítio eletrônico do portal Terra.

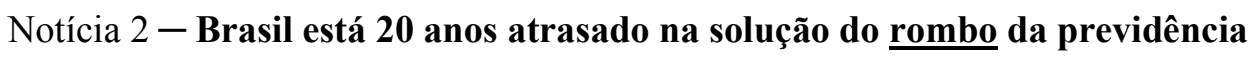 \\ TERRA - Economia (11/09/2010)}

\section{Thaís Sabino, de São Paulo}

O povo brasileiro está envelhecendo e, a cada ano, há redução nas taxas de natalidade.

O País tem hoje 1,5 trabalhador para cada aposentado e a relação ideal, segundo especialistas, é de quatro ativos para cada inativo. Como essa proporção ficou para trás em 1990, o Brasil está pelo menos 20 anos atrasado no sentido de tomar uma providência concreta para reverter a situação de colapso em que se encontra hoje, com déficit na casa dos $\mathrm{R} \$ 40$ bilhões atuais e perspectiva de piora." Chegamos ao caos para a previdência e o próximo governo vai ter que lidar com isso, sob pena de as futuras gerações não terem aposentadoria. Deixamos de ter a proporção ideal na década de 1990 e esta situação requer ajustes urgentes no funcionamento da previdência. Com o envelhecimento da população, a tendência é piorar" afirma o consultor econômico Renato Follador, especialista em previdência social. [...]. As previsões do Instituto Brasileiro de Geografia e Estatística (IBGE) deixam o quadro inquietante. Em 2000, o Brasil tinha 1,8 milhão de pessoas com 80 anos ou mais. Em 2050, o número estimado é de 13,7 milhões. Tudo isso acontece junto à diminuição do ritmo de crescimento da população. Se na década de 1950 a taxa era de 3\%, em 2004 ela baixou para $1,4 \%$. Para 2050, o IBGE estima que o crescimento anual fique em $0,24 \%$, até que, em 2062, ele chegue a zero. Os dados do IBGE relativos a 2000 mostravam que a população de 0 a 14 anos representava $30 \%$ dos brasileiros, enquanto os maiores de 65 anos eram apenas 5\% do todo. Daqui a 40 anos, a projeção indica que os dois grupos estarão iguais em $18 \%$ e a idade média do brasileiro passará de 20 
para 40 anos. "Com esta previsão, uma pessoa hoje com 25 anos vai se aposentar com muito pouco dinheiro", diz o economista. Em dinheiro, a projeção fica mais clara: em 1975, o INSS pagava um teto de aposentadoria de 20 salários mínimos. Cinco anos depois baixou para 15. Atualmente, o teto já está reduzido a 6,7 salários mínimos. O economista Follador calcula que, nesse ritmo, daqui a 15 anos ninguém se aposentará com mais de 5 salários mínimos e, daqui a 40 anos, 3 salários mínimos. "A tendência do teto da aposentadoria é cair cada vez mais, porque todo ano registramos mais de R\$ 40 bilhões de déficit anual na previdência social. O governo não vai conseguir sustentar isso por muito mais tempo, ainda mais com o crescimento dos empregos informais, aqueles que não contribuem com o INSS", afirma Newton Conde, atuário especializado em previdência. Ele explica que a situação já passou do razoável . "Se a previdência fosse sustentável com o que ela arrecada, o governo não precisaria colocar dinheiro do Tesouro Nacional lá para manter a máquina funcionando", diz ele. Segundo Conde, a subida na expectativa de vida é acompanhada pelo aumento na longevidade no trabalho, o que só agrava a situação. "Muitos trabalhadores aposentados continuam a trabalhar, não abrem espaço para novos empregados e ficam com duas fontes de renda". Conde afirma que a expectativa atual de vida no Brasil é de 82 anos e, a cada cinco anos, a previsão sobe mais um ano. "Outros países já passaram por isso e hoje a perspectiva de vida lá aumenta um ano a cada dez. No Brasil esse avanço está rápido demais porque havia muito campo para melhorar as condições de vida".

\section{No mundo}

O problema de envelhecimento, no entanto, não é particularidade do Brasil. Países europeus e os Estados Unidos já chegaram a essa fase e enfrentam os problemas da falta de Receita para sustentar os aposentados. O que muda são as maneiras e as medidas implementadas para combater o problema. Segundo Conde, os Estados Unidos, por exemplo, "têm um planejamento para daqui vinte anos, das regras que serão impostas no sistema previdenciário". No Brasil, a ausência de projetos que acompanhem o aumento da expectativa de vida obriga o pagamento do benefício ao aposentado por períodos cada vez mais longos, sem o respectivo lastro em contribuições ao sistema. Se antes, o trabalhador se aposentava aos 60 e vivia até os 70 , hoje ele para aos 60 e vive vinte anos mais. Ou seja, vai ficar dez anos a mais recebendo do governo. De acordo com o economista Renato Follador, os únicos países em que não se exige uma idade mínima para aposentadoria são Brasil, Equador, Irã e Iraque. Como a adoção de uma idade mínima é algo muito impopular, todos os governos acabam empurrando o problema com a barriga. Em 1999 o governo federal 
conseguiu instituir o Fator Previdenciário, uma equação que leva em consideração a idade ao se aposentar, o tempo de contribuição e a expectativa de vida para se chegar ao valor da aposentadoria. No caso, um homem pode se aposentar após os 30 anos de trabalho, mas, sofre descontos no valor do benefício de acordo com a idade e estimativa de vida. "O fator previdenciário ajuda a previdência a não quebrar de vez", afirma o atuário Newton Conde, especialista em previdência. No entanto, o Senado derrubou o Fator em 2008 e a Câmara dos Deputados confirmou a decisão este ano. Se o presidente da República sancionar o projeto, o Fator deixará de existir já em 2011. $\underline{\text { Seria uma vitória para quem se aposentar, mas o rombo da previdência vai crescer em }}$ mais alguns bilhões.

\section{Como garantir o futuro}

Para a demógrafa e economista, Ana Amélia Camarano, "não existe solução sem lágrimas" quando o assunto é aposentadoria. Se a idade para aposentar for adiada, o tempo de serviço aumentará e o tempo de recebimento de aposentadoria será reduzido. Se deixar como está hoje, alguém ficará sem aposentadoria no futuro. Até o incentivo ao aumento da natalidade é visto como uma boa saída pela economista. "A longo prazo, menos natalidade implica na diminuição do número de pessoas que produzem os recursos da previdência, e isso é muito ruim. Como o objetivo nunca será o de reduzir o tempo de vida, o melhor é falar em aumentar o número de contribuintes do sistema", diz ela. E para quem já está trabalhando, a saída para não ficar sem recursos quando chegar o momento de se aposentar é a previdência privada, ou qualquer outra forma de poupança. $\mathrm{O}$ economista Renato Follador sugere que o mesmo valor que é pago como contribuição ao INSS seja guardado em uma previdência privada. "Dessa forma, mesmo que o INSS pague menos do que hoje, haverá o complemento da previdência privada. É difícil guardar, mas é necessário para não ficar no aperto quando se aposentar", diz ele.

\section{Como funciona}

Há dois tipos de planos de previdência privada: o aberto e o fechado. O primeiro pode ser contratado por qualquer pessoa, enquanto o outro é destinado para grupos, como funcionários de uma empresa. Os planos privados disponíveis são o Plano Gerador de Benefício Livre (PGBL) e o Vida Gerador de Benefício Livre (VGBL). O PGBL é indicado para quem faz declaração completa do imposto de renda e permite que se deduza do imposto até $12 \%$ da renda bruta anual. O VGBL é a opção para quem preenche a declaração simplificada e não possibilita abatimento. Quando o contribuinte for sacar o dinheiro no PGBL, paga tributo sobre todo o valor. No outro caso, só sobre o do rendimento. [...]. (SABINO, 2010 - sublinhado). 
Depreende-se da leitura desta segunda notícia, em especial dos trechos sublinhados, seu caráter manifestamente opinativo e nada jornalístico. A partir de uma cobertura parcial e unívoca da questão apresentada, objetiva-se não apenas generalizar como também legitimar as "soluções" para o "rombo" previdenciário e para o "problema do envelhecimento", propostas pelo governo e favoráveis ao mercado de previdência privada.

São, assim, generalizadas em termos comunicacionais as propostas de fixação de idade mínima para a aposentadoria e do fator previdenciário como "mal necessário" para desestimular "aposentadorias precoces" (SIMÃO, 2010a - Notícia 4), bem como o recurso à solução de mercado, ou seja, à previdência privada, propagandeada como melhor “saída” para se "garantir o futuro" (Notícias 1, 2, 8 e 9; SALLOWICZ, 2010).

Nestas duas primeiras "notícias" apresentadas é negligenciado, porém, o sentido normativo da aposentadoria, seja por tempo de serviço, seja por tempo de contribuição. Esta forma de omissão jornalística se aproxima do "padrão ocultação" da grande imprensa descrito por Perseu Abramo (2003, p. 25-27).

Não se veicula, por exemplo, que o risco social objeto de proteção nesses casos corresponde ao desgaste dos anos trabalhados e seus efeitos não apenas sobre a saúde do trabalhador como também, sobretudo em termos culturais, em relação à suas possibilidades de se manter empregado.

No mais, não é noticiado que esses efeitos deletérios persistem ainda hoje, muito embora, segundo os dados "oficiais", a expectativa de sobrevida tenha aumentado. Esse aumento, porém, por si só, não representa necessariamente, frise-se, que esta sobrevida se dê uniformemente de forma digna. Se assim fosse, seria possível em parte fundamentar, juridicamente, algumas das alterações propostas a esse sistema de proteção social, tão atacado na comunicação produzida pelas organizações midiáticas em questão.

Ainda, assim, cumpre destacar que tais reformas não podem jamais afetar o núcleo fundamental/essencial dos direitos sociais relacionados, sob pena de inconstitucionalidade. (SARLET, 2007, p. 70; CORREIA, 2005, p. 263).

Nesse sentido, sobre o núcleo social dos direitos fundamentais e sua forma de limitação sobre as reformas normativas em função do "princípio do não retrocesso social", preleciona Joaquim José Gomes Canotilho (p. 2003, 340):

[...] o núcleo essencial dos direitos sociais já realizado e efetivado através de medidas legislativas ("lei da segurança social", "lei do subsídio de 
desemprego", "lei do serviço de saúde") deve considerar-se constitucionalmente garantido, sendo inconstitucionais quaisquer medidas estaduais que, sem a criação de outros esquemas alternativos ou compensatórios, se traduzam, na prática, numa "anulação", "revogação" ou "aniquilação" pura a simples desse núcleo essencial. Não se trata, pois, de proibir um retrocesso social captado em termos ideológicos ou formulado em termos gerais ou de garantir em abstrato um status quo social, mas de proteger direitos fundamentais sociais sobretudo no seu núcleo essencial. A liberdade de conformação do legislador e inerente autorreversibilidade têm como limite o núcleo essencial já realizado, sobretudo quando o núcleo essencial se reconduz à garantia do mínimo de existência condigna inerente ao respeito pela dignidade da pessoa humana.

Ademais, o que se ressalta ainda no próprio texto da notícia 2, e que se repete em praticamente todas as demais notícias comentadas nesta tese, é que o fim do fator previdenciário "seria uma vitória para quem se aposentar, mas o rombo da previdência vai crescer em mais alguns bilhões." (SABINO, 2010 - sublinhado).

Em que pese o emprego de estatísticas em todo o texto, não se apresenta o quanto esses incertos "alguns bilhões" de fato representariam se comparados proporcionalmente não apenas à arrecadação total da Seguridade Social como também ao orçamento geral da União.

Para se ter uma ideia de como essa diferente forma de apresentação dos dados levaria as mesmas notícias a perderem sua força persuasiva e aterrorizadora, bastaria mencionar que orçamento do atacado sistema de Seguridade Social, para o ano fiscal de 2010, foi estimando em "R\$ 425.520.428.223,00 (quatrocentos e vinte e cinco bilhões, quinhentos e vinte milhões, quatrocentos e vinte e oito mil e duzentos e vinte e três reais)", enquanto que, no mesmo período, tem-se uma estimativa de receita total da União, dados também oficiais embora não divulgados em conjunto, no "montante de $R \$$ 1.860.428.516.577,00 (um trilhão, oitocentos e sessenta bilhões, quatrocentos e vinte e oito milhões, quinhentos e dezesseis mil e quinhentos e setenta e sete reais)", nos termos da Lei 12.214 de 26 de janeiro de 2010. (BRASIL, 2010a).

Justamente para camuflar os valores vultosos não do suposto déficit, mas sim da arrecadação desse sistema de proteção e do Governo Federal como um todo, é que se fragmentam essas informações, não permitindo, dessa maneira, uma discussão efetiva do quanto a "vitória" dos aposentados representaria de aumento dos "gastos 
públicos", proporcionalmente às efetivas receitas desse amplo sistema de proteção social, ou seja, do efetivo custo social da negação dos direitos sociais afetados.

Como ocorre em boa parte das vezes e nas demais notícias selecionadas, ambos os textos acima transcritos terminam por sugerir abertamente o recurso à solução privatista e individual para os problemas apontados, não obstante, constitucionalmente, a cobertura desses riscos seja positivada como questão jurídica de caráter público e social.

Tais formas de comunicação apresentam-se apenas na aparência como notícia, revelando-se por sua estrutura e encadeamento lógico como efetiva propaganda de previdência privada.

Fomenta-se, ainda, a redução da confiança social neste sistema previdenciário pelo ataque à solidariedade que o sustenta. Como exemplo desse ataque à confiança e solidariedade, poderia ainda ser mencionada a descrição na notícia 2 da desvalorização gradativa do valor dos benefícios, quando comparado o seu salário de contribuição ao respectivo número de salários mínimos durante o período contributivo, feita de forma banalizada em função da ausência de questionamento jurídico dessas informações.

O mesmo ocorre com a menção sobre a imposição de um número maior de anos a se trabalhar para que o trabalhador não sofra uma significativa redução no cálculo final de seu benefício pela aplicação - como se verá, inconstitucional - do fator previdenciário.

No mais, nas notícias em questão, poderia ainda ser destacada a sutil sugestão veiculada de que os beneficiários desse sistema de proteção seriam, na verdade, pessoas privilegiadas, senão usurpadoras das "benesses" estatais e de sua "farra" orçamentária (LEITÃO; MANIERO, 2010), ao passo em que, normativamente, estas mesmas pessoas devem ser consideradas como sujeitos de direitos sociais fundamentais.

Nessa linha, na seguinte notícia 3 do jornal $O$ Globo de 06 de novembro de 2010, sugestivamente intitulada "ROMBO BILIONÁRIO: Sangria na Previdência pode chegar a $R \$$ 1,7 bilhão ao ano", são evidenciadas tanto essa forma de juízo negativo de valor quanto aos segurados da previdência, sobretudo rurais, quanto a já comentada dramatização de seu pressuposto déficit orçamentário.

Notícia 3 - $\underline{\text { ROMBO BILIONÁRIO: }}$ Sangria na Previdência pode chegar a R\$ 1,7 bilhão ao ano 
O GLOBO - País (06/11/2010)

Fábio Fabrini

BRASÍLIA - Cofre sensível e deficitário, que ameaça ser um vespeiro para a presidente eleita, Dilma Rousseff, a Previdência Social sofre uma sangria diária provocada por inúmeros erros e fraudes de pequena monta. Desde 2002, a Controladoria Geral da União (CGU) constatou pagamentos indevidos a 95,2 mil beneficiários, cujo prejuízo anual alcançava R \$1,063 bilhão. Esses pagamentos foram cancelados, mas ainda há 119,9 mil aposentadorias, pensões e auxílios, que consomem R \$ 1,7 bilhão ao ano, sob suspeita e que viraram alvo de investigação. Os dados expõem a vulnerabilidade do sistema, que já vive um problema estrutural crônico, causado pela arrecadação insuficiente, e deve fechar 2010 com R\$ 45,7 bilhões no negativo. O Instituto Nacional de Seguridade Social (INSS) admite que os valores apurados internamente superam os detectados pela CGU, embora não os revele. E trata os pequenos golpes como um desafio superior aos desvios milionários que macularam a imagem da Previdência, como o caso Jorgina de Freitas. [...]. Especialista em Previdência, o economista Marcelo Caetano, do Instituto de Pesquisa Econômica Aplicada (Ipea), diz que eliminar os pequenos golpes é impossível num sistema previdenciário tão grande e com a tecnologia disponível hoje. Embora o cruzamento de informações seja positivo, alguns benefícios escapam a esse tipo de controle. - Os aposentados do campo não precisam comprovar tempo de contribuição, mas que foram, de fato, trabalhadores rurais. Isso diminui a possibilidade de controle da Previdência. Cabe a eles levantar declarações e provas necessárias para receber a aposentadoria - exemplifica. (FABRINI, 2010 - sublinhado). Neste último texto aparentemente jornalístico, assim como nos anteriormente comentados, encontram-se expressões opinativas nada imparciais e a manifestação de "especialistas" para supostamente "noticiar" a "sangria diária" da previdência e as fraudes "inevitáveis" que esse combatido sistema propicia. Neste caso, o jornalista não apenas pressupõe a existência de déficit, prática recursiva tendo em vista a massificação dessa leitura da questão previdenciária, como, ao afinal, limita-se a reproduzir, sem qualquer contraposição, a sugestão implícita do especialista consultado no sentido de que os trabalhadores rurais têm a faculdade de fraudar esse sistema através de suas declarações. (FABRINI, 2010 - sublinhado).

Por sua vez, esse processo tendencioso de edição de notícias se repete no que diz respeito à seleção das informações acerca do fator previdenciário, realizada pelas 
grandes organizações empresariais que compõe o sistema dos meios de comunicação de massa em tela.

$\mathrm{Na}$ seguinte notícia 4, fora de seu tradicional editorial e de maneira nada imparcial, o jornal Estadão posiciona-se favoravelmente à atitude do governo de vetar parte do projeto de lei, aprovado democraticamente pelo Congresso Nacional, que tinha por fim extinguir o fator previdenciário. Isto porque, muito embora o jornal reconheça tal instituto como "redutor no cálculo do valor do benefício", o periódico em questão endossa já no título de sua notícia, sem aspas, a justificativa do chefe do Poder Executivo de que assim seria “evitado" o "incentivo à aposentadoria precoce". (SIMÃO, 2010a).

\section{Notícia 4 - Com veto, Lula evita incentivo à aposentadoria precoce \\ ESTADÃO - Economia (15/06/2010) \\ Edna Simão, da Agencia Estado}

BRASÍLIA - Ao mesmo tempo que aprovou o reajuste de 7,7\% para as aposentadorias de valor acima de um salário mínimo, o presidente Luiz Inácio Lula da Silva decidiu manter a aplicação do fator previdenciário no cálculo das aposentadorias com o objetivo de evitar um aumento descontrolado do rombo da Previdência Social. O fim do fator implicaria numa elevação de, pelo menos, $\mathrm{R} \$ 10$ bilhões nas despesas com aposentadoria.

Somente neste ano, segundo estimativas do Ministério da Previdência, o déficit deverá atingir a marca de R\$ 50 bilhões. Para impedir uma pressão adicional nesta conta, o presidente atendeu a orientação de sua equipe econômica e manteve o mecanismo. $\underline{\mathrm{O}}$ fator previdenciário funciona como redutor no cálculo do valor do benefício para desestimular as aposentadorias precoces. Ou seja, os brasileiros precisam ficar mais tempo no mercado de trabalho para não terem deduções no valor de sua aposentadoria.

Desde que foi criado pelo governo Fernando Henrique Cardoso, em 1999, o instrumento proporcionou uma economia de R\$10 bilhões aos cofres públicos. Alguns técnicos dizem até que esse valor é ainda maior, podendo chegar a R $\$ 20$ bilhões. Independentemente do montante, sem o fator, essa "economia" seria automaticamente revertida em aumento do déficit da previdência. A extinção do fator previdenciário é uma reivindicação antiga dos aposentados e sempre está na pauta de discussão dos deputados e senadores. Os aposentados defendem o fim do redutor porque acreditam que estão sendo lesados com redução de benefício. Mas o assunto ainda voltará à tona. Existe um projeto de lei do senador Paulo Paim (PT-RS), que prevê o fim do fator. Ele já foi aprovado na Comissão de Constituição e Justiça (CCJ) da Câmara e precisa agora ser apreciado pelo plenário da Casa. (SIMÃO, 2010a - sublinhado). 
$\mathrm{Na}$ notícia 4 em questão, sob uma perspectiva supostamente econômica, reproduz-se acriticamente as justificativas do governo para essa decisão, com a simples remissão à existência de análises técnicas, porém, não devidamente indicadas - "Alguns técnicos [quais?] dizem até que esse valor é ainda maior, podendo chegar a R $\$ 20$ bilhões [com base em que metodologia?]”. (SIMÃO, 2010a).

A oposição dos aposentados e suas reivindicações, muito embora genericamente mencionadas, acabam reduzidas a uma questão meramente de crença - "Os aposentados defendem o fim do redutor porque acreditam que estão sendo lesados com redução de benefício". (SIMÃO, 2010a). Por vezes, tem-se, ainda, a apresentação dos mesmos cidadãos como "lobbistas", no sentido pejorativo que este termo, em geral, é empregado no Brasil. (AE, 2010). ${ }^{230}$

Dessa maneira, a oposição ao fator previdenciário, enaltecido na notícia 4, é subjetivada, a despeito de toda fundamentação jurídica que a aplicação dessa forma de cálculo possa suscitar (FRANÇA, 2010, 116-121), bem como do fato dessa própria notícia, inicialmente, conceituar tal fator como uma espécie de "redutor no cálculo do valor do benefício para desestimular as aposentadorias precoces”. (SIMÃO, 2010a).

Embora não seja mencionado no texto jornalístico em tela, mais do que um simples "descontentamento" dos aposentados, o referido fator previdenciário é objeto de questionamentos jurídicos, especialmente no que diz respeito à sua constitucionalidade.

Nessa linha, Giselle de Amaro e França (2010, p. 116) explica como, através da citada Emenda Constitucional n. 20/1998, fora desconstitucionalizada a norma que determinava o cálculo do valor do benefício a partir da correção dos 36 (trinta e seis) últimos salários de contribuição, sendo, posteriormente editada a lei n. 9.876, em 26 de

\footnotetext{
${ }^{230}$ Nessa conotação negativa, tem-se a notícia intitulada "Lei eleva rombo do INSS de R\$ 48 bi para R\$ 118 bi", publicada no Estadão de 10 de julho de 2010, na qual o referido jornal "informa" a proposta do senador Paulo Paim de indexar os reajustes dos benefícios previdenciários ao aumento do salário mínimo. $\mathrm{O}$ periódico contrapõe essa proposta, do citado representante popular, à seguinte posição firmada pela “especialista” Sandra Cristina Filgueiras: “[...] Em 2008, as despesas com os benefícios do Instituto Nacional do Seguro Social (INSS) - urbanos e rurais, sem considerar os assistenciais com idosos e deficientes -, que foram de R\$ 199,5 bilhões, chegariam a R\$ 269 bilhões. Os dados são do estudo Salário mínimo e reajustes dos benefícios do Regime Geral de Previdência Social - RGPS, elaborado pela consultora legislativa Sandra Cristina Filgueiras. Com o impacto, analisa a autora, as despesas deixariam o patamar de 6,9\% do Produto Interno Bruto (PIB) para atingir 9,3\%. 'Há um preconceito contra discutir essa questão, ninguém quer debater, mas é preciso tocar na ferida. O lobby dos aposentados é forte, é uma população que tem uma base eleitoral crescente e ninguém quer se voltar contra ela. $O$ trabalho mostra que eles não tiveram perdas reais', disse Sandra." (AE, 2010 - grifado).
} 
novembro de 1999, criando o referido fator previdenciário como o novo critério de cálculo.

Porém, de acordo com a referida pesquisadora:

[Essa nova forma de cálculo] é inconstitucional por trazer em sua fórmula um componente redutor não amparado pela Lei Maior, qual seja a idade. $\mathrm{O}$ fator previdenciário desestimula, às escâncaras, as aposentadorias precoces, pois reduz significativamente o valor do benefício aos segurados que optam por parar de trabalhar mais cedo, não obstante tenham cumprido a carência exigida. Não se retira do órgão político competente para a formulação das políticas públicas previdenciárias a opção em estimular a permanência dos trabalhadores na ativa. No entanto, os desestímulos à aposentação não podem embutir limitações ao direito fundamental não acobertadas pelo texto constitucional. De acordo com a Constituição Federal de 1988, a idade é fator a ser considerado apenas na concessão do benefício de aposentadoria por idade, não podendo ser utilizada como um dos componentes do cálculo de qualquer benefício (inclusive dela mesma), como quer a Lei $n^{\circ}$ 9.876/99. (FRANÇA, 2010, p. 117).

Apenas recentemente, e de maneira sucinta, o Estadão (Notícia 5) divulgou esse possível questionamento jurídico relacionado à inconstitucionalidade do fator previdenciário, conforme se depreende abaixo. (Notícia 5).

\section{Notícia 5-Justiça considera fator previdenciário inconstitucional}

ESTADÃO - Economia (02/12/2010)

Pedro da Rocha, da Agencia Estado

SÃO PAULO - O fator previdenciário foi considerado inconstitucional pelo juiz federal Marcus Orione Gonçalves Correia, da $1^{\text {a }}$ Vara Federal Previdenciária em São Paulo. A decisão ocorreu em ação movida por um segurado contra o Instituto Nacional do Seguro Social (INSS).

$\mathrm{Na}$ decisão, Correia afirma que o fator previdenciário, além de ser complexo e de difícil compreensão para o segurado, é inconstitucional por introduzir elementos de cálculo que influem no próprio direito ao benefício. O juiz entende que o requisito para a obtenção do benefício - que continuaria a ser apenas o tempo de contribuição é diferente do cálculo do seu valor inicial, em que não se poderia levar em conta fatores como a expectativa de vida.

"Somente é possível se obter o benefício a partir da utilização dos elementos indispensáveis para o cálculo da renda mensal inicial. Assim, utilizando-se para a obtenção desta de elementos não permitidos pela Constituição, obviamente que o próprio direito ao benefício em si se encontra violado", argumentou.

A decisão determinou que o INSS promova o recálculo da renda mensal inicial do benefício do segurado sem levar em conta o fator. $\mathrm{O}$ fator previdenciário é um cálculo 
que leva em conta a idade, a expectativa de sobrevida e o tempo de contribuição do segurado ao se aposentar. (ROCHA, 2010).

Porém, neste caso, a informação fora veiculada sem qualquer remissão às demais notícias do mesmo jornal (ALISKI, 2010; AE, 2010; SIMÃO, 2010b), como a comentada notícia 4, nas quais de maneira inquestionável o referido fator é usualmente justificado economicamente em função do pressuposto déficit previdenciário.

Acrescente-se ainda que, embora o título da notícia 5 possa inicialmente sugerir um posicionamento do Poder Judiciário como um todo - "Justiça considera fator previdenciário inconstitucional", no corpo de seu texto, destaca-se que a mesma resume-se a uma decisão singular da Justiça Federal, num caso individualizado.

Da mesma forma, no referido texto, ao invés de se discutir os possíveis argumentos jurídicos utilizados na decisão - e o seu claro conflito em relação à comunicação diuturnamente veiculado sobre esse redutor -, a edição da informação acaba por isolar o debate dessa questão, deslocando-a como o entendimento isolado do magistrado citado, neste caso, não sendo o mesmo sequer qualificado como especialista e professor na área previdenciária. (CORREIA, 2010).

Observa-se, portanto, uma inversão no padrão de apresentação das notícias referentes à Seguridade Social, no sentido de sua manifesta e usual manipulação, já analisada por Perseu Abramo (2003).

No que diz respeito ao déficit previdenciário e à crítica à Seguridade Social como um todo, tem-se ainda que quando as versões noticiadas são contrárias à descrita posição empresarial das organizações midiáticas - como observado na notícia 5 -, as fontes consultadas não são apresentadas claramente como “especializadas” no assunto.

Assim, ao se editar as informações opostas ao senso comum construído pela mídia é destacado, já em seu título, tratar-se o noticiado de uma opinião pontual de terceiros. Podem ser citados como exemplos dessa os seguintes títulos de notícia:

Não há déficit no sistema da Previdência, diz economista (CARIELLO, 2003 - sublinhado), e

Ex-secretário da Previdência diz que déficit "desvia" verba social (FOLHA DE S. PAULO, 2003 - sublinhado). 
Outra estratégia de edição utilizada diz respeito à descontextualização das informações noticiadas, identificada por Perseu Abramo (2003, p. 27) como padrão de fragmentação.

A partir dessa técnica de manipulação da informação, ao se selecionar um dado ou declaração específica, estes acabam isolados na notícia como particularidades de um fato, perdendo, portanto, seu significado original e real para "permanecer no limbo, sem significado aparente, ou receber outro significado, diferente e mesmo antagônico ao significado real original" (ABRAMO, 2003, p. 28).

Nesse sentido, os orçamentos não apenas da previdência como da Seguridade social são usualmente divulgados na mídia como deficitários.

A FOLHA DE S. PAULO (PATU, 2009), para disfarçar a contradição da informação veiculada na seguinte notícia 6 , em relação às suas notícias anteriores sobre o mesmo tema, já em seu título, se vale da adjetivação desse orçamento como "social", descontextualizando-o não apenas das demais notícias sobre o déficit previdenciário, como do próprio assunto efetivamente tratado, ou seja, do orçamento da Seguridade Social e, por conseguinte, da previdência, que só a partir de 2009 teriam "passado", "1a vez na década", a apresentar déficit.

\section{Notícia 6-Orçamento social passa a ser deficitário}

FOLHA DE S. PAULO - Dinheiro (29/08/2009)

Pela $1^{\text {a }}$ vez na década, despesas em áreas como previdência e saúde superaram receitas das contribuições criadas para financiá-las

Entre janeiro e julho, déficit chegou a R $\$ 19$ bilhões, o equivalente ao desembolso de um ano e meio do programa Bolsa Família

Gustavo Patu, da sucursal de Brasília

Deixados para trás os recordes de arrecadação do ano passado, os resultados do Tesouro Nacional explicitam que o orçamento social do governo passou a ser deficitário pela primeira vez desde a década de 90. Levantamento feito pela Folha aponta que, de janeiro a julho, as despesas com previdência, saúde, assistência e seguro-desemprego superaram em R $\$ 19$ bilhões -o equivalente a um ano e meio de Bolsa Família- as receitas das contribuições criadas para financiar esses programas. Definido pela Constituição de 1988, o orçamento da seguridade social reúne as políticas públicas mais diretamente ligadas à subsistência das famílias, além dos 
tributos cuja arrecadação não poderia ser dirigida a outras áreas, caso das contribuições cobradas sobre a folha de salários, o lucro e o faturamento das empresas. Graças a uma brecha constitucional de caráter provisório criada em 1994, chamada DRU (Desvinculação de Receitas da União), o governo foi autorizado a utilizar livremente $20 \%$ desses recursos. $\mathrm{Na}$ apuração do resultado anual da seguridade, porém, o Tribunal de Contas da União considera as receitas integrais, critério seguido pela reportagem. A seguridade mantinha saldo positivo até o ano passado, mesmo com a inclusão, entre suas despesas, das aposentadorias do funcionalismo federal, questionada por parte dos analistas do setor. [...]. Esse superávit se tornou um dos principais argumentos dos opositores das propostas de reforma da Previdência Social destinadas a reduzir os direitos dos beneficiários. Partidos autodeclarados de esquerda, setores do governo Luiz Inácio Lula da Silva, sindicatos e economistas de linha heterodoxa argumentam que não faz sentido calcular separadamente o saldo previdenciário negativo. É preciso, afirmam, levar em conta todas as despesas e receitas listadas pela Constituição. A tese foi apresentada em um fórum oficial promovido em 2007 para debater a reforma. "O desequilíbrio orçamentário está no orçamento fiscal, e não no orçamento da seguridade social ou no orçamento da Previdência Social. A seguridade não recebe recursos do orçamento fiscal, ao contrário, parte substancialmente elevada de seus recursos financia o orçamento fiscal", afirmou, na ocasião, a pesquisadora Denise Gentil, hoje diretora-adjunta do Ipea (Instituto de Pesquisa Econômica Aplicada). Procurada pela Folha, a economista preferiu não comentar os novos números. Mas o recém-surgido deficit do orçamento social não serve de argumento apenas para os reformistas de pensamento liberal que pedem redução de gastos; os números podem ser usados também pelos que defendem o ajuste pelo lado da arrecadação, caso dos governistas em campanha pela ressurreição da CPMF. Os dados apontam que o fim da cobrança da contribuição sobre movimentação financeira ajudou, embora não de imediato, na reversão do saldo positivo da seguridade. Em 2008, primeiro ano sem o tributo, o superavit foi preservado graças aos surpreendentes resultados dos demais tributos, que superaram as estimativas mais otimistas do governo e dos analistas. Nos anos anteriores, teria havido deficit se excluída a CPMF.

\section{Despesas}

Neste ano, porém, não só a crise econômica derrubou as receitas, como as despesas sociais cresceram a taxas dignas de vésperas de eleição. O reajuste de quase $6 \%$ acima da inflação para o salário mínimo elevou aposentadorias, pensões, seguro-desemprego e benefícios assistenciais a idosos e deficientes; o Bolsa Família teve um aumento médio 
real de 4\%; os servidores da área social, a exemplo dos demais funcionários do Executivo, ganharam novos planos de carreira. Os gastos sociais, equivalentes a 12,16\% do Produto Interno Bruto no ano passado, subiram para 13,49\% do PIB estimado para os primeiros sete meses do ano. Os R $\$ 230,8$ bilhões destinados à área social representaram praticamente três quartos de todas as despesas do governo no período, excluídos os encargos da dívida pública. A maior fatia do gasto social, de longe, é a das aposentadorias. As pagas pelo INSS (Instituto Nacional do Seguro Social) somaram, de janeiro a julho, $\mathrm{R} \$ 120,6$ bilhões, e as do funcionalismo federal, $\mathrm{R} \$ 35,1$ bilhões. A área que mais cresce nos últimos anos, porém, é a da assistência social, devido a benefícios instituídos pelo Estatuto do Idoso e à criação do Bolsa Família, ambos em 2003. No cenário atual, a eventual criação da CSS (Contribuição Social para a Saúde), nova versão da CPMF com alíquota reduzida e receita prevista de $\mathrm{R} \$ 10$ bilhões anuais, seria insuficiente para restabelecer o superavit da seguridade. (PATU, 2009- sublinhado).

No mais, fora essa isolada notícia 6 , cujo título fora editado de modo a não chamar a atenção para o seu conteúdo, nas raras vezes em que se apresenta nos meios de comunicação de massa o questionamento ao difundido déficit previdenciário, ao contrário de se produzir uma reportagem, suas organizações acabam por limitar a "notícia" à mera reprodução de entrevistas devidamente editadas com tais opositores, coincidentemente não qualificados nesses textos "jornalísticos" como especialistas. (CARIELLO, 2003; FOLHA DE S. PAULO, 2003).

Numa dessas entrevistas (Notícia 7), evidencia-se em seu preâmbulo não apenas a "surpresa" dos editores da notícia com essa negativa do déficit previdenciário, como também uma sutil tentativa de desacreditá-la pela questionável utilização, num texto que se propõe jornalístico, da seguinte interjeição sublinhada: "Muito bem, a seguridade social é superavitária, confirma o consultor Marcelo Estevão”. (FOLHA DE S. PAULO, 2003).

\section{Notícia 7 - Ex-secretário da Previdência diz que déficit "desvia" verba social \\ FOLHA - Poder (22/06/2003) \\ da Folha de S.Paulo}

Muito bem, a seguridade social é superavitária, confirma o consultor Marcelo Estevão, mas ao incluir as contas desequilibradas do funcionalismo público no pacote, cometese a injustiça de drenar para a Previdência dos servidores recursos que deviam servir para combater a exclusão social. $\mathrm{O}$ ex-secretário de Previdência do Ministério da 
Previdência e Assistência Social (de 94, ainda no governo Itamar Franco, até 99, sob FHC) afirma que a ideia original, segundo a lei que regulamentou a seguridade social, era que o governo gradualmente retirasse os servidores públicos da conta. Estevão diz que os princípios gerais da reforma do governo estão corretos. Há, a seu ver, anomalias no atual sistema inconcebíveis em qualquer outro país. Afirma, no entanto, que a ausência de regras de transição pune de maneira excessiva a atual geração de servidores --a primeira verdadeiramente profissional no serviço público. (RC)

Folha - Por que falar em déficit da Previdência quando a seguridade social é superavitária?

Marcelo Estevão - É preciso analisar esse argumento da seguridade social com certo cuidado. No conceito original, ela não deveria arcar com nenhuma das responsabilidades chamadas encargos previdenciários da União. A própria lei que regulamentou o custeio da seguridade social, a lei 8212, de 91, dispunha que o governo reduziria progressivamente a parte do recurso da seguridade social que usava para pagar os encargos previdenciários da União, até que essa contribuição cessasse. $O$ fato é que o governo, não tendo como financiar esses encargos com recursos do Orçamento fiscal, posteriormente alterou a lei no sentido de acabar com qualquer tipo de limitação.

\section{Folha - Quando foi a alteração?}

Estevão - Em 1995, por meio de medida provisória. A Previdência do servidor avançou sobre recursos que deviam ser utilizados para financiar o combate à exclusão e desigualdade social. Mas tudo foi feito legalmente.

Folha - De onde viria o fundo específico para cobrir as aposentadorias dos servidores?

Estevão - Não tem como levantar recursos que não venham dos orçamentos já estabelecidos. O orçamento fiscal é apertado. O orçamento da seguridade social tem fontes de financiamento exclusivas da União, e foi aí que a União encontrou a solução para suprir a insuficiência do orçamento. Uma parte do problema do servidor se originou no fato de que a Constituição previu a criação do Regime Jurídico Único. Esse regime foi instituído em 1990, transformando todos os servidores em um regime estatutário. Os servidores que até então eram regidos pela CLT [Consolidação das Leis do Trabalho] e estavam vinculados ao INSS, passaram a ser regidos pelo regime. Houve uma irresponsabilidade muito grande. A isso se somou o fato de que havia represamento de aposentadorias, porque as pessoas tinham a expectativa de entrar nesse regime único. O segundo aspecto é que, enquanto você tinha inflação elevada, o Estado conseguia gerar superávit. Quando você passa para um regime monetário estável, a verdade das coisas se manifesta. Desde 95, começamos a observar o problema nas contas públicas. 
Folha - Como se tratava de uma situação circunstancial a tendência não é que isso volte a se equilibrar?

Estevão - Acho difícil. Você tem desequilíbrios, a conta não fecha. Não existe nenhum país do mundo, nem países mais ricos, que possa aposentar servidores com condições tão generosas. Um sistema desse, com as regras hoje vigentes, essas regras não seriam sustentáveis atuarialmente no tempo. Não dá para termos regras de Previdência para o funcionalismo mais generosas que as aplicadas no padrão mundial. É como se fôssemos pobres querendo comer caviar, enquanto os ricos estão comendo arroz com feijão. Não significa que o governo esteja estritamente correto no projeto que apresentou. Em alguns aspectos, ele errou a mão.

\section{Folha - No quê?}

Estevão - Errou não nos princípios gerais, que estão certíssimos. As pessoas têm que se aposentar mais tarde, a questão do benefício integral tem que ser revista e mesmo a paridade entre ativos e inativos é questionável se você não tem a contribuição do inativo. Mas quando você vai fazer uma mudança, é muito importante que tenha a ideia de graduá-la, de modo a não sacrificar em demasiado nenhuma geração específica. Para as pessoas que já estão aposentadas ou que podem se aposentar, nada muda, a não ser que haverá uma contribuição dos inativos. Essa medida, embora tenha gerado polêmica, não tem nada de draconiana. Mesmo com a sua adoção, as pessoas ainda vão ter uma promoção em termos de renda líquida na aposentadoria. Nenhum país do mundo assegura um rendimento líquido na aposentadoria superior ao último rendimento líquido na atividade. Isso é uma maluquice, anomalia tipicamente brasileira.

Folha - O sr. vê outros problemas?

Estevão - O grande problema da reforma é que ela está punindo demasiadamente a atual geração de servidores. O que é ruim, porque a atual geração é a primeira profissionalizada da história recente do país. Um contingente que ingressou no serviço público submetido a critérios de mérito.

\section{Folha - Que consequências isso pode ter? Corrida à aposentadoria?}

Estevão - Não. Quem já pode se aposentar está com seu direito assegurado. O problema maior é que a conta para a geração que está em processo de aquisição de direitos está muito salgada. Alternativas poderiam ser buscadas. Do que tenho medo? Toda vez que se adotou medidas draconianas no que diz respeito a reforma, a emenda acabou sendo pior que o soneto. O Judiciário poderá tombar boa parte das medidas se elas não se pautarem pelo princípio da razoabilidade. Nisso é que acho que o governo errou a mão. (FOLHA DE S. PAULO, 2003 - sublinhado). 
Na transcrita noticia 07, apesar da complexidade das críticas levantadas pelo entrevistado acerca do sistema de Seguridade Social e do sentido contrário de suas afirmações em relação ao disseminado pelos meios de comunicação de massa, a cobertura jornalística, no caso, limitou-se à referida entrevista.

Sobre essas questões tão mal debatidas na mídia, Ricardo Pires Calciolari (2009), em sua análise do orçamento da Seguridade Social, demonstra como parte de suas específicas receitas são indevidamente desvirtuadas, dentre outras coisas, para o pagamento de benefícios de servidores inativos da União, bem como de salários de seus servidores ativos, muito embora, segundo o art. 40 da Constituição Federal de 1988, os servidores públicos - ativos e inativos - estejam submetidos ao Regime Próprio de Previdência Social. Assim, conclui o referido autor:

O regime de previdência próprio dos servidores é exposto pelo art. 40 da Constituição de 1988, deixando claro que as disposições relativas ao Regime Geral de Previdência Social serão aplicadas aos servidores públicos apenas subsidiariamente (art. 40, $\S 12$, da Constituição, com a redação dada pela Emenda 20, de 15.12.1998). Assim, verificamos que o regime jurídico da previdência do regime próprio e do regime geral são diversos. Desse modo, devemos concluir que o sistema de Seguridade Social não abrange a previdência dos regimes próprios dos diversos Estados-membros, Municípios, Distrito Federal e União. Sendo assim, não poderia ser computado como despesa da Seguridade Social o custeio dos benéficos previdenciários dos inativos da União, pois, além de atacar a boa hermenêutica dos dispositivos constitucionais citados, ofende a lógica do federalismo cooperativo. (CALCIOLARI, 2009, p. 154-155).

Daí porque, ao contrário do usualmente noticiado, como bem destaca ainda Denise Lobato Gentil (2007a, p. 16), não é o sistema de previdência social o causador dos "problemas de instabilidade econômica e crise de confiança nos investidores, mas é a política econômica que atinge a previdência, a saúde pública e a assistência social, precarizando serviços essenciais à sobrevivência da classe trabalhadora."

Portanto, observa-se apenas esporadicamente a divulgação desses sentidos jurídicos na discussão pública da Seguridade Social, sobretudo em função da dinâmica já apresentada do $4^{\circ}$ programa ou "filtro de notícias" - a bateria de reações negativas como forma de disciplinar a mídia - do sistema midiático. (Notícias 5, 6 e 7; CARIELLO, 2003).

Fora essas situações de insuficiente cobertura e debate falseado, tem-se, na maioria das vezes, a reprodução como "noticia" dos dados orçamentários bimestralmente publicados pela Secretaria de Orçamento Federal - SOF, os quais, repita-se, são 
direcionados pela descrita forma contábil de sua apresentação, que desvincula as receitas e despesas previdenciárias do orçamento geral da Seguridade Social, de cujo sistema, no entanto, a previdência faz parte.

A difusão midiática ostensiva acerca do pressuposto desequilíbrio nas finanças da previdência social constrói assim o consenso, sob a forma de expectativa generalizada, acerca do questionável déficit, muito embora diversos pesquisadores tanto da área econômica quanto jurídica, bem como os relatórios da Associação Nacional dos Auditores Fiscais da Receita Federal -ANFIP, demonstrem sua falsa crise financeira (GENTIL, 2007a; CALCIOLARI, 2009; ANFIP, 2010; 2009) e a existência de mitos acerca dos sistemas de seguridade social (LEMOS et al., 2007; ORSZAG; STIGLITZ, 2001; SERAU JR, 2010).

Sobre esse efeito comunicacional, a partir do qual se generaliza como verdade a existência da crise financeira da previdência, bem como se propicia a resilente aceitação pelo público da necessidade de suas reformas, afirma Denise Lobato Gentil (2007a, p. 03):

Diante dessa avalanche de avaliações sombrias massificadas pela mídia, não é de se estranhar que pessoas comuns, políticos e até pessoas respeitáveis do meio acadêmico acreditem que é preciso, urgentemente, fazer a reforma da previdência para resolver um problema financeiro gravíssimo. O déficit, no entanto, não existe. Se investigados mais detidamente, os dados estatísticos do Brasil revelam que não há crise financeira na previdência social e, principalmente, não há crise no sistema de seguridade social. [...].Quanto ao conjunto de ações associadas à seguridade social, verifica-se que o sistema como um todo é superavitário nesse período, o que indica que o governo pôde dispor de recursos excedentes. Ao decidir sobre sua utilização, no entanto, deixou de gastá-los com serviços de saúde, previdência e assistência social, para aplicá-los no orçamento fiscal, contribuindo para os superávits primários elevados dos últimos tempos. ${ }^{231}$

Em sua análise econômico-financeira da previdência social brasileira entre 1990 e 2005, a referida autora demonstra como o desequilíbrio orçamentário do Estado brasileiro situa-se em seu orçamento fiscal e não de seguridade social, nem de seu subsistema previdenciário. Ademais, outra falácia difundida seria que a Seguridade Social

231 Ademais, para a referida autora, no que diz respeito ao sistema previdenciário "[...] tem havido uma situação muito mais tranquila do que se poderia supor, durante os anos de 1990-2005, com alguns escassos momentos de déficit, apesar da política econômica recessiva adotada nesse período, que conduziu a resultados perversos no nível de produção e no mercado de trabalho. À revelia do quadro econômico desfavorável desse período, o desempenho do sistema previdenciário foi apenas parcialmente prejudicado." (GENTIL, 2007a, p. 03). 
recebe recursos do orçamento fiscal, observando-se, na realidade o contrário, ou seja, que parte substancial do orçamento da Seguridade é que financia o orçamento fiscal, sobretudo em função da Desvinculação de Receitas da União - DRU. (GENTIL, 2007a, p. 16).

Não obstante toda essa literatura pública acerca do caráter superavitário da Seguridade Social e os desvios de tais recursos de sua finalidade constitucional, com raras exceções (Notícia 6), frise-se, tais sentidos acerca da Seguridade Social não são objeto de análise e de informação dos meios de comunicação de massa.

Num claro exercício do padrão de ocultação de manipulação da notícia (ABRAMO, 2003, p. 25-27) os citados desvios da arrecadação das contribuições sociais para outras finalidades não são efetivamente debatidos publicamente ao mesmo tempo em que seu subsistema previdenciário é diuturna e propositadamente divulgado como deficitário.

Em que pese a veiculação da incomum noticia 6 comentada, e com exceção das citadas entrevistas (Notícia 7; CARIELLO, 2003), nas demais vezes em que a FOLHA DE S. PAULO tratou do assunto (Notícias 8 e 9; SALLOWICZ, 2010), essas irregularidades descritas nas notícias 6 e 7 do mesmo jornal não foram mais consideradas.

Ademais, o referido jornal voltou a editar suas notícias valendo-se da dramatização do déficit e da banalização das medidas prejudiciais aos trabalhadores como forma de quebrar a confiança social no sistema público e reforçar a implícita propaganda realizada em benefício da expansão da previdência privada no país. (BILENKY, 2010; SOFIA, 2010; SALLOWICZ, 2010).

Essa manifesta propaganda pode ser observada nas seguintes notícias.

\footnotetext{
Notícia 8-Déficit da Previdência Social dobra em agosto e atinge R\$ 5,4 bilhões FOLHA - Mercado (20/09/2010)

Thais Bilenky de Brasilia

O déficit da Previdência Social aumentou 111,2\% em agosto comparado a julho, acumulando R \$ 5,4 bilhões no vermelho, segundo os dados divulgados pelo ministério nesta segunda-feira. No acumulado do ano, o rombo é de R \$ 30,7 bilhões, valor 1,3\% inferior ao mesmo período do ano passado.

Previdência privada cresce $16 \%$ no ano, mas só atinge $4 \%$ dos brasileiros

Peritos do INSS encerram greve após decisão judicial

Envelhecimento e queda no número de trabalhadores pressiona aposentadoria
} 
Para a pasta, o reajuste de $7,72 \%$ para as aposentadorias maiores que um salário mínimo e a antecipação do $13^{\circ}$ salário para aposentados e pensionistas explicam a alta na dívida. Descontando-se os R $\$ 1,85$ bilhões empregados nessas despesas, o deficit fica em R \$ 3,56 bilhões, ainda superior aos R 2,56 bilhões de julho. Todos os valores foram ajustados pelo INPC (Índice Nacional de Preços ao Consumidor). O ministro Carlos Eduardo Gabas disse que a estimativa de deficit para 2010 poderia ser reduzida de R $\$ 47$ bilhões a um valor entre R $\$ 46$ bilhões e R $\$ 45$ bilhões, mas a decisão do STF (Supremo Tribunal Federal) exige o reajuste de benefícios pelo teto a cerca de 154 mil pessoas, o que demandará $\mathrm{R} \$ 1,5$ bilhão da pasta e deverá manter as contas como estão. O titular da pasta disse que a quantia deve ser desembolsada ainda neste ano. "A ideia é que não fique nada pendente para o próximo governo", afirmou.

\section{PREVIDÊNCIA PRIVADA}

Apenas $4 \%$ das famílias investem em previdência privada no país, segundo estudo realizado pela Kantar Wordpanel, a pedido da Fenaprevi (Federação Nacional de Previdência Privada e Vida), entidade que reúne 65 sociedades seguradoras e 15 entidades abertas de previdência complementar. O levantamento foi extraído de uma base de 8,2 mil domicílios, amostra que representa $81 \%$ da população domiciliar brasileira e $91 \%$ do potencial de consumo residencial no Brasil. Entre janeiro e julho deste ano, o mercado de previdência privada arrecadou R $\$ 23,1$ bilhões, 16,46\% acima do resultado no mesmo período de 2009. (BILENKY, 2010 - sublinhado).

Nesta notícia 8, como fora inicialmente comentado, não só se negligência a discussão das irregularidades jurídicas que o próprio jornal noticiara no ano anterior a esta (Notícia 6) sobre os desvios orçamentários, como também resta evidente em seu texto a tentativa de desconstrução da confiança na previdência pública em sua primeira parte, para, logo a seguir e no mesmo texto, fomentar-se a previdência privada.

Realiza-se, assim, uma implícita propaganda (merchandising editorial) sendo, inclusive, utilizados juízos de valor para se referir à situação do mercado de previdência privada que "só atinge $4 \%$ dos brasileiros", de modo que "apenas 4\% das famílias investem em previdência privada no país”. (BILENKY, 2010).

Nessa mesma linha, se desenvolve a seguinte notícia:

\section{Notícia 9-Sob governo Lula, 550 mil buscam fundo de pensão}

FOLHA - Mercado (08/09/2010) 


\section{Juliana Sofia, de Brasília}

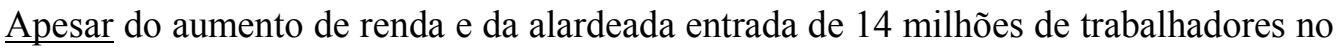
mercado formal no governo Lula, pouco mais de 550 mil pessoas ingressaram na indústria dos fundos de pensão nos últimos sete anos. A modesta inclusão de participantes representou um aumento de $26 \%$ no estoque de trabalhadores cobertos pelo sistema de previdência fechado ao final de 2002. "Diante do quadro [econômico], o resultado poderia ter sido melhor", afirma o diretor-superintendente da Previc (Superintendência Nacional de Previdência Complementar), Ricardo Pena. Segundo ele, o crescimento do mercado dos fundos de pensão depende diretamente da capacidade econômica das empresas e das pessoas. "Esse crescimento do mercado de trabalho, esses novos empregos podem talvez envolver uma questão salarial menor, não gerando ainda o estímulo para a constituição da previdência complementar", avalia Pena. Estudos apontam que o universo potencial de trabalhadores em condições de investir na aposentadoria complementar situa-se a partir da faixa de renda equivalente ao teto de benefícios do INSS (Instituto Nacional do Seguro Social), R \$ 3.400. "Mas existem fundos cujo tíquete de entrada é de $\mathrm{R} \$ 50$. Acho que falta conhecimento, uma grande campanha do mercado para desenvolver o setor", diz o diretor-superintendente. $\mathrm{E}$ acrescenta: "Faço um mea-culpa. $\underline{\mathrm{O} \text { governo deveria ter }}$ investido em uma estratégia mais arrojada de incentivo à previdência complementar, por meio dos instituidores, das pequenas e médias empresas e da própria previdência complementar do servidor público". Os instituidores fazem parte da modalidade de previdência complementar associativa. O fundo de pensão é criado por um instituidor, não há o vínculo com uma empresa (patrocinadora). Nessa modalidade, os trabalhadores são agrupados de acordo com a classe profissional. Um exemplo é o fundo de pensão da Ordem dos Advogados do Brasil. A previdência associativa surgiu no início dos anos 2000. Em 2002, havia apenas um fundo ligado a instituidor. Atualmente, são 450. Hoje, 2,7 milhões de brasileiros compõem a rede de trabalhadores e aposentados atendidos por fundos de pensão. São 366 entidades ligadas a empresas estatais e privadas. A maior parte das 2.222 patrocinadoras é de grandes empresas. (SOFIA, 2010 - sublinhado).

A notícia 9, por sua vez, demonstra claramente a efetiva política do governo de estimular a previdência privada, como se observa nas palavras do próprio diretorsuperintendente da Superintendência Nacional de Previdência Complementar — Previc: "O governo deveria ter investido em uma estratégia mais arrojada de incentivo à previdência complementar" (SOFIA, 2010 - sublinhado). 
Essa estratégia e seu investimento "abaixo do desejado" são reconhecidas sem qualquer constrangimento, em que pese a Constituição Federal de 1988, em seu artigo 194 e seguintes, impor como política pública a esse mesmo governo a execução de "um conjunto integrado de ações de iniciativa dos Poderes Públicos e da sociedade, destinadas a assegurar os direitos relativos à saúde, à previdência e à assistência social”. (BRASIL, 1988).

Em nenhum momento, a referida Carta Magna determina como política pública ou atribuição do poder executivo o estímulo da previdência privada, normatizada como de “caráter complementar" ao Regime Geral de Previdência Social e demais regimes próprios públicos, sendo, ademais, facultada tanto a sua organização pela iniciativa privada quanto, a adesão de seus participantes. A imposição constitucional nessa matéria diz respeito tão somente à sua regulação através de lei complementar, nos termos de seu artigo 202. (BRASIL, 1998).

No entanto, essa versão oficial do governo não é contraditada na transcrita notícia 9, sendo, pelo contrário, convalidada nesse texto jornalístico abertamente opinativo, apesar da contradição lógica entre esses termos. Essa adesão midiática, embora juridicamente injustificável, se explica em função dos descritos acoplamentos estruturais entre os sistemas econômico e político e as organizações empresariais que fazem parte do sistema dos meios de comunicação de massa, inclusive, sendo observados também no Brasil.

Essas relações propiciam o funcionamento do descrito $1^{\circ}$ programa/filtro de notícias - porte, propriedade e orientação para o lucro da mídia de massa - como mecanismo sistêmico orientador do código informação/não-informação, junto aos demais programas comunicacionais apresentados.

Por essas razões, essa adesão midiática não se restringe a reprodução, sem qualquer questionamento, das opiniões do representante do governo de que o "resultado [da evolução do mercado de previdência privada] poderia ter sido melhor", como também expressa juízos de valores favoráveis à expansão dessa "indústria" previdenciária ao publicar: "Apesar do aumento de renda [...] pouco mais de 550 mil pessoas ingressaram na indústria dos fundos de pensão". Em outras palavras, para o próprio jornal era de se esperar 
- e assim há que se generalizar como expectativa social - que mais pessoas "investissem"

na "indústria" previdência, o que, juridicamente, revela-se como outra contradição. ${ }^{232}$

No que diz respeito à saúde pública, tem-se o mesmo tipo de discussão centrada em seus aspectos econômicos e financeiros, apartada, portanto, dos sentidos normativos e da finalidade constitucional de suas políticas públicas.

Nesse aspecto, a Notícia 10, não só fragmenta as informações acerca desse subsistema sanitário de Seguridade social como, também, corrobora a inversão dos fatos no que diz respeito às causas de sua suposta crise orçamentária.

\section{Notícia 10 - Oposição derrota governo e Senado rejeita prorrogação da CPMF}

FOLHA - Poder (13/12/2007)

Gabriela Guerreiro, Renata Giraldi e Ana Paula Ribeiro, da Folha Online, em Brasília

O plenário do Senado rejeitou nesta quinta-feira, por 45 votos a 34 e nenhuma abstenção, a proposta de prorrogação da CPMF (Contribuição Provisória sobre Movimentação Financeira) até 2011. Após fracassarem as tentativas do governo de convencer os senadores da oposição a votarem a favor da PEC (proposta de emenda constitucional) da CPMF, a oposição conseguiu o apoio de parlamentares da base aliada para derrotar a matéria no plenário. Para passar, a proposta precisaria ser aprovada, em dois turnos, com ao menos 49 votos favoráveis em cada um. A vigência da CPMF termina no dia 31. O governo calculava arrecadar cerca de $\mathrm{R} \$ 40$ bilhões em 2008 com o chamado "imposto do cheque". O governo tentou até o último minuto convencer os senadores de oposição a votar a favor da proposta. O presidente Luiz Inácio Lula da Silva e os ministros José Múcio Monteiro (Relações Institucionais) e Guido Mantega (Fazenda) entraram pessoalmente na negociação e enviaram ao plenário do Senado uma carta-compromisso do Planalto. No documento, eles se comprometem a repassar $100 \%$ dos recursos arrecadados com a CPMF para a saúde. Hoje, só uma parcela de 0,20 da alíquota de $0,38 \%$ é destinada ao setor. Líderes governistas disseram que essa era a última cartada do governo para garantir a manutenção do "imposto do cheque" que acabou fracassada. "Ninguém pode perder essa proposta. Será muito bom para todos. O presidente Lula está comandando

\footnotetext{
${ }^{232}$ A pesquisa realizada por Marcelo Alves de Oliveira $(2006$; 2008) destaca-se como referência na discussão científica da função social da previdência complementar brasileira, bem como de seus atuais limites jurídicos e econômicos. Pode ainda ser citado como referência sobre o tema em questão, o trabalho intitulado "Previdência privada: doutrina e comentários à Lei Complementar n. 109/01", coordenado por Marcus Orione Gonçalves Correia e José Corrêa Villela (2004).
} 
diretamente as negociações", afirmou o líder do governo na Câmara, Henrique Fontana (PT-RS), antes da votação. Fontana foi acionado para negociar pessoalmente com os senadores a prorrogação da CPMF. Ele passou o dia no plenário do Senado em conversas com parlamentares, assim como outros deputados governistas que articulavam a manutenção do "imposto do cheque".

\section{Nova proposta}

A nova proposta previa o aumento de gastos para a saúde em $\mathrm{R} \$ 8$ bilhões em 2008; R \$ 12 bilhões em 2009 e R\$ 16 bilhões em 2010 e mais a correção dos repasses pelo PIB (Produto Interno Bruto) nominal. Segundo Fontana, a alteração deve ser incorporada à emenda 29 que destina recursos da União para a saúde, o que permitiria agregar mais verbas para o setor.

\section{Corpo-a-corpo}

Para tentar aprovar a proposta, os líderes governistas partiram para o corpo-a-corpo com senadores da base aliada que resistiam em votar a favor da CPMF. O líder do governo no Senado, Romero Jucá (PMDB-RR), intensificou hoje as visitas aos gabinetes dos chamados "dissidentes" em busca de votos pró-CPMF. Um dos alvos do governista foi o senador Pedro Simon (PMDB-RS), que declarou o voto contrário ao "imposto do cheque". Simon disse ter simpatia pela proposta do governo e não descartou a possibilidade de mudar de ideia. Mas cobrou, em troca, que o presidente Luiz Inácio Lula da Silva assine um documento oficializando a proposta para evitar recuos do governo no futuro. "Eu vejo com simpatia, é uma proposta nova e interessante. Eu perguntei para o Jucá: se o Lula não acredita em mim, por que eu vou acreditar em ti, Jucá?", questionou Simon.

\section{Adiamento}

Sem os votos necessários para aprovar a prorrogação da CPMF, líderes governistas chegaram a sugerir o adiamento da votação para esta quinta-feira. O senador Pedro Simon (PMDB-RS) fez um apelo para que os senadores adiassem a sessão para que tivessem mais tempo para analisar as propostas do governo oferecidas em contrapartida à prorrogação do "imposto do cheque". "O governo mandou propostas na última hora, mas mandou. Já estamos a um minuto da quinta-feira, podemos remarcar a sessão para ler e reler os documentos do governo. Faço esse apelo como um irmão mais velho de todos", afirmou. Irritado com a proposta, o senador Arthur Virgílio (PSDB-AM) bateu boca com Simon no plenário. Após ser provocado pelo peemedebista, Virgílio disse que Simon "talvez não falasse tanto se trabalhasse como

devia". O tucano disse que o peemedebista deveria se assumir como uma pessoa "que se acha acima do bem e do mal". Em resposta, Simon disse que Virgílio era um 
"gurizinho de calças curtas" quando já estava na vida política brasileira. O presidente do Senado, Garibaldi Alves (PMDB-RN), teve que intervir para que os ânimos se acalmassem na Casa. Após o mal estar, Virgílio recuou ao afirmar sua admiração e respeito por Simon. Os dois parlamentares trocaram um abraço no plenário para dar fim ao debate antes do início da votação.

\section{$\underline{\text { DRU }}$}

Para amenizar a derrota da CPMF, o Senado aprovou, por 60 votos a 18, a prorrogação da DRU (Desvinculação das Receitas da União), medida que permite ao governo federal a livre transferência de $20 \%$ das receitas da União. Atrelada à prorrogação da CPMF, a medida só foi aprovada porque foi desmembrada da Emenda Constitucional que tratava do tributo. A DRU, com vigência estendida até 2011, permite a livre destinação de verbas oriundas de impostos, contribuições sociais e de intervenção no domínio econômico. (GUERREIRO; GIRALDI; RIBEIRO, 2007).

Destaca-se a criticada fragmentação e inversão dos fatos na transcrita notícia 11 pelas seguintes razões.

No texto em questão o principal argumento para a extinção da Contribuição Provisória sobre Movimentação Financeira - CPMF seria o fato de sua receita ter sido destinada totalmente, desde sua criação, para custear as políticas públicas de saúde.

Ademais, segundo o próprio jornal e diversos autores, tal desvio decorre da existência, no Ato das Disposições Constitucionais Transitórias - ADCT, da Desvinculação de Receitas da União - DRU.

Contudo, na notícia em questão, não apenas é divulgado que na mesma seção legislativa fora prorrogada a DRU, como também, e modo totalmente acrítico e descontextualizado, o próprio jornal afirma que tal prorrogação se deu com o objetivo de "amenizar a derrota da CPMF", permitindo ao governo federal continuar a transferir "livremente" de $20 \%$ das receitas da União para outras finalidades, que não as constitucionalmente previstas, como vinha sendo feito, inclusive, com os valores da extinta CPMF se espera fossem para a saúde. (GUERREIRO; GIRALDI; RIBEIRO, 2007).

Por fim, corrobora a crítica da distorção comunicacional realizada pelos meios de comunicação de massa no Brasil acerca dos sentidos e expectativas sociais sobre as políticas públicas de previdência e assistência social e saúde pública a pesquisa realizada 
por Aglaé Silvestre (2007), intitulada: "O sujeito e o pathos na mídia: uma análise do discurso sobre saúde nas matérias de capa das revistas Veja e Época”.

Nesse trabalho, ao analisar o discurso relacionado à saúde nas matérias de capa das revistas Veja e Época, a referida pesquisadora demonstra como esses periódicos expõem, em suas capas e de modo cada vez frequente, temas ligados à saúde como fator regulador de comportamentos sob a perspectiva individual e consumista.

Essas organizações midiáticas abordam os temas medicina e saúde, sobretudo ao classificar as doenças da atualidade, no sentido de perpetuar um

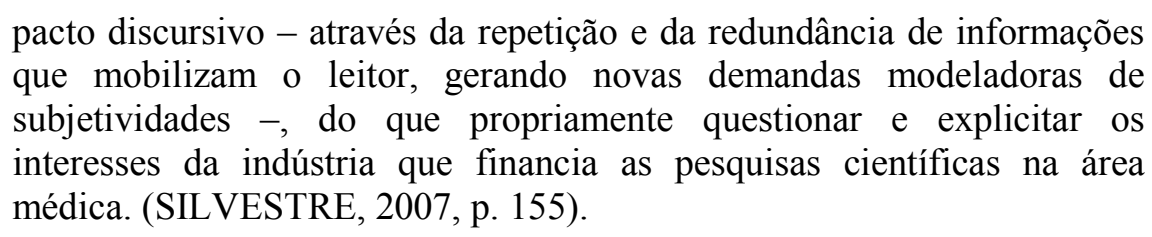

Esse conflito sistêmico entre os sentidos e expectativas sociais tanto cognitivas quanto normativas acerca da saúde fora objeto da dissertação de mestrado (CRUZ, 2007) que levou aos primeiros questionamentos que deram origem a presente tese.

No referido trabalho, foram discutidas as possíveis diferenciações funcionais dos sistemas de saúde a partir das relações entre os sistemas político, econômico e científico em torno da medicina e da atuação estatal no controle dos corpos supostamente em nome da saúde, na Europa desde o século XVIII.

A evolução do sistema sanitário nacional pode, assim, ser situada no desenvolvimento do Estado brasileiro e na organização de suas políticas públicas em saúde, durante o século XX, em comparação à conformação dos sistemas de saúde europeus, analisada por George Rosen $(1994 ; 1979)$ e por Michel Foucault $(1979 ; 1974)$ em seus estudos sobre os modelos de Medicina Social e a Crise da Medicina Moderna.

Demonstrou-se, então, a forma como o Estado brasileiro contribuiu, já no início do século passado, de maneira decisiva para a manutenção e o desenvolvimento da medicina privada, desde sua inicial vertente individualista e liberal, passando pelo posterior fomento do mercado de assistência médica em sua restrita e igualmente privada prestação de serviços aos segurados das Caixas de Aposentadorias e Pensões e dos Institutos de Aposentadorias e Pensões controlados pelo poder estatal. (CRUZ, 2007, 196-256). 
Porém, essa atuação estatal não se restringiu à cobertura dos custos e das necessidades em saúde servindo, mas, além disso, desenvolveu-se como um instrumento de "certa redistribuição econômica". Assim, o corpo, a saúde e a doença foram socializados através da Medicina Social, torando-se, em meados do século XX um "instrumento de socialização dos indivíduos". (FOUCAULT, 1974, p. 03). ${ }^{233}$

Nesse contexto, a saúde passou a representar um importante objeto de disputas políticas e econômicas, surgindo uma "nova política do corpo". ${ }^{234}$

Contudo, na medida em que o cuidado com a saúde se transformou numa das principais práticas de intervenção estatal, esta viveria em crise, posto que apesar de todo esse avanço tecnológico na luta contra as doenças e do novo papel econômico e político, sobretudo, da medicina, os mesmos não foram capazes de propiciar o "avanço do bemestar sanitário" esperado, mas pelo contrário, teriam levado "a uma curiosa estagnação da medicina e saúde pública". (FOUCAULT, 1974, p. 05). ${ }^{235}$

O sistema de saúde assume, assim, um alto grau de complexidade, diferenciando-se funcionalmente dos sistemas científico, político e econômico no que diz respeito à sua comunicação interna e aos seus acoplamentos estruturais em torno das questões sanitárias.

Importa, porém, nos limites da presente tese, retomar um dos aspectos apontados pelo referido autor como essencial para a compreensão dos sistemas sanitários modernos, qual seja, o fenômeno da "medicalização indefinida da sociedade". Tal decorre da extensão da medicina no século XX para fora de seu domínio tradicional, quer dizer, para além da

\footnotetext{
${ }^{233}$ Nesse sentido, segundo Michel Foucault (1974, p. 03), o sistema de regulação e de cobertura econômica da saúde e da doença funcionaria como mais um mecanismo de correção de parte da desigualdade de renda pois asseguraria "a todos as mesmas possibilidades de se tratar e, eventualmente, de se curar".

${ }^{234}$ Daí porque ser possível afirmar que: “[com o fim da Segunda Guerra] não há partido político, nem batalha política, em nenhum país mais desenvolvido que não se coloque o problema da saúde e da maneira como o Estado assegurará e financiará as despesas de saúde dos indivíduos”. (FOUCAULT; 1974, p. 04).

235 Dessa forma, não apenas Medicina Moderna como as próprias políticas de Saúde Pública passaram a ser dotadas de um poder autoritário com função normalizadora, não restrita à existência de doença ou à demanda do doente sendo que tudo "o que assegure a saúde do indivíduo, seja salubridade das águas, o sistema de habitação ou o regime urbanístico, é hoje um domínio da intervenção médica”. (FOUCAULT, 1974, p. 13).
} 
“demanda do doente, seu sofrimento, seus sintomas, seu mal-estar" e dos próprios limites da doença, que seriam o seu objeto de domínio habitual. (FOUCAULT, 1974, p. 12). ${ }^{236}$

As questões relacionadas ao corpo foram desse modo inseridas no mercado não apenas em razão de sua identificação como força produtiva ${ }^{237}$, mas fundamentalmente através do consumo de saúde, mediado pela medicina e, atualmente, pela comentada propaganda, explícita e implícita, difundida pelos meios de comunicação de massa.

Delineou-se, assim, a "economia política da Medicina" relacionada ao novo e principal papel econômico assumido pela Medicina Moderna, diretamente ligado à produção de riqueza em função da introdução da saúde em si no mercado, como um objeto de consumo. De acordo com Michel Foucault (1974, p. 18):

Atualmente, a medicina encontra a economia por outro caminho. Não, simplesmente, porque é capaz de reproduzir a força de trabalho, mas porque é diretamente capaz de produzir riqueza, na medida em que a saúde é objeto de desejo para uns e de lucro para outros. A saúde, enquanto objeto de consumo, enquanto pode ser produzida por uns laboratórios farmacêuticos, médicos etc. - e consumida por outros - os doentes potenciais ou atuais - tornou-se um objeto econômico importante, entrou no mercado. ${ }^{238}$

Nesse contexto, a prática e o saber médico, bem como a boa parte da comunicação disseminada pelas organizações midiáticas, como demonstrou o citado trabalho de Aglaé Silvestre (2007), foram reposicionados como intermediários entre o mercado, com destaque para indústria farmacêutica, e a demanda de seus clientes. (ANGELL, 2007, p.207-229; BARROS, 2004, p. 119). ${ }^{239}$

\footnotetext{
${ }^{236}$ Essa expansão do domínio interventivo das práticas sanitárias não mais restritas aos doentes e às doenças decorreria de seu "desbloqueio epistemológico" ocorrido no final do século XVIII, no contexto do desenvolvimento da Medicina Social. Teria sido graças à atenção para outras coisas que não apenas os doentes, como se depreende claramente do modelo urbano francês de Medicina Social, que a Medicina deixa de ser essencialmente clínica e passa a ser social, o que lhe permitiu libertar-se, desde então, da "estagnação científica e terapêutica em que se encontrava”. (FOUCAULT, 1974, p. 14).

237 Desde o século XVIII, com o desenvolvimento da Medicina Social, a saúde já era relacionada aos problemas econômicos objetivando-se, através da medicina, responder às necessidades mercantilistas, à citada aritmética política dos Estados nacionais em fase de consolidação e, posteriormente, às demandas do capitalismo relativas à manutenção e reprodução da força de trabalho. (FOUCAULT, 1979, p. 84; ROSEN, 1979, p. 147; 1994, p. 98).

${ }^{238}$ A inserção do corpo no mercado, mediada pela Medicina, ocorreu inicialmente como força de trabalho assalariada e, depois, por meio do consumo de saúde, o que, por conseguinte, teria propiciado diversas “disfunções no sistema de saúde e da medicina contemporânea". (FOUCAULT, 1974, p. 19).

239 A esse respeito, pode ser citada a reportagem do jornal FOLHA DE SÃO PAULO, de 3 de setembro de 2005, sob o título "Receita Vigiada", que noticiou a pressão exercida pelos propagandistas dos laboratórios,
} 
Contudo, não se tem observado em relação à saúde uma significativa melhoria de seus indicadores à medida que o consumo médico aumenta, ao contrário do consumo de outros bens e do que é generalizado pela mídia como expectativa cognitiva sobre o consumo de serviços médico-hospitalares, a partir da propaganda comercial como também política. ${ }^{240}$

Esse descompasso entre as expectativas da sociedade em relação ao "consumo de saúde", amplamente difundida pelos meios de comunicação de massa, e sua repercussão na real melhoria das condições sanitárias persiste atualmente a despeito dos supostos avanços da indústria farmacêutica e de seu aparente empenho no desenvolvimento de novos medicamentos que justificariam, em tese, os preços altos de seus produtos, bem como seus lucros exorbitantes. ${ }^{241}$

No que diz respeito, porém, aos sentidos jurídicos do sistema sanitário em questão, cumpre destacar a redefinição de suas expectativas normativas e das funções do Estado brasileiro em matéria de políticas públicas de saúde encampadas pela Constituição de 1988.

Tais sentidos resultam da reordenação dos processos comunicacionais e das inter-relações de diversos sistemas sociais, marcado pela generalização de expectativas em torno da redemocratização e redução das desigualdades sociais do país, tendo um impacto concreto nas novas interações entre diversos atores sociais na luta pela concretização de uma sociedade mais justa e solidária.

Dentre essas lutas sociais, situam-se as disputas entre o Movimento pela Reforma Sanitária e os sistemas econômico e político nos embates pela definição do sistema sanitário brasileiro através um novo modelo que fosse capaz de se contrapor

na posse de cópias do receituário fornecidas por farmácias, sobre profissionais da saúde no sentido de controlar a prescrição de produtos da marca por eles representada. Tal mecanismo estaria sendo utilizado para verificar se médicos beneficiados por certos "favores" dos laboratórios estariam, de fato, sendo "parceiros" da indústria farmacêutica. (COLLUCCI, 2005).

${ }^{240}$ Essa assimetria seria demonstrada ao se relacionar consumo de serviços e produtos de saúde às alterações no nível de vida. Estudos nesse sentido apontam para o fato de que "as variáveis do meio, em particular o consumo alimentar, a educação, a renda familiar, são fatores que influem muito mais do que o consumo médico". (FOUCAULT, 1974, p. 19).

241 Nesse sentido, diversos são os trabalhos que questionam os métodos dos grandes laboratórios farmacêuticos privados para manter sua alta lucratividade num mercado global cuja estimativa total de vendas de medicamentos sujeitos à prescrição médica no mundo inteiro estava em torno de 400 bilhões de dólares em 2002. (ANGELL, 2007, p. 21; NASCIMENTO, 2005; BARROS, 2004). 
àquele biomédico de cunho essencialmente curativo e mercantilista até então vigente. (CRUZ, 2007, p. 249). ${ }^{242}$

As expectativas normativas em relação à da saúde foram assim redefinidas em âmbito constitucional, situando-as entre os direitos sociais que compõem os Direitos e Garantias Fundamentais da República Federativa do Brasil (Título II, Capítulo II, art. $6^{\circ}$ ), bem como no "conjunto integrado de ações de iniciativa dos Poderes Públicos e da sociedade" que compõe a Seguridade Social (Título VIII, Capítulo II, art. 194).

No o artigo 196 da Constituição Federal de 1988 a saúde foi redefinida como “direito de todos e dever do Estado, garantido mediante políticas sociais e econômicas que visem à redução do risco de doença e de outros agravos e ao acesso universal e igualitário às ações e serviços para sua promoção, proteção e recuperação.” (BRASIL, 1988).

Nesses termos, o sistema sanitário, as políticas públicas relacionadas à sua organização e efetivação, bem como os demais sistemas sociais que compõem a sociedade brasileira tiveram suas funções redefinidas em relação à saúde. Em outras palavras, a sociedade - compreendidos seus sistemas jurídico, econômico, político e midiático, dentre outros - se comprometeu a viabilizar políticas públicas, sociais e econômicas, com o objetivo de reduzir "os riscos de doença e de outros agravos" numa dimensão preventiva, que não pode mais ser satisfeita simplesmente pela manutenção do propagandeado sistema assistencial médico-curativo, privatista e discriminador. ${ }^{243}$

\footnotetext{
${ }^{242}$ Embora não seja o objetivo deste trabalho aprofundar a discussão relativa à conceituação do modelo biomédico, cumpre aqui esclarecer que as referências a ele feitas relacionam-se à descrição de Jairnilson Silva Paim (1997, p. 20) sobre o paradigma flexneriano enquanto ao modelo biomédico hegemônico, combatido pela reforma sanitária da década de 1980, que, em linhas gerais, reduz o sistema de saúde ao conjunto de estabelecimentos de assistência médico-hospitalar, centrados no diagnóstico e na terapia alopática. Tem-se, assim, em linhas gerais que tal modelo pode ser entendido como uma prática de intervenção soberana, na qual princípios mecanicistas, biologizantes, individualistas, de especialização e tecnifícação são hegemônicos. Não seria demais relacioná-lo ao influxo das demandas e lógicas econômicas desse modelo sobre a conformação dos sistemas de saúde centrados nesse paradigma flexneriano no qual, de acordo com Amauri Moraes dos Santos (2005, p. 73), os "profissionais de saúde envoltos nesta dimensão seguem reproduzindo o modelo capitalista ortodoxo, onde a saúde e o medicamento são considerados produtos de troca, mercadorias de intensa exploração mercantil". Contrapondo-se a essa forma de conceber e organizar o sistema sanitário nacional, a Constituição de 1988 determina, assim, a conformação de um novo sistema organizacional brasileiro de saúde.

${ }^{243}$ Dessa forma, "o acesso universal e igualitário às ações e serviços para a sua promoção, proteção e recuperação" deve garantir a todos, cidadãos brasileiros ou não, o direito de não apenas serem atendidos pelos serviços assistenciais curativos do Sistema Único de Saúde - SUS, como também de serem alcançados pelas ações e demais políticas públicas voltadas à prevenção e à promoção de sua saúde de maneira geral.
} 
A promoção da saúde assume, assim, um sentido amplo e interdisciplinar relacionado à garantia da qualidade de vida enquanto questão pública intrinsecamente ligada à saúde. Portanto, não mais restrita à cura e à prevenção de doenças - as quais não deixam de ser atribuição do Estado -, nem sequer ao consumo e às práticas meramente individuais de cuidado com o corpo. Apresenta-se, pois, como "um processo que se constrói e que se modifica, sofrendo influência de todos os demais sistemas sociais". (SCHWARTZ, 2004, p. 102).

Dessa forma, conclui-se que, ao contrário do generalizado pelos meios de comunicação massa em função de seus programas sistêmicos, as expectativas sociais, sejam elas normativas ou cognitivas, relacionadas à Seguridade Social devem se conformar minimamente à Constituição, reforçando-se, assim, a confiança e solidariedade sociais, essenciais à cobertura de seus riscos e à própria redução da complexidade da sociedade. 


\section{CONCLUSÃO}

A redação deste trabalho foi empreendida com o cuidado de sistematizar não somente, no início de cada um de seus capítulos, as principais questões nele discutidas, como, ao seu final, as conclusões parciais depreendidas de seu desenvolvimento, promovendo sua articulação com as discussões seguintes e o tema geral abordado.

Assim, cabe nesta conclusão a retomada dos pontos chaves que levaram à interpretação proposta das funções sistêmicas dos meios de comunicação de massa e do sistema jurídico nacionais, bem como daqueles elementos que permitiram o exame do caráter conflituoso da generalização para toda a sociedade, empreendida por tais sistemas, acerca de quais expectativas sociais devem ser mantidas no que diz respeito tanto ao papel do Estado, quanto ao sentido de suas políticas públicas relativas à Seguridade Social, em que pese a delimitação normativa dessas questões na Constituição da República Federativa do Brasil de 1988.

A revisão e o detalhamento da intrincada Teoria da Sociedade de Niklas Luhmann (1988) permitiu diferenciar sua singular estrutura conceitual, imprescindível não apenas para a compreensão dos novos sentidos por ele atribuídos a termos, em princípio, sedimentados nas ciências humanas e de aparente senso comum, como, também, para a delimitação do objeto de estudo do presente trabalho.

Nesse contexto, foi rediscutida a visão luhmanniana dos sistemas sociais através da abordagem crítica de seus principais conceitos, demonstrando-se seus pontos de convergência e de distinção em relação a esta tese, e suas limitações em face do desenvolvimento da sociedade brasileira, sem se menosprezar os limites e contingências comunicacionais da observação sistêmica realizada, descrita nesta própria teoria.

Assumiu-se, além disso, o risco de uma interpretação diferenciada da teoria utilizada e dos demais trabalhos consultados. Tal risco, delineado no primeiro capítulo, diz respeito à inevitável incidência na elaboração em si deste trabalho da contingência dos sistemas de sentido.

Não é possível se eximir dessa contingência sistêmica, nem da decorrente impossibilidade de separação entre "sujeito" e "objeto" de pesquisa, em razão da própria 
dinâmica recursiva dos processos cognitivos humanos, em termos de sua autorreferencialidade, como demonstrado nos estudos de Maturana e Varela (1980, 2005).

Por sua vez, a discussão sistêmica do direito foi realizada a partir de sua oposição ao positivismo jurídico em termos científicos, o que não desconsidera o sistema jurídico, em si, como direito positivo.

Justificou-se, dessa forma, tanto a opção por alternativas capazes superar o isolamento dogmático do direito - e sua descrição aparentemente a-valorativa das relações sociais -, quanto a consideração do caráter autorreferencial e paradoxal de suas operações comunicacionais internas. Abdicou-se, por esses motivos, do recurso a pressuposições lógico-fictícias ou transcendentais e à criticada redução da função e conflituosidade do direito, resultante de sua compreensão em termos de um consenso idealizado da razão e do agir comunicativos.

Foi possível contextualizar o direito em suas inter-relações com os demais sistemas sociais que compõem a sociedade, justamente graças à sua descrita abertura cognitiva e à sua abordada função de generalização e manutenção contrafactual de expectativas normativas.

Demonstrou-se, nesse aspecto, que tal generalização de expectativas em termos normativos desempenha a importante função de reduzir a exposição dos sistemas sociais às frustrações de suas expectativas sistêmicas, quando meramente cognitivas.

Isto porque, a institucionalização de expectativas em termos normativos estabiliza os conflitos diretos entre expectativas contrapostas não limitadas a dois, mas a três ou mais sistemas de sentidos. Tem-se, dessa maneira, uma antecipação de expectativas que serão em parte produzidas por esses sistemas para a absorção dessas frustrações e o enfrentamento dos riscos da referida dupla-contingência comunicacional a que estão sujeitos.

Com isso, propôs-se, nesta tese, uma saída ao aparente paradoxo do direito em regular os demais sistemas igualmente autorreferenciais, em que pese o processo de diferenciação funcional do sistema social global e a impossibilidade de um controle total de suas operações a partir de uma perspectiva externa. Tal proposta foi possível, levandose em conta, dentre outras razões, a própria conclusão de Luhmann (1992, p. 1434-1435) de que a diferenciação funcional da sociedade não afasta essa função sistêmica do direito.

Quanto à esperada "contribuição original do tema à ciência jurídica brasileira", na medida do possível, reformulou-se parcialmente, através dessa tese, a metodologia de 
estudo do Direito da Seguridade Social, sendo proposta uma nova forma de se discutir, em termos tanto teóricos quanto práticos, suas inter-relações com os demais sistemas sociais, chamando-se a atenção para seus conflitos comunicacionais e para as comprovadas tensões sistêmicas em relação às informações e expectativas generalizadas pela mídia, acerca dos sentidos da Seguridade Social e da forma de atuação do Estado na implementação das respectivas políticas públicas.

Nesse sentido, a discussão empreendida sobre a lógica sistêmica dos meios de comunicação de massa pode esclarecer como seu processo de seleção das informações relativas à saúde, previdência e assistência social encontra-se direcionado para o fomento dos serviços privados nessa área, em função da limitação de sua discussão pública e da instrumentalização da quebra de confiança no Sistema de Seguridade Social Brasileiro, solapando, por conseguinte, a solidariedade social, indispensável para a construção desse combatido sistema de proteção e para o sucesso de suas políticas públicas.

Essa forma de comunicação contrapõe-se, portanto, aos sentidos dos direitos sociais e ao direcionamento das políticas públicas voltadas à sua implementação, previstos na Constituição Federal de 1988, a qual foi reinterpretada como o resultado da convergência dos processos comunicacionais de toda a sociedade e da consequente institucionalização de suas expectativas mais elementares em termos normativos.

A descrita distorção da informação resulta da programação interna do sistema dos meios de comunicação e do respectivo condicionamento de seu código informação/não-informação, através de seus principais filtros de notícias - ou, em linguagem sistêmica, "programas".

Estes filtros, por sua vez, se desenvolveram em razão da examinada concentração de suas organizações midiáticas, tanto nos EUA quanto no Brasil, num pequeno número de empresas orientadas para o lucro; do fato da propaganda constituir-se como sua principal fonte de financiamento, e de sua dependência de informações fornecidas pelo governo e por empresas supostamente especializadas, em que pese seus não divulgados conflitos de interesses e ideários majoritariamente de ordem neoliberal.

De um modo geral, foi possível expor como o modelo de propaganda adotado, uma vez aplicado à realidade brasileira, permite a compreensão do favorecimento, por parte da mídia nacional, dos interesses dos sistemas sociais parciais que financiam suas organizações, fazendo com que sua comunicação de mensagens e símbolos não se restrinja 
apenas a uma forma de divertir, informar e entreter o público, como também desempenhe uma tentativa de incutir nos indivíduos valores, credos e códigos de comportamento através de um minucioso processo de seleção de expectativas cognitivas parciais acerca da realidade, generalizadas socialmente por esses meios de comunicação.

Não obstante se reconheça a disseminação desses interesses e sentidos parciais, deve-se reforçar a comunicação contrária, tal como o objetivo mediato dessa tese, defendendo-se os sentidos previstos na Constituição Federal de 1988 em relação às políticas públicas, sua forma de organização e imprescindível efetivação. Isto porque, estes sentidos e as decorrentes expectativas normativas a serem, desse modo, generalizadas, decorrem da redefinição da sociedade brasileira em termos comunicacionais.

A referida Constituição, mais do que um simples documento, compreende, como exposto, os novos meios de comunicação simbolicamente generalizados com os quais passam a contar os sistemas sociais - não apenas jurídico e político, mas também econômico, midiático, científico, educacional, familiar, entre outros - em seus processos comunicacionais internos, delimitando suas novas fronteiras e autopoiese.

Em outras palavras, a sociedade, como um todo, se comprometeu jurídica e solidariamente a viabilizar políticas públicas, sociais e econômicas, que não podem ter seus sentidos reduzidos ao mero assistencialismo focalizado das ações estatais, nem mesmo à completa mercantilização dos serviços de saúde, previdência e assistência, sob a propagandeada e inconstitucional perspectiva predominantemente reativa, discriminadora, individual, privatista, disseminada diuturnamente pela mídia.

Como se defendeu em todo o trabalho, as expectativas sociais relacionadas ao sistema de proteção social brasileiro e às suas políticas públicas em matéria de Seguridade Social, sejam elas normativas ou cognitivas, devem se conformar minimamente à Constituição, reforçando-se, assim, a confiança e solidariedade sociais, essenciais à cobertura de seus riscos, à própria redução da complexidade da sociedade e ao efetivo respeito à dignidade da pessoa humana. 


\section{REFERÊNCIAS}

ABRAMO, Perseu. Significado político da manipulação na grande imprensa. In. ABRAMO, Perseu. Padrões de manipulação na grande imprensa. 3. reimp. São Paulo: Editora Fundação Perseu Abramo, 2003, p. 23 - 51.

AE - AGENCIA ESTADO. Lei eleva rombo do INSS de R \$ 48 bi para R\$ 118 bi. Estadão. São Paulo, 10 jul. 2010. Economia. Disponível em: $<$ http://economia.estadao.com.br/noticias/economia+geral,lei-eleva-rombo-do-inss-de-r-48-bipara-r-118-bi,26855,0.htm>. Acesso em: 09 jan. 2011.

ALEXY, Robert. Teoría de los derechos fundamentales. Madrid: Centro de Estúdios Constitucionales, 1993.

ALISKI, Ayr. Brasileiro trabalhará mais para se aposentar. . Estadão. São Paulo, 02 dez. 2010. Economia. Disponível em: $<$ http://economia.estadao.com.br/noticias/economia,brasileirotrabalhara-mais-para-se-aposentar,45835,0.htm >. Acesso em: 09 jan. 2011.

ALMANSA PASTOR, José Manuel. Derecho de la seguridad social. Madrid: Tecnos, 1977.

ANER - ASSOCIAÇÃO NACIONAL DOS EDITORES DE REVISTA. Publicidade: faturamento bruto dos meios. Brasília, 2010a. Disponível em: $<$ http://www.aner.org.br/Conteudo/1/artigo42423-1.asp>. Acesso em: 13 dez. 2010.

. Publicidade: páginas por setores econômicos. Brasília, 2010b. Disponível em: $\overline{<\mathrm{http}: / / w w w . a n e r . o r g . b r / C o n t e u d o / 1 / a r t i g o 144306-1 . a s p ~>. ~ A c e s s o ~ e m: ~} 13$ dez. 2010.

Publicidade: participação dos meios: janeiro a julho de 2010. Brasília, 2010c. Disponível em: <http://www.aner.org.br/Conteudo/1/artigo42977-1.asp>. Acesso em: 13 dez. 2010.

. Publicidade: Projeto que obriga divulgação de anunciantes é arquivado. Brasília, 2010d. Disponível em: <http://www.aner.org.br/Conteudo/1/artigo44194-1.asp>. Acesso em: 13 dez. 2010.

ANFIP - ASSOCIAÇÃO NACIONAL DOS AUDITORES FISCAIS DA RECEITA FEDERAL DO BRASIL. Análise da Seguridade Social em 2008. Brasília: ANFIP, 2009. 
Disponível em: $\quad<$ http://www.anfip.org.br/publicacoes/livros/includes/livros/arqspdfs/analise2008.pdf>.

Análise da Seguridade Social em 2009. Brasília: ANFIP, 2010. Disponível em: $<$ http://www.anfip.org.br/publicacoes/livros/includes/livros/arqs-pdfs/analise2009.pdf>. Acesso em: 09 jan. 2011.

ANGELL, Márcia. A verdade sobre os laboratórios farmacêuticos. Trad. Waldéa Barcellos. Rio de Janeiro: Record, 2007.

ANJ - ASSOCIAÇÃO NACIONAL DOS JORNAIS. Maiores setores anunciantes no jornal: maiores setores econômicos anunciantes no Meio Jornal. Brasília, ANJ, 2010. Disponível em: $<\mathrm{http}$ ://www.anj.org.br/a-industria-jornalistica/jornais-no-brasil/maiores-setores-anunciantes-nojornal>. Acesso em: 14 dez. 2010.

ANTUNES, José Engrácia. Prefácio. In: TEUBNER, Gunther. O Direito como Sistema Autopoiético. Lisboa: Fundação Calouste Gulbenkian, 1989.

ARBEX JR., José. O jornalismo canalha: a promíscua relação entre a mídia e o poder. São Paulo: Casa Amarela, 2003.

. Showrnalismo: a notícia como espetáculo. 2. ed. São Paulo: Casa Amarela, 2002.

ARENDT, Hannah. Eichmann em Jerusalém: um relato sobre a banalidade do mal. 7. reimp. Trad. José Rubens Siqueira. São Paulo: Companhia das Letras, 2007.

ARRETCHE, Marta Teresa da Silva. Emergência e desenvolvimento do Welfare State: teorias explicativas. [S.1.], 1996.

ARNAUD, André-Jean; Dulce, María José Fariñas. Introdução à Análise Sociológica dos Sistemas Jurídicos. Rio de Janeiro: Renovar, 2000.

ASSIS, Jesus de Paula. Kuhn e as ciências sociais. Estudos Avançados, v. 7, n. 19, p. 133164, 1993.

BARBERO, Jesús Martín. Dos meios às mediações. Comunicação, cultura e hegemonia. 5. ed., Rio de Janeiro: Editora UFRJ, 2008.

BARROS, José Augusto Cabral de. Políticas farmacêuticas: a serviço dos interesses da saúde? Brasília: UNESCO, 2004. 
BARROS FILHO, Clóvis; BARTOLOZZI, Pedro Lozano. Ética na comunicação: da informação ao receptor. São Paulo: Moderna, 1995.

BARROSO, Luís Roberto. Neoconstitucionalismo e constitucionalização do Direito: o triunfo tardio do Direito Constitucional no Brasil. Jus Navigandi, Teresina, ano 9, n. 851, nov. 2005. Disponível em: <http://jus2.uol.com.br/doutrina/texto.asp?id=7547>. Acesso em: 14 jan. 2007.

BAUMAN, Zygmunt. Modernidade Líquida. Trad. Plínio Dentzien. Rio de Janeiro: Jorge Zahar, 2001.

BECHMANN, Gotthard; STEHR, Nico. Niklas Luhmann. Tempo Social, Revista de Sociologia da USP, São Paulo, v. 13, n. 2, p. 185-200, nov. 2001.

BECK, Ulrich. O que é Globalização? Equívocos do globalismo: respostas à globalização. Trad. André Carone. São Paulo: Paz e Terra, 1999.

BÉLAND, Daniel; HACKER, Jacob S. (2004) Ideas, private institutions and american welfare state 'exceptionalim': the case of health and old-age insurance, 1915-1965. International Hournal of Social Welfare, n. 13, p. 42-54.

BENJAMIM, Walter. A obra de arte na época de sua reprodutibilidade técnica. In. LIMA, Luiz Costa. Teoria da cultura de massa. 7. ed. rev., São Paulo: Paz e Terra, 2000, p. 221-254.

BERCOVICI, Gilberto. Soberania e Constituição: Poder Constituinte, Estado de Exceção e os limites da Teoria Constitucional. 2005. Tese (Concurso de Professor Titular junto ao Departamento de Direito do Estado) - Faculdade de Direito da Universidade de São Paulo, São Paulo.

BERTALANFFY, Ludwig von. General System Theory. New York: Braziller, 1968.

BILENKY, Thais. Déficit da Previdência Social dobra em agosto e atinge R \$ 5,4 bilhões. Folha. Brasília, 20 set. 2010. Mercado. Disponível em: $<$ http://www1.folha.uol.com.br/mercado/801490-deficit-da-previdencia-social-dobra-emagosto-e-atinge-r-54-bilhoes.shtml>. Acesso em: 09 jan. 2011.

BIONDI, Antonio; CHARÃO Cristina. Terra de gigantes. Revista da Adusp. São Paulo, n. 42, p. 06-25, jan. 2008.

BOBBIO, Norberto; Mateucci, Nicola; Gianfranco, Pasquino. Dicionário de política. 5. ed. Brasília: Universidade de Brasília; São Paulo: Imprensa Oficial do Estado; 2000. 
BOLAÑO, César Ricardo Siqueira. Qual a lógica das políticas de comunicação no Brasil? São Paulo: Editora Paulus, 2007.

BORGES, Mônica Erichsen Nassif; CARVALHO, Natália Guiné de Mello. Produtos e serviços de informação para negócios no Brasil: características. Ciência da Informação, Brasília: IBICT, v. 27, n. 1, p. 76-81, jan./abr. 1998. Disponível em: $<$ http://revista.ibict.br/ciinf/index.php/ciinf/article/view/355/316>. Acesso em: 05 dez. 2010.

BOSCHETTI, Ivanete. Implicações da reforma da previdência na seguridade social brasileira. Psicologia \& Sociedade, Porto Alegre, v. 15, n. 1, 2003. Disponível em: $<$ http://www.scielo.br/scielo.php?script=sci_arttext\&pid=S0102-71822003000100005\&lng-pt\&nrm=iso>. Acesso em: 06 dez. 2009.

BRASIL. Código Brasileiro de Telecomunicações. Lei 4.117, de 27 de agosto de 1962. Diário Oficial de 05/10/1962, P. 10413. Brasília, DF: Senado, 1962. Disponível em: $<$ http://www.planalto.gov.br/ccivil/leis/L4117.htm>. Acesso em: 09 Dez. 2010.

BRASIL. Constituição (1946). Constituição Federal dos Estados Unidos do Brasil. 19/09/1946, P. 1. Rio de Janeiro, DF: Senado, 1946. Disponível em: $<$ http://www.planalto.gov.br/ccivil_03/constituicao/Constituicao46.htm/>. Acesso em: 09 dez. 2010.

BRASIL. Constituição (1988). Constituição da República Federativa do Brasil. Diário Oficial da União de 05/10/1988, P. 1 (ANEXO). Brasília, DF: Senado, 1988. Disponível em: $<$ http://www.planalto.gov.br/ccivil_03/constituicao/constitui\%C3\%A7ao.htm/>. Acesso em: 09 dez. 2010.

BRASIL. Decreto 1.720, de 28 de novembro de 1995 - Altera dispositivos do Regulamento dos Serviços de Radiofusão aprovado pelo Decreto $\mathrm{n}^{\circ}$ 52.795, de 31 de outubro de 1963, e modificado por disposições posteriores. Diário Oficial de 29/11/1995, P. 19519. Brasília, DF: Poder Executivo, $1995 . \quad$ Disponível em: $<$ http://www.planalto.gov.br/ccivil_03/decreto/D1720.htm>. Acesso em: 09 dez. 2010.

BRASIL. Decreto 52.795, de 31 de outubro de 1963 - Aprova Regulamento dos Serviços de Radiodifusão. Diário Oficial de 12/11/1963. Brasília, DF: Poder Executivo, 1963. Disponível em: $<$ http://www.planalto.gov.br/ccivil_03/decreto/Antigos/D52795.htm>. Acesso em: 09 dez. 2010.

BRASIL. Decreto-Lei 236, de 28 de fevereiro de 1967 - Complementa e modifica a Lei número 4.117 de 27 de agosto de 1962. Diário Oficial da União (D.O.F.C) de 28/02/1967. Brasília, DF: Senado, 1967. Disponível em: <http://www.planalto.gov.br/ccivil/DecretoLei/Del0236.htm>. Acesso em: 09 dez. 2010.

BRASIL. Decreto-Lei 4.657, de 4 de setembro de 1942 - Lei de Introdução às normas do Direito Brasileiro. Diário Oficial de 09/09/1942, P. 1, Rio de Janeiro, Poder Executivo, 1942. 
Disponível em: <http://www.planalto.gov.br/ccivil_03/decreto-lei/Del4657.htm>. Acesso em: 08 jan. 2010.

BRASIL. Emenda Constitucional 36 de 28 de maio de 2002 - Dá nova redação ao art. 222 da Constituição Federal, para permitir a participação de pessoas jurídicas no capital social de empresas jornalísticas e de radiodifusão sonora e de sons e imagens, nas condições que especifica. Diário Oficial da União, Brasília, DF, 29 maio 2002. Disponível em: $<$ http://www.planalto.gov.br/ccivil_03/Constituicao/Emendas/Emc/emc36.htm>. Acesso em: 09 jan. 2011.

BRASIL. Lei 8.080, de 19 de setembro de 1990 - Dispõe sobre as condições para a promoção, proteção e recuperação da saúde, a organização e o funcionamento dos serviços correspondentes e dá outras providências. Diário Oficial da União, Brasília, DF, 20 set. 1990. Disponível em: <http://www.planalto.gov.br/ccivil_03/Leis/L8080.htm>. Acesso em: 09 jan. 2011.

BRASIL. Lei 8.213, de 24 de julho de 1991 - Dispõe sobre os Planos de Benefícios da Previdência Social e dá outras providências. Diário Oficial da União, Brasília, DF, 25 jul. 1991. Disponível em: <http://www.planalto.gov.br/ccivil_03/Leis/L8213cons.htm>. Acesso em: 09 jan. 2011.

BRASIL. Lei 8.389 de 30 de dezembro de 1991 - Institui o Conselho de Comunicação Social, na forma do art. 224 da Constituição Federal e dá outras providências. Diário Oficial de 31/12/1991, Brasília, DF: Senado, 1991. Disponível em: $<$ http://www.planalto.gov.br/ccivil_03/Leis/L8389.htm> Acesso em: 10 jan. 2011.

BRASIL. Lei 9.876, de 26 de novembro de 1999 - Dispõe sobre a contribuição previdenciária do contribuinte individual, o cálculo do benefício, altera dispositivos das Leis nos 8.212 e 8.213, ambas de 24 de julho de 1991, e dá outras providências. Diário Oficial da União, Brasília, DF, 29 nov. 1999. Disponível em: <http://www.planalto.gov.br/ccivil_03/Leis/L9876.htm>. Acesso em: 09 jan. 2011.

BRASIL. Lei 10.610, de 20 de dezembro de 2002 - Dispõe sobre a participação de capital estrangeiro nas empresas jornalísticas e de radiodifusão sonora e de sons e imagens, conforme o $\S 4^{\circ}$ do art. 222 da Constituição, altera os arts. 38 e 64 da Lei no 4.117, de 27 de agosto de 1962, o $\S 3^{\circ}$ do art. 12 do Decreto-Lei ${ }^{\circ}$ 236, de 28 de fevereiro de 1967, e dá outras providências. Diário Oficial da União de 23/12/2002, Brasília, DF: Senado, 2002. Disponível em: <http://www.planalto.gov.br/ccivil/LEIS/2002/L10610.htm> Acesso em: 09 dez. 2010.

BRASIL. Lei 12.214 de 26 de janeiro de 2010 - Estima a receita e fixa a despesa da União para o exercício financeiro de 2010a. Diário Oficial da União de 27/01/2010, Brasília, DF: Senado, 2010. Disponível em: <http://www.planalto.gov.br/ccivil_03/_Ato20072010/2010/Lei/L12214.htm> Acesso em: 09 dez. 2010. 
BRASIL. Relatório de Avaliação do Terceiro Bimestre de 2010. Relatório de Avaliação Orçamentária. Brasília: Secretaria de Orçamento Federal, Ministério do Planejamento, 2010b. Disponível em: $<$ https://www.portalsof.planejamento.gov.br/sof/2010/Relat_Avaliacao_3_bimestre_2010.pdf $>$. Acesso em: 09 jan. 2011.

BRIGGS, Asa; BURKE, Peter. Uma história social da mídia: de Gutenberg à Internet. Trad. Maria Carmelita Pádua Dias. 2.ed. rev. ampl., Rio de Janeiro: Zahar, 2006.

BRITTOS, Valério Cruz; NAZÁRIO, Paola Madeira; SIMÕES, Denis Gerson. Conselho de Comunicação Social: possibilidades e limites. UNIrevista, v. 1, n. 3, p. 01-12, julho 2006. Disponível em: <http://www.unirevista.unisinos.br/_pdf/UNIrev_Brittos.PDF>. Acesso em: 05 dez. 2010.

BOLANÕ, César Ricardo Siqueira. Qual a lógica das políticas de comunicação no Brasil? São Paulo: Paulus, 2007.

BUCCI, Eugênio. Sobre ética e imprensa. 2. ed., 2. reimp. São Paulo: Companhia das Letras, 2008.

BUCCI, Maria Paula Dallari (Org.). Políticas públicas - reflexões sobre o conceito jurídico. Saraiva: 2006.

. Notas para uma metodologia de análise de políticas públicas. In: Fortini, Cristiana; Esteves, Júlio César dos Santos; Dias, Maria Tereza Fonseca (Org.). Políticas públicas possibilidades e limites. Belo Horizonte: Editora Fórum, 2008, p. 225-260.

. A Reforma Constitucional da Previdência. O Direito à Aposentadoria como Direito Fundamental e seu Conteúdo. Revista dos Tribunais, ano 3, n 12, p. 116-129, jul./set.1995.

BÜLLESBACH, Alfred. Princípios de teoria dos sistemas. In: KAUFMANN, A.; HASSEMER, W. (Org.). Introdução à filosofia do direito e à teoria do direito contemporâneas. Lisboa: Fundação Calouste Gulbenkian, 2002. cap. 10, p. 409-442.

CALCIOLARI, Ricardo Pires. O orçamento da Seguridade Social e a efetividade dos direitos sociais. Curitiba: Juruá, 2009.

. A crise de efetividade dos direitos sociais e a desvinculação de receitas. In ROCHA, Daniel Machado da; SAVARIS, José Antonio (Coords.). Curso de Especialização em Direito Previdenciário, volume 3 - Custeio da Seguridade Social. Curitiba: Juruá Editora, 2008.

CAMPILONGO, Celso Fernandes. Política, sistema jurídico e decisão judicial. São Paulo: Max Limonad, 2002.

. Direito e democracia. 2. ed. São Paulo: Max Limonad, 2000a. 
O direito na sociedade complexa. São Paulo: Max Limonad, 2000b.

CANARIS, Claus-Wilhelm. Pensamento sistemático e o conceito de sistema na ciência do direito. Trad. A. Menezes Cordeiro. 2. ed., Lisboa: Fundação Calouste Gulbenkian, 1996.

CANCLINI, Nestor Garcia. Consumidores e cidadãos. Conflitos multiculturais da globalização. Rio de Janeiro: Editora UFRJ, 2001.

. Culturas híbridas. Estratégias para entrar e sair da modernidade. Trad. Ana Regina Lessa, Heloísa Pezza Cintrão, Gênese Andrade. 4. ed. 3. reimp., São Paulo: EDUSP, 2008.

CANOTILHO, José Joaquim Gomes. A Constituição Europeia entre o programa e a norma. Leituras complementares - União Europeia. Ministério da Fazenda, Brasília, DF. 2004. Disponível em: $\quad<$ http://www.esaf.fazenda.gov.br/parcerias/ue/cedoc-ue/leiturascomplementares/a4-uniao-europeia.html>. Acesso em: 10 jan. 2007.

. Direito Constitucional e Teoria da Constituição. 7. ed., 4. reimpr. Coimbra: Almedina, 2003.

. Direito Constitucional e Teoria da Constituição. Coimbra: Almedina, 1997.

. Direito Constitucional. 3. ed. Coimbra: Almedina, 1983.

CAPRA, Fritjof. A teia da vida - Uma nova compreensão científica dos sistemas vivos. São Paulo: Editora Cultrix, 1996.

CARIELLO, Rafael. Não há déficit no sistema da Previdência, diz economista. Folha de São Paulo. São Paulo, 22 jun. 2003. Brasil - Poder. Disponível em: $<$ http://www1.folha.uol.com.br/folha/brasil/ult96u50392.shtml $>$. Acesso em: 09 jan. 2011.

CARVALHO, Gilson. A inconstitucional administração pós-constitucional do SUS através de normas operacionais. Ciência \& Saúde coletiva, v.6, n.2, p.435-444, 2001.

CEVASCO, Maria Elisa. Dez lições sobre estudos culturais. São Paulo: Boitempo, 2003.

. Para ler Raymond Williams. Rio de Janeiro: Paz e Terra, 2001.

CHAUI, Marilena. Simulacro e poder: uma análise da mídia. São Paulo: Editora Fundação Perseu Abramo, 2006.

CLAM, Jean. Questões fundamentais de uma teoria da sociedade: contingência, paradoxo, só-efetuação. Trad. Nélio Schneider. São Leopoldo, RS: Editora Unisinos, 2006. 
COLLUCCI, Cláudia. Receita vigiada: Farmácia espiona médicos para laboratórios. Folha de S. Paulo. São Paulo, 04 set. 2005. Cotidiano. Disponível em: $<$ http://www1.folha.uol.com.br/fsp/cotidian/ff0409200501.htm>. Acesso em: 18 set. 2007.

COMPARATO, Fábio Konder. A afirmação histórica dos direitos humanos. 2. ed. São Paulo: Saraiva, 2001.

. Comentário ao artigo $1^{\circ}$ da Declaração Universal de Direitos Humanos da ONU. 50 Anos da Declaração Universal dos Direitos Humanos - Conquistas e Desafios. Brasília: DHnet - Rede de Direitos Humanos \& Cultura. 1999. Disponível em: $<$ http://www.dhnet.org.br/direitos/deconu/coment/01.htm>. Acesso em: 05 jan. 2011.

. Ética: direito, moral e religião no mundo moderno. São Paulo: Companhia das Letras, 2006.

CONDE, Marisa Velloso Fernandez. O Banco Mundial e a saúde nos anos 90: um novo paradigma de reforma sanitária. 1996. Dissertação (Mestrado em Ciências) — Escola Nacional de Saúde Pública da Fundação Oswaldo Cruz, Rio de Janeiro.

CORREIA, Marcus Orione Gonçalves. A jurisprudência e a promoção do bem-estar social em matéria previdenciária. 1996. Tese (Doutorado em Direito) - Faculdade de Direito da Universidade de São Paulo, São Paulo.

CORREIA, Marcus Orione Gonçalves. Currículo Lattes. In: CONSELHO NACIONAL DE DESENVOLVIMENTO CIENTIFICO E TECNOLÓGICO - CNPq. Plataforma Lattes. Ministério da Fazenda: Brasília, 2010.2011 Disponível $<$ http://buscatextual.cnpq.br/buscatextual/visualizacv.jsp?id=K4798641T3>. Acesso em: 09 jan. 2011.

. Interpretação do direito da segurança social. In: ROCHA, Daniel Machado da (Coord.). Curso de especialização em direito previdenciário. v. 1. Curitiba: Juruá, 2005, p. 249-268.

. Os direitos sociais enquanto direitos fundamentais. In: ; CORREIA, Érica Paula Barcha. (Coord.) Direito Previdenciário e Constituição - Obra em homenagem ao professor Wladimir Novaes Martinez. São Paulo: LTr, 2004, p. 25-43.

. Uma introdução ao constitucionalismo social. Carta Brasileira, [S.1.], n. 3, p. 10-11, out. 2003.

; CORREIA, Érica Paula Barcha. Curso de direito da seguridade social. 4. ed. São Paulo: Saraiva, 2008. 
; CRUZ, Renato Negretti Cruz. Teoria dos Sistemas de Niklas Luhmann e os desafios para a efetivação jurisdicional do direito à saúde em matéria de medicamentos. RECIIS - R. Eletr. de Com. Inf. Inov. Saúde, v. 1, n.2, p. 262-272, 2007.

; VILLELA, José Corrêa. (Coord.) Previdência privada: doutrina e comentários à Lei Complementar n. 109/01. São Paulo: LTr, 2004.

COSTA, Eliane Romeiro. Previdência complementar na seguridade social: o risco velhice e a idade para a aposentadoria. São Paulo: LTr, 2003.

COSTA, José Ricardo Caetano. Previdência e Neoliberalismo. Porto Alegre: Livraria do Advogado, 2001.

COSTA, Rosa. Conselho de Comunicação vai ser revigorado. Regulação em debate, Observatório da Imprensa. 9 nov. 2010. Disponível em: $<$ http://www.observatoriodaimprensa.com.br/artigos.asp?cod=615IPB004>. Acesso em: 06 dez.2010.

CRUZ, Renato Negretti. A teoria dos sistemas e a força normativa constitucional do sistema jurídico sanitário. 2007. Dissertação (Mestrado em Direito) — Faculdade de Direito da Universidade de São Paulo, São Paulo.

CRUZ SOBRINHO, Sidinei. Direitos Humanos e Democracia em Jürgen Habermas. 2005. Dissertação (Mestrado em Filosofia) - Pontifícia Universidade Católica do Rio de Janeiro, Rio de Janeiro.

DALLARI, Dalmo de Abreu. Elementos de teoria geral do Estado. 20. ed. atual. São Paulo: Saraiva, 1998.

DEJOURS, Christophe. A banalização da injustiça social. Trad. Luiz Alberto Monjardim. 7. ed. 5. reimp., Rio de Janeiro: Editora FGV, 2010.

DEMO, Pedro. Pobreza política. 6. ed. Campinas: Autores Associados, 2001.

. Solidariedade como efeito de poder. São Paulo: Cortez; Instituto Paulo Freire, 2002.

DUGUIT, Léon. Fundamentos do Direito. Campinas: LZN Editora, 2003.

. Traité de Droit Constitutionnel. Tomo 1, 3. ed. Paris: Ancienne Librarie Fontemoing \& Cie, 1927. 
DURÃO, Fabio Alcelrud; ZUIN, Antônio; VAZ, Alexandre Fernandes (Orgs.) A indústria cultural hoje. São Paulo: Boitempo, 2008.

DURKHEIM, Emile. A Divisão do Trabalho Social. 3. ed. Lisboa: Editorial Presença, 1989.

DWORKIN, Ronald. Levando os direitos a sério. Trad. Nelson Boeira. São Paulo: Martins Fontes, 2002.

EPCOM - INSTITUTO DE ESTUDOS E PESQUISAS EM COMUNICAÇÃO. Os Donos da Mídia, 2002. Disponível em: <http://donosdamidia.com.br/>. Acesso em: 05 dez. 2010.

ESPIELL, Hector Gros. Los derechos económicos, sociales y culturales en el sistema interamericano. San José: Libro Libre, 1986.

ESPING-ANDERSEN, Gosta. Uma perspectiva transatlântica da política de privatização latinoamericana. In COELHO, Vera Schattan P. (org.). A Reforma da Previdência Social na América Latina. Rio de Janeiro: Editora FGV, 2003.

EVAN, William. Organization tehory. Nova York: Wiley, 1976.

FABRINI, Fábio. Rombo bilionário: sangria na Previdência pode chegar a $\mathrm{R} \$ 1,7$ bilhão ao ano. $O$ Globo. Brasília, 06 nov. 2010. País. Disponível em: $<$ http://oglobo.globo.com/pais/mat/2010/11/06/sangria-na-previdencia-pode-chegar-r-1-7bilhao-ao-ano-922964088.asp>. Acesso em: 09 jan. 2011.

FARIAS, José Fernando de Castro. A Origem do Direito de Solidariedade. Rio de Janeiro: Renovar, 1998.

FERNANDES, Antônio Sérgio Araújo. Path dependency e os estudos históricos comparados. BIB - Revista Brasileira de Informação Bibliográfica em Ciências Sociais, n.53, p.79-102, 2002.

FERNANDES, André de Godoy. Meios de Comunicação de Massa no Brasil: promoção do pluralismo, direito de concorrência e regulação. 2009. Tese (Doutorado em Direito) Faculdade de Direito da Universidade de São Paulo, São Paulo.

FERRAZ JR., Tercio Sampaio. Introdução ao estudo de direito: técnica, decisão, dominação. 2. ed. São Paulo: Atlas, 1994.

FERREIRA, Maria Nazareth. A comunicação como (des)integradora da América Latina. São Paulo: Edicon, 1995. 
FGV - FUNDAÇÃO GETÚLIO VARGAS; ABERT - ASSOCIAÇÃO BRASILEIRA DE EMISSORAS DE RÁDIO E TELEVISÃO. Perfil socioeconômico do setor de radiodifusão. Brasília: $\quad 2007 . \quad$ FGV/ABERT, Disponível em: $<$ http://www.abert.org.br/site/images/stories/pdf/perfil.pdf>. Acesso em: 10 dez. 2010.

Pesquisa sobre televisão no Brasil. Brasília: FGV/ABERT, 2008. Disponível em:

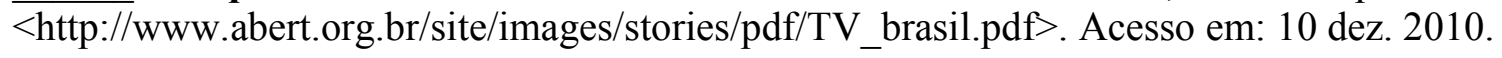

FOERSTER, Heinz von. Observing Systems. California: Intersystems, 1984.

FOLHA DE S. PAULO. Ex-secretário da Previdência diz que déficit "desvia" verba social. Folha. São Paulo, 22 jun. 2003. Brasil - Poder. Disponível em: $<$ http://www1.folha.uol.com.br/folha/brasil/ult96u50391.shtml>. Acesso em: 09 jan. 2011.

FONTENELLE, Isleide Arruda. O mundo de Ronald McDonald: sobre a marca publicitária e a socialidade midiática. Educ. Pesqui. [online]. 2002, vol.28, n.1, pp. 137-149. ISSN 1517-9702. Disponível em: <http://www.scielo.br/pdf/ep/v28n1/11661.pdf >. Acesso em: 13 dez. 2010.

FOUCAUlT, Michel. A crise atual da Medicina. Texto de Apoio PESESPEPPE. Rio de Janeiro: Escola de Saúde Pública, 1974.

. Arqueologia do Saber. 5. ed. Rio de Janeiro: Forense Universitária, 1997.

. Microfísica do Poder. Trad. Roberto Machado. Rio de Janeiro: Edições Graal. 1979.

FRANÇA, Giselle de Amaro e. O Poder Judiciário e a políticas públicas previdenciárias. 2010. Dissertação (Mestrado em Direito) - Faculdade de Direito da Universidade de São Paulo, São Paulo.

FREITAS JUNIOR, Antonio Rodrigues de. Os Direitos Sociais e a Constituição de 1988 (Crise Econômica e Políticas de Bem-Estar). Rio de Janeiro: Forense, 1993.

FREY, Klaus. Políticas públicas: um debate conceitual e reflexões referentes à pratica da análise de políticas públicas no Brasil. In: Planejamento e Política, n. 21, junho de 2000. Disponível em: $<$ http://www.usp.br/procam/docs\%20novos/artigos\%20para\%20aulas/texto\%20klaus\%20frey.pdf $>$. Acesso em: 04/08/07, p.7.

GENTIL, Denise Lobato. A falsa crise do sistema de seguridade social no Brasil: uma análise financeira do período 1990 - 2005. Brasília, 2007a. Disponível em: $<$ http://www.direitosociais.org.br/_arquivos/2007/120_a_falsa_crise_do_sistema_de_segurid ade_-_denise_gentil.pdf>. Acesso em: 09 jan. 2011. 
. A política fiscal e a falsa crise do sistema de seguridade social no Brasil: análise financeira do período recente. In SICSÚ, João (org.). Arrecadação (de onde vem?) e gastos públicos (para onde vão?). São Paulo: Boitempo, 2007b.

GERBNER, George. The importance of being critical in one's own fashion. Ferment in the Field, Journal of Communication, v. 33, n. 3, 1983, p. 355 - 362. Disponível em: $<$ http://onlinelibrary.wiley.com/doi/10.1111/j.1460-2466.1983.tb02435.x/abstract $>$. Acesso em: 09 jan.2011.

GIASANTE, Moacir et al. Cadeia de valor. Campinas: CPqD, 2004. Disponível em: $<$ http://www.fndc.org.br/arquivos/MapeamentoCadeiadeValor-CPQD.pdf $>$. Acesso em: 08 dez.2010.

GRAU, Eros Roberto. A ordem econômica na Constituição de 1988 (interpretação e crítica). 8. ed. São Paulo: Malheiros, 2003.

. O direito posto e o direito pressuposto. 4. ed. São Paulo: Malheiros, 2002.

GUARESCHI, Pedrinho Arcides; ROMANZINI, Lisie Polita; GRASSI, Lúcia Biavaschi. A "mercadoria" informação: um estudo sobre comerciais de TV e rádio. Paidéia (Ribeirão Preto) [online]. 2008, vol.18, n.41, pp. 567-580. Disponível em: $<$ http://www.scielo.br/pdf/paideia/v18n41/v18n41a12.pdf>. Acesso em: 13 dez. 2010.

GUERREIRO, Gabriela; GIRALDI, Renata; RIBEIRO, Ana Paula. Oposição derrota governo e Senado rejeita prorrogação da CPMF. Folha. São Paulo, 13 dez. 2007. Brasil - Poder. Disponível em: <http://www1.folha.uol.com.br/folha/brasil/ult96u354415.shtml>. Acesso em: 09 jan. 2011.

HABERMAS, Jürgen. Direito e Democracia: entre facticidade e validade. Trad. Flávio Bueno Siebeneichler. Rio de Janeiro: Tempo Brasileiro, 1997, 2 v.

. Direito e Moral. Trad. Sandra Lippert, Lisboa: Instituto Piaget, 1992.

. O discurso filosófico da modernidade. Trad. Ana Maria Bernardo et al. 2. ed. Lisboa: Dom Quixote, 1998.

. Teoría de la acción comunicativa, T.1: racionalidad de la acción y racionalización social. Trad. Manuel Jiménez Redondo. Madrid: Taurus, 2001.

HART, Herbert Lionel Adolphus. O conceito de direito. 3. ed., Lisboa: Fundação Calouste Gulbenkian, 2001. 
HALL, Peter A; TAYLOR, Rosemary. C. R. (2003) As três versões do neoinstitucionalismo. Lua Nova, n.58, p.193-223.

HALL, Stuart. A identidade cultural na pós-modernidade. Rio de Janeiro: Record, 2001.

HERMAN; Edward S.; CHOMSKY, Noam. A manipulação do público: política e poder econômico no uso da mídia. Trad. Bazán Tecnologia e Linguística. São Paulo: Futura, 2003.

HERNANDES, Nilton. A Revista VEJA e o discurso do emprego na globalização. Salvador/Maceió: EDUFBA/EDUFAL, 2004.

HERZ, Daniel. A história secreta da Rede Globo. 14. ed. São Paulo: Ortiz, 1991.

HESPANHA, Benedito. A autopoiese na construção do jurídico e do político de um sistema constitucional. Revista dos Tribunais, São Paulo, ano 7, n. 27, p. 59-78, abr.jun. 1999.

HESSE, Konrad. A força normativa da Constituição. Trad. Gilmar Ferreira Mendes. Porto Alegre: Sergio Antonio Fabris Editor, 1991.

HORKHEIMER, Max; ADORNO, Theodor W. A indústria Cultural. In. LIMA, Luiz Costa. Teoria da cultura de massa. 7. ed. rev., São Paulo: Paz e Terra, 2000, p. 169-214.

HOUAISS. Dicionário Houaiss da língua portuguesa. UOL - Universo Online. 2005. Disponível em: <http://houaiss.uol.com.br/busca.jhtm>. Acesso em: 02 out. 2008.

IANNI, Octavio. Enigmas da modernidade-mundo. Rio de Janeiro: Civilização Brasileira, 2000 .

JENSEN, Carl. 20 years of censored news. Carl Jensen and Project Censored. New York: Seven stories Press, 1997.

KATZ, Elihu; LAZARSFELD, Paul F. Personal Influence. Glencoe: Free Press, 3. Ed., 1970.

KELSEN, Hans. Teoria Pura do Direito. Trad. João Baptista Machado. 6. ed., São Paulo: Martins Fontes, 1998.

KILLIAN, Frederich W. Gestalt, movimento da - In: Dicionário de sociologia. 1. ed., $6^{\mathrm{a}}$ impressão. Porto Alegre: Editora Globo, 1974, p. 150-151.

KROPF, Simone Petraglia; LIMA, Nísia Trindade. Os valores e a prática institucional da ciência: as concepções de Robert Merton e Thomas Kuhn. Hist. Cienc. SaúdeManguinhos, Rio de Janeiro, v. 5, n. 3, 1999. Disponível em: 
$<\mathrm{http}: / /$ www.scielo.br/scielo.php?script=sci_arttext\&pid=S0104-

$59701999000100002 \& \operatorname{lng}=$ pt\&nrm=iso>. Acesso em: 10 out. 2009.

KÜHN, Rolf. Luhmann. In: HUISMAN, Denis (Coord.). Dicionário dos filósofos. São Paulo: Martins Fontes, 2001, p. 621-623.

KUHN, Thomas S. Estrutura das revoluções científicas. 3. ed., São Paulo: Perspectiva, 1989.

LEITÃO, Miriam; MANIERO, Valéria. A farra final. Coluna no Globo. O Globo. Rio de Janeiro, $30 \quad$ dez. $2010 . \quad$ Economia. Disponível em: $<$ http://oglobo.globo.com/economia/miriam/posts/2010/12/30/a-farra-final-353153.asp>. Acesso em: 09 jan. 2011.

LEMOS, Alexandre Zaghi. Ranking 2009: os 30 maiores anunciantes do Brasil. Observatório da Imprensa. [S.1], 09 fev. 2010. Feitos \& desfeitas. Disponível em:< http://www.observatoriodaimprensa.com.br/artigos.asp?cod=576FDS014> Acesso em: 10 Jan. 2011.

LEMOS. Alfredo Miranda; MUSSE. Juliano Sander; VAZ. Flavio Tonelli; TEIXEIRA. Carolina. Os mitos da reforma da previdência social. In: Associação Nacional dos Auditores Fiscais da Receita Federal do Brasil. Análise da seguridade social em 2006. Brasília: ANFIP, 2007, p. 39-60.

LIMA, Luiz Costa. Comunicação e cultura de massa. In. LIMA, Luiz Costa. Teoria da cultura de massa. 7. ed. rev., São Paulo: Paz e Terra, 2000, p. 13-69.

LIMA, Venício Arthur de. As concessões de radiodifusão como moeda de barganha política. Revista Adusp. São Paulo, n. 42, p. 26-33, jan. 2008.

. Mídia: Crise política e pode no Brasil. São Paulo: Fundação Perseu Abramo, 2006.

. Mídia: teoria e política. São Paulo: Fundação Perseu Abramo, 2001.

LIMONGI, Fernando. (2002) Política comparada: da teoria da modernização ao novo institucionalismo. 239f. Livre Docência (coletânea de trabalhos apresentada) - Faculdade de Filosofia, Letras e Ciências Humanas, Universidade de São Paulo, São Paulo.

LÖWY, Michael. As aventuras de Karl Marx contra o Barão de Münchhausen: marxismo e positivismo na sociologia do conhecimento. 8. ed. São Paulo: Cortez, 2003.

LUHMANN, Niklas. A posição dos tribunais no sistema jurídico. Revista da Associação dos Juízes do Rio Grande do Sul. Porto Alegre, n. 49, p. 149-168, jul. 1990a. 
. A realidade dos meios de comunicação. Trad. Ciro Marcondes Filho. São Paulo: Paulus, 2005a.

- Confianza. Trad. Amada Flores. 1. reimpresión. Rubí (Barcelona): Anthropos Editorial; México: Universidad Iberoamericana; Santiago de Chile: Instituto de Sociología. Pontificia Universidad Católica de Chile, 2005b.

. Essays on Self-Reference. New York: Columbia University Press, $1990 b$.

. Introdução à Teoria dos Sistemas. Trad. Ana Cristina Arantes. Petrópolis, RJ: Vozes, 2009. $150,1989 \mathrm{a}$.

. Law as a social system. Northwestern University Law Review, v. 83, n. 1-2, p. 136-

. Le droit comme système social. Droit et Societ, Paris, n. 11-12. p. 53-66. 1989 b.

. Legitimação pelo procedimento. Brasília: Unb, 1980.

. Operational closure and structural coupling: the differentiation of the legal system.

Cardozo Law Review, v. 13, n. 5, p. 1419-1441, march, 1992.

. Risk: a sociological theory. Translated by Rhodes Barrett. New York: Aldine de Gruyter, 1993.

. Sistemas Sociales: lineamientos para una teoría general. Trad. Silvia Pappe y Brunhilde Erker; coord. Javier Torres Nafarrate. Rubí (Barcelona): Anthropos; México: Universidad Iberoamericana; Santafé de Bogotá: CEJA, Pontifícia Universidad Javeriana, 1998.

. Social Systems. Stanford, California: Stanford University Press, 1995.

. Sociologia do Direito I. Trad. Gustavo Bayer. Rio de Janeiro: Edições Tempo Brasileiro, 1983.

. Teoría política en el Estado de Bienestar. Trad. Fernando Vallespín. 3. reimp. Madrid: Alianza Editorial, 2002.

; FUCHS, Stephan. Tautology and Paradox in the Self-Descriptions of Modern Society. Sociological Theory, v. 6, n. 1, p. 21-37, 1988. Disponível em: $<$ http//links.jstor.org/sici?sici=0735-2751\%28198821\%296\%3A1\%3C21\%3ATAPITS\%3E2.0.CO\%3B2-K>. Acesso em: 17 nov. 2006. 
MARCH, James G.; OLSEN, Johan P. (1984) The new institutionalism: organizational factos in political life. The American Political Science Review. v. 78, n. 3, p.734-749.

MARCONDES FILHO, Ciro. O capital da notícia. Jornalismo como produção social da segunda natureza. São Paulo: Ática, 1986.

MARCUSE, Herbert. Ideologia da sociedade industrial. Trad. Giasone Rebuá. 3. ed. Rio de Janeiro: Zahar Editores, 1969.

MARSHALL, Leandro. O jornalismo na era da publicidade. São Paulo: Summus editorial, 2003.

MARSHALL, Thomas Humphrey. Class, Citizenship and Social Development. New York: Garden City, 1964.

MARTINEZ, Wladimir Novaes. Curso de Direito Previdenciário, tomo I: noções de direito previdenciário. 2. ed. São Paulo: LTr, 2001.

MATTELART, Armand; MATTELART, Michèle. História das teorias da comunicação. Trad. Luiz Paulo Rouanet. 3. ed., São Paulo: Edições Loyola, 2000.

MATTOS, Sérgio Augusto Soares. História da televisão brasileira. Uma visão econômica social e política. 5. ed. rev. ampl., Petrópolis: Editora Vozes, 2010.

MATURANA, Humberto R. II. Fundamentos biológicos del conocimiento. In: La realidad: ¿Objetiva o construida? México: Anthropos/Universidad Ibero Americana/Iteso, 1996.

; VARELA, Francisco J. A árvore do conhecimento: as bases biológicas da compreensão humana. 5. ed. São Paulo: Palas Athena, 2005.

Holanda: D. Reidel, 1980.

Autopoiesis and cognition: the realization of the living. Dordrecht, De Máquinas e Seres Vivos: Autopoiese: a Organização do Vivo. São Paulo: Palas Athena, 1997.

MAZUREK, Per. Teoria analítica do direito. In: KAUFMANN, A.; HASSEMER, W. (Org.). Introdução à filosofia do direito e à teoria do direito contemporâneas. Lisboa: Fundação Calouste Gulbenkian, 2002a. cap. 8, p. 369-380. 
. Teoria(s) marxista e socialista do direito. In: KAUFMANN, A.; HASSEMER, W. (Org.). Introdução à filosofia do direito e à teoria do direito contemporâneas. Lisboa: Fundação Calouste Gulbenkian, 2002b. cap. 11, p. 443-459.

McQUAIL, Denis. Teoria da comunicação de massas. Trad. Carlos de Jesus. Lisboa: Fundação Calouste Gulbenkian, 2003.

MEDINA, Cremilda. Notícia, um produto à venda. Jornalismo na sociedade urbana e industrial. 2. Ed., São Paulo: Summus, 1988.

MELLO, Geraldo Anhaia. Muito além do cidadão Kane. São Paulo: Pagina Aberta, 1994.

MELO, Filipe Reios. Mídia como instrumento de controle social. UNIrevista, v. 1, n 3, p. 01 09, jul. 2006. Disponível em <http://www.unirevista.unisinos.br/_pdf/UNIrev_RMelo.PDF $>$. Acesso em 05 dez.2010.

MENDES, Gilmar Ferreira. Direitos fundamentais: eficácia da garantias constitucionais das relações privadas - análise da jurisprudência da corte constitucional alemão. In: ANPPREV. Introdução ao direito previdenciário. São Paulo: LTr, 1998, p. 237-253.

MERINO, Lucyla Tellez. Direitos humanos e direito do trabalho: enfoques humanistas na proteção dos direitos sociais. 2006. Dissertação (Mestrado em Direito) - Faculdade de Direito da Universidade de São Paulo, São Paulo.

MESA-LAGO, Carmelo. A reforma estrutural dos benefícios de seguridade social na América Latina: modelos, características, resultados e lições. In: COELHO, Vera Schattan P. (org.). A Reforma da Previdência Social na América Latina. Rio de Janeiro: FGV Editora, 2003, p. 227-255.

; MÜLLER, Katharina. Política e reforma da previdência na América Latina. In; COELHO, Vera Schattan P. (org.). A Reforma da Previdência Social na América Latina. Rio de Janeiro: Editora FGV, 2003, p. 13-26.

MICELI, Sérgio. O papel político dos Meios de Comunicação de Massa. In SOSNOWSKI, Saul; SCHWARTZ, Jorge (Org.). Brasil: o trânsito da memória. São Paulo: Edusp, 1994, p. 41-67.

MITCHELL, Peter R.; SCHOEFFEL, John (Org.). Para entender o poder: o melhor de Noam Chomsky. Trad. Eduardo Francisco Alves. Rio de Janeiro: Bertrand Brasil, 2005.

MORAES, Dênis de. Planeta mídia: tendências da comunicação na era global. Letra Livre, 1998. 
. (Org.) Por uma outra comunicação. Rio de Janeiro: Record, 2001.

MORAES, Maria Celina Bodin de. O conceito de dignidade humana: substrato axiológico e conteúdo normativo. In: SARLET, Ingo Wolfgang (Org.). Constituição, Direitos Fundamentais e Direito Privado. Porto Alegre: Livraria do Advogado, 2003, p. 105-148.

NASCIMENTO, Álvaro. "Ao persistirem os sintomas, o médico deverá ser consultado." Isto é regulação? São Paulo: SOBRAVIME, 2005.

NAVES, Márcio Bilharinho. Marxismo e direito: um estudo sobre Pachukanis. São Paulo: Boitempo, 2000.

NEVES, Ilídio das. Direito da segurança social: princípios fundamentais numa análise prospectiva. Coimbra: Coimbra Editora, 1996.

NEVES, Rômulo Figueira. Acoplamento estrutural, fechamento operacional e processos sobrecomunicativos na teoria dos sistemas sociais de Niklas Luhmann. 2005. Dissertação (Mestrado em Sociologia) — Faculdade de Filosofia, Letras e Ciência Humanas da Universidade de São Paulo, São Paulo.

NEVES, Marcelo. A constitucionalização simbólica. São Paulo: Martins Fontes, 2007.

NIEZEN MATOS, Gabriel. Bases para una teoria Marxista de la comunicación. 2. ed. Lima: CIC, 1985.

OLIVEIRA, Dennis. Aportes teóricos da comunicação na sociedade da informação. In: Dennis de Oliveira; Moisés dos Santos. (Org.). Atualização dos conceitos estéticos em webjornalismo. São Paulo: Centro de Estudos Latino Americanos de Cultura e Comunicação, 2006, v. 01, p. 07-18.

. Estratégias discursivas no novo ágora da Globalização Neoliberal. In: Congresso Brasileiro de Pesquisadores em Comunicação, 2002, Salvador. Anais do Congresso da Intercom. São Paulo: Intercom, 2002a. p. 37-39.

. Jornalismo alternativo, o utopismo iconoclasta. In: VII ENCONTRO NACIONAL DE PESQUISADORES EM JORNALISMO USP (UNIVERSIDADE DE SÃO PAULO), nov. 2009, São Paulo. Comunicações Coordenadas Selecionadas. São Paulo: SBPJor Associação Brasileira de Pesquisadores em Jornalismo, 2009. Disponível em: $<$ http://sbpjor.kamotini.kinghost.net/sbpjor/admjor/arquivos/dennis_de_oliveira.pdf $>$. Acesso em: 09 dez.2010. 
. Jornalismo, mediações e ideologia. In: Dennis de Oliveira; Adolpho Queiroz. (Org.).

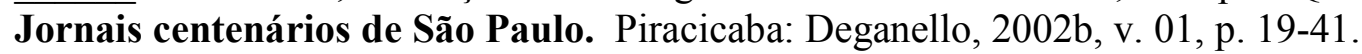

OLIVEIRA, Marcelo Alves de. Conflito dos Princípios Constitucionais Tributários da Capacidade Contributiva e da Proibição de Desigualdade Fiscal na Previdência Complementar. Revista IOB: Trabalhista e Previdenciária. São Paulo, v. 17, n. 205, julho 2006, p. 59-82.

- Riscos em planos de capitalização de contribuição definida na previdência complementar. 2008. Dissertação (Mestrado em Direito) — Faculdade de Direito da Universidade de São Paulo, São Paulo.

OLIVEIRA, Moacyr Velloso Cardoso de. Previdência social. Rio de Janeiro: Freitas Bastos, 1987.

ORSZAG, Peter; STIGLITZ, Joseph E. Rethinking Pension Reform: Ten Myths About Social Security Systems. In: HOLZMANN, Robert; STIGLITZ, J. E. (Ed.). New Ideas About Old Age Security: Proceedings of the World Bank Pension Reform Research. Washington: The World Bank, 2001, p. 17-56.

PAIM, Jairnilson Silva. O pensamento do movimento sanitário: impasses e contradições atuais no marco da relação público-privado do SUS. In: HEIMANN, Luiza Sterman; IBANHES, Lauro César; BARBOZA, Renato. (Org.). O público e o privado na saúde. São Paulo: Hucitec, Opas, IDRC, 2005.

PARSONS, Talcott. O Sistema das Sociedades Modernas. Trad. de Dante Moreira Leite. São Paulo: Livraria Pioneira Editora, 1974.

.El sistema social. Madrid: Revista de Occidente, 1966.

PAS - Suplemento de Produtos e Serviços da Pesquisa Anual de Serviços. IBGE, 2006. Disponível em: $<$ http://www.ibge.gov.br/home/estatistica/economia/comercioeservico/pas/pas2006_produtos_e_servicos /pas2006_suplemento.pdf $>$. Acesso em 05 dez.2010

PASUKANIS, Eugeny Bronilsanovich. A teoria geral do direito e marxismo. Trad. Paulo Bessa. Rio de Janeiro: Renovar, 1989.

PATU, Gustavo. Orçamento social passa a ser deficitário. Folha de S. Paulo. Brasília, 29 ago. 2009. Dinheiro. Disponível em: <http://www1.folha.uol.com.br/fsp/dinheiro/fi2908200902.htm>. Acesso em: 09 jan. 2011.

PAULANI, Leda Maria. Seguridade Social, regimes previdenciários e padrão de acumulação: uma nota teórica e uma reflexão sobre o Brasil. In FAGNANI, Eduardo; HENRIQUE, Wilnês; 
LÚCIO, Clemente Ganz. Previdência Social: Como Incluir os Excluídos? Uma agenda voltada para o desenvolvimento econômico com distribuição de renda. Campinas: UNICAMP - Instituto de Economia; Campinas: CESIT; São Paulo: LTr, 2008, p. 21-30.

PIOVESAN, Flávia. A proteção dos direitos sociais nos planos interno e internacional. In: CORREIA, Marcus Orione Gonçalves; CORREIA, Érica Paula Barcha. (Coord.) Direito Previdenciário e Constituição: Obra em homenagem ao professor Wladimir Novaes Martinez. São Paulo: LTr, 2004, p. 13-24.

. Globalização econômica, integração regional e direitos humanos. In:

(Coord.). Direitos humanos, globalização econômica e integração regional: desafios do direito constitucional internacional. São Paulo: Max Limonad, 2002, p. 39-75.

PNUD - PROGRAMA DAS NAÇÕES UNIDAS PARA O DESENVOLVIMENTO. Relatório do Desenvolvimento Humano 2002: Aprofundar a democracia num mundo fragmentado, disponível em: $<$ http://www.pnud.org.br/rdh/integras/index.php?lay=inst\&id=fuld\#rdh2002>. Acesso em 29 nov. 2010.

PONTES, Alan Oliveira. O princípio da solidariedade social na interpretação do Direito da Seguridade Social. 2006. Dissertação (Mestrado em Direito) — Faculdade de Direito da Universidade de São Paulo, São Paulo.

RAWLS, John. Justiça como Equidade: uma reformulação. Tradução de Claudia Berlinder. São Paulo: Martins Fontes, 2003.

Uma Teoria da Justiça. Tradução de Almiro Pisetta e Lenita Maria Rímoli Esteves. 2. ed., São Paulo: Martins Fontes, 2002.

RIFKIN, Jeremy. A era do acesso: a transição de mercados convencionais para networks e o nascimento de uma nova economia. Trad. Maria Lucia G. L. Rosa. São Paulo: Makron Books, 2001.

ROCHA, Maria Eduarda da Mota. O canto da sereia: notas sobre o discurso neoliberal na publicidade brasileira pós-1990. Rev. bras. Ci. Soc. [online]. 2007, vol.22, n.64, pp. 81-90. ISSN 0102-6909. Disponível em: <http://www.scielo.br/scielo.php?script=sci_arttext\&pid=S010269092007000200007\&lng=pt\&nrm=iso>. Acesso em 13 dez. 2010.

ROCHA, Pedro da. Justiça considera fator previdenciário inconstitucional. Estadão. São Paulo, 02 dez. 2010. Economia. Disponível em: $<$ http://economia.estadao.com.br/noticias/economia+geral,justica-considera-fatorprevidenciario-inconstitucional,46032,0.htm >. Acesso em: 09 jan. 2011. 
RODRÍGUEZ, Dário Mansilla; TORRES, Javier Nafarrate. Autopoiesis, la unidad de una diferencia: Luhmann y Maturana. Sociologias, Porto Alegre, n. 9, p. 106-140, jan./jun. 2003. Disponível em: $\quad<$ http://www.scielo.br/scielo.php?script=sci_arttext\&pid=S1517$45222003000100005 \& \operatorname{lng}=$ pt\&nrm=iso $>$. Acesso em: 10 nov. 2006.

ROSEN, George. Uma história da saúde pública. Trad. Marcos Fernando da Silva Moreira. São Paulo: Hucitec: Editora da Universidade Estadual Paulista; Rio de Janeiro: Associação Brasileira de Pós-Graduação em Saúde Coletiva, 1994.

. Da polícia médica à medicina social: ensaios sobre a história da assistência médica. Trad. Ângela Loureiro de Souza. Rio de Janeiro: Edições Graal, 1979.

SABINO, Thaís. Brasil está 20 anos atrasado na solução do rombo da previdência. Terra. São Paulo, 11 set. 2010. Economia. Disponível em: $<$ http://economia.terra.com.br/noticias/noticia.aspx?idNoticia=201009111000_RED_7926671 0>. Acesso em: 09 jan. 2011.

SALLOWICZ, Mariana. Previdência privada cresce $16 \%$ no ano, mas só atinge $4 \%$ dos brasileiros. Folha de São Paulo, 14 set. 2010. Mercado. Disponível em: $<$ http://www1.folha.uol.com.br/mercado/798664-previdencia-privada-cresce-16-no-ano-masso-atinge-4-dos-brasileiros.shtml>. Acesso em: 09 jan. 2011.

SALOMÃO FILHO, Calixto. Direito concorrencial: as estruturas. $2^{\text {a }}$ ed. São Paulo: Malheiros, 2002.

SANTOS, Amauri Moraes dos. Desafios e oportunidades do farmacêutico na promoção da saúde. Infarma, v. 17, n. 5-6, p. 73-78, 2005. Disponível em: $<$ http://www.cff.org.br/revistas/49/73\%20a\%2078.pdf>. Acesso em 30 dez. 2006.

SANTOS, Ronaldo Lima dos. Sindicatos e ações coletivas: acesso à justiça, jurisdição coletiva e tutela dos interesses difusos, coletivos e individuais homogêneos. São Paulo: LTr, 2003.

SARLET, Ingo Wolfgang. A eficácia dos direitos fundamentais. 9. ed., rev., atual. e ampl. Porto Alegre: Livraria do Advogado Editora, 2007.

. Dignidade da pessoa humana e direitos fundamentais na Constituição Federal de $\overline{\text { 1988. } 6}$. ed. Porto Alegre: Livraria do Advogado, 2008.

SARLO, Beatriz. Paisagens imaginárias. Intelectuais, arte e meios de comunicação. Trad. Rubia Prates Goldoni, Sérgio Molina. Reimp. São Paulo: EDUSP, 2005. 
SAVARIS, José Antonio. O Judiciário e a Política de Retração Sistemática da Previdência Social no Brasil. In FAGNANI, Eduardo; HENRIQUE, Wilnês; LÚCIO, Clemente Ganz. Previdência Social: Como Incluir os Excluídos? Uma agenda voltada para o desenvolvimento econômico com distribuição de renda. Campinas: UNICAMP - Instituto de Economia; Campinas: CESIT; São Paulo: LTr, 2008, p. 44-74.

SCHWARTZ, Germano. O Tratamento Jurídico do Risco no Direito à Saúde. Porto Alegre: Livraria do Advogado Editora, 2004.

SECOM - Secretaria de Comunicação Social da Presidência da República Publicidade: Anunciantes e Agências. Brasília: Poder Executivo Federal. 21 out. 2009. Disponível em: $<$ http://www.secom.gov.br/sobre-a-secom/licitacoes/contratos-de-integrantes-do-sicom-comagencias-de-propaganda-a>. Acesso em 14 dez. 2010.

SERAU JR., Marco Aurélio. Economia e Seguridade Social: análise econômica. Curitiba: Juruá Editora, 2010.

SILVA, Paulo Thadeu Gomes da. Constituição. In: Dicionário de Direitos Humanos, Brasília: Escola Superior do Ministério Público da União. Disponível em: $<$ http://www.esmpu.gov.br/dicionario/tiki-index.php?page=Constitui\%C3\%A7\%C3\%A3o $>$.

Última modificação em: 06 out. 2006. Acesso em 12 dez. 2009.

Constituição, sistema jurídico e questões políticas. 2005. Tese (Doutorado em Direito) - Pontifícia Universidade Católica de São Paulo, São Paulo.

. Direitos fundamentais: contribuição para uma teoria geral. São Paulo: Atlas, 2010.

. Observações sobre a justiça em Kelsen e em Luhmann. Boletim dos Procuradores da República, São Paulo, ano IV, n. 39, p. 16-26, jul. 2001.

SILVESTRE, Aglaé. O sujeito e o pathos na mídia: uma análise do discurso sobre saúde nas matérias de capa das revistas Veja e Época. 2007. Dissertação (Mestrado em Ciências da comunicação) - Escola de Comunicações e Artes da Universidade de São Paulo, São Paulo.

SIMÃO, Edna. Com veto, Lula evita incentivo a aposentadoria precoce. Estadão. Brasília, 15 jun. 2010a. Economia. Disponível em: $<$ http://economia.estadao.com.br/noticias/economia+geral,comveto-lula-evita-incentivo-a-aposentadoria-precoce,22983,0.htm>. Acesso em: 09 jan. 2011.

PEC ressuscita aposentadoria integral: proposta que beneficia juizes, defensores e procuradores já tem emenda que também estende o privilégio aos delegados das polícias. Estadão. Brasília, 28 jun. 2010b. Economia. Disponível em: $<$ http://economia.estadao.com.br/noticias/economia+brasil,pec-ressuscita-aposentadoriaintegral,25081,0.htm>. Acesso em: 09 jan. 2011. 
SMITH, Mapheus. Gestalt. In: Dicionário de sociologia. 1. ed., $6^{\text {a }}$ impressão. Porto Alegre: Editora Globo, 1974, p. 150-151.

SODRÉ, Muniz. Estratégias sensíveis. Petrópolis: Vozes, 2005.

SOFIA, Julianna. Sob governo Lula, 550 mil buscam fundo de pensão. Folha. Brasília, 08 set. 2010. Mercado. Disponível em: <http://www1.folha.uol.com.br/mercado/795454-sobgoverno-lula-550-mil-buscam-fundo-de-pensao.shtm>. Acesso em: 09 jan. 2011.

SOROKIN, Pitirim Alexandrovich. Sociedade, Cultura e Personalidade: sua estrutura e sua dinâmica. v. 1. Porto Alegre: Editora Globo, 1968.

Teorías Sociológicas Contemporáneas. Buenos Aires: Editorial Depalma, 1951.

SOUZA, Hamilton Octavio. A atualidade dos estudos do jornalista e professor Perseu Abramo. In. ABRAMO, Perseu. Padrões de manipulação na grande imprensa. 3. reimp. São Paulo: Editora Fundação Perseu Abramo, 2003, p. 15 - 22.

SPENCER-BROWN, George. Laws of Form. New York: Dutton, 1979.

STOTZ, Eduardo Navarro; ARAÚJO, José Wellington Gomes. Promoção da saúde e Cultura política: a reconstrução do consenso. Saúde e Sociedade. V.13, n.2, p. 05-19, maio/ago. 2004.

TAVARES, Marcelo Leonardo. Reforma da Previdência - um resumo da mudança. In TAVARES, Marcelo Leonardo (coord.). Direito Previdenciário. Niterói: Impetus, 2005.

TEUBNER, Gunther. Evolution of Autopoiético Law. In: new approach to law and society. Berlin: New York: Walter de Gruyter, 1988.

(Ed.) Autopoietic Law: a O direito como sistema autopoiético. Lisboa: Fundação Calouste Gulbenkian, 1989a.

. How the Law Thinks: Toward a Constructivist Epistemology of Law. Law \& Society Review, Denver, v. 23, n. 5, p. 727-757, 1989 b.

TORRES, Javier Nafarrate. Nota a la versión en lengua castellana. In: LUHMANN, Niklas. Sistemas Sociales: lineamientos para una teoría general. Trad. Silvia Pappe y Brunhilde Erker; coord. Javier Torres Nafarrate. Rubí (Barcelona): Anthropos; México: Universidad Iberoamericana; Santafé de Bogotá: CEJA, Pontifícia Universidad Javeriana, 1998, p. 17-25.

TORRES, Ricardo Lobo. Existe um Princípio estrutural da Solidariedade? In: GRECO, Marco Aurélio; GODOI, Marciano Seabra (Coord.). Solidariedade Social e Tributação. São Paulo: Dialética, 2005, p. 198-207. 
TRIBUNA DO NORTE. Reformas são urgentes. Tribuna do Norte. Natal, 19 dez. 2010. Negócios e finanças. Disponível em <http://tribunadonorte.com.br/noticia/reformas-saourgentes/167974>. Acesso em: 09 jan. 2011.

VASQUES, Denise Cristina. Comentários ao artigo $5^{\circ}$ da Lei Complementar n. 109/01. In: CORREIA, Marcus Orione Gonçalves; VILlELA, José Corrêa. (Coord.) Previdência privada: doutrina e comentários à Lei Complementar n. 109/01. São Paulo: LTr, 2004, p. 151-159.

VILLAS BÔAS FILHO, Orlando. O direito na teoria dos sistemas de Niklas Luhmann. São Paulo: Max Limonad, 2006a.

. Uma abordagem sistêmica do direito no contexto da modernidade brasileira. 2006b. Tese (Doutorado em Direito) — Faculdade de Direito da Universidade de São Paulo, São Paulo.

VILLELA, José Corrêa. Alguns pontos da "privatização" da previdência e da Lei Complementar n. 108/01. In: CORREIA, Marcus Orione Gonçalves; VILLELA, José Corrêa. (Coord.) Previdência privada: doutrina e comentários à Lei Complementar n. 109/01. São Paulo: LTr, 2004, p. 21-53.

Conceito jurídico de pobreza na construção da Segurança Social. 2006. Tese (Doutorado em Direito) — Faculdade de Direito da Universidade de São Paulo, São Paulo.

WEBER, Max. Metodologia das ciências sociais, parte 1. Trad. Augustin Wernet. 4. ed., São Paulo: Cortez; Campinas, SP: Editora da UNESP, 2001.

WILLIAMS, Raymond. Cultura e Sociedade 1880-1950. São Paulo: Editora Nacional, 1969.

WOLTON, Dominique. Elogio do grande público: uma teoria crítica da televisão. Trad. José Rubens Siqueira. São Paulo: Ática, 1996.

ZIMA, Pierre V. L'école de Francfort. Paris: Editions Universitaires, 1974.

ZUBIETA, Ana Maria. Cultura popular y cultura de masas. Conceptos, recorridos y polémicas. Buenos Aires: Paidós, 2004. 